University of Louisville

ThinkIR: The University of Louisville's Institutional Repository

Electronic Theses and Dissertations

$12-2010$

\title{
English language learners in focus : predictors of English proficiency and academic achievement.
}

Yuliya Ardasheva

University of Louisville

Follow this and additional works at: https://ir.library.louisville.edu/etd

\section{Recommended Citation}

Ardasheva, Yuliya, "English language learners in focus : predictors of English proficiency and academic achievement." (2010). Electronic Theses and Dissertations. Paper 45.

https://doi.org/10.18297/etd/45

This Doctoral Dissertation is brought to you for free and open access by ThinkIR: The University of Louisville's Institutional Repository. It has been accepted for inclusion in Electronic Theses and Dissertations by an authorized administrator of ThinkIR: The University of Louisville's Institutional Repository. This title appears here courtesy of the author, who has retained all other copyrights. For more information, please contact thinkir@louisville.edu. 


\title{
ENGLISH LANGUAGE LEARNERS IN FOCUS:
}

PREDICTORS OF ENGLISH PROFICIENCY AND

\section{ACADEMIC ACHIEVEMENT}

\author{
By \\ Yuliya Ardasheva \\ A Dissertation \\ Submitted to the Faculty of the \\ Graduate School of the University of Louisville \\ in Partial Fulfillment of the Requirements \\ for the Degree of
}

Doctor of Philosophy

College of Education and Human Development

University of Louisville, Louisville, Kentucky

December 2010 
Copyright 2010 by Yuliya Ardasheva 



\title{
ENGLISH LANGUAGE LEARNERS IN FOCUS: \\ PREDICTORS OF ENGLISH PROFICIENCY AND
}

\section{ACADEMIC ACHIEVEMENT}

\author{
By
}

Yuliya Ardasheva

B.A., Perm State Pedagogical University, 1995

M.A., Perm State Pedagogical University, 1995
A Dissertation Approved on
November 18, 2010

by the following Dissertation Committee:

Dissertation Co-Dinector

Dissertation Co-Director 


\section{ACKNOWLEDGEMENTS}

First, I would like to thank Dr. Thomas R. Tretter, my advisor, dissertation cochair, and a great mentor, for the moral and academic support he has given me over the years. His patience, wisdom, and warmth have carried me through difficult times. His willingness to share his expertise, his openness to exploring new ideas, as well as many intellectually stimulating conversations about research methods and statistical analyses we had over the years have contributed tremendously to my growth as a researcher. My special gratitude also goes to Dr. Penny B. Howell, my research mentor and dissertation co-chair, and Dr. Elizabeth B. Patton, a great academic and life mentor, for their patience, warmth, and nurturing support over the years. I would also like to thank the other committee members, Dr. Ann E. Larson and Dr. Diane W. Kyle, for their kindness, great advice, and support throughout this journey. This work would not be completed without Marti Kinny, the district's ESL coordinator, as well as other key district personnel, who helped obtaining datasets and clarified any questions relevant to conducting this study. My sincere gratitude goes to their pleasant manner, professionalism, and accessibility. I am also grateful to Dr. Rebecca L. Oxford and Dr. Kimberly A. Noels for giving me permission to use their instruments, without which this work would not be completed. Finally, my biggest and warmest thank you goes to my husband, Greg, for his understanding, patience, and great meals that gave me moral as well as physical strength to finish this work. His publishing and editing skills were also a great contribution. My warmest thank you also goes to my mother for always being there for me. 


\title{
ABSTRACT \\ ENGLISH LANGUAGE LEARNERS IN FOCUS: PREDICTORS OF ENGLISH PROFICIENCY AND ACADEMIC ACHIEVEMENT
}

\author{
Yuliya Ardasheva
}

December 2010

\begin{abstract}
Academic achievement of English language learners (ELLs), the fastest growing population in the U.S. schools, deserves greater attention. This non-experimental study investigated the unique contributions — above and beyond other individual difference and school characteristics— - of language learning strategies (LLS) to student academic outcomes in a second language (L2). The sample comprised 1,057 ELLs (651 elementary, 275 middle, and 131 high school) attending 38 schools in one urban school district.
\end{abstract}

Descriptive analysis results indicated that ELLs used a large array of LLS; yet, except for metacognitive strategies, most LLS were reportedly used only at a medium level of frequency. The results also indicated a strong awareness of strategy effectiveness among teachers: A lack of significant correlations between teacher and student LLS ratings, however, suggested that teacher beliefs may not necessarily translate into practice.

The results of Structural Equation Modeling analyses identified three positive, instructionally manipulable contributors to ELLs' L2 outcomes: metacognitive strategies, motivation, and native language (L1) literacy. Whereas metacognitive strategy use 
appeared to be stable, cognitive strategy use declined as a function of age; memory, social, affective, and compensation strategy use declined as a function of length of residence (LOR). These results confirmed Gardner et al.'s (1997) hypothesis holding that with increased L2 proficiency students may feel less need in using LLS and suggested that age and LOR may moderate the relationships between LLS and L2 outcomes.

Hierarchical Linear Modeling results indicated that metacognitive strategies, L1 literacy, and English proficiency significantly contributed to reading achievement. Controlling for other predictors, lack of prior formal schooling had no negative effect on ELLs' achievement; lack of mother formal education was a negative predictor of mathematics and science—-but not reading and social studies—scores. Higher school quality indicators predicted higher academic achievement among ELLs.

The overall results suggest that ELLs would benefit from: (a) integrated content, language, and metacognitive strategy instruction; (b) classrooms that stimulate motivation; (c) L1 literacy maintenance; (d) additional L2 support; and (e) placement in higher-performing schools. Additional research is needed to explore the potential moderator effects of age and LOR on the relationships between LLS and L2 outcomes. 


\section{TABLE OF CONTENTS}

ACKNOWLEDGMENTS............................................... ii

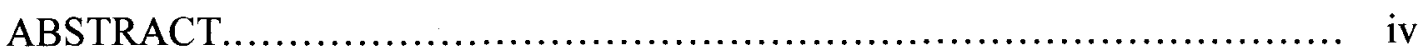

LIST OF TABLES........................................................ xiv

LIST OF FIGURES..................................................... xvi

CHAPTER 1: INTRODUCTION....................................... 1

Background to the Study........................................... 1

Historical Development of Language Support Programs: An Overview. 4

Statement of the Problem........................................... 9

Purpose of the Study ............................................ 10

Study Significance............................................... 11

Study Limitations.................................................. 12

Research Questions........................................... 12

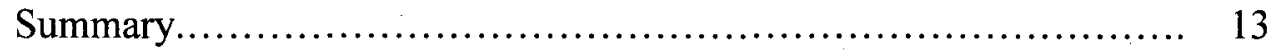

CHAPTER 2: REVIEW OF LITERATURE................................... 16

Second Language Acquisition....................................... 16

Defining the Field....................................... 16

Selected SLA Theoretical Frameworks....................... 17

Language as a Faculty of the Mind.................. 17

Language as a Cognitive Skill...................... 21 
Language as a Socially Constructed Skill............... 25

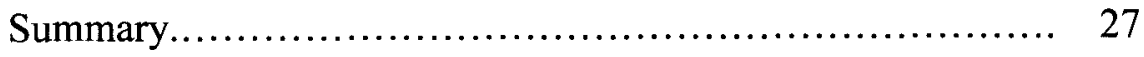

Language Proficiency............................................ 27

Defining English Proficiency.............................. 27

Research on English Language Development................. 32

Summary................................................ 37

Language Learning Strategies................................... 38

Theoretical Considerations.................................... 38

Overview, Assumptions, and Connections................ 38

Defining Language Learning Strategies................ 39

Categorizing Language Learning Strategies........... 41

Theoretical Underpinnings: LLS and Autonomous

Learning........................................... 43

Defining Strategy Instruction......................... 44

LLS: Methods and Data Sources..................... 45

Early Descriptive Research: "The Good Learner".............. 46

LLS and Language Proficiency........................... 47

Variations in Strategy Choice, Use, and Evaluation............. 52

Proficiency Level................................ 52

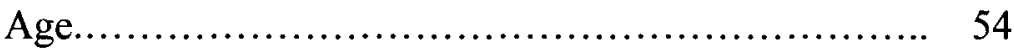

Gender........................................ 55

Culture............................................. 55

Teacher Role.................................................... 56 
Strategy Instruction........................................ 58

LLS and Academic Achievement............................ 60

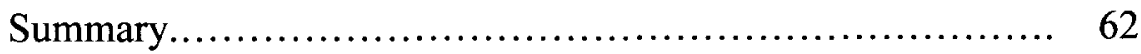

Language Learning Motivation................................... 63

Connecting Motivation, Strategy Use, and Proficiency.......... 63

Defining Language Learning Motivation....................... $\quad 64$

Theoretical Perspectives on Language Learning Motivation..... 64

Empirical Findings........................................ 68

LLS and Motivation............................... 68

Motivation and Learner Autonomy in a Classroom...... 70

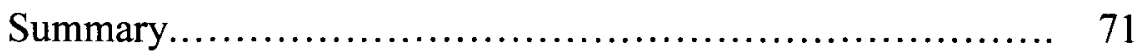

Academic Achievement in English as a Second Language.............. 72

Defining Academic Achievement $\quad 72$

Current Trends in ELLs' Academic Achievement................ 73

Theoretical Perspective Explaining the Achievement Gap....... 74

Academic Achievement Research............................ 79

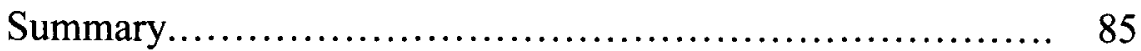

Summary and Selected Variables..................................... 86

CHAPTER 3: RESEARCH DESIGN AND METHODOLOGY.................. 92

Methods........................................................... 93

Research Design........................................ 93

Population, Research Site, and Sample..................... 94

Study Population and Research Site.................... 94 
Study Sample and Sampling Procedures

Instrumentation/Measures. .

Strategy Inventory for Language Learning (SILL)-

Student Form

98

Strategy Inventory for Language Learning (SILL)-

Teacher Form

English Language Learning Motivation Scale (ELLMS) 100

Assessing Comprehension and Communication in

English State-to-State for English Language Learners

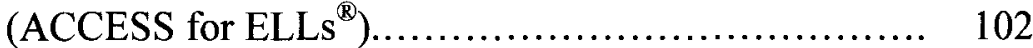

Kentucky's Core Content Tests....................... 104

Study Variables: Operational Definitions....................... 106

Data Collection Procedures................................... 109

Data Analysis Plan......................................... 112

Data Preparation....................................... 112

Research Question 1............................. 112

Research Question 2............................. 114

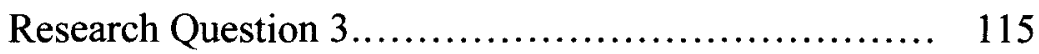

Summary...................................................... 117

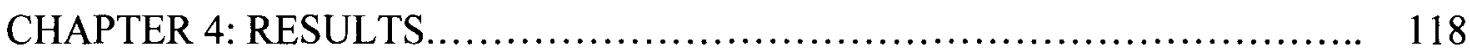

Descriptive Statistics........................................ 118

School Sample.......................................... 118

Teacher Sample.......................................... 119 
Attrition Analyses for the Student Sample................ 120

Student Sample........................................ 123

Data Preparation............................................. 126

Modified Instruments' Validity and Reliability $\ldots \ldots \ldots \ldots \ldots \ldots \ldots \ldots, 128$

English Language Learning Motivation Scale (ELLMS)....... 128

Strategy Inventory for Language Learning (SILL)—ELL

Student Form...................................... 129

Strategy Inventory for Language Learning (SILL)-ESL

Teacher Form $\ldots \ldots \ldots \ldots \ldots \ldots \ldots \ldots \ldots \ldots \ldots \ldots \ldots \ldots \ldots, 130$

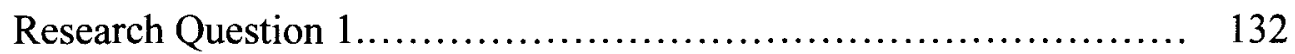

Individual Level Analyses............................... 132

Teacher Strategy Effectiveness Ratings Profile......... 137

Student Strategy Use Profile...................... 138

Comparison of Teacher and Student LLS Rank

Orderings.................................................. 139

Within-School Teacher-Student Strategy Profiles.............. 140

Elementary School................................. 145

Middle School.................................. 146

High School................................... 147

Summary of Research Question 1 Results.................. 148

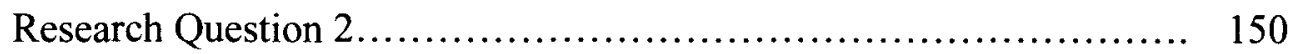

SEM Analytical Approach.............................. 150

Hypothesized Model Specification......................... 153 
Model Fitting, Evaluation, and Modification................... 156

Parameter Estimates...................................... 161

Predictors of Academic Achievement................. 161

Predictors of English Proficiency ................... 162

Predictors of Strategy Use and Intervening Effects..... 163

Correlations among Exogenous Variables............. 168

Practical Significance........................................ 168

Summary of Research Question 2 Results..................... 169

Research Question 3......................................... 172

HLM Analytical Approach................................ 172

Data Preparation.................................... 174

Reading Model........................................ 174

Model Specification................................. 175

Final Explanatory Model............................ 177

Estimating the Means..................... 181

Estimating the Slopes.................... 181

Practical significance.............................. 182

Summary ........................................ 183

Mathematics Model........................................ 184

Model Specification................................. 184

Final Explanatory Model........................... 186

Estimating the Means................... 190

Estimating the Slopes.................... 190 
Practical significance

Summary

Science Model.......................................... 192

Model Specification................................ 192

Final Explanatory Model........................... 194

Estimating the Means................... 198

Estimating the Slopes................. 198

Practical significance.............................. 199

Summary....................................... 199

Social Studies Model........................................ 201

Model Specification................................ 201

Final Explanatory Model.......................... 203

Estimating the Means................... 207

Estimating the Slopes................. 207

Practical significance.............................. 208

Summary...................................... 208

Summary of Research Question 3 Results.................... 209

CHAPTER 5: CONCLUSIONS AND IMPLICATIONS....................... 212

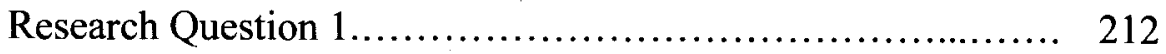

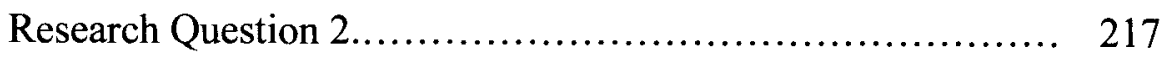

Research Question 3.................................. 222

Student L2 Profiles and Background Characteristics

Effects......................................... 223 
School Organizational and Quality Indicators

Effects.......................................... $\quad 227$

Significance and Implications................................... 228

REFERENCES.......................................................... 232

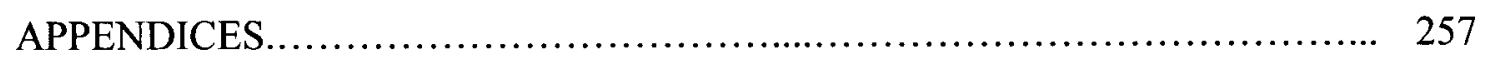

APPENDIX A $\quad$ Permission to use SILL..................................... 257

APPENDIX B $\quad$ SILL-ELL Student Form................................ 258

APPENDIX C $\quad$ SILL-ESL Teacher Form.................................. 263

APPENDIX D $\quad$ Permission to use LLOS-IEA ............................ 268

APPENDIX E $\quad$ ELLMS ........................................................ 269

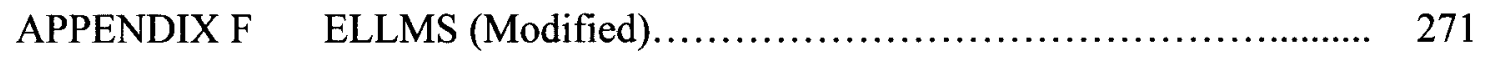

APPENDIX G SILL-ELL Student Form (Modified)........................ 272

APPENDIX H $\quad$ SILL-ESL Student Form (Modified)............................. 274

APPENDIX I Individual Level Comparison of Teacher and Student Ratings

of Learning Strategies Effectiveness by Educational Level...... 278

APPENDIX J Correlations and Descriptive Statistics for HLM Reading,

Mathematics, Science and Social Studies Model Variables....... 279

CURRICULUM VITAE .................................................... 287 


\section{LIST OF TABLES}

TABLE $1.1 \quad$ Definitions of Key Terms.................................. 14

TABLE 2.1 Study Variables and Rationale for Selection.................... 88

TABLE 3.1 Description of the Study Variables.............................. 107

TABLE $3.2 \quad$ Data Collection Procedures.................................... 110

TABLE 4.1 Descriptive Statistics for Participating Schools................... 119

TABLE 4.2 Descriptive Statistics for Teachers by Educational Level.......... 122

TABLE 4.3 Descriptive Statistics for Students by Educational Level........... 124

TABLE 4.4 Psychometric Properties of the District-Collected Study Variables

for the Total Sample................................................ 128

TABLE 4.5 Psychometric Properties of the Researcher-Collected Study

Variables for the Total Sample............................... 131

TABLE 4.6 Individual Level Descriptive Statistics for Teacher and Student

Strategy Ratings Disaggregated by Educational Level............ 134

TABLE 4.7 Rank Ordering of Teacher and Student Perceptions of Strategy

Effectiveness and Use Disaggregated by Educational Level........ 137

TABLE 4.8 Teacher-Student Strategy Profiles by Educational Level........... 145

TABLE 4.9 Within-School Correlations Between Teacher and Student

Strategy Ratings Disaggregated by Educational Level........... 148

TABLE 4.10 Goodness-of-Fit Statistics across Hypothesized and Post Hoc 
Language Learning Strategy Use Models.

TABLE 4.11 Direct Effects of Student Characteristics across Strategy Use Models

TABLE 4.12 Metacognitive Strategy Model: Estimated Correlations Among

Exogenous Variables. 168

TABLE 4.13 Full and Final Models of Reading Achievement: Fixed Effects..... 178

TABLE 4.14 Full and Final Models of Reading Achievement: Random Effects.. 180

TABLE 4.15 Full and Final Models of Mathematics Achievement: Fixed

Effects

TABLE 4.16 Full and Final Models of Mathematics Achievement: Random

Effects

TABLE 4.17 Full and Final Models of Science Achievement: Fixed

Effects.

TABLE 4.18 Full and Final Models of Science Achievement: Random

Effects

TABLE 4.19 Full and Final Models of Social Studies Achievement: Fixed

Effects.

204

TABLE 4.20 Full and Final Models of Social Studies Achievement: Random

Effects 


\section{LIST OF FIGURES}

FIGURE 1.1 The flow of information within the ACT framework............. 22

FIGURE 3.1 Profile of hypothetical teacher-student ratings of memory strategies effectiveness or use.............................. 113

FIGURE 3.2 Hypothesized relationships and directionalities among studentlevel variables.

FIGURE 4.1 Elementary school profile of teacher-student ratings of learning strategies effectiveness and use

FIGURE 4.2 Middle school profile of teacher-student ratings of learning strategies effectiveness and use

FIGURE 4.3 High school profile of teacher-student ratings of learning strategies effectiveness and use

FIGURE 4.4 Metacognitive Strategy Model: Hypothesized relationships among ELL student background characteristics, language motivation, metacognitive strategy, academic English proficiency, and academic achievement 


\section{CHAPTER 1}

\section{INTRODUCTION}

\section{Background to the Study}

Academic achievement of English language learners (ELLs) ${ }^{1}$ has become an urgent topic in education in recent years (Solórzano, 2008). ELLs are the fastest growing population in the United States. The number of school-aged English learners is expected to increase to $25 \%$ of the total student population by 2025 , and to $40 \%$ by 2050 (Goldenberg, 2008). These changes in school population demographics reflect the demographic and linguistic shift in the society at large. The National Center for Public Policy and Higher Education (NCPPHE, 2005) projects that from 1980 to 2020, the minority representation in the nation's workforce will double in the United States from $18 \%$ to $37 \%$; at the same time, the Caucasian working population will decline from $82 \%$ to $63 \%$. Quality education for this newly emerging racially, ethnically, and linguistically diverse generation of American workers is vital for the future of the United States economy. Yet, despite some progress over the last three decades, as indicated by test scores in reading and mathematics, high school completion rates, and attainment of higher degrees, linguistically diverse students are generally far less well educated than their native-English speaking counterparts (Fry, 2008; Kao \& Thompson, 2003; NCPPHE, 2005).

\footnotetext{
${ }^{1}$ All key terms used in the introduction section as well as throughout the paper are summarized in Table 1 at the end of this chapter.
} 
Past research has explored a number of variables underlying ELLs' academic achievement gap at the student, classroom, school, and community levels. Among these factors are: (a) at the student level, socioeconomic status, minimal schooling in the student's first language (Thomas \& Collier, 1997; 2002), and limited English proficiency (Solórzano, 2008; Yoko, 2007); (b) at the classroom level, ethnic stereotyping and low quality of language support services offered (Shannon \& Hakuta, 1991; Datnow, Stringfield, \& Castellano, 2005); and (c) at the school and community level, the lack of language support services in areas with a low concentration of language minority groups (Galguera \& Hakuta, 1997) and schooling in underperforming, high-poverty schools (Fry, 2008).

In their review of academic achievement literature, Kao and Thompson (2003) categorized current theoretical perspectives which attempt to explain culturally and linguistically diverse students' achievement gap into two broad categories: cultural orientations and structural position theories. Cultural orientations theories consider ethnic groups' differences in orientation toward schooling as the main cause that promotes or hinders achievement. Structural position theories ascribe differences in academic performance to ethnic/cultural groups' socioeconomic positions and experiences in society including ethnic groups' social capital (i.e., social networking). What these theories-mainly derived from sociology, anthropology, and educational research-do not directly consider is the influence of the most salient, namely, linguistic factors on the academic achievement of ELLs.

Although ethnicity, linguistic background, and English proficiency are "complementary", confounding ethnicity and language frequently obscures the role that 
linguistic issues play in ELLs' schooling experiences (Galguera \& Hakuta, 1997; Lucas \& Grinberg, 2008). For example, Thomas and Collier (2002) estimated that the number of years that it takes ELLs to acquire enough English to do grade-level work in academic content areas is equivalent to 1 to 2 years ${ }^{2}$ of interrupted schooling. The authors noted that ELLs "have to make more gains than the average native-English speaker makes every year for several years in a row to eventually catch up to grade level" (p. 8). Moreover, learning a new language is a developmental process that requires a gradual accumulation of skills over time (Genesee, Lindholm-Leary, Saunders, \& Christian, 2005); there is empirical evidence to suggest that some language skills may not be acquired before the others (Kwon, 2005; Pienemann, 1985). Studies have documented that it may take ELLs up to seven years to acquire enough English to do grade-level work in English medium classrooms (Hakuta, Butler, \& Witt, 2000; Thomas \& Collier, 1997). Students with no schooling in their native language may require up to 10 years (Thomas \& Collier, 1997; 2002).

In recent years, the discussion of linguistic factors in ELLs' schooling has received some extended attention in educational and applied linguistics literature (Dale \& Cuevas, 1992; Dutro \& Morgan, 2001; Schleppegrell, 2004), in educational assessment literature (Abedi, 2004; Abedi \& Lord, 2001; Solórzano, 2008), and in teacher education literature (Fillmore \& Snow, 2002/2005; Lucas \& Grinberg, 2008, Lucas, Villegas, \& Freedson-Gonzalez, 2008). This trend is also reflected in teacher professional organization documents (National Council of Teachers of English, 2008; National Council of Teachers of Mathematics, 2008). For example, the 2008 National Council of

\footnotetext{
${ }^{2}$ This number is rather an underestimation because it is based on students with comparable, grade-level schooling in their first language.
} 
Teachers of Mathematics position statement states, "Mathematics, like every academic field, has its own language, with a specialized grammar and vocabulary. Mathematics teachers should engage ELL students explicitly in the use of this language, integrating language objectives with goals for content understanding." Yet, the understanding of the relationship between language development and content knowledge development in ELLs remains limited (Goldenberg, 2008; Zwiers, 2006, 2007). In their systematic review of over 200 articles and reports on educational outcomes of ELLs, Genesee and colleagues (2005) noted:

There is a particularly strong need for research that examines the links between oral language and literary development on the one hand, and between oral language development and academic achievement on the other. We especially need to understand better the differential role of oral language and literacy (whether in L1 [first language] or L2 [second language]) in fostering academic achievement at different grade levels as academic subject matter becomes more abstract,' complex, and, arguably, language dependent. (pp. 379-380)

\section{Historical Development of Language Support Programs: An Overview}

Prior to 1968, no federal policies regarding ELLs existed (Wright, 2005). Wright noted that the main instructional approach to educating ELLs at the time was "sink-orswim" English immersion. Two events occurring in the 1960s have brought this issue to the public's eye. On the one hand, the 1960s' Census data revealed high drop-out rates

for language minority students. While the average schooling for Whites was 14 years, the same number for Mexican Americans was 4.7 years. On the other hand, research conducted in Southwestern states and in the state of Florida documented the successes of 
bilingual programs (i.e., programs offering instruction in native and English languages). These two events led to the passage of the 1968 Bilingual Education Act (BEA)-a legislative document exclusively focused on ELLs-which entered the federal law as Title VII of the Elementary and Secondary Education Act (ESEA). Under Title VII, schools now had an opportunity to apply for federal funds (in the form of competitive grants) to establish and support bilingual education programs. The two purposes of bilingual education programs under the legislation were (a) to teach English, and (b) to provide ELLs with access to academic content through their native language. While providing funds for bilingual programs, the BEA did not mandate that schools implement any particular language support program for ELLs.

This situation changed with the 1974 Lau v. Nichols Supreme Court decision (Diaz-Rico, 2008; Wright, 2005). In 1973, a group of Chinese students sued San Francisco Unified School district claiming that "sink-or-swim" instruction violated their civil rights of equal access to education. Lower federal courts ruled in favor of the district, but a unanimous Supreme Court decision ruled in favor of the plaintiff stating, "There is no equality of treatment merely by providing students with the same facilities, textbooks, teachers, and curriculum, for students who do not understand English are effectively foreclosed from any meaningful education" (as cited in Diaz-Rico, 2008, p. 126). Subsequently, the U.S. Commissioner for Education published in 1975 the Lau Remedies, which established standardized requirements for school districts to identify, evaluate, and provide language instruction support for ELLs. These requirements also specified teacher professional standards and procedures for transferring ELLs into allEnglish classrooms. 
While the Bilingual Education Act was applicable only to federally funded schools, the Lau Remedies served as compliance standards for all school districts and, essentially, recommended bilingual programs (Wright, 2005). The 1984 Bilingual Education Act reauthorization recognized that the administration of bilingual education programs may be impractical in districts where the number of ELLs of the same language background was small and where there was a shortage of qualified bilingual teachers. In such cases, the establishment of alternative, English-only programs was recommended. Thus, English-only programs-often referred to as English as a Second Language (ESL) or English to Speakers of Other Languages (ESOL)-became eligible for funding. Since then, the number and types of such programs have proliferated (Kaufman \& Crandall, 2005; Snow, 2001). The two most common approaches are ESL pullout (i.e., students are taught academic content in grade-level classrooms and are 'pulled-out' for English language skills instruction), and ESL academic content (i.e., integrated language and content instruction) (Peregoy \& Boyle, 2005; Thomas \& Collier, 1997).

The 2001 No Child Left Behind Act eliminated the Bilingual Education Act; instead, Title III, Language instruction for limited English proficient and immigrant students, was created (Wright, 2005). Title III emphasizes English language development and high level of academic attainment for ELLs. Through state education agencies, funds are provided for school districts to develop instructional programs that will prepare ELLs to enter all-English classrooms. The reauthorization document no longer distinguishes between bilingual and alternative, all-English, language programs such as ESL pullout and ESL academic content. 
Much evidence exists that all-English approaches are inferior to bilingual education in terms of promoting academic achievement among ELLs (Genesee, et al. 2005; Rolstad, Mahoney, \& Glass, 2005; Slavin \& Cheung, 2005; Thomas \& Collier, 2002). However, the recent changes in the federal policies, the shortage of bilingual educators, and the increasing language diversity of students across the states, ${ }^{3}$ led many school districts to opt for ESL instructional models over bilingual models. Currently, $60 \%$ of ELLs receive English-only instruction (Goldenberg, 2008). Such is the case for the present study's research site-the Jefferson County Public Schools District (JCPS) located in Louisville, Kentucky.

Much effort and expertise has been engaged for developing higher quality ESL programs. Language educators increasingly turn to content areas' subject matter as the source for academic language development in ELLs (Richardson Bruna, Roberta, \& Perales Escudero, 2007; Snow, 2001; Zwiers, 2006, 2007). Content area specialists, in turn, increasingly draw on the existing body of knowledge in the field of second language acquisition (SLA) in order to increase ELLs' academic outcomes (Amaral, Garrison, \& Klentschy, 2002; Dale \& Cuevas, 1992; Lee, Maerten-Rivera, Penfield, LeRoy, \& Secada, 2008).

One promising line of inquiry within SLA is research on language learning strategies (LLS). Language learning strategies have been defined as "specific actions consciously employed by the learner for the purpose of learning language" (Griffiths, 2007 , p. 91). Current interest in studying learner strategies is driven by practical considerations of providing ELLs with effective instruction and by a trend characteristic

\footnotetext{
${ }^{3}$ For example, the languages spoken in Kentucky include Spanish, Spanish Creole, German, French, Chinese, Japanese, Korean, Arabic, Serbo-Croatian, Vietnamese, Russian, and Tagalog (City-data, n. d.).
} 
of educational psychology in general and of second language research in particular (Oxford, 1990). In their review of research on ELLs' academic achievement conducted since 1980, Genesee et al. (2005) noted that the use of language learning strategies is characteristic of second language (L2) development because L2 learners typically begin to learn a new language at a more mature age and thus can draw on conscious, explicit strategies to enhance their learning. The review suggested that LLS support the development of oral language proficiency. In turn, "with development and increased proficiency in English, ELLs are better able to engage in more academic uses of language" (Genesee et al., 2005, p. 369).

With some notable exceptions (Gardner, Tremblay, \& Masgoret, 1997), research has linked higher strategy use with higher language proficiency. Much evidence suggests a linear relationship between the two variables (Dreyer \& Oxford, 1996; Griffiths, 2007; Kaylani, 1996; Oxford, 1999; Peacock \& Ho, 2003). Two studies found a curvilinear pattern, with intermediate proficiency students deploying more strategies than lower and higher proficiency students (Phillips, 1992; Hong-Nam \& Leavell, 2006). Two extensive reviews of LLS research conducted since the 1970s indicated that (a) strategy use has been linked to successes on various aspects of language learning (e.g., vocabulary, listening, reading; McDonough, 1999); and (b) experimental and quasi-experimental research has provided empirical evidence that explicit strategy instruction can improve student language outcomes (Hassan, Macaro, Mason, Nye, Smith, \& Vanderplank, 2005). Additionally, high strategy use has been linked to motivation for learning a second language (MacIntyre \& Noels, 1996; Nunan, 1997). 
Among strategy researchers, there is an established assumption that LLS support learner autonomy (i.e., ability and willingness to engage in independent, self-regulated learning; McDonough, 1999; Oxford, 1999). The key role of the teacher in promoting learner autonomy has been documented in recent research (Noels, 2001; Noels, Clément, \& Pelletier, 1999). Oxford and Leaver (1996) noted that whereas some learner variables are more stable (e.g., personality type) or simply given (e.g., age, gender), other variables, namely learning behaviors, motivation, and language attitudes, could be altered through instruction. Among potential benefits of strategy instruction, the authors listed:

(1) identifying and improving strategies that are currently used by the individual; (2) identifying strategies that the individual might not be using but that might be helpful for the task at hand, and then teaching those strategies; (3) helping students learn to transfer strategies across language tasks and even across subject fields; (4) aiding students in evaluating the success of their use of particular strategies with specific tasks; and (5) assisting subjects in gaining learning style flexibility by teaching them strategies that are instinctively used by students with other learning styles. (p. 227)

There is also some evidence, though limited, indicating that instructional models incorporating strategy instruction can improve student outcomes in content areas (Chamot, Dale, O'Malley, \& Spanos, 1992; Montes, 2002).

\section{Statement of the Problem}

As suggested by the preceding literature summary, language learning strategies have the potential to impact student academic outcomes in content areas either directly, through strategy transfer to content area learning tasks or indirectly, by means of 
developing oral and academic language proficiency. One example of the application of learning strategies to the learning of the academic language of the disciplines is the learning of the content area specific vocabulary (e.g., 'photosynthesis', 'pi') and syntax (e.g., passive tense and nominalized verbs typical of science, social studies, mathematics, and language arts expository texts).

However, the impact of language learning strategies on academic achievement in content areas, particularly in secondary school settings, has not been studied in systematic ways. Only two studies exploring the relationship between strategy use and ELLs' academic achievement at secondary level (Chamot et al., 1992; Montes, 2002) could be located. Moreover, even as empirical evidence suggests that teachers' beliefs underlie their instructional practices (August \& Calderón, 2006; Zwiers, 2007), little is known about teacher perceptions of the effectiveness of language learning strategies. One study suggests that teachers may be simply unaware of learners' strategies (O’Malley, Chamot, Stewner-Manzanares, Kupper, \& Russo, 1985a). Other studies found discrepancies between teacher and student perceptions of LLS (Griffiths, 2007; Griffiths \& Parr, 2001). At the same time, educators argue that teacher perceptions of strategic, autonomous learning is an important instructional factor which has a direct bearing on learning experiences of the students (Oxford, 1990; Rivera-Mills \& Plonsky, 2007).

\section{Purpose of the Study}

One objective of this research is to compare teacher perceptions of strategy effectiveness and student self-reported strategy use. Another objective is to develop and test against data a statistical model in which language learning strategy use is hypothesized to enhance ELLs' academic achievement directly and indirectly, by means 
of language proficiency. The last objective is to single out the unique contribution of language learning strategies to ELLs' academic achievement in content areas relative to other previously identified student- and school-level academic achievement predictors.

\section{Study Significance}

ELLs, a continuously growing minority group, are often targeted for educational interventions and are affected by both general education policies and policies specific to language minority groups (Galguera \& Hakuta, 1997). Studying variables that may affect ELLs' academic achievement is crucial for informing practice, policy, and theory regarding instruction for ELLs. Most of the extant research on academic achievement exploring student-level variables, however, rarely goes beyond data sets available through school districts and state education departments, thus limiting academic achievement predictor variables to demographic and language achievement data (Yoko, 2007). Such sets of predictors exclude sociocognitive (language learning strategies) and psychological (motivation and language attitudes) variables-variables that have been linked to second language development (Hassan et all., 2005; Masgoret \& Gardner, 2003; McDonough, 1999). Research on second language development, on the other hand, while including student-level sociocognitive and psychological variables, rarely explores the relationship between these variables and ELLs' academic achievement in content areas beyond language classrooms and is most often conducted in postsecondary settings.

The novelty of this research is to incorporate into statistical analyses academic outcomes predictors separately explored by academic achievement, second language development, and language learning strategy literature. One of the anticipated outcomes of this study is establishing whether or not language learning strategies can predict ELLs' 
academic achievement in content areas. Positive relationships between language learning strategies and academic achievement (if established) may have practical implications for developing teacher preparation and professional development programs for content area teachers working with English language learners.

Additionally, this study will contribute to the limited body of knowledge regarding the relationships among language learning strategy use, teacher perceptions of strategy effectiveness, and achievement in academic content areas. Lastly, the study will expand the existing body of knowledge regarding strategy use as it relates to secondary ELL population.

\section{Study Limitations}

There are three main limitations to this study: (a) for feasibility reasons, the set of predictors will include only a selected set of variables limited to the student and school levels (excluding, for example, the social capital, classroom instruction, and school climate variables), (b) data will be limited to one large urban district in Kentucky, and (c) English-only standardized achievement tests used for the present study may be an inaccurate measure of content knowledge of ELLs, possibly underestimating their actual content knowledge in part due to the language barrier.

\section{Research Questions}

This study will be guided by three research questions:

1. How do teacher perceptions of the effectiveness of language learning strategies for English language development correspond with ELL students' reported frequency of strategy use?

a. What strategy categories are the most strongly aligned between individual 
teacher and student ratings of strategy effectiveness and use at elementary, middle, and high school levels?

b. How do within school teacher-student strategy effectiveness and use rating profiles compare at elementary, middle, and high school levels?

2. What are the structural relationships among ELL student background and linguistic profile characteristics and academic achievement, considering the mediating influences of language motivation, language learning strategy use, and academic English proficiency?

3. How well does the use of language learning strategies predict academic achievement among ELLs controlling for student- and school-level variables identified as strong predictors in the research literature?

\section{Summary}

This chapter outlined the background for the study including the historical overview of language support programs in the United States, a statement of the problem, the study's purpose, significance, and limitations, the research questions, and the definitions of key terms used throughout the paper (as summarized in Table 1.1). The next chapter reviews theoretical and empirical research pertinent to the questions addressed by the study. 
Table 1.1

Definitions of Key Terms

Term Description and source

Bilingual programs

English as a foreign language

(EFL) students

English language learner (ELL)

English as a Second Language $(\mathrm{ESL})^{\mathrm{a}}$

ESL academic content

ESL pullout

ESL teachers

First language (L1)
Programs offering instruction in native and English languages (Wright, 2005).

"Nonnative-English-speaking students who are learning English in a country where English is not the primary language" (NCTE, 2008, p. 2).

"An active learner of the English language who may benefit from various types of language support programs" (NCTE, 2008, p. 2).

"Formerly used to designate ELL students, this term increasingly refers to a program of instruction designed to support the ELL" (NCTE, 2008, p. 2).

Integrated language and content instruction (Peregoy \& Boyle, 2005; Thomas \& Collier, 1997). Other terms: Structured Immersion, Sheltered Instruction.

Students are taught academic content in grade-level classrooms without any special assistance and are "pulled-out" for English language skills instruction (Peregoy \& Boyle, 2005).

Teachers of ELLs whose primarily content area of instruction is English language development (Diaz-Rico, 2008).

The first language that a child learns (Gass \& Seliker, 2008). Other terms: Mother tongue, primary language, native language (NL). 


\begin{tabular}{ll}
\hline Term & Description and source \\
\hline Second language (L2) & $\begin{array}{l}\text { An additional, new language that is being learned. (Gass \& Seliker, 2008, p. 7). Other terms: } \\
\text { Target language (TL). }\end{array}$ \\
$\begin{array}{l}\text { Second language acquisition } \\
\text { (SLA) }\end{array}$ & $\begin{array}{l}\text { A field of research; “The study of how second languages are learned" (Gass \& Seliker, 2008, p. } \\
\text { 1). }\end{array}$ \\
Language learning strategies (LLS) & $\begin{array}{l}\text { "Specific actions consciously employed by the learner for the purpose of learning language" } \\
\text { (Griffiths, 2007, p. 91). Other terms: Language learner strategies. }\end{array}$ \\
$\begin{array}{l}\text { Oxford's taxonomy of language } \\
\text { learning strategies }\end{array}$ & $\begin{array}{l}\text { A categorization schema that groups LLS into six categories: (a) memory strategies, information } \\
\text { storage and retrieval strategies; (b) cognitive strategies, comprehension and production } \\
\text { strategies; (c) compensation strategies, strategies employed to overcome limitations in linguistic } \\
\text { knowledge or performance; (d) metacognitive strategies, strategies employed to plan, organize, } \\
\text { focus, and monitor learning; (e) affective strategies, strategies employed to control motivation } \\
\text { and emotions; and (f) social strategies, cooperative strategies (Oxford, 1990). }\end{array}$ \\
& $\begin{array}{l}\text { "Any intervention which focuses on the strategies to be regularly adopted and used by language } \\
\text { learners to develop their proficiency, to improve particular task performance, or both" (Hassan et } \\
\text { al., 2005, p. 1). Other terms: Strategy training. }\end{array}$ \\
Thtrategy instruction & $\begin{array}{l}\text { The drive to learn a new language associated with effort, desire to learn the new language, and } \\
\text { attitudes toward the language studied (Gardner, 2006). Other terms: Motivation to learn a second } \\
\text { language; language motivation. }\end{array}$ \\
\hline
\end{tabular}

Note. ${ }^{\mathrm{a}}$ In higher education, the term ESL still refers to multilingual students. ${ }^{\mathrm{b}}$ The term SLA may refer to the process of acquiring/developing a second language. 


\section{CHAPTER 2}

\section{REVIEW OF LITERATURE}

This chapter comprises six main sections that summarize the theoretical and empirical knowledge base regarding second language development and academic achievement in a second language. At the end of each main section, ${ }^{4}$ there is a summary synthesizing studies and highlighting key findings relevant to the present study. The first section reviews selected second language acquisition theories that reflect representative, current trends in the field and provide a theoretical foundation for the study. The second section focuses on defining language proficiency and reviews relevant studies illuminating linguistic factors implicated in ELLs' schooling. The third section summarizes the language learning strategy research base. The fourth section identifies relevant theories and research regarding motivation for learning a second language and makes connections among motivation, language learning strategies, and proficiency. The fifth section reviews studies that have examined academic achievement in second language. The last section summarizes the present study's variables as generated from this review of the literature.

\section{Second Language Acquisition}

\section{Defining the Field}

Second language acquisition (SLA) is an interdisciplinary field that is both historically old and new (Gass \& Seliker, 2008). The field is old because the nature of

\footnotetext{
${ }^{4}$ Except the first section which integrates theory and empirical findings throughout.
} 
second language learning and teaching has fascinated scholars for centuries. In more modern terms, SLA is a young discipline which, beginning in the 1960 s, distinguished itself from applied linguistics and education (Long, 2006). SLA focuses on second language (L2), as well as second dialect, learning and loss by children and adults. As formulated by Saville-Troike (2006), SLA seeks to answer three main questions: (a) "What exactly does the L2 learner know?" (b) "How does the learner acquire this knowledge?" and (c) "Why are some learners more successful than others?" (p. 24). From its beginnings, SLA has taken a multidisciplinary approach and drawn on other established disciplines including education, linguistics, psychology, anthropology, and sociology (Gass \& Seliker, 2008).

The theoretical rationales in considering the connections between SLA and academic achievement research are twofold. First, as discussed in Chapter 1, a current focus in educational literature is on linguistic factors implicated in ELLs' schooling. In fact, many scholars find it difficult to distinguish between language proficiency and academic competence (Abedi \& Lord, 2001; Solórzano, 2008); some scholars speak in terms of academic English development (Schleppegrell, 2004) or of academic achievement in second language (Collier, 1987; Collier \& Thomas, 1989). Second, language learning strategies, the primary variable of interest to this study, have been chiefly examined from the SLA perspective.

Selected SLA Theoretical Frameworks

Language as a faculty of the mind. Early research on second language (L2) development was strongly influenced by research on first language (L1) acquisition and by nativist linguistic theories. Nativist theories posit that language acquisition is 
accomplished through the use of innate linguistic abilities. Many nativists assert that L1 and L2 acquisition are similar in that they rely on essentially the same processes.

Chomsky (1959) hypothesized that language learners construct a theory of grammar from linguistic input using a "built-in," genetically endowed hypothesisforming device, also known as the language faculty or the language acquisition device (LAD). Contrary to then-popular behaviorist ideas (Skinner, 1957), Chomsky argued that language acquisition cannot be solely attributed to learning through stimulus-responsereinforcement mechanisms. First, he pointed out that proficient speakers of a language can produce and comprehend novel, unheard-of sentences. Rather than a learned repertoire of prefabricated responses, as proposed by behaviorists, this creative ability suggests the existence of a special program, or language faculty, that assists humans in generating "an unlimited set of sentences out of a finite list of words" (Pinker, 2007, p. 9).

Second, Chomsky noted the fact that all children, largely independently of intelligence, construct grammar in comparable ways within a remarkably short time and often without explicit reinforcement on the part of their parents (as in the case of young English language learners). Chomsky proposed that these two phenomena could be explained by speakers' individual contributions such as "inborn structure, the genetically determined course of maturation and past experience" (p. 27). Pinker (2007) termed this inborn structure or program language instinct and argued that language was “a biological adaptation to communicative information" (p. 5). Chomskian ideas received a large following among linguists and psychologists; as a consequence, language acquisition came to be understood as a gradual, largely unconscious process of syntactic rules 
deduction and subsequent acquisition. Rules deduction was thought to be triggered by linguistic input and assisted by LAD.

Nativist views on L2 acquisition are exemplified by Krashen's theory of SLA. Krashen $(1985,1987)$ argued that an L2 was acquired, for the most part, unconsciously and in the presence of what he termed comprehensible input (i.e., input that contains linguistic features slightly beyond the learner's current level of proficiency). One of the key hypotheses of the theory, the Acquisition/Learning hypothesis, distinguished between language learning and language acquisition. Language acquisition was said to be an unconscious process of rules extraction equally accessible to children and adults. Language learning, on the other hand, was defined as the conscious learning of rules through formal instruction and error correction.

An additional component of Krashen's theory, the Affective Filter hypothesis, was proposed to account for individual differences in language acquisition. According to this hypothesis, affective factors (e.g., anxiety, motivation, or self-confidence) influence, on subconscious level, how much information L2 learners extract from available input. Krashen (1985) argued that the Affective Filter hypothesis was supported by research documenting faster development in "lower filter" versus "higher filter" L2 learners exposed to the same amount of L2 input. In sum, according to Krashen's SLA theory, people acquire an L2 when two conditions are met: (a) input is made available and comprehensible for language learners, and (b) learner Affective Filter is low to allow the intake of the input.

While Krashen's SLA theory attracted many followers and had a tremendous impact on L2 pedagogy in the 1980s (Spada, 1997), classroom research has provided 
counterevidence to Krashen's hypothesis that speaking would naturally "emerge" in the presence of comprehensible input. Studies have shown that in input-based instructional programs (such as L2 immersion), L2 learners achieved native-like levels in comprehension (reading and oral comprehension), but not in production (writing and speaking; Swain, 2005). Moreover, contrary to Krashen's predictions, explicit instruction was found to benefit language learning. In her review of over 40 descriptive, quasiexperimental, and laboratory studies conducted with school-aged and adult L2 learners, Spada concluded that, when combined with a focus on meaning, form-focused instruction (i.e., instruction that deliberately focuses learners' attention on L2 grammatical features) does make a positive difference in L2 acquisition.

Moreover, many researchers found Krashen's SLA theory to be inadequate when it came to explaining a much greater variability in older L2 learners (Gregg, 1984; Robinson, 1995; Schmidt, 1990). Gregg, for example, argued that older learners relied on their superior cognitive (not language-specific) abilities of logic and problem-solving in order to "construct" L2 grammar rules. Additionally, the fact that only in rare cases did older learners achieve native-like proficiency (Bialystok \& Hakuta, 1999; Hakuta, Bialystok, \& Wiley, 2003; Long, 1990) led some SLA researchers to conclude that L1 and L2 acquisition differed in some fundamental ways. Newport (1990), for example, proposed that older learners' superior cognitive abilities of memory and perception (although associated with acquisition of larger chucks of language) prohibited componential analysis available to young children, thus accounting for the child-adult discrepancies in ultimate L2 attainment. 
Several authors observed that the role of consciousness in L2 learning was considerably greater than suggested by some L1 theories (Robinson, 1995; Schmidt, 1990). O'Malley, Chamot, and Walker (1987), for example, argued that cognitive learning theories, discussed next, may provide a more appropriate framework for understanding and studying processes involved in L2 acquisition.

Language as a cognitive skill. Whereas nativist linguistic theories hold that language is a genetically endowed faculty of the mind, learning theories (Anderson, 1982,1989 ; Skehan, 1998) posit that L2 is a complex cognitive skill whose acquisition is comparable to the learning of other complex skills such as problem solving. That is, linguistic codes are thought to be acquired, stored, and retrieved from memory much in the same way as any other information (O'Malley et al., 1987). Learning is believed to be the result of language processing itself, where linguistic knowledge ("knowledge that") is transformed into linguistic performance ("knowledge how") through rules extraction, learning, and automatization (Long, 2006; Saville-Troike, 2006). Cognitive learning theories thus study how new information, including new L2 information, is processed and stored in memory. One of the cognitive theories that informed SLA research, and in particular LLS research, has been Anderson's Adoptive Control of Thought (ACT) Theory (Chamot, 2005b; O’Malley et al., 1987).

Anderson $(1982,1989)$ distinguished between two types of knowledge (or memory): (a) declarative knowledge, information stored in the form of facts; and (b) procedural knowledge, production rules mentally represented in the form of IF/THEN ${ }^{5}$ (condition-action) pairs. This declarative-procedural knowledge distinction roughly

\footnotetext{
${ }^{5}$ One example of an IF /THEN pair is, "IF the goal is to generate the present tense of HUG, THEN say HUG + s" (Anderson, 1989, p. 325).
} 
corresponds to what Chomsky termed the distinction between linguistic competence (i.e., mentally represented knowledge of grammar) and linguistic performance (i.e., the use of linguistic knowledge in language comprehension and production; as cited in Fromkin, Rodman, \& Hyams, 2007).

According to Anderson's (1989) ACT model of information flow, the interplay between declarative and procedural knowledge, which takes place in working memory, results in the learning of complex cognitive skills. Figure 1 graphically represents the flow of information within the ACT framework.

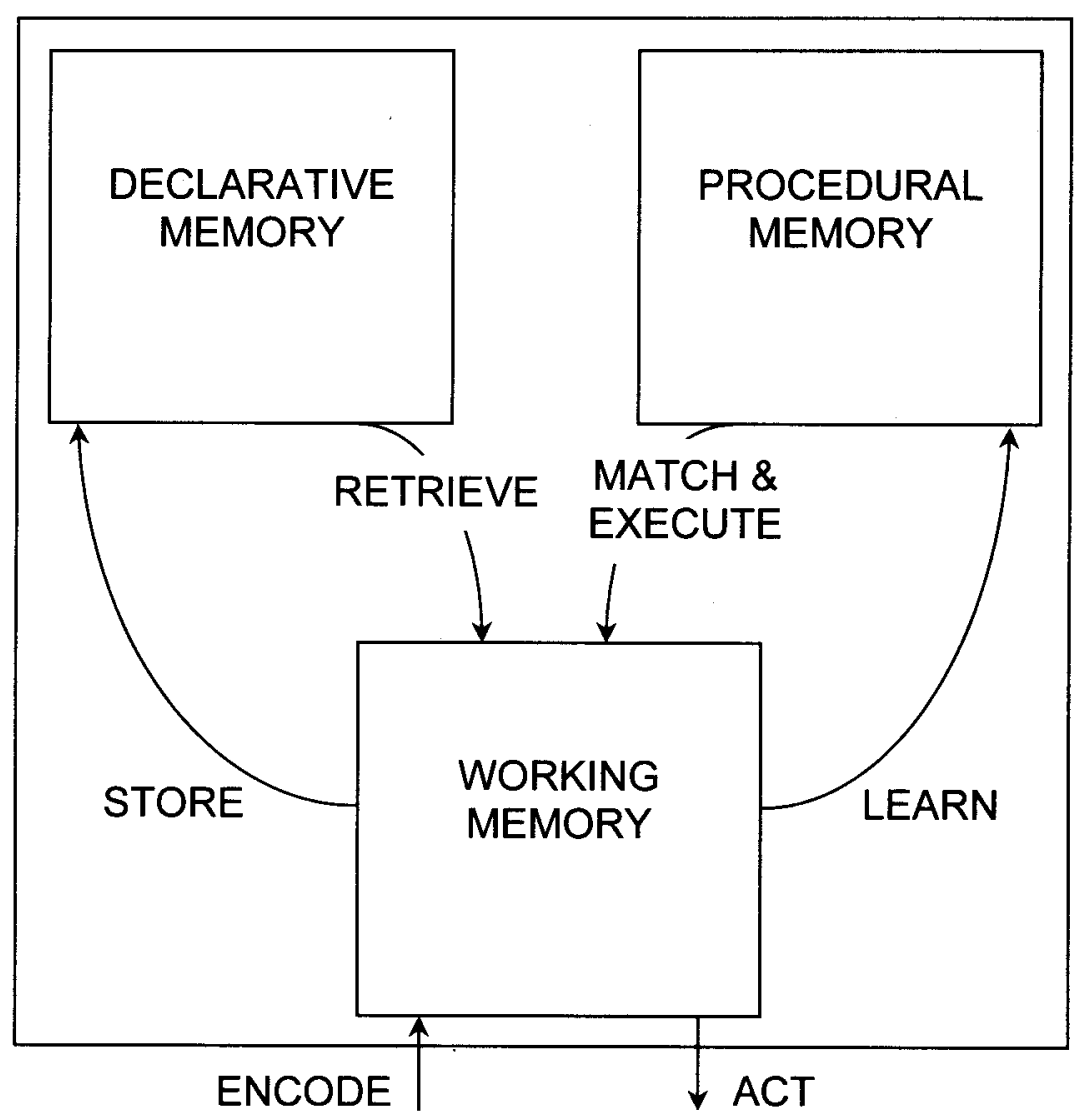

Figure 1.1. The flow of information within the ACT framework (Anderson, 1989, p. 319). 
Anderson (1982) proposed three stages ${ }^{6}$ of the skill acquisition process: (a) declarative, (b) knowledge compilation, and (c) procedural. In the declarative stage of skill acquisition, the learner consciously extracts, or receives through instruction, factual information (e.g., patterns or rules) about a skill. This declarative knowledge is rehearsed and interpreted in short-term memory to generate "primitive rules" (productions) that specify the type of actions to be taken under a given set of circumstances. At this stage, a learner's behavior is guided by a trial-and-error exploration in which the already existing productions (stored in long-term, declarative memory) are applied to new information. This interpretive process is largely conscious and places a rather taxing demand on the learner's processing capacities. O'Malley et al. (1987) argued that in terms of L2 developmental stages, Anderson's declarative stage may explain the silent period-also known as delayed production-a period during which language learners do not engage in L2 conversations. During this time, L2 learners are focused on developing a knowledge base about the new language. When first attempts at communication are made, beginning-level language learners with limited L2 declarative knowledge often recur to their L1 linguistic forms (e.g., vocabulary, grammatical structures, and discourse patterns).

The next stage, knowledge compilation, has been described as a "gradual process by which the knowledge is converted from declarative to procedural form" (Anderson, 1982, p. 370). This is realized by two processes: (a) collapsing simple production rules into single rules with an effect of a sequence (metaproductions); and (b) eliminating references to the declarative knowledge (proceduralization). That is, to perform a task,

\footnotetext{
${ }^{6}$ In some sources, these three stages are referred to as cognition, association, and autonomy (McDonough, 1999).
} 
the learner no longer needs to retrieve declarative knowledge into working memory. This stage results in a considerable speedup of the processing and ultimately allows the learner to complete a task in a single trial without verbal rehearsal in short-term memory. According to O'Malley and colleagues (1987), this stage may correspond to the development of what linguists termed interlanguage (i.e., learner intermediate linguistic system between an L1 and an L2).

In the procedural stage, the learner becomes more efficient through experience (Anderson, 1982, 1989). This process involves the gradual fine-tuning of metaproductions; that is, general rules transferrable to novel situations are extracted and the conditions under which these rules can be applied are specified. During this stage, the amount of practice and, by implication, the ability to generate opportunities for practice are key to successful skills development. This is because every time that factual or procedural information is "fired" (selected) for the performance of a particular task, knowledge is strengthened. In SLA, this stage is described as automatization (i.e., the development of effortless and largely unconscious skill performance; Skehan, 1998). Automatization corresponds to fluency development, in which the performance of a language learner gradually approaches that of a native speaker. O’Malley et al. (1987) argued that while declarative knowledge can be acquired relatively quickly, the development of procedural knowledge requires a prolonged period of time. The authors also noted that declarative knowledge is not a sufficient condition for L2 production.

An alternative explanation of processes involved in language learning was proposed by social theories. These theories "underscore the social nature" of both Ll and 
L2 learning (Gersten \& Hudelson, 2005, p. 23). The next section discusses one such theory, namely Vygotsky's (1978) sociocultural theory.

Language as a socially constructed skill. Unlike cognitive learning theories, social theories consider the quality of contact with new language (i.e., social interactions), and not the amount of L2 experience to be at the core of L2 acquisition (Long, 2006). Children are believed to develop language and, importantly, cognition over time through multiple interactions with more capable others (adults and peers). According to Vygotsky's (1978) sociocultural theory, the nature of social interactions defines the what (the content) and the how (how information is interpreted, organized, and retained) of the child's learning. Learning occurs through the transformation of simple mental activities (e.g., labeling) to higher mental activities (e.g., abstraction) by means of language, mediation, and internalization (Leong \& Bodrova, 1995). Thus, the development of language and cognition are perceived as interdependent processes.

Vygotsky (1978) wrote, "the only 'good learning' is that which is in advance of development" (p. 89). Such "good learning" can only happen with expert assistance and within the Zone of Proximal Development (ZPD), which he defined as follows: "It is the distance between the actual developmental level as determined by independent problem solving and the level of potential development as determined through problem solving under adult guidance or in collaboration with more capable peers" (p. 86).

In early developmental stages, language is external to the learner. First, children use language to solve problems on an interpersonal level (within the ZPD) when they negotiate the task with more capable others (adults or more advanced peers). Children then internalize language to develop inner or intrapersonal speech: "Instead of appealing 
to the adults, children appeal to themselves" (p. 27). Thus language becomes the planning device for organizing one's conceptual understandings with a sociocultural motivation to share with others.

As applied to L2 development, the concept of ZPD may be realized through what SLA researchers term modified input (i.e., the use of short, low syntactic complexity utterances) or modified interaction (i.e., frequent comprehension checks, clarification requests, and self- and other-repetition; Long, 1983, 1987). Modified input and interaction are the means by which language experts provide language learners with ready-to-use chunks of speech, thus enabling L2 learners to express themselves beyond their current means (Saville-Troike, 2006). Among intrapersonal speech types observed in L2 learners, Saville-Troike distinguished: (a) private speech, an audible talk to self, usually present in young children; (b) private writing, writing for oneself (e.g., lists of new words, translations into L1, or notes on the margins of a book); and (c) inner speech, inside-the-head speech. Saville-Troike reported on studies documenting L2 learners using intrapersonal speech to actively build up their L2 competence even when they were not directly engaged in L2 communication.

In sum, from Vygotsky's (1978) sociocultural perspective, learning is realized through interpersonal and intrapersonal social mediation. This model predicts differentiated performance among L2 learners depending on: (a) learners' access to and amount of participation in a learning community; (b) the amount of mediation from experts and peers; and (c) the degree to which learners use that help (Saville-Troike, 
2006). Similarly to Anderson's $(1982,1989)$ theoretical work, Vygotsky's theory has been informative to LLS research. ${ }^{7}$

\section{Summary}

This section reviewed selected SLA theories that informed research on L2 acquisition. The review suggests that $\mathrm{L} 2$ development is a complex endeavor that differs from L1 development in many not-yet-well-understood ways. From the most current theoretical perspectives, L2 development is perceived not as a purely linguistic process, but rather as a process that is linguistic, cognitive, and social in nature. These trends in thinking suggest that both student active involvement in generating L2 learning opportunities and supportive learning environments should result in increased learning by means of an increased amount and quality of L2 experiences. One way that this increased amount and quality of L2 experiences may be supported, is through the use of language learning strategies (discussed later in this chapter); this assumption will be explored in this study. In the next section, the author will define language proficiency and review relevant empirical research illuminating some linguistic factors implicated in ELLs' schooling.

\section{Language Proficiency}

\section{Defining English Proficiency}

English proficiency has been identified as a strong student-level predictor of academic achievement in ELLs (Mahon, 2006; Solórzano, 2008; Suárez-Orozc, SuárezOrozc, \& Todorova, 2008a; Yoko, 2007). However, no universally accepted definition of English proficiency across states (Solórzano, 2008) or across disciplines (Cummins,

\footnotetext{
${ }^{7}$ The ways in which Anderson's $(1982,1989)$ and Vygotsky's (1978) theories have influenced LLS research are discussed in greater detail later in the review.
} 
2008) exists. Solórzano observed that in administrative terms, the two most frequently used criteria, namely, language dominance and low scores on English proficiency tests, are used for classifying a student as limited English proficient (LEP). ${ }^{8}$ In academic terms, two opposing theoretical perspectives suggest conceptualizing language proficiency either as structural proficiency or as functional proficiency. Structural proficiency (also referred to as syntactic proficiency) refers to the mastery of discrete language elements (e.g., sounds, morphemes, and grammar rules). Functional proficiency refers to students' ability to use language appropriately given a particular context of use (e.g., classroomtype vocabulary knowledge and academic understandings). Proficiency tests reflecting the latter English proficiency definition typically include items "tied to academic subject matter (or state standards) rather than testing explicit language skills" (Solórzano, 2008, p. 290).

A more holistic definition of proficiency, which increasingly guides language policies, research, and practice (and, most recently, proficiency test development), is that proposed by Cummins (1981a, 1981b, 1984/2005, 2008). Cummins (1981a, 1981b) distinguished between social language proficiency and academic language proficiency. He defined the former-in his terminology, the Basic Interpersonal Communication Skills (BICS) - as the skills required to engage in and maintain social conversations. Such skills may be observed through "visible language proficiencies of pronunciation, basic vocabulary, and grammar" (1981a, p. 21). Academic language proficiency, or Cognitive Academic Language Proficiency (CALP), refers primarily to literacy related skills reflecting "students' ability to understand and express, in both oral and written

\footnotetext{
${ }^{8}$ Proficiency tests are used to guide decisions regarding ELLs' schooling, namely, to (a) establish appropriate (L1 vs. L2) language of instruction, (b) reclassify from LEP status, and (c) predict success in an all-English classroom.
} 
modes, concepts and ideas that are relevant to success in school" (2008, p. 71). Cummins (1984/2005) further elaborated the BICS/CALP distinction in terms of two dimensions underlying language performance, namely contextual embeddedness and cognitive demand. The author argued that in context-embedded tasks, learners' comprehension and production in L2 are supported by negotiation (e.g., feedback, paraphrase) and contextual cues (e.g., gestures, intonation, pointing). These types of tasks are more typical of everyday interactions. Moreover, everyday interactions are limited in scope; that is, they evolve around a rather limited number of "typical" topics and scenarios (e.g., greetings, exchanging news, making plans). Language learners have an opportunity to use the linguistic features of everyday conversations repeatedly and thus to develop automaticity. Automaticity, by definition, requires little cognitive resources on the part of the speaker. On the other hand, tasks and activities associated with CALP (e.g., providing conceptual definitions, or listening to a lecture) are context-reduced. These tasks rely heavily on language cues and require a firm grasp of the language itself. Moreover, academic tasks are less frequently performed (often only in school), affording the learner with fewer opportunities to develop automaticity. Thus a much greater knowledge of language and a greater level of cognitive involvement are required to ensure adequate performance on academic tasks. Research findings suggest that ELLs may achieve social language proficiency within a period of up to three years of schooling in the United States (Hakuta et al., 2000), and academic language proficiency within a period of up to seven years (Hakuta et al., 2000; Thomas \& Collier, 1997, 2002).

Scarcella (2003) criticized Cummins for conceptualizing second language proficiency in terms of a dichotomy. She argued that the BICS-CALP distinction has led 
many researchers to believe that the development of everyday and academic language proficiencies relies on two very distinct sets of variables. While Scarcella acknowledged that certain variables are more conductive to the development of one proficiency type over the other, she argued that many variables facilitate the acquisition of both. For instance, phonemic awareness is a prerequisite for the development of basic oral proficiency (BICS); at the same time, it facilitates the development of advanced reading (CALP). The National Literacy Panel on Language-Minority Children and Youth (as cited in Rothenberg \& Fisher, 2007) found a high positive correlation between oral English proficiency and reading comprehension skills. The only significant difference between good and poor readers was oral proficiency in English. Similarly, in their review of research on ELLs' academic outcomes conducted since 1980, Genesee and colleagues (2005) reported on several studies documenting a positive relation between oral English proficiency and reading skills.

In Scarcella's (2003) conceptualization of language proficiency, both CALP and BICS are composed of the same three basic components: (a) linguistic, the knowledge of the linguistic code; (b) sociocultural-psychological, culturally encoded practices in language use; and (c) cognitive, processes involved in knowledge creation, including intellectual behaviors such as making predictions or inferences. These three components, in turn, comprise several features. Namely, the linguistic component includes phonology, lexicon, grammar, sociolinguistics, and discourse. The sociocultural-psychological component includes sociocultural values, beliefs, and norms of behavior. The cognitive component comprises conceptual knowledge, higher-order thinking, metalinguistic awareness (i.e., conscious knowledge of language, often evoked to monitor or edit 
production), and strategies (i.e., behaviors called into action to enhance language learning or production).

Scarcella (2003) observed that, while both social and academic English proficiencies rely on the same linguistic, cognitive, and social features, the two registers ${ }^{9}$ differ in two fundamental ways. First, while each proficiency feature has common elements (e.g., both social and academic English employ everyday words and share the same sound systems), some elements are unique to a given register. For example, academic English employs words not frequently found in everyday speech including general academic vocabulary (e.g., "analyze," "compare") and discipline-specific technical words (e.g., "pi," "habitat," "germinate"), all of which have unique stress patterns. Second, depending on the register, some individual features will be more critical for quality performance than others. For instance, while accuracy in pronunciation and adherence to discourse norms (e.g., topic opening and closure) are more important for social interactions (BICS), theses features are less important for performing academic tasks. Features that are critical for quality performance on academic tasks (CALP), on the other hand, include the mastery of grammar and the ability to engage knowledge (both declarative and procedural), higher-order thinking, and metalinguistic abilities. According to Scarcella, vocabulary, sociolinguistics, and strategies features play a nearly equal role for performance in both registers.

Since Cummins' influential conceptualization of language proficiency, many researchers and educators have recognized the challenges inherent in academic language development (Fillmore \& Snow, 2002/2005; Schleppegrell, 2004; Zwiers, 2006, 2007).

\footnotetext{
${ }^{9} \mathrm{~A}$ register is a set of language features associated with a particular context of use (Fromkin, Rodman, \& Hyams, 2007).
} 
This emphasis on academic language, however, in no ways diminishes the importance of oral language (Genesee et al., 2005; Rothenberg \& Fisher, 2007). Scarcella (2003) pointed out that academic English is "advanced" through literacy, which, according to the most recent views, involves both basic language skills and higher-order thinking. The importance of both oral language skills and English literacy skills has been recognized by U.S. federal laws as reflected in the gradual progression of the English proficiency definition. In the original Bilingual Education Act of 1968, the English proficiency definition was limited to speaking ability; reading and writing were added to the definition in the 1978 law Reauthorization (Wright, 2005). The most recent 2001 Reauthorization requires that all states develop English proficiency standards and assessments evaluating ELLs' speaking, listening, reading, writing, and comprehension skills in K-12 settings.

\section{Research on English Language Development}

Among the main foci of English development research, Suárez-Orozc and colleagues (2008) outlined the following: individual student characteristics, family background, L2 exposure (i.e., the amount of L2 in the environment), and instructional variables. A review of research presented in this section includes quantitative studies that primarily focus on student-level variables. The studies are presented in chronological order.

In a secondary data analysis study of 1,210 ELLs (Grades 5, 7, and 9) enrolled in Toronto school systems, Cummins (1981a) examined the rate of approaching English performance grade norms (the rate of English development) as a function of: (a) age on arrival (AOA) and (b) length of residence (LOR) in the host country. Proficiency 
measures included two tests (Picture Vocabulary Test and English Competence Test) normed on native English speakers. Data plots showed a gradual increase in student L2 performance (i.e., students' performance improved with each additional year spent in the country) up to five years of residence, after which the increase in scores "flattened" around the grade norms. While older and younger learners approached the grade norms at comparable rates, older learners showed superior performance. For instance, students who arrived at the age of 14 to 15 acquired more English vocabulary in one year than the 4- to 5-year-old arrivals did in 7 years. Cummins concluded that: (a) ELLs in the sample required at least five years to reach grade-level norms in English proficiency, and (b) both AOA and LOR played a substantial and largely independent role from each other in L2 development.

Hakuta et al. (2000) examined the time it takes ELLs to develop oral proficiency and academic proficiency as a function of LOR (operationalized as time from kindergarten to the current grade level) in a sample from two California districts, ${ }^{10}$ referred to as District A and District B. Academic proficiency was measured by tests normed on native English speakers (the Idea Proficiency Test and the Woodcock Language Proficiency Battery). In District A, the sample included 1,872 students in Grades 1-6, the majority of whom were of Vietnamese and Spanish linguistic backgrounds. The sample in District B included 122 Spanish-background students randomly selected in Grades 1, 3, and 5. Results indicated a steady increase in English proficiency by each additional grade. Across districts, students required more time to acquire academic proficiency ( 4 to 7 years) than they did to acquire oral proficiency ( 2 to

\footnotetext{
${ }^{10}$ The authors also studied student data from two districts in Canada; these findings are not reviewed here.
} 
5 years). ${ }^{11}$ The researchers further disaggregated District A data by school poverty level $(10 \%, 25 \%, 50 \%$, and $70 \%$ free lunch) and found that students in the $70 \%$ poverty category lagged behind the other three groups on measures of proficiency and redesignation (i.e., redesignation to "fluent English proficient" status). Students from high-poverty schools were estimated to be one year behind in English acquisition compared to students from more economically advantaged schools. In District B, researchers compared students' time to proficiency by parents' self-reported educational level (i.e., less than high school, some high school, high school diploma, and beyond high school). By fifth grade, students whose parents had education beyond the high school level outperformed students in all other categories on all measures. The authors concluded that SES measures, both at the student and school level, appeared to influence the rate of English language development.

In her dissertation research, Páez (2002) examined predictors of English proficiency in a sample of 209 middle school ELLs (73 Chinese, 69 Dominican, and 67 Haitian) enrolled in four Boston-area school districts. The mean age of the students was 13. Data for the study came from the third year of the Longitudinal Immigrant Student Adaptation Study (LISA), a study of patterns of cultural adaptation among new immigrants. The Bilingual Verbal Abilities Test (BVAT), administered in an oral interview format, served as a measure of English proficiency. The seven examined predictor variables were operationalized as child background variables (age and time in the United States), group variables (country of origin), family background variables (parental education and self-reported English skills), and language variables (English

\footnotetext{
${ }^{11}$ The authors cautioned that these results may be an underestimation because mobile students and recent immigrants, two of the most vulnerable populations, were not included in the sample.
} 
exposure and use in formal and informal contexts and self-reported L1 skills). The final fitted multiple regression model explained about $52 \%$ of the variance in English language proficiency. Students' L1 skills did not enter the final model. Parental education, LOR, and English exposure and use were the strongest predictors of English proficiency. Parental English skills and age did not maintain significance in the final model.

MacSwan and Pray (2005) examined rates of English language development in a group of 89 elementary and middle grades Spanish-background students enrolled in highpoverty urban schools in Central Arizona. The rate of English language acquisition was operationalized as time between the student's scoring 1, No English, and 5 or 6 , Proficient English, on the Bilingual Syntax Measure (BSM). While MacSwan and Pray did not distinguish between BICS and CALP and defined language proficiency as "a singular construct, purely linguistic in nature" (p. 658), the BSM's characteristics suggest that the measure primarily evaluates BICS skills. More specifically, the instrument is administered in an oral interview format and measures student knowledge of grammar and conversational appropriateness. Data analyses indicated that, on average, it took students 3.31 years $(S D=1.31)$ to score in the Proficient English range. The rate of acquisition ranged from $.92(n=1)$ to 6.5 years $(n=1)$. An ANOVA test indicted that there was a significant difference in the rate of English acquisition by grade of first enrollment $(p<.001)$. An examination of the group means indicated that students first enrolled in Kindergarten needed more time to achieve proficiency than students first enrolled in Grades 1, 2, or 3. Grade level accounted for about $27 \%$ of the variance in English proficiency. The authors concluded that there were significant individual 
differences in the rate of English acquisition in the study's sample and that younger students needed more time to achieve proficiency.

Carhill, Suárez-Orozco, and Páez ${ }^{12}$ (2008) examined student, context, and school quality factors contributing to the development of English proficiency in a sample of 274 (mean age of about 16) students from Chinese, Central American, Dominican, Haitian and Mexican backgrounds. All ELLs in the sample had been in the United States for an average of seven years and were schooled in eight different school districts in the Boston and San Francisco metropolitan areas. The authors selected eight predictors of English proficiency, grouped them into four sets representing a continuum ranging from the most "proximal" (Individual and Home) to the most "distal" (Social Context and School) factors, and entered the sets into a model predicting English proficiency in four steps: (1) age and LOR (operationalized as time in the United States); (2) maternal education and parental self-reported English skills; (3) patterns of English use in informal settings and in school; and (4) ELA proficiency rate (the percent of students who reached proficiency on the state exam in English Language Arts) and school poverty rate (the percentage of low-income students). School poverty rate did not maintain significance in the final model. The results of regression analyses revealed that the 7-predictor model explained the most variance in student data $\left(R^{2}=.45\right)$. (This result represents a substantial improvement over 2-, 4- , and 6-predictor models that explained $14 \%, 26 \%$, and $33 \%$ of the variance in English proficiency, respectively.) ELA proficiency rate, one of the two school quality indicators examined, explained an additional $12 \%$ of the variance in students' performance. In fact, the ELA proficiency rate was the strongest predictor of

\footnotetext{
${ }^{12}$ The researchers analyzed data from the $5^{\text {th }}$ year of the LISA study (for more details see Páez's 2002 study reviewed earlier).
} 
English proficiency $(\beta=.38, p<.001)$, followed by time in the United States $(\beta=.20, p$ $<.001)$, English use in informal settings $(\beta=.19, p<.001)$, and age ${ }^{13}(\beta=-.17, p<$ .001). Additionally, the researchers found that after seven years of residence in the United States, only $7.4 \%$ of the sample $(N=19)$ reached proficiency as measured by the BVAT. ANOVA, followed by post hoc analysis, revealed that Chinese students had a significantly higher level of English proficiency when compared to other country of origin groups. Further analyses of school quality indicators revealed that Chinese students tended to attend schools with higher SES and achievement characteristics. Chinese families in the sample also tended to have higher levels of education. Given the study's findings, the authors recommended using larger samples and Hierarchical Linear Modeling techniques to improve the estimation of school quality variables' effects on English proficiency development.

\section{Summary}

This section reviewed studies examining student- and school-level predictors of English language development. Much evidence suggests that L2 development increases with each additional year of residence in the country of immigration (Carhill et al. , 2008; Cummins, 1981a; Hakuta et al., 2000; Páez, 2002), and that older school-aged learners acquire L2 literacy skills at a higher rate than younger learners (Cummins, 1981a; MacSwan \& Pray, 2005). The evidence is less clear regarding the acquisition of oral language skills, and there is evidence to suggest that younger students may ultimately

\footnotetext{
${ }^{13}$ The latter finding indicates that older students were less proficient and appears to contradict an earlier study's (Cummins, 1981a) results. In fact, this finding supports Cummins' claim that younger learners ultimately (i.e., over time) show superior results. Carhill et al.'s (2008) study may be considered a case in support of this claim given that all ELLs in their sample have been in the United States for about seven years.
} 
achieve higher L2 proficiency (Carhillet al., 2008; Cummins, 1981a). Additionally, students from low SES backgrounds were found to acquire English proficiency at a slower rate than more advantaged children (Hakuta et al., 2000). Parental educational level appeared to have a positive influence on L2 development (Carhillet al., 2008, Hakuta et al., 2000; Páez, 2002). At the school level, attending schools with higher SES and achievement profiles appeared to have a positive impact on student L2 development (Carhill et al., 2008; Hakuta et al., 2000). In this study, the predictors of English language development identified by the literature review will be incorporated into statistical modeling analyses as covariates in order to better ascertain the relative contributions of language learning strategies - a variable of particular interest to this study (see below) to student English language, as well as academic outcomes. In the next section, the author will summarize the language learning strategy research base.

\section{Language Learning Strategies}

\section{Theoretical Considerations}

Overview, assumptions, and connections. Language learning strategy research is a line of inquiry within the broader field of SLA. Interest in studying learner_strategies is driven by a trend characteristic of educational psychology in general and of SLA research in particular. In educational psychology, there is an increased interest in studying learning processes and the acquisition of higher-order cognitive skills (Anderson, 1993). In SLA, this trend reflects a shift in focus from studying what is learned when a new language is acquired (the product or outcome of learning) to studying how a new language is learned (the process of learning; Griffiths, 2007; Oxford, 1990). Process-oriented research has led researchers to study learner characteristics including 
language learning strategies (LLS; Dreyer \& Oxford, 1996). Examples of language learning strategies for reading include using a dictionary, paraphrasing, and note-taking. Another example for speaking is rehearsal.

Inquiry into LLS seems to be of particular relevance to research on the academic achievement of ELLs. First, two main assumptions of LLS research, largely supported by research in language classrooms, are that strategies (a) facilitate language learning, and (b) can be taught. There is evidence that higher strategy use is associated with higher L2 proficiency (Oxford, 1999). In turn, "with development and increased proficiency in English, ELLs are better able to engage in more academic uses of language" (Genesee et al., 2005, p. 369). Additionally, LLS researchers claim that strategies can be transferred across learning tasks and contents. Chamot and O’Malley (1994) pointed out that strategy instruction has been successfully applied to L1 tasks including reading (Paris, Cross, \& Lipson, 1984), retention of verbal material (Ausubel, 1960), vocabulary, mathematics, science, and problem-solving (Pressley, Woloshyn, \& Associates, 2000). Second, several instructional models that combine academic content, language, and strategy instruction have been developed and applied around the globe (Kidd \& Marquardson, 1996). One such model developed in the United States is Chamot and O'Malley's (1994) Cognitive Academic Language Learning Approach (CALLA). While limited, there is evidence that speaks to the effectiveness of CALLA in enhancing ELLs' academic outcomes (Chamot, Dale, O'Malley, \& Spanos, 1992).

Defining language learning strategies. Learner strategy researchers have adopted the definition of learning from psychology, where learning is commonly defined 
as the process of storing and retrieving information (Rubin, 1981). Strategies ${ }^{14}$ have been described as techniques or devices used by learners to gain knowledge (Rubin, 1975), or as conscious actions or steps toward achieving a given objective (Cohen, Weaver, \& Li, 1996; Oxford, 1990). Oxford described learning strategies ${ }^{15}$ as "specific actions taken by the learner to make learning easier, faster, more enjoyable, more self-directed, more effective, and more transferable to new situations" (p. 8).

In SLA literature, there are some discrepancies and conflicting views in defining the term language learning strategies (Cohen, 1998; Dörnyei, 2003; Macaro, 2006). LLS may be referred to as tactics, techniques, study skills, or learning behaviors. These terms often overlap with, and in some instances incorporate, related terms such as communication strategies (strategies employed to facilitate language use) and learning styles (culturally encoded ways of learning and knowing; Griffiths, 2007). Oxford (1990) viewed LLS as learner activities directed specifically at improving linguistic competence in the newly acquired language. Other researchers argued that LLS may simply be a subset of general learning strategies that are particularly beneficial for language development (O’Malley et al., 1985b). In defining LLS, several authors emphasized the role of consciousness (Cohen, 1998; Cohen, Weaver, \& Li, 1996; Macaro, 2006). Cohen argued that "the element of consciousness is what distinguishes strategies from those processes that are not strategic" (p. 4). He noted that language learners, especially older learners, may have a keen awareness of what language features should be learned. In a similar vein, Genesee et al. (2005) observed that the use of LLS is characteristic of

\footnotetext{
${ }^{14} \mathrm{~A}$ recent trend in educational psychology is to include the discussion of learning strategies under the umbrella of self-regulatory learning (Dörnyei, 2003).

${ }^{15}$ An important distinction should be made between learning and teaching strategies. The former are controlled by the student, and the latter are controlled by the teacher (O'Malley et al., 1985a).
} 
second language development because $\mathrm{L} 2$ learners typically begin to learn a new language at a more mature age and thus can draw on conscious, explicit strategies to enhance their learning.

The present study adopts the most commonly used LLS definition as formulated in Griffiths (2007). She defined LLS as "specific actions consciously employed by the learner for the purpose of learning language" (p. 91).

Categorizing language learning strategies. Strategies have generally been described as "metacognitive (to do with awareness of the learning), cognitive (to do with the behaviors and mental processes of the learning) and socioaffective (to do with personality traits and interactions with others)" (Hassan et al., 2005, p. 1). However, discrepancies remain in defining some specific strategies and strategy categories, and there is certain overlap between categories (Griffiths, 2007; O'Malley et al., 1985a).

Cohen (1998) and Cohen et al. (1996) distinguished between language learning and language use strategies. The authors defined the former as behaviors aimed at facilitating language learning (e.g., grouping vocabulary by topics, applying rules to new contexts, seeking feedback) and the latter as behaviors that facilitate communication in a new language (e.g., rehearsal, circumlocution). Cohen (1998) proposed that both language learning and language use strategies can be further differentiated as being cognitive, metacognitive, social, or affective- the domain categorization schema devised by O'Malley and colleagues (1985b).

Unlike Cohen and colleagues, Rubin (1981) and Oxford (1990) did not distinguish between language learning and language use strategies. ${ }^{16}$ Instead, the authors

\footnotetext{
${ }^{16}$ In fact, Oxford (1999) noted that each instance of language use stimulates language learning, and, at the same time, language learning is preparation for language use.
} 
categorized strategies as being direct and indirect. Oxford (1990) defined direct strategies as those requiring mental processing of linguistic information and indirect strategies are those "that support and manage language learning without (in many instances) directly involving the target language" (p. 135). In a similar vein, Rubin noted that direct strategies contribute directly to learning while indirect strategies permit learning.

Among direct strategies, Oxford (1990) distinguished memory, cognitive, and compensation strategies. Memory strategies (e.g., grouping, using context) help the learner to (a) store and retrieve information, (b) cope with a large L2 vocabulary, and (c) move from factual (knowledge) to procedural (skill) levels through automatization. Cognitive strategies (e.g., practicing, skimming, note-taking) involve "manipulation or transformation" of the new linguistic material. One of the major functions of cognitive strategies is to aid comprehension and production. Compensation strategies (e.g., guessing, asking for help, using gestures) allow students to use language despite gaps in knowledge, thus allowing for more practice.

Among indirect strategies, Oxford (1990) distinguished metacognitive, affective and social strategies. Metacognitive strategies (e.g., focusing attention, planning for learning, evaluation) allow learners to control their cognition. Affective strategies (e.g., lowering anxiety, self-encouragement, "taking emotional temperature") assist in regulating emotions, attitudes, and motivation. Last, social strategies (e.g., asking questions, cooperation) assist interaction. A recent confirmatory factor analysis established that Oxford's six-factor taxonomy provided the most consistent account for student data when compared to other current theoretical models of strategy use (Hsiao \& Oxford, 2002). 
Theoretical underpinnings: LLS and autonomous learning. Inquiry into LLS

has been primarily driven by practical considerations, namely by the desire to learn what makes some L2 learners more successful and to teach what has been learned to less successful students. Although currently no single, commonly accepted theoretical framework concerning LLS exists ${ }^{17}$ (Macaro, 2006; Rivera-Mills \& Plonsky, 2007; Skehan, 1998), two theories, Anderson's Adoptive Control of Thought theory and Vygotsky' sociocultural theory of learning, ${ }^{18}$ have been particularly informative in guiding LLS research and illuminating findings (Chamot, 2005b; Chamot \& O’Malley, 1994; Macaro, 2006; O’Malley et al., 1987).

O'Malley and colleagues (1985a), for example, argued that if learning is generated through cognitive processing (Anderson, 1982, 1989), then "strategies that promote the greatest amount of mental activity should result in the most learning" (p. 24). McDonough (1999) noted that LLS researchers commonly perceived strategies as "learning-to-learn activities." Based on Anderson's theorized stages of skill acquisition (i.e., cognition, association, and autonomy), the researcher claimed that strategies promoted autonomous, self-regulated learning. Macaro (2006) went even further by arguing that strategies didn’t simply make learning more independent and efficient, but were "the raw material without which L2 learning cannot take place" (p. 332).

Similarly to McDonough, Oxford (1999) argued that LLS were key to the learner's autonomous learning (which she defined as the ability and willingness to take responsibility for one's own learning). According to Oxford, strategies are learnerinitiated actions directed at improving learning; thus, by definition, strategies "reflect the

\footnotetext{
${ }^{17}$ Several authors are currently working on enhancing the field's theoretical rigor (Macaro, 2006).

${ }^{18}$ These theories have been discussed in greater detail in the previous sections of the review.
} 
learners' degree of autonomy and are mechanisms by which the learner develops still greater autonomy" (p. 111).

Though recognizing learner autonomy as an individual quality, Oxford also stressed the importance of social factors in developing student self-regulated learning behaviors. Drawing on Vygotsky's (1978) ideas, Oxford observed that strategies were internalized via social interaction. Thus, she argued, the development of an independent, problem-solving learner also relied on the help of more capable others, including peers and teachers. In a similar vein, McDonough (1999) observed that while some language learners deployed LLS spontaneously, others needed instruction in order to operate the strategies independently.

Defining strategy instruction. In the literature, strategy instruction (also referred to as strategy training or strategies-based instruction) has been defined as "any intervention which focuses on the strategies to be regularly adopted and used by language learners to develop their proficiency, to improve particular task performance, or both" (Hassan et al., 2005, p. 1). Alternatively, Cohen et al. (1996) defined strategy instruction as a learner-centered approach to language classroom with two main components: (a) explicit teaching of the why, when, and how of strategy use in relation to language learning and use tasks (i.e., strategy training that includes strategy description, modeling, and practice, as well as elicitation of additional strategies from students) and (b) integration of strategies into class materials and language tasks (i.e., the teacher analyzes established curricula for potential strategy use and/or uses spontaneous "teachable" moments to reinforce strategy use). The goal of strategy instruction is to increase 
learners' awareness of the most effective methods of language learning and to help students improve their $\mathrm{L} 2$ comprehension and production skills.

LLS: Methods and data sources. Research on LLS has employed a large array of qualitative and quantitative methods of data collection to examine language learner behavior. These methods include observations, interviews, think-aloud protocols (i.e., learners are asked to verbalize their thoughts during an L2 task completion), written diaries (i.e., records of reflections on daily language learning activities), questionnaires, and, most recently, computer tracking (Chamot, 2005a; Cohen, 1998; Cohen \& Scott, 1996; McDonough, 1999). The latter method allows researchers to study the use of strategies supplied by the computer (e.g., dictionaries, style and spell checkers, and grammar tutorials). As most strategies are mentalistic (i.e., taking place within the learner's head), they may not be directly observable (Cohen \& Scott, 1996; Oxford, 1990). For instance, selective attention may be difficult to observe compared to notetaking. Observations have been reported to have little productivity (i.e., yielding meager results), especially when compared to other methods of data collection (O'Malley et al., 1985a, 1985b; Rubin, 1981). Thus the methods employed by researchers studying learner strategies are primarily self-report, which allows the researchers to access unobservable, cognitive processes that take place within the learner (Chamot, 2005a; Cohen \& Scott, 1996). Currently, the most frequently used instrument in LLS research is Oxford's (1990) Strategy Inventory for Language Learning (SILL). The SILL measures frequency of strategy use and is based on Oxford's taxonomy of LLS discussed earlier in this chapter. 


\section{Early Descriptive Research: “The Good Learner”}

Research on language learning strategies was pioneered in the 1980 s by Stern and Rubin (McDonough, 1999). Rubin (1975) argued that observing "good language learners" (i.e., those identified as effective in acquiring a new language) and studying processes that help them become successful may inform theories of language processing. This information, in turn, could be taught to less successful language learners.

In describing cognitive processes employed by "good learners" studied in California and Hawaii, Rubin (1975) noted that these learners were adept at: (a) using different types of clues to guess intelligently; (b) using linguistic (e.g., paraphrase, circumlocution) and nonlinguistic (e.g., gestures) means to successfully convey meaning in the new language; (c) dealing with ambiguities and anxiety (i.e., willingness to appear "foolish" and to learn from mistakes); (d) attending to form (i.e., grammatical patterns) through analysis, synthesis, and categorization; (e) seeking out opportunities for practice; (f) attending to message correctness; and (g) monitoring contextual appropriateness of the message.

Other researchers have expanded on Stern and Rubin's pioneering work by identifying and describing additional types of social and cognitive strategies and by examining the developmental aspects of strategy use (Chesterfield \& Chesterfield, 1985; O’Malley et al., 1985a, 1985b; Rubin, 1981). The 30 years of descriptive research on "good learners" was succinctly summarized by Chamot (2005a). The following were identified among strategies characteristic of effective learners: alertness, conscious monitoring of comprehension and production, engaging in communication, using prior 
linguistic and general knowledge, using memorization strategies, asking for clarifications, and selecting strategies appropriate for tasks at hand.

One of the main contributions of the early descriptive research has been the identification and description of strategies employed by learners to both learn and communicate in the target language. These findings allowed for the development of strategy categorization taxonomies (reviewed previously in this chapter) and research instruments that in turn informed further LLS research and were used in the development of curricula and teacher preparation programs.

\section{LLS and Language Proficiency}

Despite some inconsistencies (Nisbet, Tindall, \& Arroyo, 2005; Takeuchi, 1993) and evidence to the contrary (Gardner et al., 1997), a positive relationship between LLS use and language proficiency has been documented in a number of studies, both in second and foreign language contexts (Dreyer \& Oxford, 1996; Lan \& Oxford, 2003; Peacock \& Ho, 2003; see also Cohen \& Macaro, 2007; Oxford, 1999). These studies measured language proficiency in several ways: (a) general language proficiency tests, (b) oral language proficiency tests, (c) language course grades, and (d) self-rated proficiency (Oxford \& Burry-Stock, 1995). Although much research reported a linear relationship between LLS and proficiency (i.e., higher strategy use was associated with higher proficiency; Oxford, 1999), there have been some exceptions: Two studies found a curvilinear pattern, with intermediate proficiency students deploying strategies more frequently than lower and higher proficiency students (Phillips, 1992; Hong-Nam \& Leavell, 2006). 
Oxford (1999) summarized 12 studies examining the relationship between LLS use (as measured by Strategy Inventory for Language Learning [SILL]; see methods section) and L2 proficiency conducted in foreign $(N=8)$ and second $(N=4)$ language learning contexts. Four studies used multiple regression analysis; eight studies used correlational analysis and/or analysis of variance. The amount of variance in L2 proficiency accounted for by LLS use ranged from $21 \%$ (a study of 904 Taiwanese students learning English in middle schools, high schools, and a university) to $58 \%$ (a study of 78 first-year English learners in a Japanese women's college). The correlations between LLS and L2 proficiency measures ranged from a moderate correlation with compensation strategy category $(r=.21$; a study of 332 EFL university students in Korea with L2 proficiency measured by Test of English as a Foreign Language ${ }^{19}$ [TOEFL]) to high correlations with cognitive and metacognitive strategy category $(r=.40$ and $r=.36$, respectively; a study of 73 high school English learners in Turkey with L2 proficiency measured by end-of-the-year grades) and with the total SILL score ( $r=.73$; a study of ESL learners in South Africa). Oxford concluded that "language learning strategies do indeed make a significant difference in language proficiency" (p. 117).

Dreyer and Oxford (1996) examined predictors of L2 proficiency (as measured by TOEFL) in a sample of 305 Afrikaans learners of English taking a college-level ESL course in South Africa. ${ }^{20}$ The predictors included learning style, personality type, and strategy use. The results of stepwise regression analysis indicated that strategy use accounted for the largest proportion of variation in the TOEFL score (about 45\%). Personality type accounted for one additional percent of the variance. Additionally,

\footnotetext{
${ }^{19}$ TOEFL is used as a measure of English proficiency both in second language and foreign language contexts (Oxford, 1999).

${ }^{20}$ In South Africa, English is one of 11 languages that have official language status.
} 
overall strategy use and proficiency were positively, highly correlated. The strongest correlations were between metacognitive strategies and three TOEFL sections: readingvocabulary $(r=.64, p<.001)$, listening $(r=.55, p<.001)$, and structures $(r=.54, p<$ $.001)$. Independent sample $t$ tests demonstrated that students with higher proficiency used strategies more frequently.

Similar, Lan and Oxford (2003) found a linear relationship between overall strategy use and English proficiency (measured by language placement test scores) in a sample of 379 sixth-grade students in a public school in Taiwan. ANOVA results followed by post hoc analyses indicated that high-proficiency students used significantly more strategies than did medium- and low-proficiency students; medium-proficiency students outperformed low-proficiency students. Regarding individual strategy categories, MANOVA results indicated that high-proficiency students had significantly higher strategy use in four LLS categories (metacognitive, cognitive, compensation, and affective); however, there were no differences in strategy use between medium- and lowproficiency students.

Unlike previous studies, Hong-Nam and Leavell (2006) found a curvilinear relationship between overall strategy use and $\mathrm{L} 2$ proficiency (measured by placement test scores as well as by self-ratings) in a group of 55 students enrolled in a pre-admissions ESL program at a U.S. university. The researchers found that "students at the intermediate level reported using more overall strategies than beginners or advanced language learners" (p. 410). The researchers hypothesized that this rather unexpected finding could be attributed to the proficient students' ability to use strategies automatically; that is, without conscious awareness. (Overall, beginning and intermediate 
students in the study reported using metacognitive strategies most often; advanced students preferred social strategies.) Similar results were reported by Phillips (1992). The researcher examined the relationships between frequency of LLS use and English proficiency among 141 Asian international students (mean age of about 23) enrolled in intensive English programs ${ }^{21}$ in seven public and private western U.S. universities. Proficiency was operationalized as TOEFL performance. In an ANOVA analysis, the researcher found that medium-proficiency students reported significantly higher strategy use (operationalized as the mean number of most frequently used strategies) than did low- and high-proficiency students.

Peacock and Ho's (2003) study of 1,006 EFL learners in Hong Kong found that among 50 strategies listed in SILL, 27 had a significant positive association with proficiency as measured by a battery of tests in speaking, listening, reading, writing, grammar, and work and study skills in English (59\% of these strategies were cognitive and metacognitive). In a study of 78 learners of English enrolled in a woman's college in Japan, Takeuchi (1993) found that LLS explained a substantial percent in student L2 test scores (60\% in listening, $34 \%$ in structure, $35 \%$ in vocabulary, and $58 \%$ in total score). Notably, the examination of individual LLS indicated that strategy contributions varied by the outcome measure; whereas several individual cognitive and metacognitive strategies contributed the most to listening, structure, and total scores, a memory strategy - followed by a metacognitive strategy — contributed the most to vocabulary score. Less optimistically, several individual strategies—across all but cognitive strategy category-were negative predictors of L2 outcomes.

\footnotetext{
${ }^{21}$ Intensive English programs typically provide about five hours of daily language instruction.
} 
In a study of 168 Chinese university, English major students with advanced levels of L2 proficiency and a minimum of seven years of EFL instruction, Nisbet et al., (2005) found that metacognitive strategies-reported by the students as being the most frequently used - significantly correlated with TOEFL scores $(r=.17, p<.05)$; correlations with other strategy categories, however, were not significant. Further, multiple regression revealed that SILL strategies accounted for only a small percent (4\%) of the variance in English proficiency scores. Among possible explanations for their low correlations between LLS and L2 outcomes the authors listed: (a) inappropriate or unorchestrated use of strategies by the students; (b) the use of idiosyncratic — not listed in the SILL - strategies; and (c) the influence of intervening factors (e.g., intelligence, motivation, anxiety, or sociocultural influences).

In contrast to previous studies, Gardner et al. (1997) found -using Structural Equation Modeling (SEM) techniques-that overall strategy use was a negative predictor of L2 outcomes in a sample of 102 Canadian university French-as-a-second language learners. The authors proposed two plausible explanations for their unexpected finding. First, the authors argued, students may have adopted their own LLS, not listed on the SILL. Second, the negative relationship between LLS and L2 performance may have been due to levels of L2 proficiency; that is, whereas less proficient students may still have used a substantial number of LLS to advance their learning, more advanced students - all participants in the sample had at least nine years of L2 instruction-may no longer have felt a need to use strategies. Less than optimal sample size ${ }^{22}$ and model fit indices $(\mathrm{AGFI}=.70, \Delta 2=.85, \mathrm{NNFI}=.83$ ), however, suggested that the results of this study should be interpreted with caution. Interestingly, the results of preliminary,

${ }^{22}$ In case of SEM analyses, small sample size may produce biased results (Byrne, 2001). 
exploratory factor analyses indicated that measures of language learning motivation had substantial loadings on the LLS factor suggesting that these two latent constructs' may be "not mutually exclusive" (p. 335).

\section{Variations in Strategy Choice, Use, and Evaluation}

Investigators working under the umbrella of LLS research have discovered that several variables directly related to "the choice, use, or evaluation" of language learning strategies (Oxford \& Leaver, 1996, p. 227). Among these variables, researchers identified proficiency level, age, gender, culture, instructional context, and motivation. (Research on LLS and motivation will be reviewed later in Chapter 2).

Proficiency level. Using a focused observation technique, Chesterfield and Chesterfield (1985) examined patterns of strategy use over time in 14 Mexican-American students enrolled in bilingual education programs. Based on standardized English proficiency test results, the researchers grouped ELLs into three subgroups: English only, minimal oral English proficiency, and more than minimal oral English proficiency. The students were observed four times at the beginning and end of kindergarten and first grade. During each observation period, which lasted for the equivalent of one school day for each student, the researchers tallied the use of 12 observable strategies. The researchers found that students developed strategies following the same overall sequencing pattern. That is, students with minimal English proficiency mainly employed memorization and repetition strategies. Children at higher proficiency levels added "formulaic expressions" and "attention getters" to their repertoire. The researchers concluded that increasing proficiency seemed to imply the ability to use more sophisticated strategies progressing from receptive strategies to more interactive 
strategies. (Monitoring strategies were developed last and only by a few students by the study's conclusion.) Interestingly, more socially active students in the sample appeared to progress in their strategy development at a faster rate.

In a similar vein, Phillips (1992), in an item-by-item analysis on individual SILL strategies used by 141 international students in university-level English programs, found that the lower proficiency group used significantly more strategies within the memory and affective categories, while the higher group used significantly more strategies within the cognitive and compensation categories. The two groups also seemed to prefer different strategies within the metacognitive category. In particular, one practice strategy was significantly more used by the lower group, while one goal-setting strategy was significantly more used by the higher group.

Similarly, Kaylani (1996) demonstrated different patterns of strategy use by proficiency. In this study of 80 high school learners in Jordan, proficiency was operationalized as the $11^{\text {th }}$-grade final score in English. The students in the sample were selected from eight intact classrooms. The top 5 students from each class were labeled as successful learners, the bottom 5 as unsuccessful learners. The results of MANOVA indicated that the successful learners used memory, cognitive, and metacognitive strategies more frequently than did unsuccessful students. No significant differences were found in the use of compensation, affective, and social strategies by proficiency. By contrast, Hong-Nam and Leavell (2006) found that advanced students used more social strategies, while beginning and intermediate students reported using metacognitive strategies more often. 
Age. In a study of $480 \mathrm{ESL}^{23}$ students enrolled in primary $(N=168)$, secondary $(N=175)$, and tertiary $(N=137)$ public educational institutions in Botswana, Magogwe and Oliver (2007) found that students in different age groups preferred different strategies. Whereas primary students preferred social strategies $(M=3.21, S D=.50)$, secondary- and tertiary-level (i.e., higher education) students preferred metacognitive strategies $(M=3.22, S D=.40$ and $M=3.26, S D=.35$, respectively). The authors further investigated the relationship between language proficiency (rated by teachers or lecturers based on students' grades) and strategy use for each age group. A set of one-way ANOVAs followed by post hoc analysis revealed that: (a) in primary school, higher proficiency students used significantly more strategies than intermediate and lower proficiency levels, (b) in secondary school, intermediate proficiency students used significantly more strategies than lower proficiency levels, and (c) no significant differences were found in tertiary institution students. Across the three groups, the highest overall strategy use was reported by higher proficiency elementary students; the lowest by lower proficiency secondary students. The authors called for further examination of relationships among age, proficiency level, and strategy use.

Unlike in the previous study, Peacock and Ho (2003) found that older students in their sample of 1,006 English for Academic Purposes students enrolled in 55 Hong Kong universities used more strategies than younger students. It is worthwhile to note that their sample did not include secondary-level students. The results of a MANOVA indicated that older students ( 23 and over) used significantly more strategies in four categories:

\footnotetext{
23 "In Botswana, English is an official language used in education and commerce and Setswana is the national language spoken by $85 \%$ of the Batswana (the people of Botswana)" (Magogwe \& Oliver, 2007, p. $343)$.
} 
memory, metacognitive, affective, and social. Interviews with low strategy use students indicated low motivation in learning a foreign language.

Gender. Several authors found that females tended to use more strategies (particularly social strategies) than males (Hong-Nam \& Leavell, 2006; Kaylani, 1996; Dreyer \& Oxford, 1996). In the Peacock and Ho (2003) study, for example, females reported significantly higher strategy use than males in all six SILL categories. Kaylani (1996), however, found that difference in strategy use by gender was less important than that associated with proficiency. While gender explained $15 \%$ of the variance in strategy use profile, proficiency (operationalized as the end-of-the-year grade in English) accounted for $30 \%$ of the variance in a sample of 80 high school English learners in Jordan.

Culture. Another interesting finding resulting from LLS research indicates that different cultural background groups tend to use different strategies. In comparing strategy use among four groups of students from Japan, China, Korea, and Other (i.e., students from Brazil, Germany, Indonesia, Malaysia, Thailand, and Togo), Hong-Nam and Leavell (2006) found that Japanese students used significantly more metacognitive strategies than Other students. While this difference was the only statistically significant finding, mean differences indicated some additional preferences by nationality. Namely, while Japanese, Korean, and Other students preferred metacognitive strategies, Chinese students favored social strategies.

Similarly, in his experimental study of strategy training impact, O'Malley (1987) observed cross-cultural differences between Hispanic and Asian students (predominantly from Southeast Asia). The author found that even as Hispanic students in the sample 
adopted novel vocabulary strategies (i.e., grouping, imagery, and self-evaluation), Asian students persisted in using "more customary" rote memorization strategies. Given that in the two studies just discussed, Asian students demonstrated a variety of strategy preferences, one may suggest that other variables, such as individual differences, context, or teaching style, should also be taken into consideration when examining LLS use.

\section{Teacher Role}

A common assumption among LLS researchers is that strategies are internalized via social interactions with teachers (and peers; Chamot, 1995; Oxford, 1990, 1999). A growing body of knowledge indicates that student self-regulated, autonomous learning behaviors can be supported or hindered by teacher and classroom variables (Noels, 2001; Noels, Clément, \& Pelletier, 1999). ${ }^{24}$ For example, Nunan (1997) found that teaching practices of some University of Hong Kong instructors precluded students from using LLS in English-medium content-area lecture classrooms. Strategy instruction interventions, both in L1 and L2 contexts, have been shown to increase strategy knowledge (Nunan, 1997; Paris, Cross, \& Lipson, 1984) and strategy use (Hassan et al. 2005; Chamot \& O'Malley, 1994). In his review of LLS research, McDonough (1999) observed that strategy instruction research:

Provides a firm basis for the claim that strategy-based instruction makes a measurable difference in both how students perform (that is, their performance strategies and modes of action) and in how well they perform (that is, the quality of their performance of the set tasks). (p. 13)

\footnotetext{
${ }^{24}$ Studies by Noels (2003), Noels, Clément, and Pelletier (1999), Nunan (1997) and O'Malley et al. (1985) are discussed in greater detail in other parts of this chapter.
} 
Accordingly, educators argue that teacher perceptions of strategic, autonomous learning are an important instructional factor that has a direct bearing on the learning experiences of the students (Oxford, 1990). Yet even as empirical evidence suggests that teacher beliefs underlie teacher instructional practices (August \& Calderón, 2006; Zwiers, 2007), limited research has explored teacher perceptions of learning strategies.

One study (Griffiths, 2007) of 34 teachers of English and 131 students from 13 nations at a private English school in New Zealand found a high percent (71\%) of agreement between student self-reported LLS use (measured by a researcher-developed, SILL-based instrument) and teacher ratings of strategy importance. However, the author identified several discrepancies between student and teacher perceptions. For example, while students reported "doing homework" and "using a dictionary" among the most frequently used strategies, these same strategies were not rated as highly important by teachers. Another discrepancy was that out of 17 strategies rated as highly important by teachers, only five were reported as frequently used by learners. Similarly, Griffiths and Parr (2001) found substantial discrepancies between teacher and student strategy perceptions in a sample of 30 teachers and their 569 adult English learners, particularly with regard to memory strategy ranked first by the teachers and last by the students. Further, students in the study reported using social and metacognitive strategies the most, whereas teachers ranked these strategies only $3 \mathrm{rd}$ and $4^{\text {th }}$.

In another study (O’Malley et al., 1985a), interviews with high school ESL and content-area teachers $(N=22)$ employed by three Eastern school districts in the United States revealed that teachers were simply unaware of learners' strategies. These findings suggest some gaps between teacher and student perceptions of LLS; these gaps, "if not 
properly addressed, could hinder strategy instruction" (Rivera-Mills \& Plonsky, 2007, p.

542) or may result in precluding L2 learners from effectively using LLS in school.

\section{Strategy Instruction}

In their systematic review of strategy instruction literature, the most comprehensive review to date, Hassan et al. (2005) synthesized research conducted from 1960 to 2002 in second and foreign language contexts across the globe (the initial number of potentially relevant studies was 567). The main purpose of the review was to "evaluate the strength of evidence" regarding the effectiveness of LLS training in L2 teaching and learning (p. 1). The number of experimental studies ${ }^{25}$ (controlled or randomized) that met the selection criteria ${ }^{26}$ for inclusion in the review was 25 . The selected studies compared intervention groups' outcomes with those of controls or alternative treatments. Intervention outcomes in L2 speaking, reading, writing, overall language ability, vocabulary, and listening were measured using a variety of instruments including researcher-designed instruments, end-of-term tests or grades, and standardized proficiency tests. All studies were evaluated independently by two raters initially, then by the whole research team, and assigned a certain weight of evidence judged against three criteria: trustworthiness, appropriateness of the design and analyses, and relevance. The resulting narrative synthesis revealed that: (a) 17 studies reported positive results, 6 studies reported mixed results, and 2 studies reported negative results research; (b) 16 studies were judged to be of high or medium weight, and (c) evidence for strategy

\footnotetext{
${ }^{25}$ The total number of descriptive and experimental studies included in the published review was 38 (16 studies were conducted in the United States; 14 studies were conducted in ESL contexts; 11 studies involved secondary students; none of the studies included students at the elementary level). The present review reports only on the results of the experimental studies' analyses.

${ }^{26}$ To be included in the review, the study needed to be: (a) on strategy training intervention in L2 learning, (b) primary empirical research, (c) experimental in design, and (d) carried out in formal instructional settings.
} 
training effectiveness was stronger for reading comprehension and writing skills than it was for listening, speaking, and overall proficiency. The authors concluded that there was enough evidence to suggest that strategy instruction was effective in improving students' language outcomes. Two studies that match the selection criteria outlined in Hassan et al. (2005), but not included in the review, ${ }^{27}$ are discussed in greater detail next.

In his experimental study of 75 intermediate proficiency ELLs enrolled in three high schools in an Eastern metropolitan area of the United States, O'Malley (1987) examined the impact of strategy instruction on student performance on three tasks: speaking, listening, and vocabulary learning. Students (Hispanics, Asians, and Europeans) were randomly assigned to three treatment conditions: (a) metacognitive group (metacognitive and cognitive strategy instruction); (b) cognitive group (cognitive strategy instruction); and (c) control. After 8 days of intensive (50 minutes per day) strategy training, the adjusted posttest results demonstrated that experimental groups significantly outperformed the control group on oral presentation tasks $\left(\mathrm{p}<.01, R^{2}=\right.$ .20). While the posttest results in listening fell just under significance level, experimental groups significantly outperformed controls on two out of four in-training listening tests. The researcher concluded that strategy instruction was effective for increasing students' learning of listening and speaking skills.

Nunan (1997) examined the effects of strategy training on motivation, student knowledge of LLS, student-perceived utility of LLS, and LLS use in a group of 60 firstyear college students enrolled in a compulsory academic English course (English for Arts Students) at the University of Hong Kong. Students were randomly assigned to

\footnotetext{
${ }^{27}$ Nunan's (1997) study was identified by Hassan and colleagues, but the report was retrieved only after the cut-off date.
} 
experimental and control groups. The language course for the experimental group $(N=$ 30) was enhanced with strategy instruction and delivered over a period of one semester. The control group received regular language instruction for the same period of time. Chisquare analysis on the percent of students who improved or did not improve from pretest to posttest revealed that the experimental group outperformed the comparison group on three out of four measures examined: motivation for learning English $(p<.05)$; student LLS knowledge $(p<.001)$; and perceived utility of LLS $(p<.05)$. On posttests, both experimental and control groups reported increased strategy use. Qualitative analyses of interviews and classroom observations revealed that (a) teaching practices of academic discipline professors lecturing in English often precluded students from using LLS taught during the intervention, and (b) students' willingness to use a particular strategy depended on its perceived effectiveness.

\section{LLS and Academic Achievement}

Though limited, there is evidence to suggest that strategy instruction may enhance ELLs' academic outcomes. A case in point is the Cognitive Academic Language Learning Approach (CALLA), an instructional approach developed in the United States by Chamot and O'Malley (1994). CALLA is delivered by ESL teachers and is designed to provide transitional instruction from ESL and bilingual classrooms to grade-level content-area instruction. The approach incorporates three main components: (a) curriculum (i.e., integration into ESL classrooms of high-priority topics defined by the national standards for each content area); (b) academic language (e.g., reading scientific texts, writing lab reports, and reading, solving, and communicating solutions for word problems in mathematics); and (c) learning strategies for learning language and content 
(Chamot, 2005b). Learning strategy instruction is considered as the main tool for delivering content-ESL instruction (Chamot \& O’Malley, 1994).

Two independent evaluations studies ${ }^{28}$ conducted by Thomas (CALLA-math evaluation) and Galland (CALLA-science evaluation) found positive impact of the program on ELLs' academic outcomes (as cited in Chamot, 1995, and Chamot, Dale, O'Malley, \& Spanos, 1992). Both program evaluation studies were conducted in a small suburban school district (about 16,800 students) in Arlington, VA. The study of the CALLA secondary ESL-Mathematics program conducted during the forth year of implementation found that CALLA students made gains in computation, mathematics concepts, and applications (as measured by standardized tests) at a higher rate than the national comparison group. The study found an average gain of 7 NCEs in computation and an average gain of 10 NCEs in concepts and application. The impact of the CALLA ESL-Science program was examined by comparing the progression of the end-of-the year science grades over five years in comparison and treatment groups of ELLs. A grade of B or higher served as the criterion of success. The results indicated that while $29 \%$ of the middle school and $22 \%$ of the high school students in the comparison group reached this benchmark, the comparable age-group percentages for CALLA students were $57 \%$ and $54 \%$, respectively. The analysis of classroom observations and teacher reports revealed a high level of motivation and engagement among CALLA students. Similar, Montes (2002) found a positive effect of enhancing content area classroom instruction with CALLA-based strategies on middle school ELLs' $(N=277)$ academic outcomes as measured by state standardized scores in reading and mathematics.

\footnotetext{
${ }^{28}$ The original reports could not be located neither through library search nor through library request.
} 
In their study of 32 low to intermediate English proficiency CALLA students (9 elementary; 13 middle school; 10 high school), Chamot et al. (1992) examined (a) high versus low CALLA implementation impact on students' ability to solve mathematics word problems and (b) patterns of strategy use applied to solving word problems across different mathematics proficient students. Data collection consisted of administering a researcher-developed mathematics test including two word problems and a learning strategy interview protocol. Student transcripts were coded by two independent raters for (a) correctness and appropriateness of the mathematics problems solutions, and (b) evidence of learning strategy use. A set of ANOVAs indicated that students in high CALLA implementation classes significantly outperformed students from low implementation classes on: (a) number of correctly solved mathematics problems $(F=$ $5.27, p<.05)$ and (b) number of metacognitive strategies used $(F=5.67, p<.05)$. There were also significant differences in the number of correctly solved problems and the frequency of cognitive and metacognitive strategy use by mathematics proficiency. Higher mathematics proficiency students used the most metacognitive $(M=10.17)$ and cognitive strategies $(M=4.83)$. Lower mathematics proficiency students used the least metacognitive $(M=4.00)$ and cognitive strategies $(M=1.33)$.

\section{Summary}

This section summarized the language learning strategy research base. With some notable exceptions (Gardner et al., 1997), the review suggests that higher strategy use is associated with higher L2 outcomes (Dreyer \& Oxford, 1996; Kaylani, 1996; Oxford, 1999). Further, strategy choice, use, and evaluation have been linked to several student and classroom variables. In particular, students appeared to demonstrate different patterns 
of strategy use depending on their age (Magogwe \& Oliver, 2007; Peacock \& Ho, 2003) and proficiency levels (Chesterfield \& Chesterfield, 1985; Kaylani, 1996; Phillips, 1992). ${ }^{29}$ Moreover, evidence suggests that strategy instruction may increase LLS use (Nunan, 1997), L2 outcomes (Hassan et al., 2005; O’Malley, 1987), and academic achievement in content areas (Chamot, 1995; Chamot et al., 1992; Montes, 2002). These findings suggest that LLS—a potentially instructionally manipulable student characteristic-may play an important mediating role between language learners' background variables and their learning outcomes; this assumption will be explored in this study. In the next section, the author will discuss relevant theories and research regarding motivation for learning a second language.

\section{Language Learning Motivation}

\section{Connecting Motivation, Strategy Use, and Proficiency}

In this study, motivation for learning English is hypothesized to play a mediating role, through LLS use and English proficiency, in supporting academic achievement in ELLs. The reasons for considering motivation as one of the key factors in ELLs' schooling are two. First and foremost, motivation has been linked to strategy use (MacIntyre \& Noels, 1996; Oxford \& Nyikos, 1989; Schmidt \& Watanabe, 2001) and learner autonomy (Noels, 2001). That is, motivated learners were found to take a more active, self-directed role in their L2 development. Second, there is a growing body of knowledge indicating that motivation and self-directed, autonomous learning can be supported by classroom variables (Noels, 2001; Noels, Clément, \& Pelletier, 1999),

\footnotetext{
${ }^{29}$ Research also suggests that students may demonstrate different patterns of strategy use depending on their gender (Dreyer \& Oxford, 1996; Hong-Nam \& Leavell, 2006; Kaylani, 1996) and culture (Hong-Nam \& Leavell, 2006; O'Malley, 1987); exploring these influences, however, is outside of the scope of this study.
} 
including strategy instruction (Nunan, 1997). Much of the research in these areas, however, has been conducted with older learners and in foreign language (FL) settings. The generalizability of these findings to younger L2 learners needs to be examined. Finally, motivational effort-although not part of this investigation—was linked to higher L2 proficiency (Gardner, 2006; Masgoret \& Gardner, 2003). Indeed, as theorized by Krashen $(1985,1987)$, motivated learners have a much lower affective filter and, thus, are able to develop L2 at a faster rate.

\section{Defining Language Learning Motivation}

Gardner (2006) defined motivation to learn a second language as the drive to learn a new language associated with effort, desire to learn the language, and attitudes toward the language studied. Motivation for learning a new language is "a unique situation even within motivational psychology" given the unique role of language in human experience:

Language is at the same time: (1) a communication coding system that can be taught as a school subject; (2) an integral part of the individual's identity involved in almost all mental activities (think of sentences like: "This does not sound like me"); and also (3) the most important channel of social organization embedded in the culture of the community where it is used. (Dörnyei, 1996, p. 72)

In second language contexts, language is also the medium through which instruction is delivered and through which ELLs express their content knowledge (Fillmore \& Snow, 2002/2005).

\section{Theoretical Perspectives on Language Learning Motivation}

Motivational theories seek to explain why people do what they do (Dörnyei, 1996). As suggested in Dörnyei (2003), language learning motivational theories may be 
grouped into two broad categories: social and cognitive. Social theories, while considering language learners' ethnolinguistic attitudes (i.e., attitudes toward the new language and toward the cultural group that speaks this language), are primarily focused on societal variables such as power relationships among ethnic groups, multilingualism, and language contact. Cognitive theories primarily consider individual learner traits such as locus of control (self-determination theory), perceptions of success (attribution theory), and goals (goal theory) as essential elements underlying motivational dispositions. Two theories that have been particularly influential in the study of language learning motivation are Gardner's (2006) Socio-Educational Model and Deci and Ryan' (1985) self-determination theory.

Gardner's (2006) Socio-Educational Model, first developed in the 1960s in Canada, is grounded in social psychology. The theory's main assumption is that language learners' positive attitudes toward the studied language and culture lead to higher motivation and effort and, consequently, to higher language achievement. Central to the social dimension of motivation is the construct of integrative motivational orientation or integrativeness, "an openness to other cultures in general, and an interest in the target language in particular" (p. 247). Gardner argued that individuals who are high on integrativeness are "willing and able to take on features of another language group" (p. 247). The second motivational type considered by Gardner is instrumental motivational orientation or instrumentality. Instrumentality refers to motivational dispositions grounded in "practical or utilitarian" purposes. In other words, instrumentally oriented learners perceive learning an additional language as a means for enhancing their social or economic status. 
Deci and Ryan's (1985) self-determination theory holds that the individual's "capacity to choose and to have those choices" determines the individual's actions (p. 38). The authors argued that humans have an "innate propensity" to engage in interesting behaviors (p. 38). The desire to accommodate within society, on the other hand, also plays an important role in motivating human behavior. Thus, two types of motivation central to self-determination theory are distinguished, namely intrinsic motivation ${ }^{30}$ and external motivation. Deci and Ryan defined internal and external motivation as follows: Intrinsically motivated behavior has an internal perceived locus of causality: the person does it for internal rewards such as interest or mastery; extrinsically motivated behavior has an external perceived locus of causality: the person does it to get an extrinsic reward or to comply with an external constraint. (p. 49) Noels et al. (1999) noted that the source of intrinsic motivation lies within the activity itself, or rather within the pleasure that the learner experiences from accomplishing the task. An example of internal motivation is a student who "finds delight in learning a new way to express an idea in the L2" (p. 24). Extrinsically motivated behaviors, on the other hand, are carried out not because of the interest in the activity per se, but for some instrumental ends, such as getting praise or avoiding punishment. Even as Deci and Ryan (1985) argued that self-determination is an individual quality, they also stressed that environmental factors (e.g., teacher and classroom variables) may either hinder or support the person's self-determining behaviors, behaviors that in education are often associated with learner autonomy (Oxford, 1999).

\footnotetext{
${ }^{30}$ A recent study (Noels, 2003) examining a hypothesized overlap between Gardner's integrated motivation and Deci and Ryan's intrinsic motivation revealed that intrinsic motivation was a better predictor of learning outcomes (e.g., motivational intensity, persistence, and positive L2 attitudes). Integrative orientation, on the other hand, better predicted cross-cultural patterns of communication (e.g., frequency of L2 contact, quality of L2 contact, and L2 cultural identity).
} 
Noels et al. (1999) argued that Deci and Ryan's (1985) self-determination framework permitted one to systematically organize and study reasons for learning a new language suggested by the literature (e.g., interest, curiosity, personal challenge, or the need for achievement and personal development). Accordingly, the theory has received further development in L2 motivational research. One current conceptualization of intrinsic motivation, originally put forward by Vallerand (as cited in Noels et al., 2000), distinguished three types of intrinsic motivation: (a) knowledge, engaging in an activity in order to expand one's knowledge; (b) accomplishment, motivation resulting from experiencing positive feelings about an accomplished goal; and (c) stimulation, motivation based on positive sensations such as esthetic pleasure. Moreover, Noels and her colleagues $(1999,2000)$ argued that the intrinsic-extrinsic distinction was not a dichotomy but rather a continuum on the self-determination scale. The authors suggested that extrinsic motivation itself may be more or less self-determined and differentiated among three types of extrinsic motivation: (a) external regulation, behavior motivated by external means such as reward or punishment; (b) introjected regulation, performance motivated by an internalized pressure such as guilt reduction or a desire to impress others; and (c) identified regulation, effort based on the perceived personal value of the activity such as viewing L2 learning as a more- or less-valued goal.

Noels and her colleagues $(1999,2000)$ further argued that distinguishing between more self-determined motivational orientations (intrinsic motivation and identified regulation) and less self-determined motivational orientations (external and interjected motivation) may provide a more nuanced perspective on motivation. According to this perceptive, more self-determined students are expected to be more autonomous and to 
engage in more sustained learning. In the next section, empirical research examining the relationships among motivation, LLS, and learner autonomy is discussed.

\section{Empirical Findings}

LLS and motivation. In examining the relationship between self-rated motivation and LLS use (measured by an earlier 121 -item version of SILL), Oxford and Nyikos (1989) found that more motivated students used strategies more frequently than did less motivated students in a sample of 1,200 foreign language learners enrolled in a U.S. Midwestern university. A series of ANOVAs on SILL factor scores revealed that motivation had a significant effect on frequency of strategy use on four out of five strategy categories examined (i.e., rule-related practice, functional practice, conversational input elicitation, and general study strategies). Moreover, the researchers found a significant relationship between LLS use and the number of years of language study, a variable that the authors considered to be related to motivation. Students who studied L2 for a minimum of five years used significantly more cognitive (functional practice) strategies. Students with four years of L2 study used significantly more social (conversational input elicitation) strategies.

In an experimental intervention study (discussed earlier), Nunan (1997) found that, from pre- to posttest, a significantly greater number of first-year University of Hong Kong students who received strategy training in an English for Academic Purposes language classroom increased their motivation for learning English when compared to students in control classrooms.

MacIntyre and Noels (1996) found that the overall frequency of strategy use was significantly correlated with motivation in a group of 138 university foreign language 
learners. The results of regression analyses on individual strategies revealed that strategy knowledge, perceived strategy effectiveness, and perceived strategy difficulty were significant predictors of strategy use (explaining, on average, $60 \%$ of the variance in individual strategy use). The comparison of higher versus lower motivation students revealed that high motivation learners reported knowing more strategies and tended to find strategies more effective and easier to use.

Schmidt and Watanabe (2001) examined the relationship between seven motivational constructs, LLS use, and student ratings of classroom practices in a group of 2,089 foreign language learners at a large U.S. university. The researchers found positive significant associations between the composite motivational score and LLS scales across the five language groups studied. The correlations ranged from .40, $p<.001$ (for learners of Spanish) to $.58, p<.0001$ (for learners of French). Strategies most highly affected by motivation were cognitive and metacognitive. Notably, many of the variables associated with different motivational constructs (e.g., intrinsic motivation, integrative motivation, and instrumental motivation) loaded on one factor, which the authors labeled Value. Factor analysis results led the authors to conclude:

It does not appear to be the case that some of the learners in our sample are instrumentally oriented towards language study, others have a general interest in languages and culture, and yet others just enjoy language learning. Instead we find that our learners either see value in learning the foreign language they are studying for all of these reasons or for none of them. (p. 347)

Value had the second strongest correlation with strategy use, preceded only by Motivational Strength. Another interesting finding is that six measures of motivation 
positively correlated with favorable ratings of challenging L2 learning activities, indicating that motivated learners felt less intimidated by challenges inherent in language learning.

To clarify quantitative findings in a study of LLS use by 1,006 English for Academic Purposes college students in Hong Kong, Peacock and Ho (2003) selected and interviewed a sample of 48 students identified as high and low strategy users. Interviews with low strategy use students indicated low motivation for L2 learning. These students reported lack of enjoyment, interest, and confidence in learning English. High strategy users, on the other hand, reported being highly motivated. These students perceived learning English as being important to them and enjoyed learning about English language and culture.

Motivation and learner autonomy in a classroom. Research on the relationships among motivation, learner autonomy, and classroom variables is a relatively recent but promising trend in SLA. This research agenda has been pursued by Noels and her colleagues and conducted primarily in postsecondary settings. In their 1999 study, Noels et al. found that intrinsic motivation had a significant positive correlation with teacher "autonomy-supportive" ratings (.34) and a significant negative correlation with teacher "controlling" ratings (- .29) in a group of 78 students (mean age of about 22), enrolled in a French immersion program in Ottawa, Canada. Additionally, teacher "autonomy-supportive" ratings had significant positive correlations with L2 outcomes (i.e., motivational intensity and persistence). Significant negative correlations were found between "classroom-control" and two measures of self-determination, namely, intrinsic motivation (-.29) and identified regulation (-.45). These findings suggested that teachers' 
"autonomy-supportive" practices corresponded to students' increased sense of autonomy and self-determination. Notably, measures of extrinsic motivation did not significantly correlate with any teacher and classroom perceptions measures, suggesting that externally motivated students may be less influenced by classroom variables.

In her 2001 study, Noels used structural equation modeling techniques to examine the relationships among student perceptions of the teacher (as being controlling, negative, congenial, or informative) and student self-reported autonomy and language proficiency in a sample of 322 Spanish language learners (mean age of about 20) at a California university. The results of path analysis indicated that student autonomy significantly and positively predicted all four types of intrinsic and extrinsic motivation examined; the highest associations were with more self-determining motivational orientations (i.e., indentified regulation, .49 , and intrinsic motivation, .45 ). At the same time, controlling teachers significantly and negatively predicted student autonomy (-.17). The author concluded that certain teacher behaviors may enhance student autonomy and, consequently, L2 motivation.

\section{Summary}

This section surveyed language learning motivation research. The review suggests that motivation is positively associated strategy use (MacIntyre \& Noels, 1996; Oxford \& Nyikos, 1989; Peacock \& Ho, 2003; Schmidt \& Watanabe, 2001) and learner autonomy (Noels, 2001). Moreover, higher motivation learners appeared to know more strategies, tended to find strategies more effective and easier to use (MacIntyre \& Noels, 1996), and tended to provide more favorable ratings of challenging L2 learning activities (Schmidt \& Watanabe, 2001). These findings suggest that motivated students may have higher levels 
of confidence and autonomy and may ultimately reach higher levels of L2 proficiency. In other words, motivation may play a mediating role in L2 development, in particular, through the use of LLS; this latter assumption will be explored in this study.

Additionally, research demonstrated that classroom variables could support or hinder motivation and autonomous learning (Noels, 2001; Noels et al., 1999), suggesting that motivation and autonomous learning may be instructionally manipulated. Much of the research in these areas, however, has been conducted with older learners and in foreign language settings and the generalizability of these findings to younger L2 learners should be examined. The next section reviews research on ELLs' academic achievement.

\section{Academic Achievement in English as a Second Language}

\section{Defining Academic Achievement}

In the literature, academic achievement has been defined either narrowly, as performance on standardized achievement tests, or more broadly, as measures of general academic outcomes including grade point average (GPA), academic persistence, and school-related attitudes (Genesee et al., 2005). Discussion of ELLs' academic achievement inevitably involves language proficiency. Some researchers consider English proficiency (both literacy and oral language skills) as an academic outcome in and of its own right, along with content area achievement (Genesee et al., 2005; Yoko, 2007). Others speak of the unitary construct termed academic English or academic achievement in the second language (Collier, 1987; Collier \& Thomas, 1989). All of these views are reflected in the NCLB legislation's stated purposes for ELLs' education. These purposes include (a) attaining English proficiency, (b) developing "high levels of academic attainment in English," and (c) meeting states' academic content standards (as 
cited in Wright, 2005, p. 23). For feasibility reasons, the present study adopts the narrow definition of academic achievement as performance on standardized content-area achievement tests. English proficiency, along with LLS and L2 motivation, is considered as a mediating variable between ELLs' background characteristics and performance on standardized tests.

\section{Current Trends in ELLs' Academic Achievement}

Despite some improvements over the last three decades, the ELL achievement gap remains a reality (Fry, 2008; Kao \& Thompson, 2003; NCPPHE, 2005). Thomas and Collier (2002) estimated that the typical achievement gap between ELLs and nativeEnglish speakers was about 25 NCEs (normal curve equivalents). Analyses of the U.S. Department of Education databases for the 2004-2005 school year in five states with largest ELL populations indicated that ELLs are less likely to score at proficiency levels in mathematics and reading (Fry, 2007, 2008). The comparison of mathematics achievement in 2004-2005 school year in five states with large ELL populations, for example, yielded a native-to-ELL gap that ranged from $18 \%$ (Texas) to $35 \%$ (Arizona) for elementary grades and form $42 \%$ (California) to $53 \%$ (Texas) in middle grades (Fry, 2008). Another trend noted by Fry is that ELL populations tend to attend schools with lower overall standardized test scores. These schools typically have "a set of characteristics generally associated with poor standardized test performance-such as high student-teacher ratios, high student enrollments, and high levels of students living in or near poverty" (p. $i)$.

However, language minority status implies neither an achievement gap nor similarity across individuals within a particular cultural group (Kao \& Thompson, 2003). 
For instance, 1990 SAT data in reading showed the following average scores across ethnolinguistic groups: 442 for Whites, 410 for Asian Americans, 388 for Native Americans, 380 for Mexican Americans, and 352 for Blacks. The same year's average results in mathematics, however, showed a lead by Asian Americans (528), followed by Whites (491), Native Americans (437), Mexican Americans (429), and Blacks (385). One study (Suárez-Orozc et al., 2008a) found that the general pattern of decline in GPA over time observed in a sample of new immigrants from Central America, China, Haiti, Mexico, and the Dominican Republic was not uniform either across countries of origin or across individuals. About $30 \%$ of students showed a stable GPA and about $11 \%$ increased their GPA by about .74 points by the fifth year of the study. Carhill et al. (2008) documented that Chinese students, the highest performers in their sample, tended to live in households with higher levels of education and to enroll into schools with higher SES and achievement characteristics. These findings suggest the importance of considering the influences of both school characteristics and individual student and family background characteristics on ELLs' academic achievement.

\section{Theoretical Perspective Explaining the Achievement Gap}

In a review of recent academic achievement literature, Kao and Thompson (2003) categorized current theoretical perspectives that attempt to explain achievement gaps into two broad categories: cultural orientations theories and structural position theories. Cultural orientations theories consider ethnic groups' differences in orientation toward schooling as the main cause that promotes or hinders achievement. For example, the academic successes of Asian students have been attributed to this group's cultural beliefs. Studies have documented that students from South Asian cultures prioritize achievement, 
believe in education, feel an obligation to succeed, and believe that academic success is their responsibility to their families.

By contrast, structural position theories attribute differences in academic performance to ethnolinguistic groups' economic positions and experiences in society. Namely, these theories consider parental socioeconomic status as the main explanation of academic achievement differences. The underlying assumption is that parents' economic and social standing is associated with educational experiences for children (e.g., parental involvement, parental social network, and schooling opportunities, including the quality of teachers and peers). However, the authors noted that while SES was "probably the best predictor of eventual academic outcomes among youth," some unexplained variance in achievement persisted, suggesting the existence of other "unmeasured differences" (p. 431).

Although providing valuable insights into plausible causes of achievement differences among diverse cultural groups, these theories, mainly derived from sociology and anthropology, do not consider the influence of the most salient, namely, linguistic factors on academic achievement of ELLs. A recent trend in educational and applied linguistics literature (Dale \& Cuevas, 1992; Dutro \& Morgan, 2001; Schleppegrell, 2004; Zwiers, 2007), in educational assessment literature (Abedi, 2004; Abedi \& Lord, 2001; Solórzano, 2008), and in teacher education literature (Fillmore \& Snow, 2002/2005; Lucas \& Grinberg, 2008, Lucas, Villegas, \& Freedson-Gonzalez, 2008) indicates increased attention given to linguistic factors in explaining and confronting the ELL academic achievement gap. 
Since Cummins' (1981b, 1984/2005) influential conceptualization of language proficiency, many researchers and educators have recognized the challenges inherent in academic language development (Fillmore \& Snow, 2002/2005; Schleppegrell, 2004) and came to recognize that language proficiency was "closely intertwined with academic content" (Chamot \& O'Malley, 1994, p. 41; Zwiers, 2006, 2007). Thomas and Collier (2002), for example, estimated that the number of years that it takes ELLs to acquire enough English to do grade-level work in academic content areas is equivalent to 1 to 2 years ${ }^{31}$ of interrupted schooling. The authors noted that ELLs "have to make more gains than the average native-English speaker makes every year for several years in a row to eventually catch up to grade level" (p. 8). Chamot and O'Malley (1994) pointed out that in order to explain how a word problem is solved or justify the conclusions derived from a science experience, a student needs to draw on substantial discipline-specific linguistic resources. In a similar vein, Schleppegrell (2004) observed that the mastery of academic language included (a) the explicit knowledge of a large variety of linguistic features of school texts and tasks, and (b) the ability to make appropriate linguistic choices to realize conceptual knowledge and relationships among concepts within the discipline. Academic language, also referred to as content area literacy by educational researchers, came to be understood as an entity embodying "the cognitive, linguistic, cultural, and discipline specific features of discourse found in school and beyond" (Zwiers, 2006, p. 318). Thus, applied linguists and educators speak of the many school-based disciplinary language registers $^{32}$ (e.g., the language of science, the language of history, or the language of

\footnotetext{
${ }^{31}$ This is rather an underestimation because it is based on students with comparable, grade-level schooling in their first language.

${ }^{32}$ In the literature, language register has been defined as a set of language features associated with a particular social or professional context of use (Fromkin et al., 2007; Wardhaugh, 2006).
} 
mathematics). All of these registers need to be mastered by students in order to be successful in school (Delpit, 1995; Gay, 2000; Nieto, 2002/2005; Schleppegrell, 2004).

In fact, many authors (Abedi, 2004; Solórzano, 2008; Zwiers, 2006) noted difficulties in distinguishing language proficiency and academic competence. For example, in comparing performance differences in reading, mathematics calculation, and mathematics analytical in third, sixth, and eighth graders, Abedi (2004) found that: (a) the ELL/non-ELL gap was smaller on tasks that had lower language demands (the average effect sizes were .213 for reading, .160 for analytical, and .083 for calculation); and (b) the gap increased as the grade level increased. The author attributed the latter finding to higher language demands in higher grade tests. In another study examining linguistic factors implicated in schooling, Abedi and Lord (2001) found that linguistic modification of test items from the National Assessment of Educational Progress (NAEP) mathematics assessment (e.g., shortening nominal phrases and substituting passive voice and lowfrequency vocabulary) resulted in a slight but significant improvement in performance in eighth grade ELLs. In his literature review, Solórzano (2008) reported on a study documenting significantly higher performance on native language standardized tests versus comparable English tests both in limited and fluent English proficient elementary ELL students.

The intricacies of the interplay among English language proficiency, native language proficiency, and academic achievement have been long recognized. In synthesizing findings from their systematic review of over 200 articles and reports on educational outcomes of ELLs, Genesee et al. (2005) concluded that bilingual proficiency and biliteracy have a positive relationship with academic achievement in both English 
and native languages. The authors noted that positive correlations between L1 and L2 reading, $L 1$ reading and $L 1$ mathematics, and $L 2$ reading and $L 2$ mathematics reported in the research suggest "complex but supportive interdependencies in the language, literacy, and academic development" of ELLs (p. 376). Mahon (2006) found that about 50\% of the variance in English reading and writing scores was accounted for by elementary students' $(N=127)$ reading and writing scores in L1. A linear combination of English proficiency and Spanish academic achievement accounted for about $73 \%$ of the variance in ELLs performance on English standardized tests. Reading and writing in L1 and L2 were positively and significantly correlated ( $r=.73$ for reading; $r=.76$ for writing).

The National Literacy Panel on Language-Minority Children and Youth (August \& Shanahan, 2006a, 2006b) concluded that L1 oral and literacy skills were related to the development of English oral skills and literacy. Evidence suggests that ELLs may transfer their linguistic knowledge (e.g., speech discrimination, vocabulary, or reading strategies) from native to English language. The authors noted that "students who are literate in their first language are likely to be advantaged in the acquisition of English literacy" (2006a, p. 5). In a meta-analysis of 17 experimental studies comparing elementary bilingual and English-only reading programs, Slavin and Cheung (2005) concluded in favor of bilingual programs based on a positive weighted effect size $(.33, p$ $<.05$ ), suggesting the importance of L1 support in promoting academic achievement among ELLs.

Research literature on ELLs' academic achievement primarily consists of program evaluation, program description, and program comparison studies (Genesee et al., 2005). Given that a program effectiveness comparison is beyond the scope of this study, only 
quantitative studies that explored the relationships among student- and school-level variables related to ELLs' academic achievement (beyond instructional program contexts) are included in the following review of empirical research.

\section{Academic Achievement Research}

Collier and Thomas (1989) reported on two longitudinal academic achievement studies conducted in a relatively affluent suburban area on the East coast. The studies examined patterns of academic performance over a period of six years in a group of 2,014 "advantaged" ELLs enrolled in public schools (Grades 4, 6, 8, and 11). The researchers defined "advantaged" students as those with previous schooling in the home country. Only students at or above grade-level norms in their L1 schooling were selected. Also, although classified as low SES by the United States standards, a large percent of students' families were from middle or upper class backgrounds in their home countries. Students in the study originated from 75 different first language backgrounds $(65 \%$ Asian, 20\% Hispanic, 15\% Other) and were serviced by ESL programs for a maximum of three years. Considering their advantaged sample, the researchers expected to estimate the minimum time required for ELLs to reach grade-level norms as measured by Science Research Associates (SRA) standardized tests in reading, language arts, mathematics, social studies, and sciences. After two years of schooling in the United States, students at all grade levels achieved and surpassed the 50th percentile on the SRA mathematics test. The researchers attributed this finding to transfer of knowledge from L1 to L2. With other content areas, results were not so uniform, and age on arrival (AOA) appeared to have a differentiating effect on student outcomes. Researchers estimated that 12- to 16year-old arrivals were the lowest achieving group in the study. They attributed this 
finding to increasing complexity on tests in upper grades and to a shorter length of residence (LOR). Students whose AOA was 8 to 11 made the fastest progress and reached the 50th percentile on all measures within a period from two (mathematics) to five (reading) years. By comparison, students with AOA of 4 to 7 demonstrated much slower progress for their LOR. The latter group did not achieve the 50th percentile within the six years of data collection. Researchers projected that these students would need 7 to 10 years to achieve on-grade norms. Having at least two years of native language schooling appeared to be a significant variable influencing students' academic achievement in English. Researchers concluded that content areas achievement in L2 is a developmental process requiring significant number of years even for the most advantaged students: "How many years depends on the student's level of cognitive maturity in first language and subject mastery in first language schooling" (p. 35).

Thomas and Collier (1997) summarized findings from a study of five moderate to large urban and suburban school districts across the United States implementing different types of bilingual and ESL instructional programs. In a series of quantitative case studies ${ }^{33}$ of participating school districts, the researchers studied long-term student achievement as measured by performance on national standardized tests over a period of 4-10 years. To allow for comparison across districts' achievement tests, researchers used NCEs (i.e., equal-interval percentiles). Students' reaching the 50th NCE percentile on standardized tests served as a criterion of successful schooling in L2. From 1982 to 1996 , researchers collected 700,000 student records. The student sample included 42,317 students from 150 language backgrounds who attended the studied schools for a minimum of four years. Spanish speakers represented $63 \%$ of the sample. The researchers

\footnotetext{
${ }^{33}$ The studies combined cross-sectional and longitudinal data collection and analysis.
} 
estimated that, to reach the 50th percentile on the U.S. standardized tests, English learners required different amounts of time, depending on their background characteristics and the types of programs they attended in the United States. Bilingually schooled students, who performed on grade level in their first languages, required 4 to 7 years; "advantaged" students (i.e., those with 2 to 5 years of on-grade level home country schooling) required 5 to 7 years; and "less advantaged" students schooled in English-only programs required 7 to 10 years. Also, researchers found that, despite some initial shortterm differences, in the long run, speakers of different first languages progressed at the same rate, given similar levels of cognitive and academic development in L1. Based on findings confirmed in all five school districts, researchers concluded that the amount of schooling in the students' L1s (whether in the home country or in the United States), LOR, SES, and the type of instructional program were all strong predictors of students' long-term academic achievement. The amount of $\mathrm{L} 1$ support explained the most variance in student achievement. Findings from two sites (where data were available) indicated that the amount of parents' formal schooling was a better predictor of academic success than SES, as measured by free and reduced-price lunch.

In their National Study of School Effectiveness for Language Minority Students, Thomas and Collier (2002) continued to examine patterns of ELLs' long-term academic achievement (over 4 to 12 years) in reading, writing, mathematics, social studies, and science. This particular study was conducted in five school districts from 1996 to 2001 and included 210,054 student records. The study findings confirmed, to a large extent, results from an earlier study (Thomas \& Collier, 1997) discussed in the previous paragraph. Socioeconomic status, the amount of L1 schooling, program type, and number 
of years of program participation were strong predictors of students' long-term academic achievement. Researchers found that the shortest time to reaching grade-level achievement norms in L2 was four to seven years, given that students received gradelevel schooling through their two languages. ESL programs (typically offered for one to three years) closed about half of the total achievement gap. Students with no prior L1 schooling never reached grade-level performance in L2. Students whose parents waived language support services were the lowest achievers and had a higher chance of dropping out of school. Although SES was found to be a significant predictor of academic achievement (e.g., SES accounted for $3 \%$ to $12 \%$ of the variance in student achievement in reading), in some instances, effects of SES were moderated by other variables. In one research site, where about $50 \%$ of language minority students in the sample were United States-born, proficiency in English upon entry had stronger predictive power than SES. Moreover, years of L1 schooling (four years or more), either in the home country on in the United States, had more explanatory power than SES.

Yoko (2007) investigated the relationship among ELLs' background variables, school variables, and academic achievement using data from the Ohio Department of Education. Data were obtained for ELL students from 24 language backgrounds enrolled in 613 school districts in 4 th grade $(N=2,544)$ and 6th grade $(N=1,985)$. Statemandated standardized tests (Ohio Achievement Test and Ohio Proficiency Test) served as the measures of academic achievement in reading, writing, and mathematics. Using structural equation modeling (SEM) techniques, the author examined individual contributions (both direct and indirect) of student background variables and English 
proficiency (measured by $\operatorname{ELDA}^{34}$ ) to academic achievement. Background variables included LOR (operationalized as years in the U.S. school systems), native language, gender, ethnicity (Hispanic/Non-Hispanic), SES, and migrant status. The final fourth- and sixth-grade SEM models explained $75.5 \%$ and $75.2 \%$ of variance in ELLs' academic achievement, respectively; gender and ethnicity did not correlate significantly with any other variable. Explained variance by academic content ranged from $58.8 \%$ (fourth-grade mathematics) to $90.3 \%$ (sixth-grade reading). The total direct and indirect effect of English proficiency on academic achievement in both grade levels was .87 . However, the selected predictors of English proficiency accounted for only a small portion of its variance: $14.1 \%$ and $22.9 \%$ in fourth and sixth grades, respectively. The author concluded that there were some additional significant variables not included in the model.

In the next step, the author used an HLM technique to examine two levels of academic achievement predictors: (a) student background variables (ethnicity, gender, SES, and ELL status); and (b) school quality indicators (campus mobility and campus poverty). Results indicated that the proportion of variance in total student achievement accounted for by schools ranged from $15 \%$ (fourth grade) to $23 \%$ (sixth grade). The proportion of variance in achievement accounted for by student-level variables ranged from $7 \%$ (reading and math in fourth grade) to $13 \%$ (reading in sixth grade). Campus poverty had the most influence on the academic achievement of individual students. The performance of ELLs attending higher poverty schools was lower than that of students schooled in lower poverty schools. The overall study results indicated that, among the examined variables, school poverty, English proficiency, and student SES had the most

\footnotetext{
${ }^{34}$ ELDA - English Language Development Assessment, a state-developed assessment measuring BICS and CALP in reading, writing, listening, and speaking.
} 
explanatory power. A large portion of the variance in English proficiency, the strongest student-level predictor of academic achievement, remained unexplained. The author concluded that additional variables need to be examined in order to better explain student-level effects and suggested further investigating L2 motivation and attitudes, prior schooling in the home country, and family background.

Suárez-Orozc, Suárez-Orozc, \& Todorova (2008a, 2008b) examined predictors of academic achievement in a sample of 309 ELLs (mean age of about 16) from Chinese, Central American, Dominican, Haitian and Mexican backgrounds using the fifth-year data of the LISA ${ }^{35}$ study. A standardized achievement test in reading and mathematics, the Woodcock-Johnson Test of Achievement-R (WJTA-R), and GPA served as measures of academic outcomes. Researchers examined ELLs' academic outcomes from two distinct perspectives: (a) student-centered (i.e., considering student-level predictors only); and (b) school-centered (i.e., considering school-level predictors only). Predictors included in the student-centered model were five: English proficiency (measured by BVAT), behavioral engagement (self-reported participation and effort to perform academic tasks), father's employment, maternal educational level, and two-parent household. Multiple regression analyses testing student-centered model revealed that (a) English proficiency and behavioral engagement were significant predictors of GPA $\left(R^{2}=\right.$ .29), and (b) English proficiency was the only significant predictor of standardized scores $\left(R^{2}=.74\right)$. (With English proficiency removed, maternal educational level and behavioral engagement became significant and together accounted for about $10 \%$ of the variance in standardized scores.) Multiple regression analysis testing the school-centered

\footnotetext{
${ }^{35}$ Longitudinal Immigrant Student Adaptation Study, a study of patterns of cultural adaptation among new immigrants. For more details see Páez (2002) and Carhill et al. (2008).
} 
model revealed that all four school-quality variables examined-ELA proficiency rate (the percent of students who reached proficiency on the state exam in English Language Arts in each school), school poverty (percentage of low income students), racial representation (percentage of diverse students), and the average daily attendance ratewere significant predictors of standardized scores. The four-predictor model accounted for: (a) about $32 \%$ of the variance in standardized scores, and (b) about $15 \%$ of the variance in GPA. Among school-level variables tested, ELA proficiency rate was the best predictor of ELLs' academic outcomes.

\section{Summary}

This section reviewed studies examining patterns and predictors of ELLs' academic achievement. The review identified English proficiency as one of the key student-level predictors of academic outcomes (Mahon, 2006; Solórzano, 2008; Thomas \& Collier, 2002; Suárez-Orozc et al., 2008a; Yoko, 2007). Much evidence suggests that ELLs may require 4 to 10 years to reach grade norms (Collier \& Thomas, 1989; Thomas $\&$ Collier, 1997, 2002). Older school-aged learners appear to approach grade norms at a higher rate than younger learners, but may not reach academic achievement benchmarks given their shorter length of residence (Collier \& Thomas, 1989; Thomas \& Collier, 1997, 2002). These patterns correspond, to some extent, to the patterns of English language development suggested by the SLA research literature.

Other student-level variables that have been linked to ELLs' academic achievement include the amount of formal schooling in Ll (Collier \& Thomas, 1989; Thomas \& Collier, 1997, 2002), native language literacy (August \& Shanahan, 2006b; Genesee et al., 2005; Mahon, 2006), family SES (Kao \& Thompson, 2003), and parental 
educational level (Kao \& Thompson, 2003; Thomas \& Collier, 1997). At the school level, attending schools with higher SES and achievement profiles appeared to have positive impact on ELLs' academic outcomes (Suárez-Orozc et al., 2008a; Thomas \& Collier, 1997, 2002; Yoko, 2007). These findings suggest the importance of considering the influences of both school and individual and family background characteristics on ELLs' academic achievement. In this study, the predictors of ELLs' academic achievement identified by the literature review will be incorporated into statistical modeling analyses as covariates in order to better ascertain the relative contributions of language learning strategies—a variable of particular interest to this study—to student academic as well as English language outcomes. The next section concludes Chapter 2 and summarizes the present study's variables generated from the review.

\section{Summary and Selected Variables}

This chapter surveyed the current state of knowledge regarding factors implicated in ELLs' schooling experiences. The review included theoretical and empirical research on SLA, L2 development, language learning strategies, language learning motivation, and academic achievement in the second language.

Based on the literature review, the author selected several variables to be explored in the present study. The selection criteria were four: (a) the variable's relevance to answering the present study's research questions; (b) empirical evidence has.linked the variable to ELLs' academic outcomes; (c) where little or no empirical research has been conducted, theory and indirect evidence suggest that the variable may have a substantial impact on ELLs' academic outcomes; and (d) feasibility of the data collection (i.e., availability of the data, access to the data, and time constraints). 
The selected variables, as summarized in Table 2.1 , are conceptually categorized as student background characteristics (i.e., nonmanipulable variables), mediating variables (i.e., potentially manipulable variables which, based on the literature review, are hypothesized to mediate the relationships between student background characteristics and their academic outcomes), and school-level variables identified by the literature as potentially hindering or promoting students' academic achievement.

The relationships among the selected variables will be explored in order to answer the following three research questions:

1. How do teacher perceptions of the effectiveness of language learning strategies for English language development correspond with ELL students' reported frequency of strategy use?

a. What strategy categories are the most strongly aligned between individual teacher and student ratings of strategy effectiveness and use at elementary, middle, and high school levels?

b. How do within school teacher-student strategy effectiveness and use rating profiles compare at elementary, middle, and high school levels?

2. What are the structural relationships among ELL student background and linguistic profile characteristics and academic achievement, considering the mediating influences of language motivation, language learning strategy use, and academic English proficiency?

3. How well does the use of language learning strategies predict academic achievement among ELLs controlling for student- and school-level variables identified as strong predictors in the research literature? 
Table 2.1

Study Variables and Rationale for Selection

\begin{tabular}{ll}
\hline Variables & Relevant findings and selected sources \\
\hline $\begin{array}{l}\text { Background } \\
\text { characteristics }\end{array}$ & \\
Age & $\begin{array}{l}\text { Older learners acquire academic language skills at a higher rate, but may not reach grade norms given } \\
\text { shorter length of residence (Collier \& Thomas, 1989; Thomas \& Collier, 1997, 2002). }\end{array}$ \\
& Older learners acquire oral L2 skills at a higher rate (Cummins, 1981a; MacSwan \& Pray, 2005). \\
& Younger students ultimately achieve higher L2 proficiency over time (Carhill et al., 2008; Cummins, \\
& 1981a). \\
& L1 reading was positively and significantly related to L2 reading and L1 mathematics (Genesee et al., \\
& 2005); L1 reading and writing predicted L2 reading and writing (Mahon, 2006). \\
L1 literacy & Bilingual proficiency and biliteracy have a positive relationship with academic achievement in both \\
& English and native languages (Genesee et al., 2005). \\
& $\begin{array}{l}\text { Instructional programs that support L1 development better promote L2 academic achievement } \\
\text { (Cummins, 1981b; Slavin \& Cheung, 2005; Rolstad, Mahoney, \& Glass, 2005). }\end{array}$ \\
L1 skills may be transferred to support L2 development (August \& Shanahan, 2006b); L1 skills were not \\
a significant predictor of L2 oral proficiency (Páez, 2002).
\end{tabular}




\begin{tabular}{|c|c|}
\hline Variables & Relevant findings and selected sources \\
\hline Prior formal schooling & $\begin{array}{l}\text { The amount of formal schooling in the students' L1 was a strong predictor of students' long-term } \\
\text { academic achievement in English (Collier \& Thomas, 1989; Thomas \& Collier, 1997, 2002). } \\
\text { L1 academic achievement predicted L2 academic achievement (Mahon, 2006). }\end{array}$ \\
\hline Length of residence & $\begin{array}{l}\text { ELLs required } 4 \text { to } 10 \text { years to reach grade norms in academic content areas (Collier \& Thomas, 1989; } \\
\text { Thomas \& Collier, 1997, 2002). } \\
\text { LOR had a substantial positive effect on L } 2 \text { development (Cummins, 1981a; Hakuta et al., 2000); LOR } \\
\text { was a strong predictor of L2 proficiency (Carhill et al., 2008; Páez, 2002). }\end{array}$ \\
\hline Parental education & $\begin{array}{l}\text { Parental SES and educational level are positively related to students' academic achievement (August \& } \\
\text { Shanahan, 2006b; Kao \& Thompson, 2003). } \\
\text { The amount of parents' formal schooling was a better predictor of long-term academic achievement than } \\
\text { SES as measured by free and reduced lunch (Thomas \& Collier, 1997). } \\
\text { Parental educational level predicted L2 proficiency (Carhill et al., 2008, Hakuta et al., 2000; Páez, } \\
\text { 2002). }\end{array}$ \\
\hline Mediating variables & \\
\hline English proficiency & $\begin{array}{l}\text { English proficiency predicted performance on standardized academic content area tests (Mahon, 2006; } \\
\text { Solórzano, 2008; Suárez-Orozc et al., 2008a, 2008b; Yoko, 2007); English proficiency predicted long- } \\
\text { term academic achievement (Thomas \& Collier, 2002). } \\
\text { ELLs performed better on lower language demand tests (Abedi, 2004; Abedi \& Lord, 2001). }\end{array}$ \\
\hline
\end{tabular}




\begin{tabular}{|c|c|}
\hline Variables & Relevant findings and selected sources \\
\hline \multirow[t]{3}{*}{$\begin{array}{l}\text { Language learning } \\
\text { strategies (LLS) use }\end{array}$} & $\begin{array}{l}\text { Strategy instruction enhanced ELL's academic outcomes (Chamot et al., 1992; Montes, 2002); Strategy } \\
\text { instruction enhanced L2 outcomes (Hassan et al., 2005; O'Malley, 1987). }\end{array}$ \\
\hline & $\begin{array}{l}\text { LLS predicted higher L2 proficiency (Oxford, 1999; Dreyer \& Oxford, 1996; Kaylani, 1996); LLS } \\
\text { positively related to L2 proficiency (Oxford, 1999; Peacock \& Ho, 2003); Strategy use was a negative } \\
\text { predictor of L2 outcomes (Gardner et al., 1997). }\end{array}$ \\
\hline & $\begin{array}{l}\text { Students at different proficiency levels preferred different strategies (Chesterfield \& Chesterfield, 1985; } \\
\text { Kaylani, 1996; Phillips, 1992); Students at different ages showed different patterns of strategy use } \\
\text { (Magogwe \& Oliver, 2007; Peacock \& Ho, 2003). }\end{array}$ \\
\hline \multirow[t]{3}{*}{ English Motivation } & $\begin{array}{l}\text { Motivated students used LLS more frequently (MacIntyre \& Noels, 1996; Oxford \& Nyikos, 1989; } \\
\text { Peacock \& Ho, 2003; Schmidt \& Watanabe, 2001). }\end{array}$ \\
\hline & $\begin{array}{l}\text { Higher motivation learners reported knowing more strategies and tended to find strategies more effective } \\
\text { and easier to use (MacIntyre \& Noels, 1996). }\end{array}$ \\
\hline & $\begin{array}{l}\text { Motivation positively correlated with favorable ratings of challenging L2 learning activities (Schmidt \& } \\
\text { Watanabe, 2001). }\end{array}$ \\
\hline \multicolumn{2}{|l|}{ School-level predictors } \\
\hline \multirow[t]{2}{*}{ School poverty rate } & $\begin{array}{l}\text { School poverty was a significant predictor of academic achievement (Suárez-Orozc et al., 2008a; Yoko, } \\
\text { 2007); ELLs tend to enroll in schools with higher poverty rates (Fry, 2008). }\end{array}$ \\
\hline & $\begin{array}{l}\text { Students from high-poverty schools were estimated to be one year behind in English development as } \\
\text { compared to students from more economically advantaged schools (Hakuta et al., 2000). }\end{array}$ \\
\hline
\end{tabular}


Variables

School proficiency rate
Relevant findings and selected sources

Attending schools with higher percent of proficient students predicted academic test performance (Suárez-Orozc et al., 2008a, 2008b).

Attending schools with higher percent of proficient students predicted L2 proficiency (Carhill et al., 2008).

ELLs tend to enroll in schools with characteristics associated with poor standardized test performance (Fry, 2008).

School ELL proficiency rate

Not directly examined, but conceptually linked to school proficiency rate; This variables focuses only on proficiency of the target group.

LLS effectiveness

The impact on academic achievement has not been directly examined; indirect evidence suggests that the variable may be related to L2 and academic outcomes.

Teachers' beliefs about L2 learning and teaching influenced their instructional practices (August \& Calderón, 2006; Zwiers, 2007).

Teacher "autonomy-supportive" practices significantly correlated with student autonomous learning and L2 motivation (Noels, 2001; Noels et al., 1999); Teacher practices prevented students from using LLS in content area classrooms (Nunan, 1997).

Teachers were unaware of LLS (O'Malley et al., 1985a); Despite a high percent of teacher-student agreement, there were some discrepancies between student LLS use and teacher ratings of strategy importance (Griffiths, 2007; Griffiths \& Parr, 2001). 


\section{CHAPTER 3}

\section{RESEARCH DESIGN AND METHODOLOGY}

The purpose of this study was to investigate the relationship between language learning strategies (LLS) and academic achievement among ELLs receiving ESL language services. This general purpose was supported by three research objectives. The first objective was to compare teacher perceptions of strategy effectiveness and student self-reported strategy use. The second objective was to develop and test against data a statistical model in which LLS use, along with student background characteristics and language learning motivation, is hypothesized to enhance ELLs' academic achievement directly and indirectly, by means of language proficiency. The last objective was to single out the unique contribution of language learning strategies to ELLs' academic achievement in content areas after controlling for other previously identified student- and school-level academic achievement predictors. School-level academic achievement predictors also included teacher perceptions of strategy effectiveness, a variable that has received little attention in the past.

The research site of this study was a large Midwestern urban school district. The data sources included: demographic background variables (district provided demographic information and researcher-collected background questionnaire); English Language Learning Motivation Scale (ELLMS); Strategy Inventory for Language Learning (SILL)-Student and Teacher Forms; Assessing Comprehension and Communication in English State-to-State for English Language Learners (ACCESS for ELLs); School 
Quality Indicators, and Kentucky Core Content Test (KCCT) in reading, math, science, and social studies. The purpose of this chapter is to outline the study methodology including research design, population and sample, instrumentation, study variables, data collection procedures, and data analysis procedures.

\section{Methods}

\section{Research Design}

This study employed nonexperimental design and analyzed cross-sectional data collected by the Jefferson County Public School (JCPS) district and additional data collected by the researcher in 2008-2009 school year. The analytical procedures included descriptive statistics, correlational analyses, and statistical modeling techniques. The use of nonexperimental design and statistical modeling analysis techniques for this study was warranted for two reasons.

First, the main purpose of the study was to evaluate plausible causal mechanisms that may explain ELLs' academic achievement. Explanatory power was strengthened by incorporating into statistical analyses academic achievement predictors identified by second language development and academic achievement literature. Literature has supported the use of nonexperimental designs and statistical modeling for causal inferences. Shavelson (1996) noted that although establishing causality with nonexperimental methods may be problematic, introducing multiple variables into correlational studies allows, in some cases, for making legitimate causality claims. He noted that the key to examining causal relationship between variables was including mediating variables "that challenge the hypothesized causal relationship" (p. 175) thus allowing for postulating and testing several alternative causal models. Similarly, two 
recent reports by National Research Council's research committees (as cited in Schneider, Carnoy, Kilpatrick, Schmidt, \& Shavelson, 2007) emphasized the appropriateness of statistical modeling for making causal inferences regarding educational practices when the randomized field trial is not warranted or feasible. The authors noted, "Developing conceptual models and using statistical analysis to identify associations among elements of the model is an important and necessary precursor to designing randomized controlled experiments" (p. 84).

Second, a rather large set of variables identified by SLA and achievement literature to have significant impact on ELLs' academic outcomes are nonmanipulable (i.e., variables that cannot be manipulated experimentally such as age [Shadish, Cook, \& Campbell, 2002]). Shadish, Cook, and Campbell noted that the study of nonmanipulative attributes may "eventually help us to find manipulable agents that can be then used to ameliorate the problem at hand" (p. 8.). One of the anticipated outcomes of this study was establishing whether or not language learning strategies, a potentially manipulable variable, can predict ELLs' academic achievement in content areas.

\section{Population, Research Site, and Sample}

Study population and research site. The targeted population for this study constituted K-12 ELLs enrolled in grade-level classrooms in U.S. public schools. The study sample was drawn from a pool of elementary, middle, and high school ELLs receiving ESL services and enrolled in grade-level classrooms in Jefferson County Public Schools (JCPS), a large Midwestern urban school district. In the 2008-2009 school year, the district serviced more than 98,000 students enrolled in 155 schools and learning centers ( 90 elementary, 24 middle, 21 high, and 20 other learning centers) and employed 
over 6,000 teachers. The number of ELLs in the same school year was $4,850 .{ }^{36}$ All new JCPS' ELLs complete Home Language Survey and a state-mandated placement test, WIDA ACCESS Placement Test (W-APT). The district uses the results of these tests to identify limited English proficient (LEP—referred to as ELLs in this study) students and to screen for candidates for ESL services. Students who are (a) age appropriate for Grades 6 and higher, (b) are in their first year of enrollment in a U.S. school, and (c) have low English proficiency scores are placed in the district's ESL Newcomer Academy where they receive sheltered instruction, typically for about one year. ${ }^{37}$ Otherwise, students are placed in grade-level classrooms and receive additional ESL support. Once students score as proficient, they are reclassified from LEP status and are exited from ESL services. Parents of ELLs have an option of waiving ESL support services for their children. The district provides content-based instruction (integrated language and content instruction) as the primary ESL service supported by bilingual aides available in all district schools with ESL services.

Study sample and sampling procedures. The study employed purposive sampling of schools (i.e., a "selection of individuals/groups based on specific questions/purposes of the research in lieu of random sampling and on the basis of information available about these individual/gro" [Tashakorri \& Teddlie, 1998, p. 76]). To be included in the study schools had to provide: (a) grade-level content area instruction for ELLs, and (b) ESL services. The former criterion is directly linked to the dependent variables of this study and excludes the ESL Newcomer Academy from the

\footnotetext{
${ }^{36}$ ESL Department, personal communication, December 11, 2008.

${ }^{37}$ In most cases, students spend up to one year at the Newcomer Academy. In some cases, when a student arrives in the Spring, the student's time at the Newcomer Academy might span 3 semesters (JCPS ESL Department, personal communication, January 12,2008 ).
} 
sample. The latter criterion was selected because schools with ESL services have high concentrations of ELLs and allow for access to the students through ESL teachers. The total number of schools meeting the selection criteria was 40 ( 25 elementary, 8 middle, 7 high).

The inclusion criteria for ELLs within the selected schools were: (a) participation in ESL programs; (b) completion of the 2008-2009 school year within the district; and (c) enrollment in Grades 3-8, 10-11 (i.e., grades in which state-required tests in reading, math, science, and social sciences are administered). The second and third selection criteria identified students measured on the variables of interest to this study (i.e., academic achievement and English proficiency). The first selection criterion targeted students classified as LEP. As defined by federal and state laws, LEP students are ELLs who have:

[...] sufficient difficulty speaking, reading, writing, or understanding the English language and whose difficulties may deny the individual opportunity to meet the state's proficient level of achievement on state assessments and to successfully achieve in classrooms where the language of instruction is English. (KDE, 2008) To be classified as LEP, the student must be: (a) three to twenty-one years old; (b) be enrolled or preparing to enroll in secondary education institutions; (c) have a native language other than English (this includes persons born outside of the United States as well as persons born inside the country such as Native Americans or Alaska Natives), and (d) come from environments in which a language other than English is dominant.

All ELL students judged by their ESL teachers as having meaningful accesseither through adequate English skills or appropriate L1 or L2 accommodations--to the 
intent of the questions on measures collected for the study were considered as eligible for study participation. This was judged as an adequate decisional criteria because ESL teachers (a) can make a sound judgment regarding ELLs' English proficiency levels based on their everyday experiences of working with the students and on students' English proficiency data, including_W-APT placement scores not collected for this study; (b) can match, when feasible, bilingual aids - available in all ESL schools in the district—with ELLs according to the students' L1s; and (c) are experienced ${ }^{38}$ in providing accommodations to ELL students at different English proficiency levels.

Students who met the inclusion criteria-participation in ESL programs, completion of the 2008-2009 school year within the district, and enrollment in Grades 3$8,10-11$ - were identified with the help of the district's Accountability, Research, and Planning department. The total number of students meeting these criteria within $40 \mathrm{ESL}$ schools was 1,569 ELLs (Grades 3-8, 10-11).

The inclusion criteria for teachers within the eligible schools were: (a) currently employed as an ESL teacher, (b) working with ELLs in grades 3-8 and 10-11, and (c) agreed to participate in the study. ESL teachers are teachers of ELLs whose primarily content area of instruction is English language development (Diaz-Rico, 2008). Because this study was primarily interested in investigating the impact of linguistic factors on ELLs' academic achievement and because ESL teachers are the primary source of school-based language instruction for their ELL students, ESL teachers' ratings of strategy effectiveness were examined as a potential school-level predictor of student

\footnotetext{
${ }^{38}$ All ESL teachers in the district receive rigorous training on how to provide language accommodations during testing to ELLs at different English proficiency levels without influencing student responses. Accommodations may include: L1 support (e.g., oral word-for-word translation, dictionaries), reading to the student, paraphrasing, and the use of extended time.
} 
academic achievement. The number of ESL teacher who met the selection criteria was 61.

\section{Instrumentation/Measures}

Strategy Inventory for Language Learning (SILL)-ELL Student Form. This study adopted Oxford's (1990) Strategy Inventory for Language Learning (SILL version 7.0 for ESL/EFL learners), the most widely used instrument in language learning strategy research both in second and foreign language contexts. The SILL is designed to measure frequency of strategy use by language learners. The permission to use the SILL for current research given by the instrument developer, Dr. Oxford, and the copy of the instrument are provided in Appendices A and B. Average Cronbach alpha coefficient for the instrument reported in studies ranges from .67 (Hong-Nam \& Leavell, 2006) to .95 (Dreyer \& Oxford, 1996). The self-report instrument comprises 50 items grouped into six categories: (a) memory strategies ( 9 items); (b) cognitive strategies (14 items); (c) compensation strategies ( 9 items); (d) metacognitive strategies ( 9 items); (e) affective strategies (6 items); and (f) social strategies (6 items). A recent confirmatory factor analysis established that, among 15 strategy classification models examined, Oxford's six-factor taxonomy provided the most consistent account for student data (Hsiao \& Oxford, 2002). The answer categories for the five-point Likert type scales are: $1=$ Never or almost never true of me; $2=$ Usually not true of me; $3=$ Somewhat true of me; $4=$ Usually true of me; $5=$ Always or almost always true of me. Items in each category can be collapsed to produce six composite scores and a total composite score. The resulting means for each category (as well as the overall mean result) have been interpreted using 
Oxford's (1990) three level reporting scale: (a) high usage $=3.5-5.0$; (b) medium usage $=2.5-3.4 ;$ and $(\mathrm{c})$ low usage $=1.0-2.4$.

To insure comprehension by elementary ELL students (the youngest students in the study were in Grade 3; approximately 8 years old), the wording of some SILL items was simplified by a panel of elementary and ESL education specialists including an early childhood educator, an elementary teacher with background in ESL, and an ESL teacher. The modified SILL was supplemented with examples and pictures and piloted (Dillman, 2007) with a group of six third-grade ELLs with varied levels of English proficiency. Pilot testing followed a think-aloud format (i.e., the respondents read or listened to the questions and verbalized their thinking). The procedure served to evaluate item clarity (how well the respondents comprehend the questions) and to provide information about how each item "is being interpreted and whether the intent of each question is being realized" (p. 142). The results of the pilot indicated that the modified items were appropriate for elementary ELL students; in most cases, students correctly understood both the items' content and intent. The items identified as problematic (12 out of 50) were further modified based on student feedback (e.g., children understood the word "student" more easily that the word "learner"). After modifications, the readability level of the instrument was 3.2 . The validity and reliability of the modified instrumentreferred to as SILL-ELL Student Form for the remainder of this dissertation-was examined using factor analysis; the results of the validation investigation are summarized in Chapter 4. The last section of the instrument included a demographic questionnaire which collected student demographic, parental education, and native language proficiency data (see Table 3.1). 


\section{Strategy Inventory for Language Learning (SILL)-ESL Teacher Form.}

Following methodology used in a recent study (Griffiths, 2007), the researcher developed the SILL-ESL Teacher Form based on the SILL-ELL Student Form by replacing all first-person pronouns "I" with third-person nouns "students". For example, the SILLELL Student Form item, "I use flashcards to remember new English words", was paraphrased to "Students use flashcards to remember new English words" in the SILLESL Teacher Form. The instrument elicited teacher perceptions of strategy effectiveness for developing English proficiency. Teachers were asked to rate the same strategy effectiveness on a five-point Likert type scale ranging from $1=$ Very unlikely [to be effective] to $5=$ Very likely [to be effective]. The last section of the instrument collected demographic data (i.e., gender, years of teaching experience, native language, proficiency in a second language, and grades and subjects taught). These data were used to develop a descriptive profile of JCPS' ESL teachers. The SILL-ESL Teacher Form was piloted with two volunteers drawn from a pool of potential respondents (two middle school ESL teachers) following the same procedures as described in the SILL-Student Form section. The copy of the instrument is provided in Appendix C.

English Language Learning Motivation Scale (ELLMS). This study adopted four subscales from Noels, Pelletier, Clément, and Vallerand's (2000) Language Learning Orientations Scale-Intrinsic Motivation, Extrinsic Motivation, and Amotivation Subscales (LLOS-IEA). The permission of use and the copy of the instrument subscales are provided in Appendixes D and E. The subscales included: (a) Intrinsic MotivationKnowledge ( $\alpha=.85$ ); (b) Intrinsic Motivation-Accomplishment ( $\alpha=.88$ ); (c) Introjected Regulation ( $\alpha=.67$ ); and (e) External Regulation ( $\alpha=.75$ ). Each subscale comprises three 
items. To insure the continuity of scales across instruments (Dillman, 2007), the original 7-point scale was modified to a 5-point scale with the following answer categories: $1=$ Strongly disagree; $2=$ Disagree $; 3=$ Unsure $; 4=$ Agree $; 5=$ Strongly agree. All motivational items represent different reasons for learning a second language. Because the original instrument was developed for adult second/foreign language learners it was modified to better fit the present study's secondary school context. As recommended by Dillman (2007), all modifications were conducted with the help of a panel of experts and included two stages. First, the wording of original LLOS-IEA items was simplified by a panel of elementary and ESL education specialists (i.e., an early childhood educator, an elementary ESL teacher, and an ESL specialist). Second, a new panel of experts (three specialists with expertise in educational psychology, ESL, and education) rated the modified items on consistency with the original. Items rated as Somewhat Consistent to Somewhat Inconsistent were further modified using the panelists' suggestions and researcher judgment before entering the final version of the instrument.

The modified instrument-referred to as English Language Learning Motivation Scale (ELLMS) for the remainder of the dissertation, was piloted (Dillman, 2007) with six third-grade ELLs with varied levels of English proficiency. Individual pilot testing followed a think-aloud format (i.e., the respondents read or listened to the questions and verbalized their thinking). The results of the pilot indicated that the modified items were appropriate for elementary ELL students; in most cases, students correctly understood both the items' content and intent. The items identified as problematic (four out of 12) were further modified based on student feedback (e.g., children understood the expression "difficult things" more easily than the expression "difficult tasks" or "hard 
tasks"). After all modifications, the readability level of the instrument as a whole was 3.4; this was judged as an adequate reading level for Grade 3 students because data for this study were collected at the end of the school year when students begin to develop Grade 4 reading level skills. The validity and reliability of the modified instrument were examined using factor analysis; the results of the ELLMS validation investigation are summarized in Chapter 4.

\section{Assessing Comprehension and Communication in English State-to-State for}

\section{English Language Learners (ACCESS for ELLs ${ }^{\circledR}$ ). English language proficiency data} were obtained from the state-mandated English proficiency test, ACCESS for ELLs ${ }^{\circledR}$ : Form 201 (WIDA, 2008). For simplicity, the instrument will be referred to as ACCESS throughout the remainder of the paper. ACCESS is a battery of tests evaluating the English proficiency needed for successful academic performance in grade-level classrooms. Language proficiency is defined in terms of performance encompassing three criteria: "linguistic complexity-the amount and quality of speech or writing for a given situation; vocabulary usage-the specificity of words or phrases for a given context; and language control-the comprehensibility of the communication based on the amount and types of errors" (WIDA, 2007, p. ii).

ACCESS is a standards-based assessment instrument. Language performance is measured against English language proficiency standards operationalized as a set of grade-level performance indicators. The performance indicators are aligned with: (a) English proficiency levels, and (b) grade-level content area standards. English proficiency is specified by six levels representing the language development continuum ranging from $1=$ Entering the process to $6=$ Reaching the attainment of English 
language proficiency (WIDA, 2007). Level 6 indicates the student's readiness to perform in English-only classroom without additional support. Test items are designed to measure academic English language skills associated with five grade-level content area domains:

(a) social/instructional English, (b) language arts, (c) mathematics, (d) science, and (e) social studies.

The test is adoptive. That is, the level of task difficulty in each of the five measured content areas is gradually increased until the student reaches tasks beyond his or her current proficiency level. ACCESS is composed of four subsets measuring English proficiency across four language domains: listening, reading, writing, and speaking. A weighted composite score (15\% listening and speaking and 35\% reading and writing) based on the four subscales is also provided. Scores are reported in two formats: (a) proficiency levels (Level 1= Entering to Level $6=$ Reaching), and (b) standardized scale scores (100 to 600). Scaling of the scores across the test's subsets, allows for comparison across proficiency levels within and across grade levels.

The instrument has undergone multiple reiterations and pilot and field tests (Kenyon, 2006). The pilot and field tests were conducted with representative samples of ELLs in three and nine states, respectively. The total sample in the field test was 6,662 . The reported reliability indices for the four subsets range from .82 to .97 . Concurrent validity of ACCESS was established in a correlational analysis study (Gottlieb \& Kenyon, 2006). The study compared ELLs' $(N=4,985)$ performance on ACCESS and four older generation English proficiency tests, the Language Assessment Scales (LAS), the IDEA Proficiency Test (IPT), the Language Proficiency Test Series (LPTS), and the Revised Maculaitis II (MAC II). The correlations between performance on ACCESS and 
the four older generation English proficiency tests were moderate to strong. Kenyon (2006) noted that the absence of very high correlations supported the developers' claim that ACCESS measured a different construct of language proficiency, namely, academic language proficiency.

Currently, 24 states, including Kentucky, have adopted ACCESS as an annual assessment of their ELLs' progress in English. In a recent standards-to-standards alignment study (Cook \& Wilmes, 2007), 41 Kentucky curriculum and ESL specialists, reviewed the alignment between the Kentucky's Core Content for Assessment in Reading, Mathematics, and Science and the WIDA's English Language Proficiency Standards within the same content areas. The study found that, while the correspondence (i.e., depth and breadth of the content goals addressed by a standard) among the standards was moderate, the linkage (i.e., match between standards in terms of coverage) was strong. The authors concluded that the NCLB alignment requirements were adequately met. The reliability indices among reviewers ranged from .82 to .98 .

Kentucky's Core Content Tests. The Kentucky Core Content Test $(\mathrm{KCCT})^{39}$ is a criterion-referenced test that measures student progress in meeting state expectations by individual content areas and grade levels as outlined in the Kentucky Core Content for Assessment (KDE, 2005). The KCCT's measures of interest to the present study include tests in reading (administered in Grades 3-8), mathematics (administered in Grades 3-8 and in Grade 11), science (administered in Grades 4, 7, and 11), and social studies (administered in Grades 5, 8, and 11). Each content area test has six forms. Reading, mathematics, science and social studies are tested with a combination of six open-

\footnotetext{
${ }^{39}$ As the state transitions to Common Core State Standards (Common Core State Standards Initiative, 2008), KCCT use will discontinue.
} 
response and 24 multiple-choice questions. All open-response items are scored against standardized rubrics by trained scorers (on a 4-point scale). Multiple-choice items are scored as correct or incorrect. The open-response items are assigned twice as much weight as multiple-choice items. Raw scores are converted into scaled scores ranging from 0 to $80 .^{40}$

Establishing the test's reliability and validity is an ongoing process. For years 2000-2004, the reported median reliability coefficients across KCCT forms by grade and subject ranged from .81 in social science, to .89 in mathematics (KDE, 2005). Using student $(N=67,620)$ data from 1999-2002 period, a concurrent validity study (Dickinson Bacci, Koger, Hoffman, \& Thacker, 2003) found moderate to high correlations between students' KCCT and ACT (American College Test) scores. The average correlations between the same-subject tests ranged from .61 in reading, to .74 in mathematics.

JCPS' LEP students participate in all, but writing portfolio, KCCT tests after 240 days of schooling in the U.S. school systems. ${ }^{41}$ Starting with the third year of enrollment, LEP students are tested in all KCCT assessments. KCCT accommodations/modifications for a LEP student are those specified in the student's Individual Education Plan (IEP) or those that have been used with the student as part of regular instruction during the school year (KBE, 2004; KDE, 2005). LEP accommodations may include: reading to the student, paraphrasing directions, oral word-for-word translation, and the use of extended time, technology, manipulatives, and grammar- or spell-checker.

\footnotetext{
${ }^{40}$ For reporting purposes, the scale scores are differentiated by grade level using hundreds; that is Grade 3 scores are reported on a 300 to 380 scale, Grade 4 scores are reported on a 400 to 480 scale, and so forth.

${ }^{41}$ JCPS ESL Department, personal communication, March 3, 2009.
} 


\section{Study Variables: Operational Definitions}

Study variables are conceptually grouped into four student- and school-level categories. Student-level variables include: (a) background characteristics (i.e., age, L1 literacy, prior formal schooling, length of residence, and parental education); and (b) L2 profile (i.e., motivation for learning English, LLS use, and English proficiency). Schoollevel variables include: (a) school quality indicators (i.e., school poverty rate, school proficiency rate, and school ELL proficiency rate); and (b) perceived effectiveness of self-directed L2 learning (i.e., LLS effectiveness). Table 3.1 provides descriptions of each of the variables above. 
Table 3.1

Description of the Study Variables

Variables

Descriptions

\section{Dependent variables}

Reading achievement (RACH) KCCT score in reading in 2009.

Math achievement (MACH) KCCT score in math in 2009.

Science achievement (SACH) KCCT score in science in 2009.

Social studies achievement $\quad$ KCCT score in social studies in 2009.

(SSACH)

\section{Student-level predictors}

1. Background characteristics

Age

In years.

L1 literacy (L1 literacy)

Self-rated literacy skills in native language measured by two items ${ }^{\mathrm{a}}$ in the student background questionnaire: (a) "How well do you read your native language?" (b) How well do you write your native language?". The items are rated on a 4-point scales $(0=$ not at all, $1=$ not well, $2=$ well, $3=$ very well; score range from 0 to 6 ).

Prior formal schooling ${ }^{\mathrm{b}}$ Amount of formal schooling in native country: No (PRIORSC) formal education $=1$; Some formal education $=0$.

Length of residence (LOR) Time since first US school enrolment beginning from Kindergarten [in months].

Parental education (PED)

Parental educational collected by two student background questionnaire items (separately for each parent): (a) school attendance (i.e., yes/no school); and (b) the highest educational level obtained $($ Elementary school $=1$; Middle school $=$ 2 ; High school diploma $=3$; Some college $=4$; College degree $=5$; Don't know $=6$ ) . 


\section{Variables}

2. L2 profile ${ }^{c}$

English Motivation (MOTIVE)

LLS use (LLSUSE)

English proficiency (ENPROF)

School-level predictors

3. School organizational and quality indicators

High school (HSLEVEL)

Middle school (MSLEVEL)

Elementary school (reference group)

School poverty rate (POVR)

School proficiency rate

(PRRATE)

School ELL effectiveness

(ELLEFF)

4. Perceived importance of selfdirected L2 learning

LLS effectiveness (LLSEFF)
Descriptions

Composite score on ELLMS.

Composite score on SILL-Student Form.

ACCESS scores in 2009.
$0=$ not high school; $1=$ high school

$0=$ not middle school 1 = middle school

0's on MSLEVEL and HSLEVEL

Percent of students in each individual school qualified for free or reduced-price lunch.

Percent of students in each individual school scoring Proficient or Distinguished on KCCT content area assessments.

ELL-to-total difference in percent scoring Proficient or Distinguished across KCCT content area assessments within each individual school.

Average score on SILL-ESL Teacher Form ${ }^{\mathrm{c}}$ across ESL teachers in each individual school.

Note. ${ }^{\text {A} A d o p t e d ~ f r o m ~ C a r h i l l, ~ S u a ́ r e z-O r o z c o, ~ a n d ~ P a ́ e z ’ ~(2008) ~ P a r e n t a l ~ E n g l i s h ~}$

Language Skills scale (the original scale had 4 items; $\alpha=.90$ ). ${ }^{\mathrm{b}}$ These data are collected by the district as a measure of limited-or-no-formal-schooling status. Limited-or-noformal-schooling status is assigned if a student meets any of the following criteria: (a) 
enrollment in a school with school calendar less than six months a year, (b) enrollment in a school that meets for less than 20 hours a week, and (c) no school access or attendance for two or more years [District personnel, Jan 22, 2010]. ' In some analyses (e.g., correlations and SEM), scores on Motivational Assessment, SILL-Student Form, and ACCESS' subscales were treated as separate variables. ${ }^{\mathrm{d}}$ In correlational analyses, scores on SILL-ESL Teacher Form will be treated as separate variables.

\section{Data Collection Procedures}

The district collected and provided access to all de-identified student demographic and achievement data. The author collaborated with the district on the collection of the SILL (ELL Student and ESL Teacher Forms) and ELLMS; this collaboration included data collection logistics and monitoring. The timetable for data collection is summarized in Table 3.2. 
Table 3.2

Data Collection Procedures

\begin{tabular}{|c|c|c|c|c|}
\hline Data sources/Instruments & Variable measured & $\begin{array}{l}\text { Instrument } \\
\text { administrator }\end{array}$ & Time of administration & Results availability \\
\hline SIS & Demographic information & JCPS & Time of enrolment & $\begin{array}{l}\text { December 2009/January } \\
2010\end{array}$ \\
\hline ACCESS & English Proficiency & ESL teachers & January/February 2009 & May 2009/June 2009 \\
\hline $\mathrm{KCCT}$ & $\begin{array}{l}\text { Academic achievement in } \\
\text { reading, math, science, } \\
\text { and social studies }\end{array}$ & $\begin{array}{l}\text { Content area } \\
\text { teachers }\end{array}$ & April/May 2009 & $\begin{array}{l}\text { December } 2009 / \text { January } \\
2010\end{array}$ \\
\hline ELLMS & $\begin{array}{l}\text { Motivation for learning } \\
\text { English }\end{array}$ & ESL teacher & May 2009 & June 2009/August 2009 \\
\hline SILL: ELL Student-Form & Strategic learning & ESL teacher & May 2009 & June 2009/August 2009 \\
\hline SILL: ESL Teacher-Form & $\begin{array}{l}\text { Perceptions of strategy } \\
\text { effectiveness }\end{array}$ & Self & May 2009 & June 2009/August 2009 \\
\hline
\end{tabular}

Note. SIS $=$ Student Information System (district's software application used to manage student data). ACCESS = Assessing

Comprehension and Communication in English State-to-State for English Language Learners. KCCT $=$ Kentucky Core Content Test.

ELLMS = English Language Learning Motivation Scale. SILL = Strategy Inventory for Language Learning; the instrument collects some additional demographic data. 
All student data were collected using student district ID numbers. This insured the protection of students' privacy while allowing the researcher to match data. All teacher data were collected anonymously and matched to that of students' by school numbers. School quality data were obtained from open-to-public School Report Cards. These data as well as district-provided data served to derive school quality indices (e.g., poverty rate, school proficiency rate, and school ELL proficiency rate).

The district's Student Information System, SIS, (i.e., the software application used to manage student data) served as the main source of student demographic data. Additional demographic data were collected by the demographic section of SILL. ACCESS and KCCT are administered under secure conditions following the timetable, regulations, and procedures set by the district. ACCESS is administered by ESL teachers in January/February of each year. Students' tests are scored by the test developer and reported around June. KCCT is administered during the Spring testing window (2 weeks in April [high school] and 3 weeks in May [elementary and middle school]) by content area teachers and send for scoring to a third party. SILL and ELLMS were administered in May. Both instruments were stapled together, along with detachable identification information slips (e.g., name, birthday, school, and grade) and placed into manila envelopes prepared for each individual ESL teacher. Each envelope contained: (a) a letter from the district's ESL coordinator explaining the purpose of the study; (b) directions for the instruments' administration and data handling; (c) student-form instruments with a demographic questionnaire, Ll proficiency scale, and parental education scale; and (d) teacher-form instrument with a demographic questionnaire. 
The teachers were instructed to read and explain the directions to the students and to provide language accommodations and/or L1 support that have been used with the students as part of regular instruction during the school year. Teachers were also instructed to fill out their instruments anonymously and to return all completed teacher and student instruments to the district's ESL department using internal post system. The district's employees removed detachable identification information slips, affixed preprinted adhesive labels with student district IDs, and contacted the researcher for packets pick-up. Because (a) study procedures represented normal school practices, (b) data were collected by the district's employees, and (c) the researcher never had access to participants' names (i.e., student district IDs are assigned and kept by the district; the researcher did not have access to the link between IDs and participants' names), a waiver of consent/assent was requested and granted by IRB.

The following paragraphs summarize a research plan for data analyses. The analyses themselves will be reported in Chapter 4 .

\section{Data analysis plan}

Data preparation. Data preparation will include: (a) investigation of the modified SILL and ELLMS instruments, and (b) data cleaning for statistical modeling analyses (e.g., checking for assumptions, identifying and dealing with missing data, outliers, and miscodings). The investigation of the modified instrument will use a crossvalidation procedure supported by confirmatory factor analysis (CFA) and exploratory factor analysis (EFA).

Research Question 1. Analyses for Research Question 1 will be performed at: (a) individual level and (b) school level. At individual level, descriptive statistics of mean 
scores on the SILL-ELL, Teacher and Student Forms, as well as rating distributions will be reported to provide comparison data for teacher perceptions of strategy effectiveness and actual use by the learners disaggregated by educational level (elementary, middle, and high school) and strategy category (i.e., memory, cognitive, metacognitive, compensation, social, and affective).

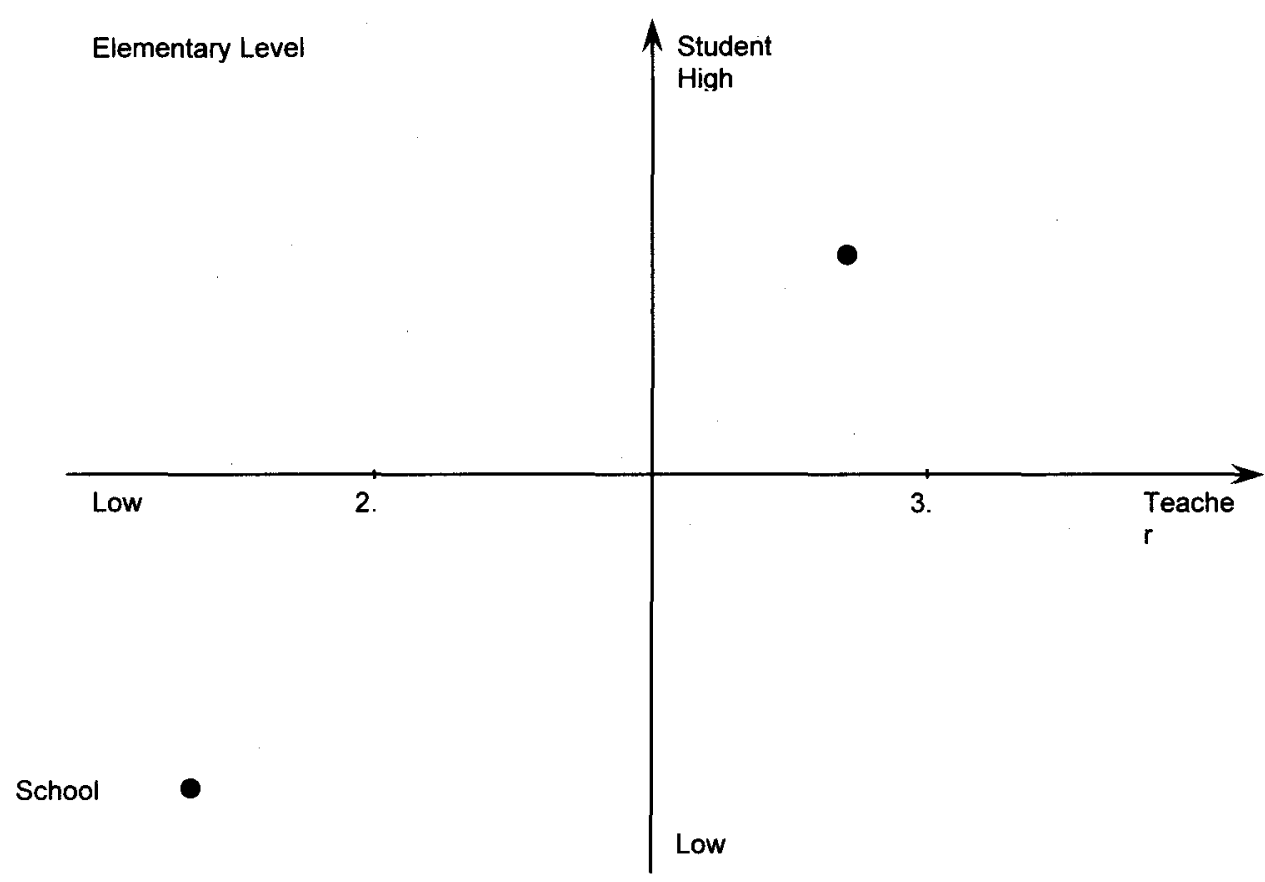

Figure 3.1. Profile of hypothetical teacher-student ratings of memory strategies effectiveness or use.

At the school level, average teacher and student ratings will be computed for each individual school and a teacher-student strategy profile for each educational level will be plotted on a quadrant with the horizontal axis representing teacher ratings from low to high, and the vertical axis representing student use from low to high. See Figure 3.1 for an illustration. This analysis will allow establishing which strategy categories have the 
most consistent agreement between teachers and students as being the most and the least effective or used. Lastly, and the strength and directionality of the relationships between teacher strategy effectiveness ratings and student strategy use computed for each individual school will be evaluated using bivariate correlational statistics.

Research Question 2. Structural Equation Modeling (SEM) will used to explore the relative contributions (both direct and indirect) of student-level variables to academic achievement. SEM refers to a family of a priori statistical procedures used to develop and test models of reality (Kline, 2005). That is, the researcher develops a model which specifies "which variables are assumed to affect other variables and the directionalities of these effects" (p. 10) and tests the fit of this model against the data. Model specifications reflect the researcher's hypotheses informed by theory, research, and intuition. The analysis will be conducted using Multiple Indicator Multiple Independent Cause (MIMIC) modeling techniques, representing a special case of SEM (Brown, 2006). MIMIC modeling is particularly appropriate because of the hypothesized interdependence and simultaneous causation among some of the student-level variables. The procedure will allow examining the direct and mediating effects of language motivation, LLS use, and academic English proficiency on academic achievement, while accounting for differential impact of relevant background predictors (also referred to as covariates) on other variables in the model. The analysis will include the following steps: (a) measurement and structural model specification and identification; (b) measurement and structural model tests of goodness of fit; (c) in case on inadequate fit, model modifications; and (d) parameter estimation (for more details see Chapter 4). The 
hypothesized relationships and directionalities among student-level predictor, mediating, and outcome variables are visually represented in Figure 3.2.

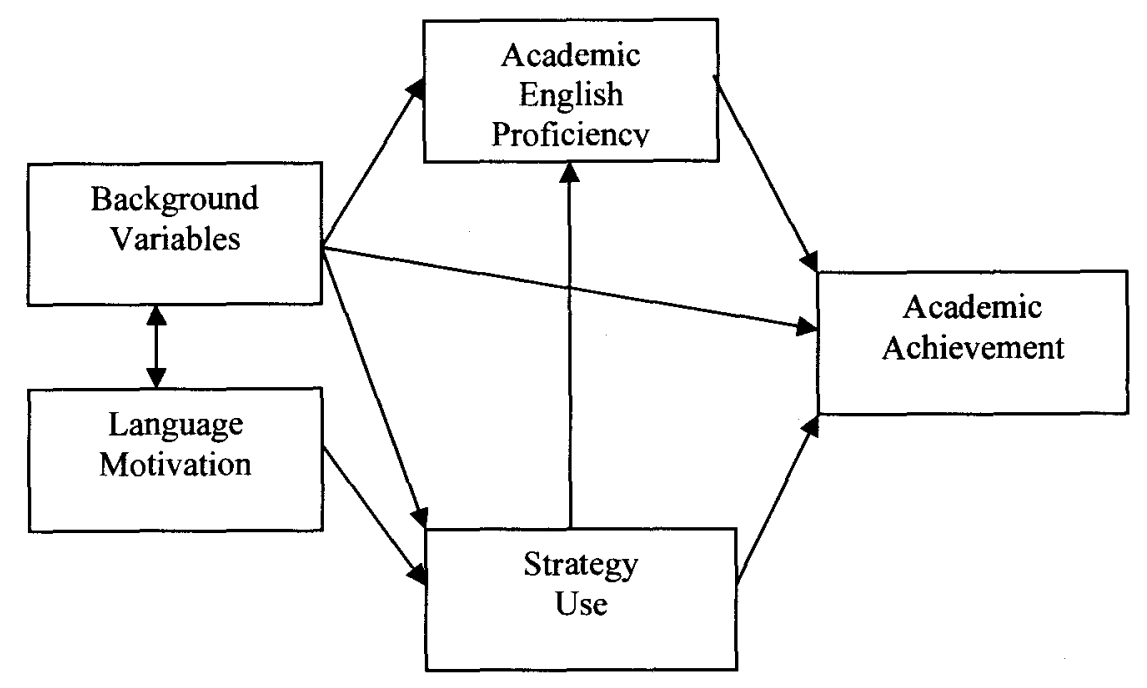

Figure 3.2 Hypothesized relationships and directionalities among student-level variables.

Research Question 3. Two-level Hierarchical Linear Modeling (HLM) will be used to ascertain the effects of student and school variables on academic achievement in specific content areas. This analysis will allow establishing the unique contributions and interaction effects—if present- of LLS on ELLs' academic achievement relative to other student- and school-level predictors. Two-submodels, one nested within a person (a student) and the other nested within an organization (a school) (Raudenbush \& Bryk, 2002) will be developed. The student-level submodel will include variables identified as direct contributors to ELLs' academic achievement by SEM analyses. The initial candidates for the model identified by the literature review include: age, LOR (length of residence), prior schooling, parental education (PED), L1 literacy, motivation for learning English (motivation), LLS use, and English proficiency. To accommodate categorical nature of the parental education data, this variable will be dummy coded. Variables at the 
school level will include educational level, campus poverty rate, school proficiency rate, school ELL effectiveness, and teacher perceptions of strategy effectiveness (LLS effectiveness). A separate HLM analysis will be conducted for each content area (i.e., reading, mathematics, social studies, and science). The hypothesized relationships among student- and school-level predictors are summarized in the following equation:

$$
\begin{aligned}
& Y_{\mathrm{ij}}=\beta_{0 \mathrm{j}}+\beta_{\mathrm{lj}}\left(\mathrm{age}_{\mathrm{ij}}\right)+\beta_{2 \mathrm{j}}\left(\mathrm{LOR}_{\mathrm{ij}}\right)+\beta_{3 \mathrm{j}}\left(\mathrm{L} 1 \text { literacy }_{\mathrm{ij}}\right)+\beta_{4 \mathrm{j}}\left(\text { prior schooling }_{\mathrm{ij}}\right) \\
& +\beta_{5 \mathrm{j}}\left(\operatorname{PED}_{\mathrm{ij}}\right)+\beta_{6 \mathrm{j}}\left(\text { motivation }_{\mathrm{ij}}\right)+\beta_{7_{\mathrm{j}}}\left(\text { LLS use }_{\mathrm{ij}}\right)+\beta_{8 \mathrm{j}}\left(\text { English proficiency }_{\mathrm{ij}}\right)+r_{\mathrm{ij}} \\
& Y_{\mathrm{ij}}=\text { test score for student } i \text { in school } j[Y=\text { reading OR mathematics OR } \\
& \text { social studies OR science] } \\
& \beta_{0 \mathrm{j}}=\text { the school KCCT mean score for each content area [reading OR } \\
& \text { mathematics OR social studies OR science] } \\
& \beta_{\mathrm{pj}}=\text { expected change in } Y_{\mathrm{ij}} \text { for a unit change in } \mathrm{X}[\mathrm{X}=\mathrm{age}, \mathrm{LOR}, \mathrm{L} 1 \\
& \text { literacy, prior schooling, PED , motivation, LLS use, English proficiency] } \\
& r_{\mathrm{ij}}=\text { unique random effect (error) for student } i \text { in school } j \text { on the test score } \\
& \left(Y_{\mathrm{ij}}\right) \\
& \beta_{0 \mathrm{j}}=\gamma_{00}+\gamma_{01}(\text { MSLEVEL })+\gamma_{02}\left(\text { HSLEVEL) }+\gamma_{03} \text { (school poverty) }+\gamma_{04}\right. \text { (school } \\
& \text { proficiency })+\gamma_{05}(\text { ELL effectiveness })+\gamma_{06} \text { (LLS effectiveness) }+u_{0 j} \\
& \gamma_{00}=\text { mean KCCT score for each content area [reading OR mathematics } \\
& \text { OR social studies OR science] for an elementary school that is average on } \\
& \mathrm{W}[\mathrm{W}=\text { school poverty rate, school proficiency rate, school ELL } \\
& \text { effectiveness, and LLS effectiveness] } \\
& \gamma_{0 j}=\text { change in } \beta_{0 j} \text { for a unit change in } \mathrm{W}[\mathrm{W}=\text { level, school poverty rate, } \\
& \text { school proficiency rate, school ELL effectiveness, and LLS effectiveness] }
\end{aligned}
$$


$u_{0 j}=$ unique random effect of school $j$ (error) on $\beta_{0 j}$ with $\mathrm{W}$ predictor variables controlled

$\beta_{\mathrm{pj}}=\gamma_{\mathrm{p} 0}+\gamma_{\mathrm{p} 1}($ MSLEVEL $)+\gamma_{\mathrm{p} 2}($ HSLEVEL $)+\gamma_{\mathrm{p} 3}($ school poverty $)+\gamma_{\mathrm{p} 4}($ school proficiency $)+\gamma_{\mathrm{p} 5}($ ELL effectiveness $)+\gamma_{\mathrm{p} 6}$ (LLS effectiveness $)+u_{\mathrm{pj}}$ $\gamma_{\mathrm{p} 0}=$ predicted (mean) X-test score slope across schools [X $=$ age, $\mathrm{LOR}$, L1 literacy, prior schooling, PED, motivation, LLS use, English proficiency]

$\gamma_{\mathrm{pj}}=$ change in the predicted $\mathrm{X}$-test score slope $(\beta \mathrm{pj})$ for a unit of change in $\mathrm{W}[\mathrm{W}=$ level, school poverty rate, school proficiency rate, school ELL effectiveness, and LLS effectiveness] $u_{\mathrm{pj}}=$ unique random effect of school $j$ (error) on the predicted X-test score slope $(\beta \mathrm{pj})$ after controlling for $\mathrm{W}$.

\section{Summary}

This chapter outlined the study's methodology including: (a) research design and justification; (b) the description of the research site, population, and sample; (c) instrumentation; (d) operational definitions of the study variables; (e) data collection procedures; and (f) a research plan for data analyses. The next chapter will provide detailed descriptions of data analyses and results. 


\section{CHAPTER 4}

\section{RESULTS}

This chapter first provides the descriptive statistics of the participating schools, teachers, and students (including attrition analysis). Then, data preparation and modified instrument validation procedures are briefly described. Finally, the statistical analyses performed and the results obtained for each research question addressed by this study are reported.

\section{Descriptive Statistics}

School sample. The number of schools who met the selection criteria—schools provide (a) ESL services and grade-level content area instruction for ELLs-was 40. Among these schools one elementary and one high school did not participate (did not administer the study instruments); thus, the final study sample at the school level included 38 schools ( 24 elementary, 7 middle, 7 high). The mean poverty rate was $69 \%$ of students on free/reduced lunch status. Average school proficiency rates ranged from $55 \%$ (reading) to $39 \%$ (social studies) of students scoring Proficient/Distinguished on KCCT test. The average ELL effectiveness rate was $-18.67 \%$. Descriptive statistics for participating schools are summarized in Table 4.1. 
Table 4.1

Descriptive Statistics for Participating Schools

\begin{tabular}{lccc}
\hline & $M$ & $S D$ & Range \\
\hline Poverty rate (POVR) & 69.1 & 17.5 & $32.6-93.9$ \\
Reading proficiency rate (PRREAD) & 55.0 & 13.4 & $26.4-81.1$ \\
Mathematics proficiency rate (PRMATH) & 46.5 & 16.6 & $15.8-83.1$ \\
Science proficiency rate (PRSC) & 40.0 & 17.8 & $8.5-71.6$ \\
Social studies proficiency rate (PRSS) & 38.7 & 17.2 & $12.1-88.8$ \\
ELL effectiveness (ELLEFF) & -18.7 & 15.6 & $-60.7-15.7$ \\
LLS effectiveness (LLSEFF) & 3.9 & 0.39 & $2.5-4.6$ \\
\hline
\end{tabular}

Note. $N_{\text {schools }}=38$

Teacher sample. The total number of teachers who met the selection criteria-(a) currently employed as an ESL teacher, (b) working with ELLs in grades 3-8 and 10-11, and (c) agreed to participate in the study - was 54 (89\% Female, $72 \%$ White, $2 \%$ Black, 13\% Hispanic, 6\% Asian/Pacific Islander, and 4\% Other). The sample included 31 elementary, 11 middle, and 12 high school teachers working in 37 schools (one teacher in a participating school did not return a completed survey). About $59 \%$ of teachers with completed demographic data were certified to teach ESL and about $94 \%$ had an ESL endorsement. On average, the participants have taught ESL for about 9 years $(M=8.78$, $S D=7.00$, range from 0 to 31 ); their overall average teaching experience-including the year of the study - was about 14 years $(M=14.09, S D=8.82$, range from 1 to 40$)$. About $30 \%(n=16)$ were non-native speakers of English. About $89 \%$ of teachers $(n=48)$ 
reported speaking at least one language in addition to English ${ }^{42}$ with an intermediate selfrated proficiency measured by a three-point scale ranging from $1=$ Beginner to $3=$ Advanced $(M=1.90, S D=0.75)$. Table 4.2 summarizes teacher demographic information by educational level.

Attrition analyses for the student sample. The total number of students within the original 40 schools who met the selection criteria at the student level-(a) participation in ESL programs, (b) completion of the 2008-2009 school year within the district, and (c) enrollment in Grades 3-8, 10-11-was 1,569 ELLs (828 elementary, 485 middle, and 256 high school students). The total attrition in the study was $33 \%(n=511)$ and included: (a) ELL students whose schools or ESL teachers refused to participate in the study, (b) ELL students who returned incomplete surveys or were absent on the day of the instrument administration, and (c) ELL students with no meaningful access to the survey contents as identified by ESL teachers (i.e., ELLs with limited English skills or no access to appropriate L1 support; see details for "b" and "c" below). Chi square analyses indicated that significantly more students at middle and high school levels dropped out of the study, $\chi^{2}(2)=103.933, p<.001$. Attrition by age level was $21 \%, 43 \%$, and $49 \%$, at elementary, middle, and high school level, respectively. However, the study participants did not significantly differ from those ELLs who dropped out of the study in terms of SES ${ }^{43}$ Ethnicity, and Gender, $\chi^{2}(1)=0.759, p=.384, \chi^{2}(4)=8.129, p=.09$, and $\chi^{2}(1)=$ $3.828, p=.05$, respectively. The marginally non-significant $p$ for gender indicated that slightly more males than females dropped out of study (i.e., $35 \%$ and $30 \%$, respectively). Students in the final sample had significantly higher English proficiency, as measured by

\footnotetext{
${ }^{42}$ On average, the teachers spoke two additional, other-than-English languages $(M=1.75, S D=0.91$, range 1 to 4 ).

${ }^{43}$ As measured by eligibility for free and reduced-price lunch.
} 
ACCESS proficiency level scores, $\chi^{2}(1)=4.749, p<.05$. This was not a concern because the selection criteria targeted students who had access to surveys administered in English—either through more advanced English skills or through native language support-thus, higher English proficiency among students in the sample was expected. In aggregate, attrition analyses results suggested that the sample was reasonably representative of its targeted population, provided that the majority of ELLs in the district are in elementary schools (about $15 \%$ of the total population at the elementary school level in contrast to about $5 \%$ at the middle and high school levels). 
Table 4.2

Descriptive Statistics for Teachers by Educational Level

\begin{tabular}{|c|c|c|c|c|}
\hline \multirow[b]{3}{*}{ Categorical } & \multicolumn{3}{|c|}{ Educational Level } & \multirow{2}{*}{$\begin{array}{c}\text { Total } \\
\text { Sample }\end{array}$} \\
\hline & Elementary & Middle & High & \\
\hline & $n(\%)$ & $n(\%)$ & $n(\%)$ & $n(\%)$ \\
\hline \multicolumn{5}{|l|}{ Gender } \\
\hline Female & $27(87 \%)$ & $10(91 \%)$ & $11(92 \%)$ & $48(89 \%)$ \\
\hline \multicolumn{5}{|l|}{ Race } \\
\hline Caucasian & $23(74 \%)$ & $8(73 \%)$ & $8(67 \%)$ & $39(72 \%)$ \\
\hline African American & $1(3 \%)$ & & & $1(2 \%)$ \\
\hline Hispanic & $4(13 \%)$ & $1(9 \%)$ & $2(17 \%)$ & $7(13 \%)$ \\
\hline Asian/Pac. Islander & $2(7 \%)$ & & $1(8 \%)$ & $3(6 \%)$ \\
\hline Other & & $1(9 \%)$ & $1(8 \%)$ & $2(4 \%)$ \\
\hline Missing & $1(3 \%)$ & $1(9 \%)$ & & $2(4 \%)$ \\
\hline \multicolumn{5}{|l|}{ ESL certification } \\
\hline Yes & $19(61 \%)$ & $6(55 \%)$ & $7(58 \%)$ & $32(59 \%)$ \\
\hline Missing & $2(7 \%)$ & $1(9 \%)$ & $1(8 \%)$ & $4(7 \%)$ \\
\hline \multicolumn{5}{|l|}{ ESL endorsement } \\
\hline Yes & $30(97 \%)$ & $11(100 \%)$ & $10(83 \%)$ & $51(94 \%)$ \\
\hline Missing & & & $1(8 \%)$ & $1(2 \%)$ \\
\hline Continuous & $M(S D)$ & $M(S D)$ & $M(S D)$ & $M(S D)$ \\
\hline Years teaching ${ }^{a}$ & $13.90(8.38)$ & $13.55(8.02)$ & $15.18(11.29)$ & $14.09(8.82)$ \\
\hline Years in $\mathrm{ESL}^{\mathrm{a}}$ & $7.90(6.07)$ & $12.95(9.52)$ & $7.09(5.36)$ & $8.78(7.00)$ \\
\hline Total N & 31 & 11 & 12 & 54 \\
\hline
\end{tabular}

Note. ${ }^{\mathrm{a}} n=53$. 
Student sample. After discarding incomplete and outlier (all 1's or all 5's) surveys $(n=58 ; 5 \%)$, the final sample included 1,057 ELL students ( $48 \%$ Female, $8 \%$ White, 27\% Black, 49\% Hispanic, 11\% Asian/Pacific Islander, 5\% Other) receiving English-as-a-second language (ESL) services and enrolled in grade-level classrooms in a large Midwestern urban school district. The sample included 651 elementary (Grades 35), 275 middle (Grades 6-8), and 131 high (Grades 10 and 11) school students attending 38 schools; this represented $22 \%$ of the total ELL population in the district. On average, as measured by ACCESS proficiency level scores, English proficiency of ELLs in the sample was intermediate, approaching advanced intermediate (Median $=3.7)$. The age of students ranged from 9 to 21 years old $(M=12.21, S D=2.80)$. About $93 \%$ of students were eligible for free and reduced-price lunch. The students spoke over 40 native languages. The top five languages included Spanish (48.3\%), Maymay (12.5\%), Somali (7.2\%), Karen (3.8\%), and Turkish (3.5\%). Other languages spoken by about 1 to $3 \%$ of students included: Arabic, Vietnamese, Swahili, Bosnian, Kirundi, Russian, Chinese (Mandarin) and world Englishes. Average time in the U.S. schools was 42.87 months (SD $=21.44$ ), or about 3.6 years. Table 4.3 summarizes demographic information by educational level. 
Table 4.3

Descriptive Statistics for Students by Educational Level

\begin{tabular}{|c|c|c|c|c|}
\hline \multirow[b]{3}{*}{ Qualitative } & \multicolumn{3}{|c|}{ Educational Level } & \multirow[b]{2}{*}{ Total Sample } \\
\hline & Elementary & Middle & High & \\
\hline & $n(\%)$ & $n(\%)$ & $n(\%)$ & $n(\%)$ \\
\hline \multicolumn{5}{|l|}{ Gender } \\
\hline Female & $313(48 \%)$ & $140(51 \%)$ & $56(43 \%)$ & $509(48 \%)$ \\
\hline Missing & $2(<1 \%)$ & $1(<1 \%)$ & $2(2 \%)$ & $5(<1 \%)$ \\
\hline \multicolumn{5}{|l|}{ Race } \\
\hline Caucasian & $55(8 \%)$ & $22(8 \%)$ & $11(8 \%)$ & $88(8 \%)$ \\
\hline Black & $143(22 \%)$ & $93(34 \%)$ & $47(36 \%)$ & $283(27 \%)$ \\
\hline Hispanic & $341(52 \%)$ & $118(43 \%)$ & $52(40 \%)$ & $512(48 \%)$ \\
\hline $\begin{array}{l}\text { Asian/Pacific } \\
\text { Islander }\end{array}$ & $73(11 \%)$ & $25(9 \%)$ & $16(12 \%)$ & $115(11 \%)$ \\
\hline Other & $37(6 \%)$ & $16(6 \%)$ & $4(3 \%)$ & $58(6 \%)$ \\
\hline Missing & $2(<1 \%)$ & $1(<1 \%)$ & $1(1 \%)$ & $1(<1 \%)$ \\
\hline \multicolumn{5}{|l|}{ SES } \\
\hline $\begin{array}{l}\text { Free/reduced } \\
\text { price lunch }\end{array}$ & $603(93 \%)$ & $259(94 \%)$ & $120(92 \%)$ & $982(93 \%)$ \\
\hline Missing & $2(<1 \%)$ & $1(<1 \%)$ & $2(2 \%)$ & $5(<1 \%)$ \\
\hline \multicolumn{5}{|l|}{ PRIORSC } \\
\hline $\begin{array}{l}\text { No/limited } \\
\text { prior school }\end{array}$ & $97(15 \%)$ & $75(27 \%)$ & $28(21 \%)$ & $200(19 \%)$ \\
\hline Missing & $2(<1 \%)$ & $1(<1 \%)$ & $2(2 \%)$ & $5(<1 \%)$ \\
\hline
\end{tabular}




\begin{tabular}{|c|c|c|c|c|}
\hline \multirow[b]{3}{*}{ Qualitative } & \multicolumn{3}{|c|}{ Educational Level } & \multirow[b]{2}{*}{ Total Sample } \\
\hline & Elementary & Middle & High & \\
\hline & $n(\%)$ & $n(\%)$ & $n(\%)$ & $n(\%)$ \\
\hline \multicolumn{5}{|l|}{$\begin{array}{l}\text { Mother school } \\
\text { attendance }\end{array}$} \\
\hline $\begin{array}{l}\text { Some formal } \\
\text { educaton }\end{array}$ & $537(83 \%)$ & $201(73 \%)$ & $96(73 \%)$ & $834(79 \%)$ \\
\hline \multicolumn{5}{|l|}{ Missing } \\
\hline \multicolumn{5}{|l|}{$\begin{array}{l}\text { Mother highest } \\
\text { degree }\end{array}$} \\
\hline No school & $114(18 \%)$ & $74(27 \%)$ & $35(27 \%)$ & $223(21 \%)$ \\
\hline Elem. school & $45(7 \%)$ & $14(5 \%)$ & $4(3 \%)$ & $63(6 \%)$ \\
\hline Middle school & $35(5 \%)$ & $25(9 \%)$ & $15(12 \%)$ & $75(7 \%)$ \\
\hline High school & $74(11 \%)$ & $45(16 \%)$ & $31(24 \%)$ & $150(14 \%)$ \\
\hline Some college & $45(7 \%)$ & $11(4 \%)$ & $13(10 \%)$ & $69(7 \%)$ \\
\hline $\begin{array}{l}\text { College } \\
\text { diploma }\end{array}$ & $104(16 \%)$ & $39(14 \%)$ & $19(15 \%)$ & $162(15 \%)$ \\
\hline Missing & $234(36 \%)$ & $67(24 \%)$ & $14(11 \%)$ & $315(30 \%)$ \\
\hline Quantitative & $M(S D)$ & $M(S D)$ & $M(S D)$ & $M(S D)$ \\
\hline Age & $10.43(1.12)$ & $13.70(1.10)$ & $17.95(1.28)$ & $12.21(2.80)$ \\
\hline LOR (in months) & $39.96(19.39)$ & $50.98(22.91)$ & $40.30(23.67)$ & $42.87(21.44)$ \\
\hline L1 literacy & $3.16(2.05)$ & $3.09(2.13)$ & $4.36(21.82)$ & $3.29(2.08)$ \\
\hline Total $N$ & 651 & 275 & 131 & 1057 \\
\hline
\end{tabular}

Note. Percent do not sum up to $100 \%$ due to rounding. $\mathrm{LOR}=$ Length of residence. 


\section{Data Preparation}

The skewness and kurtosis statistics were within an acceptable range (-2 to 2) indicating reasonably normal (univariate) data distribution across all study variables (see Tables 4.4 and 4.5 ). To test for multivariate normality and multivariate outliers, multiple regression analyses — separately for each dependent variable — were conducted accompanied by casewise diagnostics for Mahalanobis Distances (i.e., the distance of a given case from the center cluster of the remaining cases). The examination of the histograms indicated that the data met the assumption of multivariate normality. The Mahalanobis Distances test with a cut-of-criterion of $43.82(d f=19, p<0.001)$ identified nine multivariate outliers (2, 3, and 4 in elementary, middle, and high school samples); these cases were deleted from SEM and HLM analyses.

There were two types of missing data: (a) a missing value on a single item (nonresponse) within a scale (L1 literacy, ELLMS, or SILL); and (b) a missing value on a single.variable (e.g., no ACCESS, PED, or KCCT score for an individual child). Missing L1 literacy, ELLMS, and SILL scores (3 to 18\%) were imputed using series means function (i.e., replacing the missing value with the sample-based item mean score). This decision was adequate because not a single item on these three instruments had more than $2.5 \%$ (i.e., 26 out of 1057) missing scores. Because the percentage of missing ACCESS and KCCT score was small ( $<5 \%$ ), pairwise (SEM analysis) or listwise (HLM analyses) deletion of missing data was accepted as a reasonable solution.

Parental education - school attendance and the highest educational level

obtained — had the largest amount of missing data. About $35 \%$ of students had missing Mother Education data (no school-attendance response: 1\%; no mother-educational-level 
response: $34 \%$ ); $38 \%$ of students had missing Father Education data (no schoolattendance response: $7 \%$; no father-educational-level response: $31 \%$ ). Because all surveys in the final sample had parental education data - either school attendance or highest educational level—for at least one parent, this issue was addressed by retaining only Mother Education (the variable with the least amount of missing data) for further analyses and by substituting missing Mother Education data with existing Father Education data. This decision was adequate because Mother and Father Education highly and significantly correlated, $r_{\mathrm{s}}(588)=.82, p<.001$, suggesting that the parents in the same household tended to have similar educational backgrounds. This solution resulted in no missing data for mother school attendance; however, a substantial amount of missing data on mother highest-educational-level-attained remained $(36 \%, 24 \%$, and $11 \%$ in elementary, middle, and high school samples, respectively). 
Table 4.4

Psychometric Properties of the District-Collected Study Variables for the Total Sample

\begin{tabular}{lccccccc}
\hline & \multicolumn{7}{c}{ Range } \\
\cline { 2 - 8 } & $n$ & $M$ & $S D$ & Potential & Actual & Skew & Kurtosis \\
\hline L2 proficiency & 999 & 339.40 & 32.49 & $100-600$ & $187.0-418.0$ & -0.456 & 0.240 \\
KCCT Read & 857 & 33.01 & 17.50 & $0-80$ & $0.0-80.0$ & 0.073 & -0.250 \\
KCCT Math & 874 & 29.26 & 21.50 & $0-80$ & $0.0-80.0$ & 0.318 & -0.764 \\
KCCT Science & 316 & 26.19 & 17.14 & $0-80$ & $0.0-78.0$ & 0.342 & -0.393 \\
KCCT Social Studies & 330 & 23.40 & 17.34 & $0-80$ & $0.0-80.0$ & 0.457 & -0.209 \\
\hline
\end{tabular}

Note L2 proficiency $=$ ACCESS composite scale score. $\mathrm{KCCT}=$ Kentucky Core Content

Test. KCCT sample sizes vary because of the districts' by-grade testing pattern: Reading was tested in Grades 3-8 and 10; mathematics in Grades 3-8 and 11; science in Grades 4, 7, and 11; and social studies in Grades 5, 8, and 11.

\section{Modified Instruments' Validity and Reliability}

English Language Learning Motivation Scale (ELLMS). The validation of

ELLMS for use with school-aged ELLs was informed by the instrument validation methodology developed by Byrne $(1993)^{44}$ and was conducted in three steps. The three steps included: (a) randomly splitting the data into two halves (i.e., calibration and validation samples) and testing the ELLMS' four-factor measurement model with the calibration sample using confirmatory factor analysis techniques (CFA; Byrne, 2001); (b) using exploratory factor analysis (EFA) and CFA post-hoc techniques, to identify areas of misfit and to propose and test alternative models; and (c) to cross-validate the

\footnotetext{
${ }^{44}$ In Byrne's (1993) study, a general measure of work-related burnout (the Maslach Burnout Inventory) was validated for use with elementary-, middle-, and high-school teachers.
} 
alterative model in validation sample. The results indicated that ELL data were best explained by a three-factor solution: (a) Intrinsic Motivation ${ }^{45}$ (IM; 6 items, $\alpha=.75$ ); (b) Introjected Regulation (INR; 2 items, $\alpha=.69$ ); and (c) External Regulation (EXR; 4 items, $\alpha=.58$ ). The overall reliability coefficient was .80 . Appendix F summarizes the modified ELLMS. Although the reliability coefficients were lower than those reported in the original LLOS-IEA validation study (Noels et al., 2000) they were within the acceptable norms in social research and were most likely due to the instrument's being administered in a non-native language. The validation procedures are reported in greater detail in Ardasheva, Tong, and Tretter (2010). Table 4.5 summarizes the ELLMS' psychometric properties.

Strategy Inventory for Language Learning (SILL)_ELL Student Form. The validation of the SILL-ELL Student Form included two stages. The procedures used in Stage 1 repeated those employed for the ELLMS' validation described earlier. The results of Stage 1 revealed that the 50-Item SILL was inadequate for use with school-aged ELL students. In Stage 2, a shorter version of SILL designed for use with school-aged ELLs was developed based on recommendations in the language learning strategy literature (e.g., Cohen, 1998; Hsio \& Oxford, 2002). ${ }^{46}$ The development of this sorter version was based on information learned in Stage 1, expert input, language learning strategy literature, and EFA. The final model developed using CFA techniques provided the most

\footnotetext{
${ }^{45}$ This conceptualization of IM as a unique construct is consistent with earlier SDT conceptualizations (Deci \& Ryan, 1985; Deci et al., 1991; Noels et al., 1999) and recent research (Noels, 2001; Pae, 2008). ${ }^{46}$ Among areas of suggested SILL improvement Hsiao and Oxford (2002), for example, recommended: (a) establishing the same level of item specificity (i.e., insuring that items are non-generic, worded in such a way that the context of strategy application is clear for the respondents); (b) distinguishing items that are appropriate for second versus foreign language contexts (i.e., while watching shows in L2 contexts represents a conscious learning strategy on the part of a foreign language learner, the same behavior may simply represent an everyday reality for a second language learner); and (c) reclassifying strategies to produce a more clear distinction among categories (i.e., rephrasing or eliminating strategies that may be categorized in more than one category).
} 
adequate account of school-aged ELL student data. This model retained the six-factor structure and included 28 original SILL items: (a) Memory Strategies (MEM; 7 items, $\alpha$ $=.77$ ); (b) Cognitive Strategies (COG; 5 items, $\alpha=.63$ ); (c) Compensation Strategies (COMP; 5 items, $\alpha=.63$ ); (d) Metacognitive Strategies (META; 4 items, $\alpha=.72$ ); (e) Affective Strategies (AFF; 3 items, $\alpha=.71$ ); and (f) Social Strategies (SOC; 4 items, $\alpha=$ $.75)$. The overall reliability coefficient was .90 . The validation procedures are reported in greater detail in Ardasheva and Tretter (2010). Appendix G summarizes the modified SILL_ELL Student Form. Psychometric properties of the SILL_ELL Student Form are summarized in Table 4.5.

Strategy Inventory for Language Learning (SILL)-ESL Teacher Form. Due to small sample size, only the reliability of the teacher form scales was examined. The reliability indices for the subscales (same number of items per scale as SILL-ELL Student form) varied between $.53-.82$. The overall reliability coefficient was .90 . Appendix H summarizes the modified SILL_ESL Student Form. The psychometric properties of the SILL_ESL Teacher Form are summarized in Table 4.5. 
Table 4.5

Psychometric Properties of the Researcher-Collected Study Variables for the Total Sample

\begin{tabular}{|c|c|c|c|c|c|c|c|c|}
\hline & \multicolumn{8}{|c|}{ Range } \\
\hline & $n$ & $M$ & $S D$ & $\alpha$ & Potential & Actual & Skew & Kurtosis \\
\hline \multicolumn{9}{|c|}{$\begin{array}{l}\text { SILL-ELL } \\
\text { Student Form }\end{array}$} \\
\hline Memory & 1057 & 3.12 & 0.85 & .77 & $1-5$ & $1.0-5.0$ & -0.19 & -0.45 \\
\hline Cognitive & 1057 & 3.45 & 0.84 & .63 & $1-5$ & $1.0-5.0$ & -0.21 & -0.51 \\
\hline Comp. & 1057 & 3.05 & 0.87 & .63 & $1-5$ & $1.0-5.0$ & -0.00 & -0.62 \\
\hline Meta. & 1057 & 4.01 & 0.82 & .72 & $1-5$ & $1.0-5.0$ & -0.84 & 0.15 \\
\hline Affective & 1057 & 2.76 & 1.10 & .71 & $1-5$ & $1.0-5.0$ & 0.15 & -1.04 \\
\hline Social & 1057 & 3.45 & 1.04 & .75 & $1-5$ & $1.0-5.0$ & -0.33 & -0.73 \\
\hline Total & 1057 & 3.30 & 0.69 & .90 & $1-5$ & $1.3-5.0$ & -0.09 & -0.42 \\
\hline \multicolumn{9}{|c|}{$\begin{array}{l}\text { SILL_ESL } \\
\text { Teacher Form }\end{array}$} \\
\hline Memory & 54 & 4.01 & 0.58 & .76 & $1-5$ & $2.1-5.0$ & -0.87 & 1.68 \\
\hline Cognitive & 54 & 4.04 & 0.62 & .73 & $1-5$ & $2.0-5.0$ & -0.83 & 0.86 \\
\hline Comp. & 54 & 3.74 & 0.50 & .53 & $1-5$ & $2.2-5.0$ & -0.16 & 1.10 \\
\hline Meta. & 54 & 4.04 & 0.72 & .86 & $1-5$ & $1.8-5.0$ & -0.60 & 0.58 \\
\hline Affective & 54 & 3.09 & 0.86 & .69 & $1-5$ & $1.0-4.7$ & -0.38 & -0.49 \\
\hline Social & 54 & 4.04 & 0.76 & .82 & $1-5$ & $1.8-5.0$ & -1.01 & 1.27 \\
\hline Total & 54 & 3.88 & 0.47 & .90 & $1-5$ & $2.5-4.9$ & -0.66 & 1.37 \\
\hline
\end{tabular}




\begin{tabular}{ccccccccc}
\hline & \multicolumn{7}{c}{ Range } \\
\cline { 2 - 9 } & $n$ & $M$ & $S D$ & $\alpha$ & Potential & Actual & Skew & Kurtosis \\
\hline ELLMS & & & & & & & & \\
IM & 1057 & 3.91 & 0.75 & .75 & $1-5$ & $1.0-5.0$ & -0.78 & 0.53 \\
INR & 1057 & 3.83 & 1.12 & .69 & $1-5$ & $1.0-5.0$ & -0.91 & 0.06 \\
EXR & 1057 & 4.27 & 0.70 & .58 & $1-5$ & $1.3-5.0$ & -1.06 & 0.93 \\
Total & 1057 & 4.02 & 0.63 & .80 & $1-5$ & $1.1-5.0$ & -0.76 & 0.70 \\
L1 literacy & 1057 & 4.32 & 2.08 & .87 & $0-6$ & $0.0-6.0$ & -0.22 & -1.20 \\
\hline
\end{tabular}

Note. SILL $=$ Strategy Inventory for Language Learning. Comp $=$ Compensation strategies. Meta $=$ Metacognitive strategies. ELLMS = English Language Learning Motivation Scale. $\mathrm{IM}=$ Intrinsic Motivation. $\mathrm{INR}=$ Introjected Regulation. $\mathrm{EXR}=$ External Regulation.

\section{Research Question 1}

The purpose of Research Question 1 was to compare teacher perceptions of strategy effectiveness and student self-reported strategy use. In addressing this research question, two types of analyses were performed: (a) at individual level and (b) at school level.

\section{Individual Level Analyses}

At individual level, the data obtained from the SILL-ELL (Student and Teacher Forms) were analyzed using (a) descriptive statistics and (b) rank orderings (see below). Means were calculated in order to determine the average levels of strategy effectiveness and use reported by the participants for each individual strategy category as well as for the overall (total) strategy use. Table 4.6 summarizes individual level descriptive 
statistics for teacher and student strategy ratings disaggregated by educational level. To maintain continuity in interpreting teacher and students data, the obtained means were examined using Oxford's (1990) three-level interpretative scale, where strategy use and effectiveness average scores were categorized as high (range: $3.5-5.0$ ), medium (range: $2.5-3.4$ ), and low (range: $1.0-2.4$ ). 
Table 4.6

Individual Level Descriptive Statistics for Teacher and Student Strategy Ratings Disaggregated by Educational Level

\begin{tabular}{|c|c|c|c|c|c|c|}
\hline & \multicolumn{6}{|c|}{ Educational level } \\
\hline & \multicolumn{2}{|c|}{ Elementary } & \multicolumn{2}{|c|}{ Middle } & \multicolumn{2}{|c|}{ High } \\
\hline & $M(S D)$ & Range & $M(S D)$ & Range & $M(S D)$ & Range \\
\hline \multicolumn{7}{|l|}{ Teacher } \\
\hline Memory & $4.15(0.44)$ & $3.14-5.00$ & $4.01(0.58)$ & $3.00-5.00$ & $3.65(0.76)$ & $2.14-4.86$ \\
\hline Cognitive & $4.06(0.60)$ & $2.80-4.80$ & $4.11(0.54)$ & $3.40-5.00$ & $3.92(0.76)$ & $2.00-4.80$ \\
\hline Compensation & $3.68(0.50)$ & $2.20-4.80$ & $3.71(0.38)$ & $3.20-4.40$ & $3.90(0.60)$ & $2.80-5.00$ \\
\hline Metacognitive & $4.02(0.60)$ & $3.00-5.00$ & $4.09(1.04)$ & $1.75-5.00$ & $4.02(0.72)$ & $2.50-5.00$ \\
\hline Affective & $3.07(0.74)$ & $1.67-4.33$ & $3.18(1.04)$ & $1.00-4.67$ & $3.04(1.02)$ & $1.67-4.67$ \\
\hline Social & $4.07(0.71)$ & $2.25-5.00$ & $4.02(0.94)$ & $1.75-5.00$ & $3.98(0.76)$ & $2.00-5.00$ \\
\hline Total & $3.90(0.38)$ & $3.25-4.64$ & $3.90(0.60)$ & $2.54-4.86$ & $3.78(0.57)$ & $2.46-4.68$ \\
\hline$N$ & \multicolumn{2}{|c|}{31} & \multicolumn{2}{|c|}{11} & \multicolumn{2}{|c|}{12} \\
\hline
\end{tabular}




\begin{tabular}{|c|c|c|c|c|c|c|}
\hline & \multicolumn{6}{|c|}{ Educational level } \\
\hline & \multicolumn{2}{|c|}{ Elementary } & \multicolumn{2}{|c|}{ Middle } & \multicolumn{2}{|c|}{ High } \\
\hline & $M(S D)$ & Range & $M(S D)$ & Range & $M(S D)$ & Range \\
\hline \multicolumn{7}{|l|}{ Student } \\
\hline Memory & $3.16(0.86)$ & $1.00-5.00$ & $3.05(0.87)$ & $1.00-5.00$ & $3.06(0.74)$ & $1.00-4.71$ \\
\hline Cognitive & $\mathbf{3 . 5 0}(0.85)$ & $1.00-5.00$ & $3.30(0.82)$ & $1.40-5.00$ & $3.47(0.79)$ & $1.20-5.00$ \\
\hline Compensation & $3.04(0.88)$ & $1.00-5.00$ & $3.03(0.84)$ & $1.00-5.00$ & $3.10(0.85)$ & $1.00-5.00$ \\
\hline Metacognitive & $4.03(0.82)$ & $1.25-5.00$ & $3.89(0.84)$ & $1.00-5.00$ & $4.13(0.78)$ & $1.75-5.00$ \\
\hline Affective & $2.81(1.21)$ & $1.00-5.00$ & $2.51(1.15)$ & $1.00-5.00$ & $3.00(1.16)$ & $1.00-5.00$ \\
\hline Social & $3.48(1.05)$ & $1.00-5.00$ & $3.28(1.04)$ & $1.00-5.00$ & $3.66(0.97)$ & $1.00-5.00$ \\
\hline Total & $3.33(0.70)$ & $1.43-5.00$ & $3.19(0.70)$ & $1.25-4.86$ & $3.37(0.63)$ & $1.36-4.71$ \\
\hline$N$ & \multicolumn{2}{|c|}{651} & \multicolumn{2}{|c|}{275} & \multicolumn{2}{|c|}{131} \\
\hline
\end{tabular}

Note. The means are interpreted based on three-level scale adopted from Oxford (1990): (a) high effectiveness or use (means range: 3.5-5.0); (b) medium effectiveness or use (means range: 2.5 - 3.4); and (c) low effectiveness or use (means range: $1.0-2.4)$.

Numbers in bold represent high strategy use (student) or effectiveness (teacher) scores. 
Further, to compare trends in teacher versus student data, strategy rank orderings were created separately for the teachers and for the students from their respective mean scores. This was conducted as follows: (a) teacher average responses were rank ordered in order from 1 = most effective (i.e., the highest mean score) to $6=$ least effective (i.e., the lowest mean score); and (b) student average responses were rank ordered in order from 1 = most frequently used (i.e., the highest mean score) to $6=$ least frequently used (i.e., the lowest mean score). This analysis allowed evaluating the relative standing of each individual strategy category in comparison to other strategy categories with regard to its effectiveness and frequency-of-use evaluations by teachers and students. These results disaggregated by educational level are summarized in Table 4.7 (for a graphic representation of the data see Figure I1, Appendix I). 
Table 4.7

Rank Ordering of Teacher and Student Perceptions of Strategy Effectiveness and Use Disaggregated by Educational Level

\begin{tabular}{|c|c|c|c|}
\hline \multirow[b]{2}{*}{ Rank ordering } & \multicolumn{3}{|c|}{ Educational Level } \\
\hline & Elementary & Middle & High \\
\hline \multicolumn{4}{|l|}{ Teacher } \\
\hline 1 (most effective) & Memory & Cognitive & Metacognitive \\
\hline 2 & Social & Metacognitive & Social \\
\hline 3 & Cognitive & Social & Cognitive \\
\hline 4 & Metacognitive & Memory & Compensation \\
\hline 5 & Compensation & Compensation & Memory \\
\hline 6 (least effective) & Affective & Affective & Affective \\
\hline$N$ & 31 & 11 & 12 \\
\hline \multicolumn{4}{|l|}{ Student } \\
\hline 1 (most frequent) & Metacognitive & Metacognitive & Metacognitive \\
\hline 2 & Cognitive & Cognitive & Social \\
\hline 3 & Social & Social & Cognitive \\
\hline 4 & Memory & Memory & Compensation \\
\hline 5 & Compensation & Compensation & Memory \\
\hline 6 (least frequent) & Affective & Affective & Affective \\
\hline$N$ & 651 & 275 & 131 \\
\hline
\end{tabular}

Teacher strategy effectiveness ratings profile. Consistently across educational levels, teachers participating in this study reported ascribing a high level of effectiveness to LLS. The overall averages by educational level were: $M=3.90(S D=0.38), M=3.90$ 
$(S D=0.60)$, and $M=3.78(S D=0.57)$, for elementary, middle, and high school, respectively (see Table 4.6). Further, all individual strategy use categories but affective ( $M=3.07, M=3.18$, and $M=3.04$, for elementary, middle, and high school, respectively) were reportedly ascribed a high level of effectiveness, suggesting a strong awareness of the effectiveness of LLS among teachers.

As indicated by the small standard deviations, there was relatively high level of agreement among teachers regarding strategy ratings. That is, teacher scores dispersed relatively tightly around the mean scores suggesting that teachers-within the same educational level — tended to provide similar effectiveness ratings to individual strategy categories. However, as illustrated in Table 4.7, there were some discrepancies in terms of strategy rank ordering by educational level. The top $\left(1^{\text {st }}\right)$ ranking strategy categories within each educational level were: memory $(M=4.15)$, cognitive $(M=4.11)$, and metacognitive $(M=4.02)$ for elementary, middle, and high school teachers, respectively. Affective strategy category consistently had the lowest rank orderings across levels. The rank ordering of memory category decreased by educational level, from the top position at the elementary school level to the $4^{\text {th }}$ and $5^{\text {th }}$ positions at the middle and high school level, respectively. By contrast, the rank ordering of metacognitive category increased, from the $4^{\text {th }}$ position at the elementary school level to the $2^{\text {nd }}$ and $1^{\text {st }}$ positions at the middle and high school level, respectively. These results suggest that teacher perceptions of strategy effectiveness may be influenced by the age of their students.

Student strategy use profile. Consistently across educational levels, students who participated in this study reported an overall medium frequency of strategy use ( $M=$ 3.33, $S D=0.70 ; M=3.19, S D=0.70$; and $M=3.37, S D=0.63$ ), for elementary, middle, 
and high school, respectively (see Table 4.6). With some notable exceptions (discussed next), this frequency range was typical for most of the individual strategy categories; none of the strategy categories were reportedly used at a low rate of frequency.

Consistently across educational levels, a high rate of frequency was reported for metacognitive category $(M=4.03, M=3.89$, and $M=4.13$ for elementary, middle, and high school, respectively). Further, social and cognitive categories were reportedly used at a high rate of frequency — or at a rate approaching the-high-rate-of-frequency benchmark-by high and elementary school students. The overall results suggest a potential need for the students to increase their strategy use in order to facilitate their L2 learning.

As indicated by standard deviations and score ranges, individual students tended to vary greatly with regard to their strategy use. However, on average, there were striking similarities in terms of strategy rank ordering across educational levels (see Table 4.7). This was especially evident for elementary and middle school students. Strategy rank ordering for these two groups of students were: metacognitive strategies at the top, followed by cognitive, social, memory, compensation, and affective strategies. In contrast to elementary and middle school students, social and compensation strategies ranked higher and cognitive and memory strategies ranked lower among high school students. Regardless of educational level, students consistently reported using metacognitive strategies most (see above) and affective strategies least $(M=2.81, M=2.51$, and $M=$ 3.0 for elementary, middle, and high school, respectively).

Comparison of teacher and student LLS rank orderings. Although student SILL_ELL average scores tended to be lower than that of the teachers (see Table 4.6), 
the comparison of teacher and student LLS rank orderings revealed a perfect and a near perfect alignment at the high and middle school levels, respectively (see Table 4.7). The only discrepancy at the middle school level was the rank ordering of the top two strategy categories - metacognitive and cognitive-ranked, in reverse order, as the top and second to the top by both students and teachers. This is an encouraging results because of the potentially "good accord between students and teachers" and "positive consequences in terms of classroom dynamics" (Griffiths, 2007, p. 96).

A possible area of concern may be the discrepancies in LLS rank orderings by elementary school teachers and students. Although there was much agreement or near agreement between teachers and students with regard to social, cognitive, compensation, and affective category rankings, metacognitive strategies received the top student rank ordering, but only $4^{\text {th }}$ teacher rank ordering. In reverse, memory strategies, received the top teacher rank ordering, but only $4^{\text {th }}$ student rank ordering. As noted by a number of authors (e.g., Oxford, Ehrman, \& Lavine, 1991; Griffiths, 2007; Griffiths \& Parr, 2001), such perceptual gaps may be disruptive for classroom dynamics.

It is also important to keep in mind that while there were substantial similarities between teachers' and students' LLS category rank orderings, teacher and student scores differed qualitatively, with most of the teacher scores being above the high level benchmark and most of the student scores within the medium level benchmark.

\section{Within-School Teacher-Student Strategy Profiles}

Within-school strategy profiles were examined in two ways. First, to identify strategy categories having the most consistent agreement between teachers and students as being the most and the least effective or used, average category ratings computed for 
each individual school and disaggregated by educational level (elementary, middle, high school) were plotted on a quadrant with the horizontal axis representing teacher ratings from low to high, and the vertical axis representing student use from low to high. Similar to analyses reported above, the obtained within-school means were examined using Oxford's (1990) three-level reporting scale, where strategy use and effectiveness ratings were categorized as high (range: $3.5-5.0$ ), medium (range: $2.5-3.4$ ), and low (range: $1.0-2.4)$. Second, the within-school relationships between teacher and student strategy ratings were examined using correlational analyses, using schools (23 elementary, 7 middle, and 7 high) as the unit of analysis.

Plots of within-school teacher-student strategy ratings by educational level are depicted in Figures 4.1 through 4.3. Table 4.8 summarizes the results of these analyses. The examination of the data plots revealed four distinct trends in teacher-student strategy profiles including: (1) fully-crossed ratings (e.g., high-high or medium-medium); (2) partially-crossed ratings (e.g., high-medium/high); (3) adjacent, non-crossed ratings (e.g., high-medium); and (4) no detectable pattern of agreement. Representing different points on a teacher-student level-of-agreement continuum these trends were labeled as follows: (a) high agreement (fully-crossed ratings); (b) moderate agreement (partially-crossed ratings); (c) moderate disagreement (adjacent, non-crossed ratings); and (d) strong disagreement (no detectable pattern of agreement). However visual examination of the data (see Figures 4.1 through 4.3 ) reveals that none of the strategy categories elicited perfect alignment in teacher-student strategy ratings. Thus, the four profiles discussed below represent tendencies in the data rather than absolute, exclusive categories. 

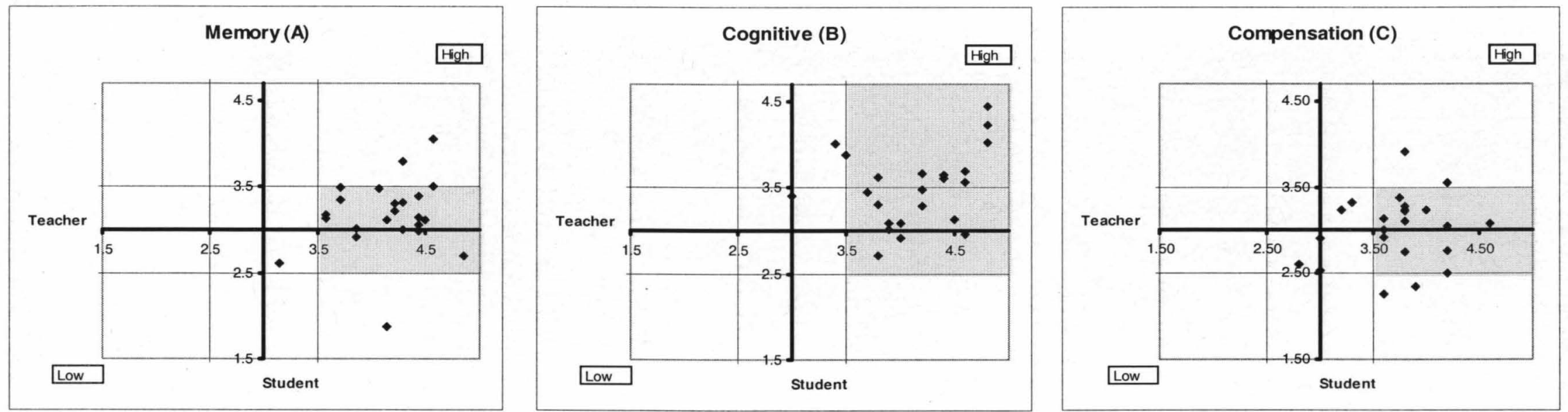

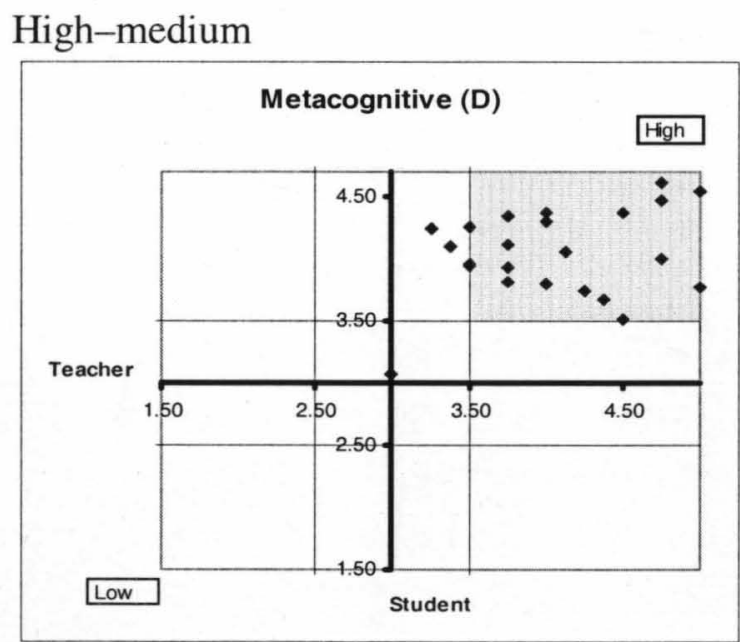

High-high
High-medium/high

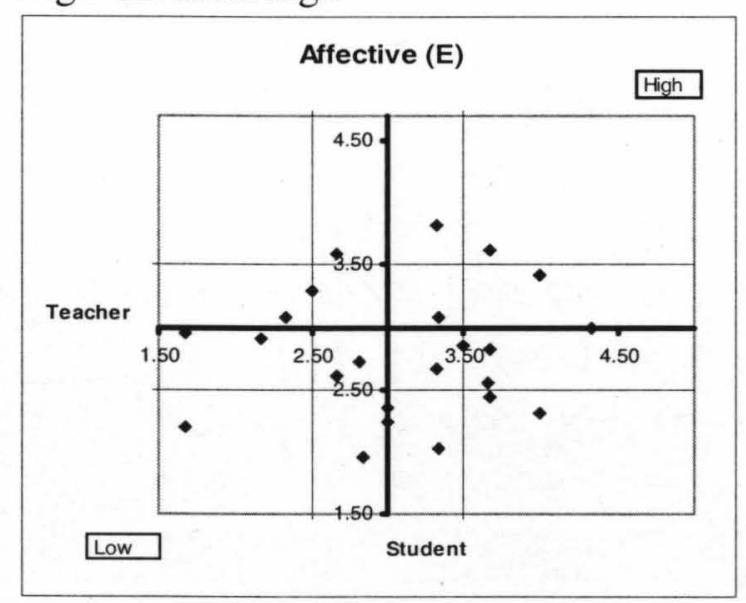

No detectable pattern

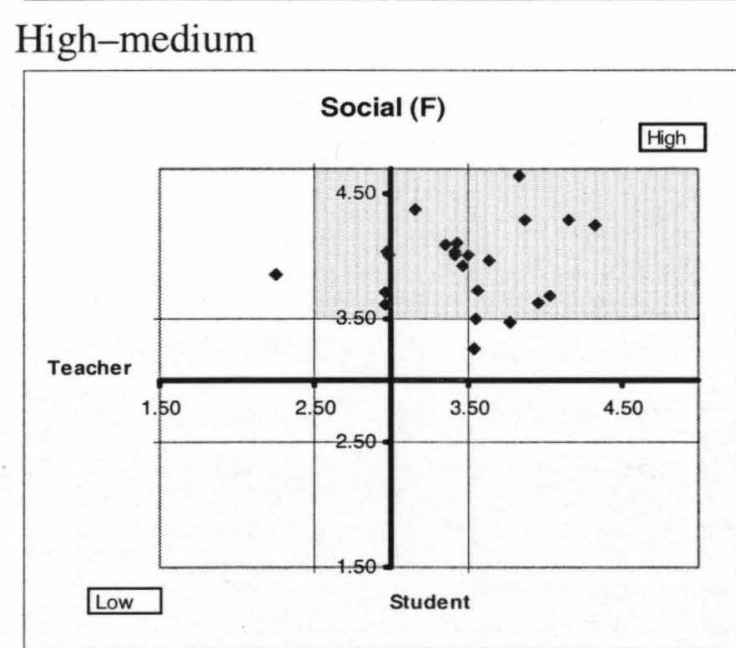

High/medium-high

Figure 4.1. Elementary school profile of teacher-student ratings of learning strategies effectiveness and use. $N_{\text {schools }}=23$. Shaded areas represent "common ground" (areas of most teacher-student agreement). 

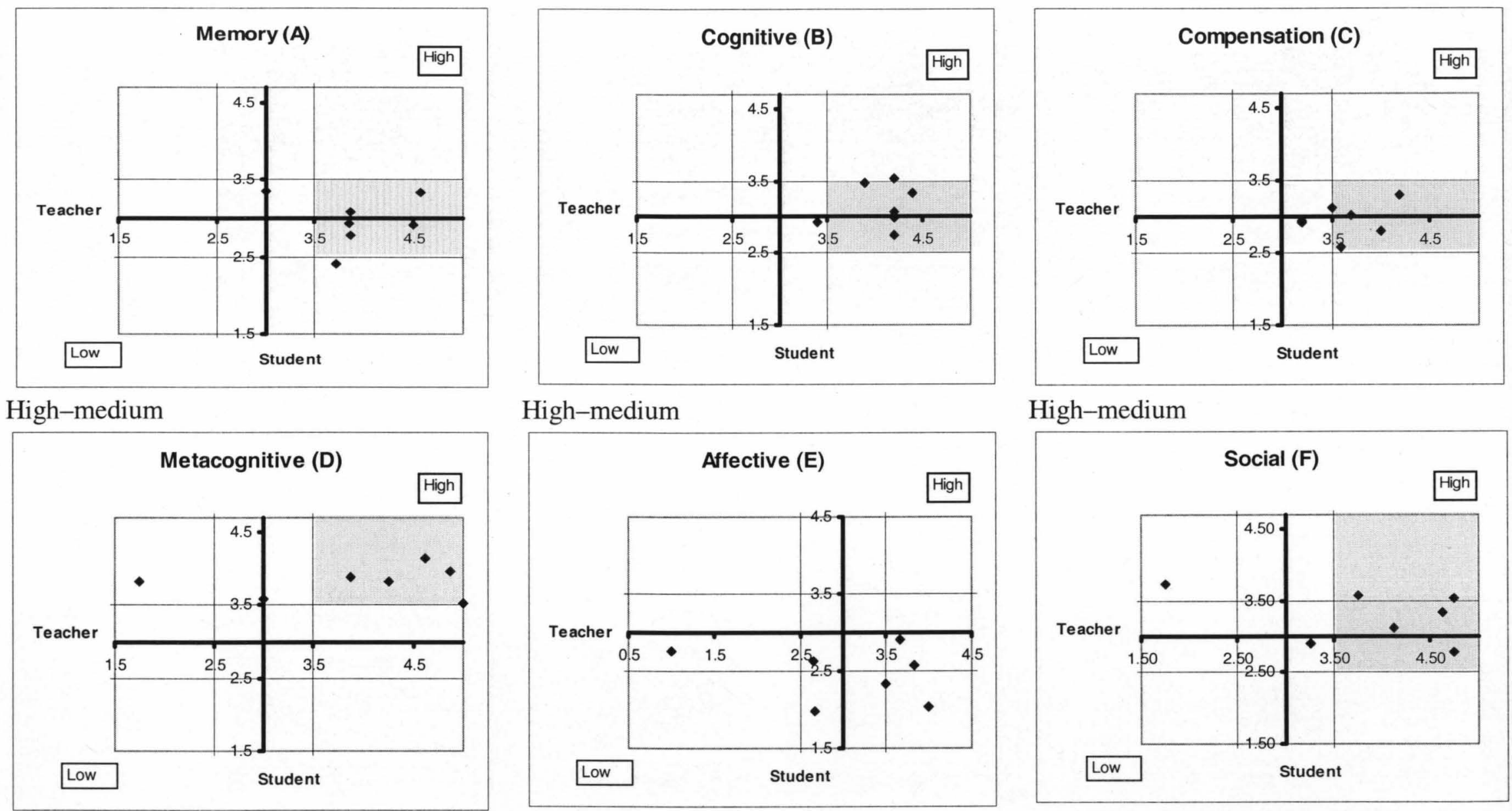

High-high

No detectable pattern

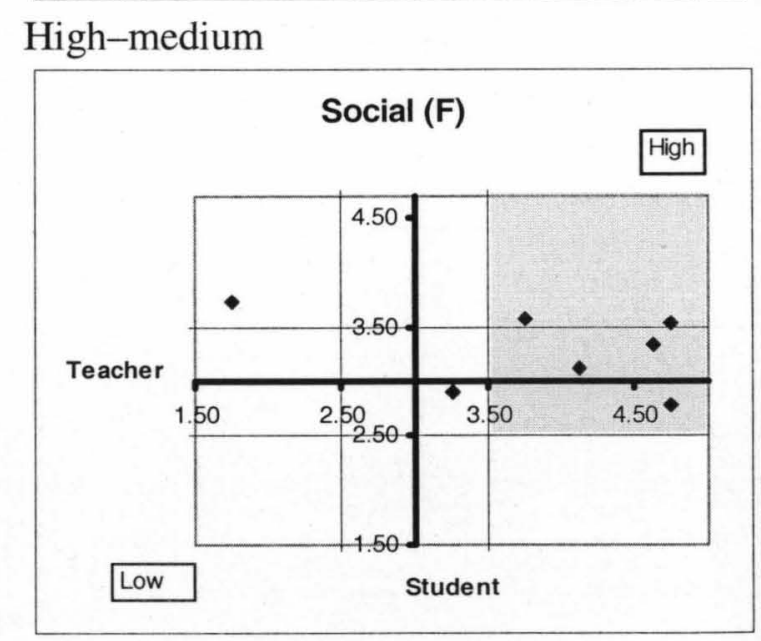

High-medium/high

Figure 4.2. Middle school profile of teacher-student ratings of learning strategies effectiveness and use. $N_{\text {schools }}=7$. Shaded areas represent "common ground" (areas of most teacher-student agreement). 

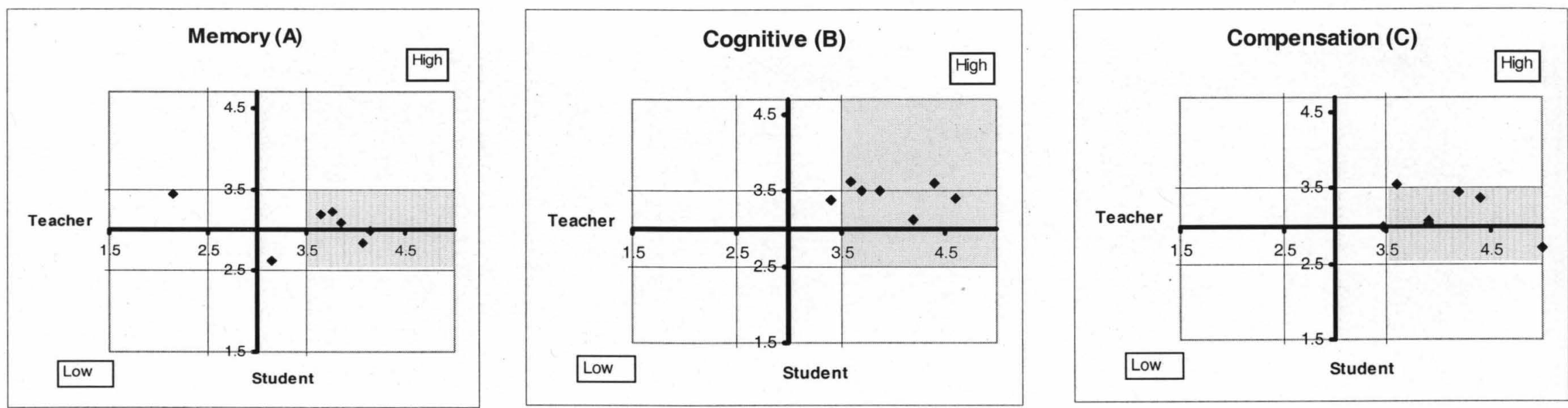

High-medium

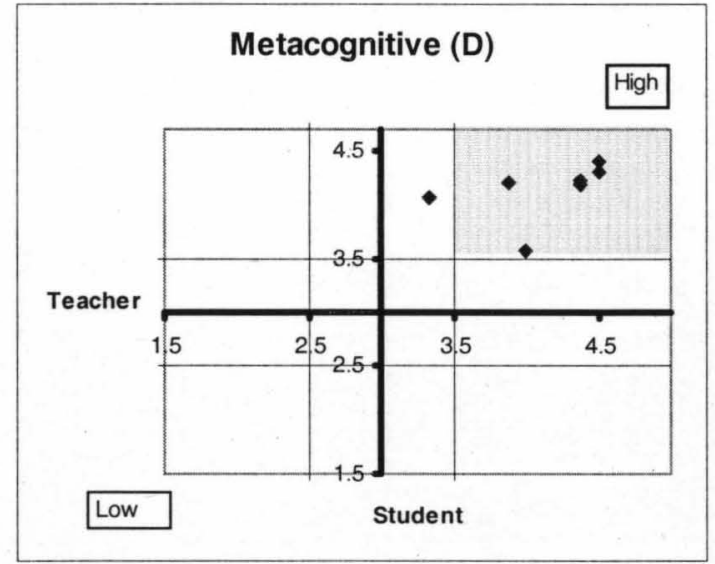

High-high

High-medium/high

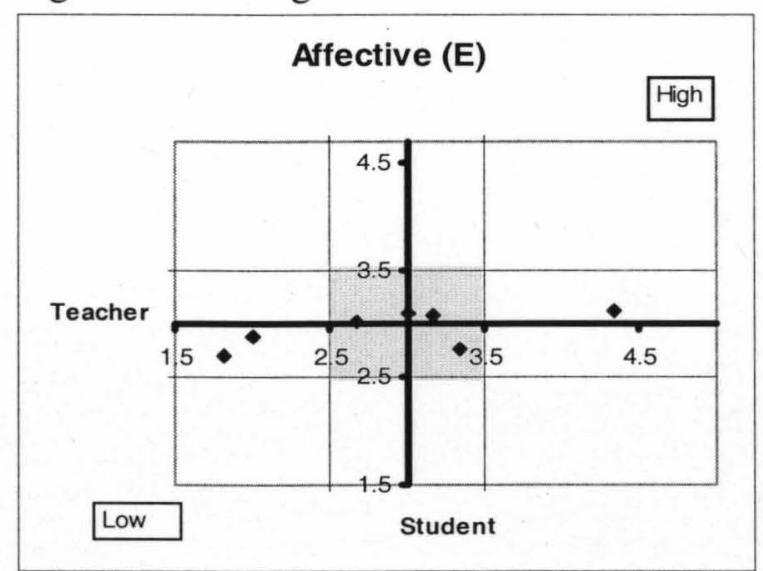

Medium-medium

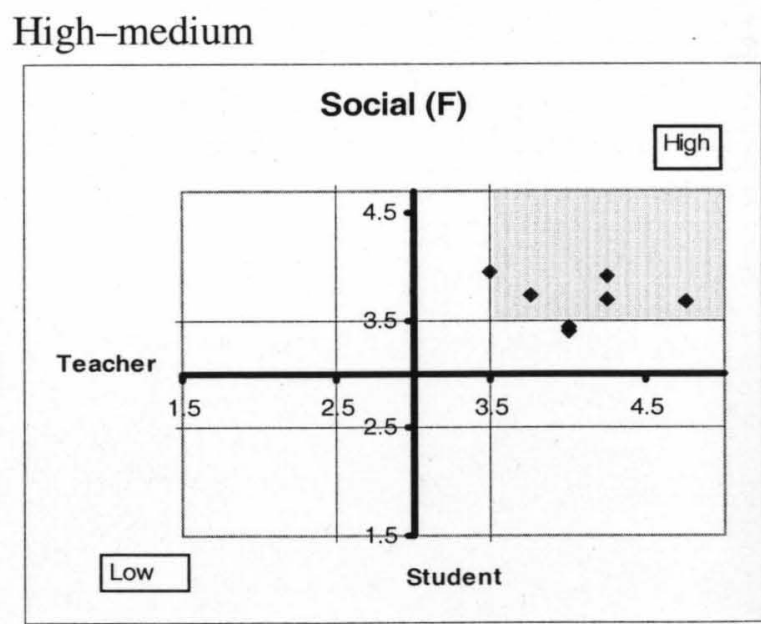

High-high

Figure 4.3. High school profile of teacher-student ratings of learning strategies effectiveness and use. $N_{\text {schools }}=7$. Shaded areas represent "common ground" (areas of most teacher-student agreement). 
Table 4.8

Teacher-Student Strategy Profiles by Educational Level

\begin{tabular}{|c|c|c|c|}
\hline & \multicolumn{3}{|c|}{ Educational Level } \\
\hline & Elementary & Middle & High \\
\hline \multicolumn{4}{|l|}{ Agreement } \\
\hline \multirow[t]{3}{*}{ High } & Metacognitive $(\mathrm{H}-\mathrm{H})$ & Metacognitive $(\mathrm{H}-\mathrm{H})$ & Metacognitive $(\mathrm{H}-\mathrm{H})$ \\
\hline & & & Social $(\mathrm{H}-\mathrm{H})$ \\
\hline & & & Affective (M-M) \\
\hline \multirow[t]{2}{*}{ Moderate } & Cognitive $(\mathrm{H}-\mathrm{M} / \mathrm{H})$ & Social $(\mathrm{H}-\mathrm{M} / \mathrm{H})$ & Cognitive $(\mathrm{H} / \mathrm{M}-\mathrm{H})$ \\
\hline & Social $(\mathrm{H} / \mathrm{M}-\mathrm{H})$ & & \\
\hline \multicolumn{4}{|c|}{ Disagreement } \\
\hline \multirow[t]{3}{*}{ Moderate } & Memory (H-M) & Memory (H-M) & Memory (H-M) \\
\hline & Compensation (H-M) & Compensation (H-M) & Compensation (H-M) \\
\hline & & Cognitive (H-M) & \\
\hline Strong & Affective (NDP) & Affective (NDP) & \\
\hline$N$ & 23 & 7 & 7 \\
\hline
\end{tabular}

Note. In teacher-student strategy rating profiles (e.g., H-H), the letter before the dash stands for a tendency in teacher ratings and the letter after the dash stands for a tendency in student ratings. $\mathrm{H}=$ high ratings; $\mathrm{M}=$ medium ratings; $\mathrm{L}=$ low ratings; $\mathrm{NDP}=$ no detectable pattern.

Elementary school. Analyses of elementary school data revealed the following tendencies in the distribution of teacher-student strategy profiles: (a) high agreement: metacognitive strategy category, (b) moderate agreement: cognitive and social strategy category; (c) moderate disagreement: memory and compensation strategy categories; and (c) strong disagreement: affective strategy category (see Table 4.8 and Figure 4.1). 
Metacognitive strategies was the sole category that elicited the most consistent agreement between teachers and students; the two groups tended to rate this category as being the most effective and most frequently used. Whereas teachers had a tendency to give high ratings to memory, compensation, and cognitive strategy categories, students reported only moderate (moderate to high for cognitive strategy) usage of these strategies. Data showed no detectable pattern for affective strategy category. These results confirm individual-level analyses and suggest an overall low level of within-school agreement between teacher and student strategy ratings at the elementary school level. None of the within-school correlations between teacher and student strategy ratings were statistically significant (see Table 4.9).

Middle school. Analyses of middle school data revealed the following tendencies in the distribution of teacher-student strategy profiles: (a) high agreement: metacognitive strategy category; (b) moderate agreement: social strategy category; (c) moderate disagreement: memory, cognitive, and compensation strategy categories; and (c) strong disagreement: Affective strategy category (see Table 4.8 and Figure 4.2). Similar to elementary school results, metacognitive strategy elicited high ratings and the most consistent agreement between teachers and students. The majority of middle school teachers gave higher ratings to social, memory, cognitive, and compensation strategy categories than did their students who reported only moderate (moderate to high for social strategy) usage of these strategies. Similar to elementary school results, data showed no detectable pattern for affective strategy category. These results contradict individual level analysis and suggest an even lower level of within-school agreement between teacher and student strategy ratings at the middle school level. None of the 
within-school correlations between teacher and student strategy ratings were statistically significant (see Table 4.9).

High school. Analyses of high school data revealed the following tendencies in the distribution of teacher-student strategy profiles: (a) high agreement: metacognitive, social, and affective strategy categories; (b) moderate agreement: cognitive strategy category; and (c) moderate disagreement: memory and compensation strategy categories. No patterns of strong disagreement were apparent in high school data (see Table 4.8 and Figure 4.3). These results suggested that unlike elementary and middle school participants, high school teachers and their students appeared to be more in agreement with each other in terms of their strategy rating profiles. Encouragingly, both teachers and students had a tendency to rate metacognitive and social strategies as being the most effective and the most frequently used; affective strategy category tended to elicit medium effectiveness-usage ratings from both groups. There was a slight disagreement between teachers' and their students' ratings of cognitive strategies, rated high by the teachers but high to moderate by students. Memory and compensation strategies were the only areas of disagreement: Whereas teachers had a tendency to perceive these strategies as highly effective, their students reported only moderate use of these strategies. Similar to elementary and middle school analyses, none of the within-school correlations between teacher and student strategy ratings were statistically significant (see Table 4.9). 
Table 4.9

Within-School Correlations Between Teacher and Student Strategy Ratings

Disaggregated by Educational Level

\begin{tabular}{|c|c|c|c|c|c|c|}
\hline \multirow[b]{3}{*}{ Strategy category } & \multicolumn{6}{|c|}{ Educational level } \\
\hline & \multicolumn{2}{|c|}{ Elementary } & \multicolumn{2}{|c|}{ Middle } & \multicolumn{2}{|c|}{ High } \\
\hline & $r\left(R^{2}\right)$ & $p$ & $r\left(R^{2}\right)$ & $p$ & $r\left(R^{2}\right)$ & $p$ \\
\hline Memory & $.19(.03)$ & .40 & $-.01(.00)$ & .98 & $-.41(.17)$ & .36 \\
\hline Cognitive & $.30(.09)$ & .17 & $.20(.04)$ & .66 & $-.18(.03)$ & .70 \\
\hline Compensation & $.17(.03)$ & .43 & $.29(.08)$ & .53 & $-.37(.14)$ & .41 \\
\hline Metacognitive & $.30(.09)$ & .16 & $.16(.03)$ & .73 & $.44(.19)$ & .33 \\
\hline Affective & $.09(.01)$ & .69 & $-.27(.07)$ & .56 & $.59(.35)$ & .16 \\
\hline Social & $.06(.00)$ & .78 & $-.41(.17)$ & .36 & $-.18(.03)$ & .71 \\
\hline Total & $.20(.04)$ & .34 & $.06(.00)$ & .90 & $-.29(.08)$ & .53 \\
\hline$N$ & 23 & & 7 & & 7 & \\
\hline
\end{tabular}

\section{Summary of Research Question 1 Results}

Individual level analyses. Analyses at the individual level revealed the following results:

- With the exception of metacognitive category - and to some extent social and cognitive categories-students reported only medium frequency of strategy use.

- Regardless of educational level, students consistently reported using metacognitive strategies most and affective strategies least. 
- Except for affective strategies, teachers at all educational levels reported ascribing a high level of effectiveness to LLS.

- The top ranking strategy categories varied by educational level. Whereas memory strategies received the top rank ordering among elementary teachers, among middle and high school teachers, respectively, cognitive and metacognitive strategies received the top rank orderings.

- The individual level comparison of teacher and student LLS rankings revealed a close alignment at the high and middle school levels.

- Teacher and student strategy ratings differed qualitatively, with most of the teacher scores being above the high level benchmark and most of the students' scores within the medium level benchmark.

- Elementary school teachers and students had some substantial discrepancies in LLS rankings, particularly with regard to metacognitive (the top rank ordering among students) and memory (the top rank ordering among teachers) strategies.

School-level analyses. Within-school analyses revealed the following results:

- Across educational levels, the following tendencies ${ }^{47}$ in teacher-student alignment of LLS perceptions were identified: (a) high agreement: metacognitive strategy category, (b) moderate agreement: cognitive and social strategy category, (c) moderate disagreement: memory and compensation, and (c) strong disagreement: affective strategy category.

${ }^{47}$ Comparison of strategy ratings by the teachers and students in the same school buildings revealed that none of the strategy categories elicited perfect alignment in teacher-student strategy ratings. Thus, the four profiles found in this study represent tendencies in the data rather than absolute, exclusive categories. 
- The overall within-school agreement between teacher and student strategy ratings was the highest at the high school level and —in contrast to individual-level analyses--the lowest at the middle school level.

- Across educational levels, none of the within-school correlations between teacher and student strategy ratings were statistically significant.

\section{Research Question 2}

The primary purpose of Research Question 2 was to examine structural relationships among ELL student background and linguistic profile characteristics and academic achievement, considering the mediating influences of language motivation, language learning strategy use, and English proficiency.

\section{SEM Analytical Approach}

In addressing Research Question 2, Multiple Indicator Multiple Independent Cause (MIMIC) model—a special case of Structural Equation Modeling (SEM)—served as the primary analytical tool. As all SEM applications, MIMIC models comprise a measurement component and a structural component. Measurement models relate latent variables (i.e., unobserved variables identified on theoretical basis, such as language motivation) and indictor variables (i.e., observed variables, such as survey scores) that underlie the latent constructs. Because scores on indicator variables are a linear function of their respective latent constructs, this family of indicators is referred to as effect indicators (MacCallum \& Browne, 1993). Structural models, in turn, describe the relationships among latent constructs.

In addition to effect indicators, MIMIC models specify some observed variables as cause indicators (i.e., predictors of latent constructs). That is, a significant direct effect 
from a cause indicator to the latent variable suggests that the latent factor scores differ at different levels of the cause indicator (Brown, 2006). One of the advantages of MIMIC modeling includes its ability to detect direct associations between cause (e.g., LOR) and effect (e.g., L2 speaking) indicators after controlling for the latent factor (e.g., English proficiency).

Because SEM applications specify an a priori theoretical model representing "a series of hypotheses about how the variables in the analysis are generated and related" (Hu \& Bentler, 1999, p. 2), the assessment of how well SEM models fit the data and the estimation of the parameters specified by the models are of primary concern. The assessment of fit of theoretical (single-solution) models typically involves the evaluation of the $\chi^{2}$ goodness-of-fit statistic supplemented by a set of more easily interpretable fit indices quantifying "the degree of fit along a continuum" (p. 2). In case of inadequate fit of the theoretical model, the selection and assessment of alternative (competing) solutions is supplemented by theoretically meaningful modification indices (MIs; "the expected drop in overall $\chi^{2}$ value if the parameters were to be freely estimated in a subsequent run," Byrne, 2001, p. 90) and tests of significance in chi square change $\left(\Delta \chi^{2}\right)$; both statistics assess the extent to which alternative models provide an improvement in fit to the data over previous models.

Because individual fit indices have limitations (e.g., sensitivity to sample size or model complexity), SEM literature (e.g., Hu \& Bentler, 1999; Marsh \& Hau, 1996) recommends using combinations of fit indices from different measurement families. Such measurement families include: goodness-of-fit indices, quantify the amount of variance and covariance explained by the model; incremental fit indices, assess the improvement 
of model fit in comparison to more restricted models; and residual-based fit indices, quantify discrepancy between the model and the sample variance and covariance matrices. With normed ( 0 to 1 ) indices, smaller values of residual-based fit indices (i.e., close to .05), and larger values of goodness-of-fit and incremental fit indices (i.e., close to 1) indicate an acceptable model fit.

The specific indices assessed in this study included: goodness-of-fit index (GFI), comparative fit index (CFI), the standardized root mean square residual (SRMR), and root mean square error of approximation (RMSEA). The first two indices represent goodness-of-fit and incremental fit index families, respectively; the latter two indices are residual-based. As indicators of acceptable model fit, this study used values close to .95 for GFI (Shevlin \& Miles, 1998) and for CFI (Bentler, 1990) and values close to .08 and .06 for SRMR and RMSEA, respectively (Hu \& Bentler, 1999). Three criteria guided the selection and assessment of alternative models: (a) substantial and theoretically meaningful MIs; (b) chi square change ( $\Delta \chi 2$; a statistical test of model fit improvement); and (c) CFI change (a practical test of model fit improvement). Regarding the latter criterion, a CFI change of greater than .01 (Byrne, 2010) was considered as practically meaningful improvement in model fit. Thus, statistical, practical, and theoretical considerations guided the building and assessment of alternative models.

Regarding causal links, three types of path coefficients were estimated: (a) direct effects (the direct effect of one variable on another); (b) indirect effects (the product of direct effects linking several variables); and (c) total effects ("the sum of all direct and indirect effects of one variable on another"; Kline, 2005, p.129). Critical ratios (C.R.; parameter value divided by its corresponding standard error) served as a test of statistical 
significance for all types of path coefficients as well as other model parameters. C.R.

operates as a z-statistic; its values larger than \pm 1.96 indicate that the estimated parameter is statistically different from zero at $p$ level of .05 (Byrne, 2010).

Because — due to the district's testing patterns ${ }^{48}$ - high school students' data did not meet one of the key SEM requirements, namely, fully crossed data sets, only data from elementary and middle school students were used in SEM analyses. After deleting multivariate outliers and conducting pairwise deletion of missing data, the final sample included 805 ELLs (549 elementary and 256 middle school students; $M_{\text {age }}=11.51$ years $[S D=1.86$, range: $9-16] ; M_{\mathrm{LOR}}=46.76$, months $[S D=18.36$, range: $7-117)$. All estimations were computed using maximum likelihood (ML) estimation method; covariance matrices-as opposed to correlation matrices—served as data input. All SEM analyses were conducted using AMOS 6 software.

\section{Hypothesized Model Specification}

A major purpose addressed by Research Question 2 was to investigate the structure of the relationships among ELL student background and language profile characteristics and academic achievement in the presence of mediating and predictor (control) variables. The hypothesized relationships and directionalities among studentlevel variables were formulated based on findings from empirical research. Accordingly, MIMIC models discussed in this section are empirically derived and include: (a) background characteristics (AGE, LOR, and L1 literacy) ${ }^{49}$; (b) L2 profile variables

\footnotetext{
${ }^{48}$ High school students were assessed in reading and mathematics—-the two academic achievement indicators discussed in the next section-at different grade levels.

${ }^{49}$ Two additional, originally intended background variables - mother school attendance and student prior schooling - were not included in SEM analyses because model estimation using the weighted least square estimation method-a method recommended for modeling categorical variables-resulted in inadmissible solution. The effects of these two variables will be explored later in the study using HLM techniques, which are more flexible in terms of modeling categorical variables.
} 
(language motivation, ${ }^{50}$ individual strategy category, and English proficiency), and (c) academic achievement. Although LLS use was originally intended to be represented as a single construct (see Gardner et al., 1997), a preliminary confirmatory factor analysis indicated that ELL student data was best described by a six-factor solution identifying each strategy category as a unique latent construct. This finding confirmed the results of an earlier study by Hsiao and Oxford (2002). Accordingly, the structural relationships of each strategy category with other variables of interest were examined separately resulting in six individual MIMIC models: (a) metacognitive strategy model, (b) cognitive strategy model, (c) memory strategy model, (d) affective strategy model, (e) social strategy model, and (f) compensation strategy model.

The hypothesized relationships among predictor, mediating, and outcome variables (see Figure 4.4 for an example of graphically represented structural relationships for the metacognitive strategy model) were specified as follows. After controlling for native language literacy (Genesee et al., 2005; Mahon, 2006), age (Abedi, 2004; Fry, 2008), and English proficiency (Mahon, 2006; Solórzano, 2008), LLS use was hypothesized to influence academic achievement directly (Chamot et al., 1992; Montes, 2002) and indirectly through the mediating effect of English proficiency.

\footnotetext{
${ }^{50}$ ELLMS subscales' composite scores—as opposed to mean scores—served as indicators of language motivation.
} 


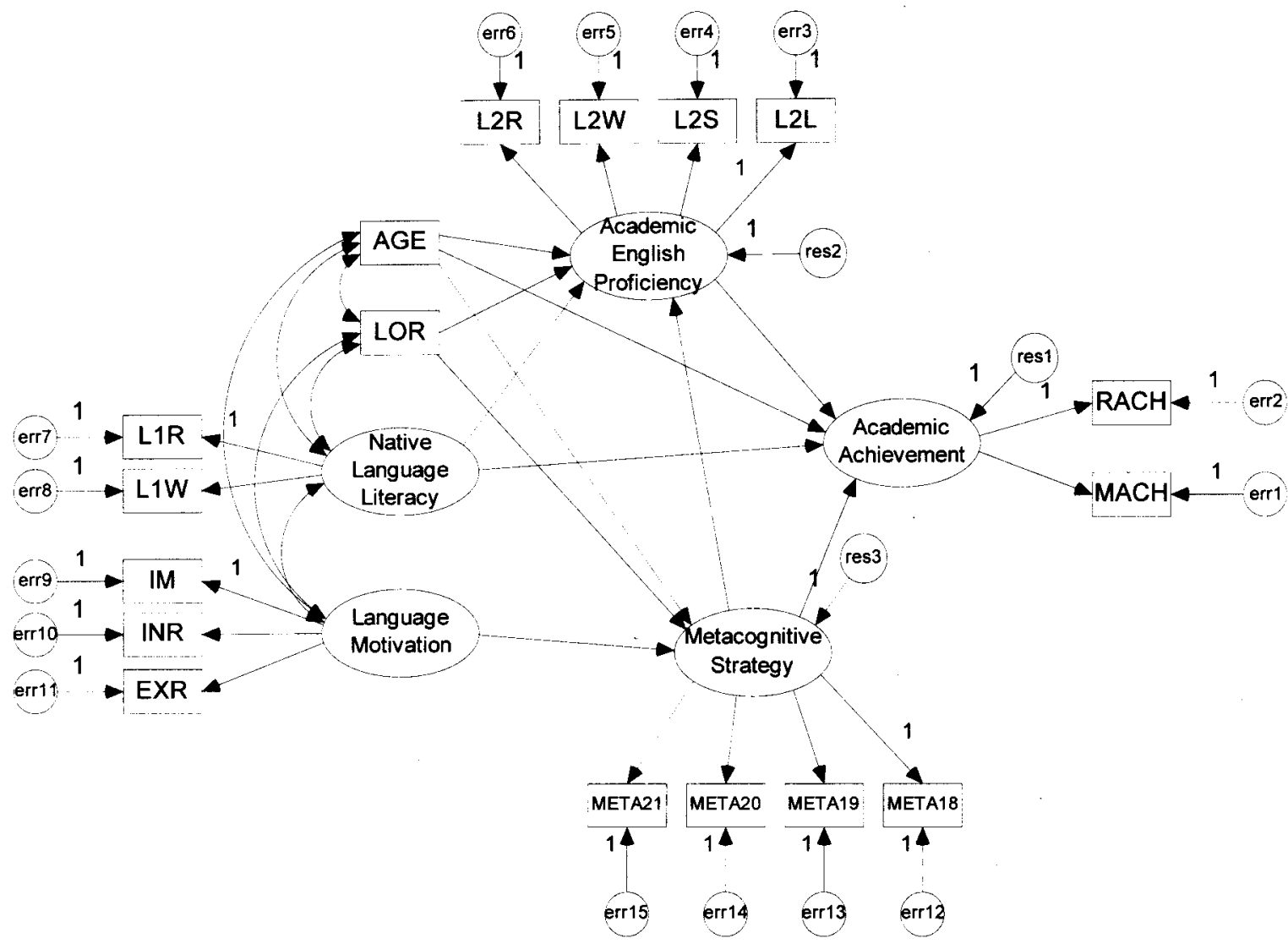

Figure 4.4. Metacognitive Strategy Model: Hypothesized relationships among ELL student background characteristics, language motivation, metacognitive strategy, English proficiency, and academic achievement.

Only reading and mathematics scores were selected as academic achievement indicators for two reasons. First, a lack of fully crossed data sets—due to the district's subject area testing pattern at different grade levels ${ }^{51}$ - prohibited using science and social studies scores as academic achievement indicators. Second, reading and mathematics scores are routinely used in educational assessment practice (e.g., NAEP) to gauge student academic progress.

\footnotetext{
${ }^{51}$ In the year of the study, the district's testing pattern by subject area was: (a) reading: Grades 3-8, 10; (b) mathematics: Grades 3-8, 11; (c) science: Grades 4, 7, 11; and (c) social studies: Grades 5, 8, 11 .
} 
Further, LLS use was hypothesized to directly influence English proficiency (Oxford, 1999; Oxford \& Burry-Stock, 1995), after controlling for native language literacy (August \& Shanahan, 2006b; Genesee et al., 2005), LOR (Hakuta et al., 2000; Thomas \& Collier, 2002), and age (Cummins, 1981a; MacSwan \& Pray, 2005). Grounded in empirical evidence (Hong Kong et al., 2003; MacIntyre \& Noels, 1996; Oxford \& Nyikos, 1989; Schmidt \& Watanabe, 2001), language learning motivation was hypothesized to have a direct effect on LLS use and an indirect effect on English proficiency through LLS use.

Two additional paths were specified from age and LOR on LLS. These paths were specified based on evidence documenting different patterns of strategy use as a function of age (Magogwe \& Oliver, 2007) and L2 progression over time (Chesterfield \& Chesterfield, 1985; Oxford \& Nyikos, 1989). Language learning motivation and native language literacy were specified as exogenous latent variables with no predictors. In other words, the model did not attempt to explain the sources of these variables. Lastly, LOR and AGE were specified as exogenous cause indicators underlying differential student performance on relevant latent variables. Assumed to be measured without error, these predictors were specified without measurement error terms. The next steps in MIMIC modeling included: (a) measurement and structural model tests of goodness of fit; (b) in case of inadequate fit, model modifications; and (c) parameter estimation.

\section{Model Fitting, Evaluation, and Modification}

Because an adequate fit of measurement models is prerequisite for valid interpretations of structural relationships tests (Kline, 2005), the measurement components of the MIMIC models—which did not include background variables—were 
assessed first. As indicated by goodness of fit indices, the fit of individual measurement models was acceptable and ranged from $\chi^{2}(125)=299.187, \mathrm{GFI}=.960, \mathrm{CFI}=.963$, $\operatorname{SRMR}=.040, \mathrm{RMSEA}=.042, \mathrm{CI} 90 \%[.036, .048]($ memory strategy model $)$ to $\chi^{2}(80)=$ $195.333, \mathrm{GFI}=.969, \mathrm{CFI}=.973, \mathrm{SRMR}=.031, \mathrm{RMSEA}=.042, \mathrm{CI} 90 \%[.035, .050]$ (social strategy model).

Second, background characteristics and structural paths outlined in the previous section were introduced into the models. Less than optimal GFI and CFI values (see Table 4.10) indicated that the hypothesized models did not adequately describe student data. The inspection of MIs across all models suggested three post hoc modifications; all three were associated with direct paths from background characteristics to observed indicators. The first suggested path—age to L2 writing (MIs ranged from 75.10 for metacognitive model to 75.30 for compensation model)—was judged as theoretically plausible and was found to be statistically significant. This re-specification resulted in both statistical and practical improvement in model fit (see Table 4.10); across models, chi square change was statistically significant and there was a practically meaningful improvement in CFI ( $\triangle \mathrm{CFI}>.01$; Byrne, 2010).

Two other re-specifications-_LOR on mathematics achievement (MIs ranged from 31.00 for metacognitive model to 32.04 for affective model) and LOR on L2 speaking (MIs ranged from 26.43 for memory model to 26.57 for compensation model)were not implemented based on parsimony grounds. This decision was adequate because (a) the size of the MIs was moderate; (b) specifying these parameters as freely estimated did not results in practically meaningful improvement in model fit $(\Delta \mathrm{CFI}<.01)$; and (c) as indicated by fit indices, the final post hoc models described student data exceptionally 
well. Table 4.10 summarizes goodness of fit indices across MIMIC hypothesized and post hoc models.

The final models were not trimmed (i.e., the non-significant paths were not removed). This decision was made because the causal relationships among LLS and language outcomes-particularly among young language learners-have been underexplored (Grenfell \& Macaro, 2007) and the knowledge base regarding interrelationships among linguistic factors and academic achievement is limited (Genesee et al., 2005). Thus, the exploration of both significant and non-significant causal paths is of interest for advancing knowledge in the fields of ELL education and applied linguistics. . 
Table 4.10

Goodness-of-Fit Statistics across Hypothesized and Post Hoc Language Learning Strategy Use Models

\begin{tabular}{|c|c|c|c|c|c|c|c|c|c|}
\hline Model & $x^{2}$ & $d f$ & GFI & CFI & SRMR & RMSEA & {$[90 \% \mathrm{CI}]$} & $\Delta \chi^{2}$ & $\Delta d f$ \\
\hline \multicolumn{10}{|l|}{ Metacognitive } \\
\hline 1. Hypothesized & 418.292 & 104 & .942 & .937 & .047 & .061 & {$[.055, .068]$} & -- & -- \\
\hline 2. Post hoc & 322.182 & 103 & .955 & .956 & .042 & .051 & {$[.045, .058]$} & $96.11^{* * *}$ & 1 \\
\hline \multicolumn{10}{|l|}{ Cognitive } \\
\hline 1. Hypothesized & 412.441 & 120 & .947 & .937 & .043 & .055 & {$[.049, .061]$} & -- & -- \\
\hline 2. Post hoc & 316.169 & 119 & .959 & .958 & .039 & .045 & {$[.039, .051]$} & $96.27 * * *$ & 1 \\
\hline \multicolumn{10}{|l|}{ Memory } \\
\hline 1. Hypothesized & 482.274 & 155 & .944 & .939 & .051 & .051 & {$[.046, .056]$} & -- & -- \\
\hline 2. Post hoc & 385.974 & 154 & .954 & .957 & .042 & .043 & {$[.038, .049]$} & $96.3 * * *$ & 1 \\
\hline \multicolumn{10}{|l|}{ Affective } \\
\hline 1. Hypothesized & 364.497 & 89 & .948 & .941 & .048 & .062 & {$[.055, .069]$} & -- & -- \\
\hline 2. Post hoc & 268.305 & 88 & .961 & .961 & .042 & .050 & {$[.044, .057]$} & $96.12 * * *$ & 1 \\
\hline
\end{tabular}




\begin{tabular}{|c|c|c|c|c|c|c|c|c|c|}
\hline Model & $\chi^{2}$ & $d f$ & GFI & CFI & SRMR & RMSEA & {$[90 \% \mathrm{CI}]$} & $\Delta \chi^{2}$ & $\Delta d f$ \\
\hline \multicolumn{10}{|l|}{ Social } \\
\hline 1. Hypothesized & 376.385 & 104 & .950 & .945 & .042 & .057 & {$[.051, .063]$} & - & -- \\
\hline 2. Post hoc & 280.147 & 103 & .962 & .964 & .036 & .046 & {$[.040, .053]$} & $96.24 * * *$ & 1 \\
\hline \multicolumn{10}{|l|}{ Compensation } \\
\hline 1. Hypothesized & 440.510 & 120 & .945 & .930 & .048 & .058 & {$[.052, .063]$} & -- & -- \\
\hline 2. Post hoc & 344.202 & 119 & .956 & .951 & .044 & .049 & {$[.043, .055]$} & $96.31 * * *$ & 1 \\
\hline
\end{tabular}

$\bar{g} \quad$ Note. $N=805$. GFI = goodness-of-fit index. $\mathrm{CFI}=$ comparative fit index. $\mathrm{SRMR}=$ standardized root mean square residual. RMSEA $=$ root mean square error of approximation. $90 \% \mathrm{CI}=90 \%$ confidence interval. 


\section{Parameter Estimates}

Predictors of academic achievement. The examination of regression weights associated with LLS categories across models revealed that - after controlling for the direct effects of L1 literacy, age, and English proficiency—only metacognitive strategy category had a significant direct effect on academic achievement $(\beta=.07, p<.01)$. The total standardized effect--the sum of the direct effect of metacognitive strategy on academic achievement and indirect effect on academic achievement through English proficiency-was $.13($ S.E. $=.046$, C.R. $=2.85, p<.01) .{ }^{52}$ Because total effects are interpreted in the same way as path coefficients - they represent a total effect of one variable on the other "via all presumed direct and indirect causal links between these variables" (Kline, 2005, p.129) — this result predicted a .13 standard deviation increase in ELL student academic achievement for each standard deviation increase in metacognitive strategy. Further, English proficiency and metacognitive strategy use mediated the language learning motivation effect on academic achievement: The total effect of language learning motivation on academic achievement via metacognitive strategy use and English proficiency was $.10($ S.E. $=.033$, C.R. $=2.91, p<.01)$.

Across models, English proficiency contributed the most to academic achievement; this effect was followed in magnitude by age and L1 literacy (see Table 15). For example, in the metacognitive strategy model, the direct effect of English proficiency on academic achievement was $\beta=.68, p<.001$. This indicated that, after controlling for other variables in the model, each standard deviation increase in English

\footnotetext{
${ }^{52}$ Not automatically computed by AMOS, all standard errors for total and indirect effects reported in this study were estimated using bootstrapping method (Kline, 2005). The bootstrapped errors were estimated across 200 computer-generated samples based on the input covariance matrix. Critical ratios were computed by dividing parameter estimates by their standard errors.
} 
proficiency predicted .68 standard deviations increase in academic achievement. The direct effects of age and L1 literacy on academic achievement were $\beta=-.52(p<.001)$ and $\beta=.10(p<.01)$, respectively. English proficiency moderated the negative effect of age and enhanced the positive effect of L1 literacy; that is, the total effects of age and L1 literacy—including direct and indirect effects via English proficiency—were -.38 (S.E. = .043 , C.R. $=-8.77, p<.001)$ and .24 (S.E. $=.042$, C.R. $=5.60, p<.001)$, respectively. The indirect effect of LOR on academic achievement via English proficiency was positive and significant $(\beta=.31$, S.E. $=.026$, C.R. $=11.73, p<.001)$.

Predictors of English proficiency. The examination of regression weights associated with LLS categories across models revealed that-after controlling for the direct effects of L1 literacy, LOR, and age-only metacognitive strategy category had a significant positive direct effect on English proficiency $(\beta=.09, p<.05)$. Unexpectedly, the effect of cognitive strategy on English proficiency was negative, though statistically non-significant $(\beta=-.03, p=.474)$; the direct effects associated with social, memory, affective, and compensation strategies were negative and marginally to highly statistically significant $(\beta=-.07, p<.10 ; \beta=-.10, p<.05 ; \beta=-.20, p<.001 ;$ and $\beta=$ $.13, p<.01$, respectively). This may be attributed to intervening effects of age and LOR (see below).

LOR and age were the biggest positive contributors to English proficiency. For example, in the metacognitive strategy model, the direct effects of LOR and age were $\beta=$ $.45, p<.001$ and $\beta=.22, p<.001$, respectively. In addition, after controlling for English proficiency factor, age had a significant direct effect on L2 writing $(\beta=.25, p<.001)$. 
That is, regardless of an overall level of English proficiency, older students had substantially better scores in writing.

Predictors of strategy use and intervening effects. Notably, metacognitive strategy use did not vary as a function of age $(\beta=-.03, p=.338)$ or $\operatorname{LOR}(\beta=.00, p=$ .948 ) indicating that students of different ages and with different lengths of tenure in the U.S. schools used metacognitive strategies at comparable levels. These results are consistent with the results of Research Question 1 indicating that students at all educational levels (elementary, middle, and high school) used metacognitive strategies frequently. This suggests that metacognitive strategy use may capture a student characteristic that is relatively stable.

By contrast, cognitive strategy use declined as a function of age $(\beta=-.13, p<.01)$ indicating that older students used cognitive strategies less frequently. Further, the use of the remaining four strategy categories-memory, affective, social, and compensationsignificantly declined as a function of $\operatorname{LOR}(\beta=-.10, p<.01 ; \beta=-.13, p<.001 ; \beta=-.14$, $p<.001$; and $\beta=-.11, p<.05$, respectively). This suggested that with increased exposure to English-and the concurrent increase in English proficiency (see Predictors of English Proficiency above)—students felt less need (or value) in using these strategies (Gardner et al., 1997), thus "masking" the true relationships among these strategy categories and English proficiency. In other words, these findings "challenged" the causal relationships (Shavelson, 1996) between cognitive, memory, affective, social, and compensation LLS and English proficiency reported above.

In essence, these results indicated that age (for cognitive strategy) and LOR (for social, memory, affective, and compensation strategy) underlie differential LLS use by 
ELL students and, consequently, may have an intervening influence on the relationship between these LLS categories and English proficiency. This hypothesis was confirmed by examining the indirect effects of AGE and LOR on English proficiency via cognitive (COG), social (SOC), memory (MEM), affective (AFF), and compensation (COMP) strategy categories:

$$
\begin{aligned}
& \text { Age } \rightarrow \text { COG } \rightarrow \text { L2 proficiency: } \beta=.004, \text { S.E. }=.005, \text { C.R. }=0.8, p=.42 ; \\
& \text { LOR } \rightarrow \text { SOC } \rightarrow \text { L2 proficiency: } \beta=.010, \text { S.E. }=.006, \text { C.R. }=1.7, p<.10 \text {; } \\
& \mathrm{LOR} \rightarrow \mathrm{MEM} \rightarrow \mathrm{L} 2 \text { proficiency: } \beta=.010, \text { S.E. }=.006, \mathrm{C} . \mathrm{R} .=1.7, p<.10 \\
& \mathrm{LOR} \rightarrow \mathrm{AFF} \rightarrow \mathrm{L} 2 \text { proficiency: } \beta=.026 \text {, S.E. }=.010, \text { C.R. }=2.6, p<.01 ; \\
& \mathrm{LOR} \rightarrow \mathrm{COMP} \rightarrow \mathrm{L} 2 \text { proficiency: } \beta=.014 \text {, S.E. }=.007, \text { C.R. }=2.0, p<.05 \text {. }
\end{aligned}
$$

These results indicated that, taking the intervening (moderator) effects of age and LOR into consideration, all relationships among LLS and English proficiency were positive and —except for cognitive strategy-marginally (social and memory strategy category) to highly (affective and compensation strategy category) significant. Further, the small size coefficients reflected only a linear relationship among these variables (Kline, 2005). These results also indicated that the findings reported earlier with regard to the relationships among these strategy categories and L2 academic and language outcomes should be interpreted with caution and suggested a need for future research to explore moderator effects of age and LOR (this topic is discussed in Chapter 5).

As expected, language motivation was the strongest positive predictor of all LLS categories. Its contribution, however, varied slightly depending on the individual strategy category and ranged from $\beta=.73, p<.001$ (metacognitive strategy model) to $\beta=.51, p<$ .001 (affective strategy model). 
Table 4.11

Direct Effects of Student Characteristics across Strategy Use Models

\begin{tabular}{|c|c|c|c|c|}
\hline Model & Factor (\% variance explained) & Factor/Covariate Effects & $\beta$ & S.E. \\
\hline \multirow[t]{11}{*}{ Metacognitive } & Academic Achievement (54.4\%) & Metacognitive Strategy & $.07 *$ & .035 \\
\hline & & L1 Literacy & $.10^{* *}$ & .036 \\
\hline & & English Proficiency & $.68 * * *$ & .031 \\
\hline & & Age & $-.52 * * *$ & .036 \\
\hline & English Proficiency $(28.5 \%)$ & Metacognitive Strategy & $.09^{*}$ & .038 \\
\hline & & L1 Literacy & $.20^{* * *}$ & .034 \\
\hline & & Length of Residence & $.45^{* * *}$ & .033 \\
\hline & & $\mathrm{Age}^{\mathrm{a}}$ & $.22 * * *$ & .034 \\
\hline & Metacognitive Strategy $(53.4 \%)$ & Language Motivation & $.73^{* * *}$ & .034 \\
\hline & & Length of Residence & .002 & .036 \\
\hline & & Age & -.03 & .036 \\
\hline \multirow[t]{11}{*}{ Cognitive } & Academic Achievement (54.4\%) & Cognitive Strategy & .06 & .041 \\
\hline & & L1 Literacy & $.10^{* *}$ & .033 \\
\hline & & English Proficiency & $.69 * * *$ & .032 \\
\hline & & Age & $-.52 * * *$ & .038 \\
\hline & English Proficiency (27.9\%) & Cognitive Strategy & -.03 & .037 \\
\hline & & L1 Literacy & $.20 * * *$ & .032 \\
\hline & & Length of Residence & $.45^{* * *}$ & .034 \\
\hline & & Age & $.21^{* * *}$ & .036 \\
\hline & Cognitive Strategy (45.7\%) & Language Motivation & $.66^{* * *}$ & .038 \\
\hline & & Length of Residence & -.03 & .037 \\
\hline & & Age & $-.13 * *$ & .042 \\
\hline
\end{tabular}

Continued 


\begin{tabular}{|c|c|c|c|c|}
\hline Model & Factor (\% variance explained) & Factor/Covariate Effects & $\beta$ & S.E. \\
\hline \multirow[t]{11}{*}{ Memory } & Academic Achievement (54.1\%) & Memory Strategy & .000 & .036 \\
\hline & & L1 Literacy & $.10^{* *}$ & .035 \\
\hline & & English Proficiency & $.68^{* * *}$ & .033 \\
\hline & & Age & $-.53 * * *$ & .038 \\
\hline & English Proficiency $(28.6 \%)$ & Memory Strategy & $-.10^{*}$ & .039 \\
\hline & & L1 Literacy & $.20^{* * *}$ & .039 \\
\hline & & Length of Residence & $.43^{* * *}$ & .031 \\
\hline & & Age & $.21 * * *$ & .033 \\
\hline & Memory Strategy (39.3\%) & Language Motivation & $.61^{* * *}$ & .033 \\
\hline & & Length of Residence & $-.10^{* *}$ & .036 \\
\hline & & Age & -.04 & .038 \\
\hline \multirow[t]{11}{*}{ Affective } & Academic Achievement (54.3\%) & Affective Strategy & -.05 & .039 \\
\hline & & L1 Literacy & $.11^{* *}$ & .035 \\
\hline & & English Proficiency & $.67^{* * *}$ & .033 \\
\hline & & Age & $-.53 * * *$ & .037 \\
\hline & English Proficiency $(31.4 \%)$ & Affective Strategy & $-.20 * * *$ & .039 \\
\hline & & L1 Literacy & $.20^{* * *}$ & .033 \\
\hline & & Length of Residence & $.41^{* * *}$ & .034 \\
\hline & & Age & $.20^{* * *}$ & .035 \\
\hline & Affective Strategy $(29.3 \%)$ & Language Motivation & $.51^{* * *}$ & .039 \\
\hline & & Length of Residence & $-.13 * * *$ & .042 \\
\hline & & Age & -.05 & .040 \\
\hline \multirow[t]{3}{*}{ Social } & Academic Achievement (54.2\%) & Social Strategy & .01 & .037 \\
\hline & & L1 Literacy & $.10^{* *}$ & .039 \\
\hline & & English Proficiency & $.68 * * *$ & .031 \\
\hline
\end{tabular}

Continued 


\begin{tabular}{|c|c|c|c|c|}
\hline Model & Factor (\% variance explained) & Factor/Covariate Effects & $\beta$ & S.E. \\
\hline & & Age & $-.53 * * *$ & .036 \\
\hline & English Proficiency (28.3\%) & Social Strategy & $-.07 \dagger$ & .038 \\
\hline & . & L1 Literacy & $.20^{* * *}$ & .037 \\
\hline & & Length of Residence & $.43^{* * *}$ & .037 \\
\hline & & Age & $.21 * * *$ & .033 \\
\hline & Social Strategy $(44.5 \%)$ & Language Motivation & $.64 * * *$ & .034 \\
\hline & & Length of Residence & $-.14^{* * *}$ & .035 \\
\hline & & Age & .003 & .038 \\
\hline \multirow[t]{11}{*}{ Compensation } & Academic Achievement (54.2\%) & Compensation Strategy & .02 & .044 \\
\hline & & L1 Literacy & $.10^{* *}$ & .033 \\
\hline & & English Proficiency & $.69^{* * *}$ & .033 \\
\hline & & Age & $-.53^{* * *}$ & .037 \\
\hline & English Proficiency $(29.4 \%)$ & Compensation Strategy & $-.13 * *$ & .038 \\
\hline & & L1 Literacy & $.20^{* * *}$ & .032 \\
\hline & & Length of Residence & $.43^{* * *}$ & .035 \\
\hline & & Age & $.21^{* * *}$ & .036 \\
\hline & Compensation Strategy (28.4\%) & Language Motivation & $.52 * * *$ & .044 \\
\hline & & Length of Residence & $-.11 *$ & .040 \\
\hline & & Age & -.01 & .042 \\
\hline
\end{tabular}

Note. $N=805 . \beta=$ Standardized regression coefficient. S.E. $=$ Standard error.

${ }^{a}$ Age had a significant direct effect on L2 writing after controlling for English Proficiency factor $(\beta=.25$, S.E. $=.026, p<.001)$; the magnitude of this effect was similar across all models.

${ }^{* * *} p<.001 .{ }^{* *} p<.01 .{ }^{*} p<.05 .{ }^{\dagger} p<.10$. 
Correlations among exogenous variables. Lastly, the examination of correlations among exogenous variables (see Table 4.12) revealed that only two pairs of variables were significantly correlated: (a) LOR and age ( $r=.20, p<.001)$, and (b) LOR and L1 literacy skills $(r=-.27, p<.001)$. This suggested that older students tended to have longer tenure in the U.S. schools—which is expected-and that longer tenure in the U.S. schools was associated with decline in L1 literacy skills. The latter finding may be attributed to the non-bilingual educational context of this study. Notably, language motivation had no significant associations with any other exogenous background variable suggesting that motivation to learn English is not related to student age, length of residence in the U.S. schools, or proficiency in a native language.

Table 4.12

Metacognitive Strategy Model ${ }^{a}$ : Estimated Correlations Among Exogenous Variables

\begin{tabular}{lllll}
\hline & LOR & AGE & L1 literacy & L2 Motivation \\
\hline LOR & -- & & & \\
AGE & $.20^{* * *}$ & -- & & \\
L1 literacy & $-.27^{* * *}$ & .03 & -- & \\
L2 Motivation & -.06 & -.02 & .03 & -- \\
\hline
\end{tabular}

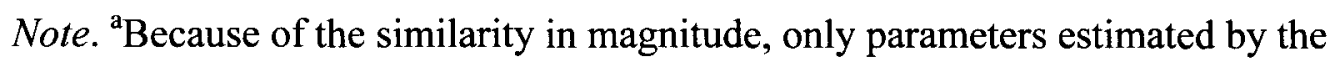
metacognitive strategy model are reported here.

${ }^{* * *} p<.001$.

\section{Practical Significance}

All six MIMIC models had an exceptionally good fit to the data suggesting that the theoretical models captured well the directionalities of the relationships among the 
constructs of interest. Some theoretically unexpected findings produced by cognitive, social, compensation, memory, and affective models, however, suggest a need for exploring alternative model specifications in future research.

The models accounted for an about equal percent ${ }^{53}$ (about 54\%) of the variance in academic achievement. This suggested that a substantial amount of variance in ELLs' academic performance was accounted by student individual differences (i.e., studentlevel variables); it should be noted, however, that the length of residence in the U.S. schools (LOR) is a measure that captures the amount of instruction in and through English-as-a-second language received by the students thus reflecting instructional influences on ELLs' achievement. The amount of accounted-for-variance in academic English proficiency varied slightly across models and ranged from $28 \%$ (cognitive strategy model) to $32 \%$ (affective strategy model). The amount of the accounted variance in individual strategy category varied across models and ranged from $53 \%$ (metacognitive strategy model) to $28 \%$ (compensation strategy model). The amount of unexplained variance - particularly with regard to English proficiency and strategy usesuggested a need to explore additional student, and, perhaps, school and classroom variables not explored in this study. ${ }^{54}$

\section{Summary of Research Question 2 Results}

The purpose of Research Question 2 was to examine structural relationships among ELL student background and linguistic profile characteristics and academic achievement, considering the mediating influences of language motivation, language

\footnotetext{
${ }^{53}$ This similarity is not surprising because the models differed in only one aspect, namely, individual strategy category.

${ }^{54}$ Contributions of several school-level predictors to ELLs' academic achievement are explored in Research Question 3.
} 
learning strategy use, and academic English proficiency. The following paragraphs summarize the results of the six MIMIC models.

\section{Predictors of academic achievement.}

- Among six LLS categories examined, only metacognitive strategy had a significant direct effect on academic achievement; the mediating effect of English proficiency further enhanced this positive effect. This suggested that students with higher metacognitive strategy use were more successful academically.

- Consistently across models, academic English proficiency was the strongest positive contributor to ELLs' academic achievement.

- L1 literacy positively contributed to ELLs' academic achievement. The mediating effect of English proficiency enhanced the positive effect of L1 literacy suggesting that students with higher language skills in both English and their native language were more successful academically.

- Age negatively related to ELLs' academic achievement, suggesting a decline in academic performance among older students; this effect was less pronounced $^{55}$ among students with higher English proficiency.

- Length of residence - a variable that captured the amount of instruction in and through English-as-a-second language received by the students—-had a positive indirect effect on academic achievement via the mediating effect of academic English proficiency.

\section{Predictors of strategies.}

\footnotetext{
${ }^{55}$ The negative effect of age was moderated (minimized) by English proficiency.
} 
- Across models, language motivation was the strongest positive predictor of LLS suggesting that more motivated students used more strategies.

- Notably, metacognitive strategy use did not vary as a function of age or length of residence suggesting that metacognitive strategy use may capture a student characteristic that is relatively stable.

- By contrast, other strategy categories appeared to be less stable: Whereas cognitive strategy use declined as a function of age, the use of the remaining four strategy categories - memory, affective, social, and compensationsignificantly declined as a function of length of residence. This suggested that with increase in English proficiency (see below) students may have felt less need (or value) in using these particular strategies (Gardner et al., 1997).

\section{Predictors of English proficiency.}

- Metacognitive strategy category had a significantly positive direct effect on English proficiency. This indicated that higher metacognitive strategy use was associated with higher English proficiency scores.

- No definitive conclusions could be made regarding the relationship between English proficiency and cognitive, social, memory, affective, and compensation strategies because of the intervening effects of age (for cognitive strategy) and length of residence (for social, memory, affective, and compensation strategy).

- Across models, length of residence was the strongest positive contributor to academic English proficiency indicating that students with longer tenure in the U.S. schools had higher English proficiency scores. 
- The effect of length of residence was followed in magnitude by age indicating that older students had higher English proficiency scores. After controlling for academic English proficiency factor, age had a significant direct effect on L2 writing, indicating that—regardless of an overall level of English proficiency—older students had substantially better scores in writing.

- L1 literacy positively contributed to ELLs' English proficiency.

\section{Correlations among exogenous variables.}

- Across models, length of residence and L1 literacy skills were significantly and negatively related suggesting that longer tenure in the U.S. schools was associated with decline in L1 literacy skills. This is discouraging because the results of this study indicated that students with higher native language literacy skills were more successful academically.

- Length of residence and age were significantly and positively related suggesting that older students tended to have longer tenure in the U.S. schools.

- Notably, language motivation had no significant associations with other background variables.

\section{Research Question 3}

The purpose of Research Question 3 was to ascertain unique contributions of language learning strategies to ELLs' academic achievement relative to other studentand school-level variables identified as strong predictors in the research literature.

\section{HLM Analytical Approach}

In addressing Research Question 3, two-level HLM models were estimated separately for each content area (reading, mathematics, science, and social studies) using 
maximum-likelihood estimation method. Tables J1-J8 (see Appendix J) display descriptive statistics and intercorrelations among Level-1 and Level-2 variables for each content area. At the student level, variables that were found to contribute directly to ELLs' academic achievement in SEM analyses as well as two additional variables entered HLM models: These variables included age, L1 literacy, metacognitive strategy use, English proficiency, prior schooling, and mother education.

To capture differences in family background characteristics typical of ELL populations, mother education was captured by two variables: (a) formal education (i.e., school attendance); and (b) postsecondary education. ${ }^{56}$ The former was labeled MED1 and coded as follows: $0=$ formal education (comparison group); $1=$ no formal education . The latter was labeled MED2 and coded as follows: $0=$ less than college (comparison group); 1 = some college or college degree. Specifying mother education in such a manner insured sufficient within-schools sample sizes. However, the estimated postsecondary education effect should be interpreted with caution ${ }^{57}$ due to a substantial amount of missing data- $-36 \%, 24 \%$, and $11 \%$ in elementary, middle, and high school samples, respectively —on the highest educational level attained. Level 1 equation below summarizing the abovementioned modifications. ${ }^{58}$

$$
\begin{aligned}
& Y_{\mathrm{ij}}=\beta_{0 \mathrm{j}}+\beta_{1 \mathrm{j}}\left(\text { age }_{\mathrm{ij}}\right)+\beta_{2 \mathrm{j}}\left(\text { prior schooling }_{\mathrm{ij}}\right)+\beta_{3 \mathrm{j}}\left(\mathrm{MED}_{\mathrm{ij}}\right)+\beta_{4 \mathrm{j}}\left(\mathrm{MED} 2_{\mathrm{ij}}\right)+\beta_{5 \mathrm{j}}(\mathrm{L} 1 \\
& \text { literacy } \left._{\mathrm{ij}}\right)+\beta_{6 \mathrm{j}}\left(\mathrm{META}_{\mathrm{ij}}\right)+\beta_{7 \mathrm{j}}\left(\text { English proficiency }_{\mathrm{ij}}\right)+r_{\mathrm{ij}}
\end{aligned}
$$

At the student level, all variables with a meaningful zero (prior schooling, MED1, MED2, L1 literacy) entered the equation uncentered; other variables (age, metacognitive

\footnotetext{
${ }^{56}$ Further differentiation by highest educational level attained was not feasible because of insufficient within-schools sample sizes and missing data.

${ }^{57}$ Because it is reasonable to assume that some highly educated mothers were coded as having less than college education, the effect is likely to be downwardly biased.

${ }^{58}$ For notation explanations and Level 2 equations see Chapter 3.
} 
strategy, and English proficiency) were group-mean centered. All continuous schoollevel variables - campus poverty rate, school proficiency rate, school ELL effectiveness, teacher perceptions of strategy effectiveness - were grand mean centered.

Data preparation. HLM analyses were performed separately for reading (Grades 3-8, 10), mathematics (Grades 3-8, 11), science (Grades 4, 7, 11), and social studies (Grades $5,8,11$ ). Schools with less than two students tested in a given content area were excluded; a minimum within-school sample size of two was judged as adequate because HLM has the advantage of borrowing strength from the entire sample in estimating individual school equations (Raudenbush \& Bryk, 2002). One elementary school had a missing LLS strategy effectiveness score, which was replaced with an average score across all elementary schools; no other data at the school level were missing. After deleting schools with insufficient within-school sample sizes and a listwise deletion of missing data, the final samples were: (a) 840 students nested in 37 schools (reading); (b) 858 students in 38 schools (mathematics); (c) 312 students nested in 34 schools (science); and (d) 322 students in 37 schools (social studies).

\section{Reading Model}

The two-level reading model was estimated using maximum-likelihood estimation procedure. The initially hypothesized model regressed reading achievement on: (a) at Level 1: age, L1 literacy, prior schooling, mother formal education (MED1), mother postsecondary education (MED2), metacognitive strategy use (META), and English proficiency and (b) at Level 2: educational level (ESLEVEL [baseline], MSLEVEL and HSLEVEL), school poverty, school reading proficiency, ELL effectiveness, and LLS 
effectiveness. Table J1 and Table J2 (see Appendix J) display descriptive statistics and correlations among Level-1 and Level-2 variables.

Model specification. ${ }^{59}$ In order to estimate the amount of variance in reading achievement that was within (Level 1) and between (Level 2) schools, the HLM analysis began with a one-way random-effects ANOVA model. This initial unconditional model - the null model—estimated an average reading score across schools of 33.75 . The between-school variation, $\tau_{00}=54.76$, was statistically significant, $\chi^{2}(36)=238.22, p<$ .001 , indicating significant differences among schools in their mean achievement levels. The estimated interclass correlation coefficient of .18 indicated that about $18 \%$ of the variance in reading scores was due to schools. The within-school variation was $\sigma^{2}=$ 247.74 .

Next, the author estimated the school-level model (means-as-outcomes regression model) with no student-level predictors. School-level predictors were entered in three steps: (1) educational level (MSLEVEL and HSLEVEL); (2) school quality indicators (school poverty, school proficiency, and ELL effectiveness); and (3) LLS effectiveness. The results of the model produced by the first step revealed a significant association between MSLEVEL and reading achievement, $\gamma_{\mathrm{MSLEVEL}}=-10.6, t(34)=-3.58, p<.01$, suggesting that-without controlling for other school level characteristics—-the average reading achievement in middle schools was lower than that in elementary schools. Although reading achievement of high school students was lower, the difference was not statistically significant $\gamma_{\mathrm{HSLEVEL}}=-4.4, t(34)=-1.20, p=.240$. Once other school level characteristics entered the model in steps two and three, the MSLEVEL effect did not

\footnotetext{
${ }^{59}$ During model specification (exploratory) stage a less stringent criterion for significance testing (i.e., $p<$ .10) was applied for retaining the initial set of predictors.
} 
maintain its significance. The overall results of the means-as-outcomes regression model indicated that - relative to other school-level predictors examined-only school proficiency and ELL effectiveness significantly related to mean reading achievement, $t(30)=4.19, p<.001$ and $t(30)=6.94, p<.001$, respectively. Taken together, school proficiency and ELL effectiveness accounted for $84 \%$ of the between-school variability in schools' mean reading achievement; the remaining ${ }^{60}$ school-level predictors were removed from further analyses estimating school means.

The next step was to estimate a student-level model (the random-coefficient regression model). This model regressed reading achievement on age, L1 literacy, prior schooling, mother formal education (MED1), mother postsecondary education (MED2), metacognitive strategy use (META), and English proficiency. No school predictors entered this model. The results indicated that prior schooling and MED2 did not reach significance ( $p=.816$ and $p=.194$, respectively) and were removed from subsequent models. The non-significant prior schooling effect indicated that there were no significant differences in reading performance between ELLs students with and without limited-orno-formal-schooling history controlling for other student-level background characteristics. The non-significant postsecondary education effect is surprising, suggesting some amount of maternal education, may have more impact on student achievement than her achieving higher educational degree. Five student-level variablesage, MED1, L1 literacy, META, and English proficiency-were significantly related to reading achievement, $p<.10$ (as noted earlier, this less stringent criterion for significance

${ }^{60}$ Excluded variables: MSLEVEL, $t(30)=-0.09, p=.933$; HSLEVEL, $t(30)=-0.345, p=.731$; POVR, $t(30)=-1.462, p=.154$; and LLSEFF, $t(30)=0.27, p=.788$. 
testing was applied during the initial model-building stages). Taken together, the retained student-level variables explained $36 \%$ of the within-school variability.

Finally, a full two-level model of academic achievement in reading was estimated. The Level 1 model included the intercept (the estimate of the average reading achievement) and five slopes (the estimates of student-level effects): age, MED1, L1 literacy, META, and English proficiency. School reading proficiency and ELL effectiveness served as predictors of Level 1 means in the Level 2 model. Based on preliminary analyses, age, MED1, L1 literacy, and META slopes were re-specified as fixed; English proficiency was re-specified as nonrandomly varying over schools as a function of school organizational and quality indicators. This decision was based on the results of slope homogeneity tests, which involved the examination of chi square statistics associated with variance components. The variance components of age, MED1, L1 literacy, and META slopes were not statistically different from zero $(p>.05)$ suggesting that these effects were similar across schools, regardless of educational level and school quality indicator. The results of slope homogeneity tests also indicated that the variance associated with English proficiency was "absorbed" (explained; Raudenbush \& Bryck, 2002) by school-level predictors. Only variables that predicted reading scores at $p$ $<.05$ were retained for the final, explanatory model. Table 4.13 displays estimates produced by the full and the final models (variance components are reported in Table 4.14).

Final explanatory model. 
Table 4.13

Full and Final Models of Reading Achievement: Fixed effects

\begin{tabular}{|c|c|c|c|c|}
\hline & \multicolumn{2}{|c|}{ Full Model } & \multicolumn{2}{|c|}{ Final Model } \\
\hline & Coefficient (SE) & tratio & Coefficient (SE) & tratio \\
\hline \multicolumn{5}{|l|}{ School mean $\left(\beta_{0 \mathrm{j}}\right)$} \\
\hline Base $\left(\gamma_{00}\right)$ & $32.66(1.08)$ & $30.22 * * *$ & $32.08(1.02)$ & $31.41^{* * *}$ \\
\hline $\operatorname{PRREAD}\left(\gamma_{01}\right)$ & $0.49(0.06)$ & $7.82 * * *$ & $0.49(0.06)$ & $7.90 * * *$ \\
\hline $\operatorname{ELLEFF}\left(\gamma_{02}\right)$ & $0.42(0.06)$ & $7.56^{* * *}$ & $0.44(0.06)$ & $7.85^{* * *}$ \\
\hline \multicolumn{5}{|l|}{ Age slope $\left(\beta_{1 \mathrm{j}}\right)$} \\
\hline Base $\left(\gamma_{10}\right)$ & $-1.79(0.42)$ & $-4.24 * * *$ & $-1.85(0.42)$ & $-4.41 * * *$ \\
\hline \multicolumn{5}{|c|}{ L1 literacy slope $\left(\beta_{2 \mathrm{j}}\right)$} \\
\hline Base $\left(\gamma_{20}\right)$ & $0.47(0.23)$ & $2.04^{*}$ & $0.54(0.23)$ & $2.36^{*}$ \\
\hline \multicolumn{5}{|l|}{ MED1 slope $\left(\beta_{3 j}\right)$} \\
\hline Base $\left(\gamma_{30}\right)$ & $-1.97(1.22)$ & -1.62 & & \\
\hline
\end{tabular}




\begin{tabular}{|c|c|c|c|c|}
\hline & \multicolumn{2}{|c|}{ Full Model } & \multicolumn{2}{|c|}{ Final Model } \\
\hline & Coefficient $(S E)$ & tratio & Coefficient $(S E)$ & tratio \\
\hline \multicolumn{5}{|l|}{ META slope $\left(\beta_{4 j}\right)$} \\
\hline Base $\left(\gamma_{40}\right)$ & $0.33(0.15)$ & $2.27^{*}$ & $0.33(0.15)$ & $2.27^{*}$ \\
\hline \multicolumn{5}{|c|}{ English proficiency slope $\left(\beta_{5 \mathrm{j}}\right)$} \\
\hline $\operatorname{Base}\left(\gamma_{50}\right)$ & $0.33(0.02)$ & $13.68 * * *$ & $0.33(0.02)$ & $15.95^{* * *}$ \\
\hline $\operatorname{MSLEVEL}\left(\gamma_{51}\right)$ & $0.09(0.05)$ & $1.71^{\dagger}$ & $0.12(0.04)$ & $2.85^{* *}$ \\
\hline $\operatorname{HSLEVEL}\left(\gamma_{52}\right)$ & $-0.01(0.09)$ & -0.14 & & \\
\hline $\operatorname{POVERTY}\left(\gamma_{53}\right)$ & $0.003(0.002)$ & $1.92^{\dagger}$ & $0.003(0.002)$ & $2.00^{*}$ \\
\hline $\operatorname{PRREAD}\left(\gamma_{54}\right)$ & $0.005(0.003)$ & $1.94^{\dagger}$ & $0.006(0.002)$ & $2.65^{* *}$ \\
\hline $\operatorname{ELLEFF}\left(\gamma_{55}\right)$ & $-0.001(0.002)$ & -0.56 & & \\
\hline
\end{tabular}

Note. Values are reported in scale score points.

${ }^{* * *} p<.001 .{ }^{* *} p<.01 .{ }^{*} p<.05 .{ }^{\dagger} p<.10$. 
Table 4.14

Full and Final Models of Reading Achievement: Random effects

\begin{tabular}{llllll}
\hline & \multicolumn{2}{c}{ Full Model } & & \multicolumn{2}{c}{ Final Model } \\
\cline { 2 - 3 } \cline { 5 - 6 } & Variance $(d f)$ & Chi-square & & Variance $(d f)$ & Chi-square \\
\hline Mean achievement $\left(\tau_{00}\right)$ & $11.48(34)$ & $100.96^{* * *}$ & & $11.50(34)$ & $101.00^{* * *}$ \\
Level-1 $\operatorname{effect}\left(\sigma^{2}\right)$ & 157.21 & & 157.76 & \\
\hline
\end{tabular}

Note. $* * * p<.001$. 
Estimating the means. The results indicated that the average reading score for a reference student was $32.08\left(\gamma_{00}\right.$; see 4.13). This reference student was average in age, metacognitive strategy use, and English proficiency, was not literate in his or her native language, and attended a school with average quality indicators (i.e., proficiency rate and ELL effectiveness). School reading proficiency rate $\left(\gamma_{01}\right)$ and the average reading score were positively related, with each percentage increase in reading proficiency rate predicting an increase in reading scores by 0.49 scale points. For example, in the school with the highest reading proficiency rate in the sample (i.e., a school in which the percentage of students scoring Proficient or Distinguished was higher than that in the average school by $27 \%$ ), the average reading score was higher by 13.23 points. A similar relationship was found between the average reading score and ELL effectiveness $\left(\gamma_{02}\right)$ predicting an increase in reading scores of 0.44 scale points for each unit increase in ELL effectiveness.

Estimating the slopes. Results for the final models in 4.13 also display the unique effects associated with student-level predictors and their interactions, when present, with school-level predictors. The within-school effect of age was negative and significant: One year increase in age predicted a 1.85-point decline in students' reading scores $\left(\gamma_{10}\right)$. Higher language skills in both native and English language positively contributed to ELLs' reading scores: With each unit increase in L1 literacy and English proficiency, reading performance increased by $0.54\left(\gamma_{20}\right)$ and $0.33\left(\gamma_{50}\right)$ points, respectively. As indicated by a significant interaction effect between English proficiency and MSLEVEL $\left(\gamma_{51}\right)$, the predictive power of English proficiency on reading achievement was larger in middle schools by .12 points, for a total predicted increase of .45 points $\left(\gamma_{50}+\gamma_{51}\right)$ per 
one-point increase in English proficiency. Seemingly small, this effect translates into a sizable 45-point increase per 100-scale-point (roughly one proficiency level) increase in English proficiency ${ }^{61}$ Further, poverty and reading proficiency rates had significantthough small in size-interactions with English proficiency. That is, English proficiency contribution to reading achievement increased by $0.003\left(\gamma_{53}\right)$ and $0.006\left(\gamma_{55}\right)$ points per one-point increase in poverty and reading proficiency rates, respectively (these effects are discussed below). Finally, after controlling for all other variables in the model, each unit increase in metacognitive strategy use predicted a 0.33-point increase in ELLs' reading scores $\left(\gamma_{40}\right)$ suggesting that higher use metacognitive strategies predicted better reading performance.

Practical significance. Following Raudenbush and Bryck's (2002) recommendation, practical significance of the results was evaluated by estimating the increase in proportion of variance explained at each level from the unconditional to the final model. At Level 1, the final model explained $36 \%$ of within-school variance in reading achievement, suggesting that it may be fruitful to explore other student level variables. At Level 2, between-school variation in average reading achievement was substantially reduced by $79 \%$. However, as indicated by chi-square statistic associated with the coefficient's variance component ( $\tau_{00}$; see Table 4.14$)$, a substantial amount of between-school variance for average reading achievement remained unexplained. This unexplained variance may be attributed to classroom variables (e.g., amount of second language development support, teacher ESL preparedness, instructional methods, etc.) not included in this study. Future research may expand the present model to a 3-Level HLM (student-classroom-school) to account for these classroom effects.

${ }^{61}$ ACCESS scale score range: 100-600; proficiency level range 1-6. 
Summary. The results of bivariate correlational analyses (see Tables J1 and J2, Appendix J) indicated that - -with the exception of poverty rate and LLS effectivenessall student- and school-level variables explored in this study were significantly related to ELLs' reading achievement. However, the results of the final HLM model (see Table 4.13) indicated that — relative to other predictors —only four student-level and two school-level predictors remained significant (in addition, there were some interaction effects; discussed below).

Whereas age was a negative predictor, each unit increase in metacognitive strategy, L1 literacy, and English proficiency predicted an increase in reading performance. Controlling for other variables, disadvantaged educational backgrounds (i.e., student's lack of prior education and his or her mother's lack of formal education) and mother college education had no significant impact on ELLs' reading achievement. This is encouraging because—unlike student educational backgrounds—L1 literacy, metacognitive strategy, and English proficiency are instructionally manipulable.

The average reading score of ELLs was higher in schools with higher reading proficiency and ELL effectiveness rates. Although reading scores of middle school students tended to be lower than those of elementary students, these differences were not statistically significant once school quality indicators (i.e., school proficiency and ELL proficiency rates) were controlled. English proficiency interacted with school organizational and quality indicators: The predictive power of English proficiency on reading achievement was larger in middle schools and in schools with higher poverty and reading proficiency rates. The middle school effect may be attributed to students' becoming increasingly exposed to more academically demanding texts (e.g., expository 
as opposed to narrative texts; Fang, 2008) as they transition from elementary school. The latter two effects may be attributed to a stronger dependence on English proficiency in higher "competition"- either with more advanced peers in higher performing schools or for more stretched resources (including teacher attention) in higher poverty schoolscontexts.

\section{Mathematics Model}

The two-level mathematics model was estimated using maximum-likelihood estimation procedure. The initially hypothesized model regressed reading achievement on: (a) at Level 1: age, L1 literacy, prior schooling, mother formal education (MED1), mother postsecondary education (MED2), metacognitive strategy use (META), and English proficiency and (b) at Level 2: educational level (ESLEVEL [baseline], MSLEVEL and HSLEVEL), school poverty, school mathematics proficiency, ELL effectiveness, and LLS effectiveness. Table J3 and Table J4 (see Appendix J) display descriptive statistics and correlations among Level-1 and Level-2 variables.

Model specifications. ${ }^{62}$ Similar to reading analyses, the author began model specification by separately estimating the unconditional (one-way random-effects ANOVA; i.e., no student- or school-level predictors), Level 2 (means-as-outcomes regression model; i.e., no student-level predictors), and Level 1 (random-coefficient regression model; i.e., no school-level predictors) models. The results of the unconditional model estimated an average mathematics score across schools of 29.49. The between-school variation was statistically significant, $\tau_{00}=85.53, \chi^{2}(37)=218.17, p$ $<.001$, indicating significant differences among schools in their mean achievement

\footnotetext{
${ }^{62}$ During model specification (exploratory) stage a less stringent criterion for significance testing (i.e., $p<$ $.10)$ was applied for retaining the initial set of predictors.
} 
levels. About $18 \%$ of the variance in mathematics scores was due to schools. The withinschool variation was $\sigma^{2}=382.95$

The results of the model produced by the first step of the stepwise means-asoutcomes regression model (school-level model) revealed a significant association between educational level and mathematics achievement, $\gamma_{\mathrm{MSLEVEL}}=-14.7, t(35)=-4.59$, $p<.001$ and $\gamma_{\text {HSLEVEL }}=-13.2, t(35)=-3.49, p<.01$. This suggested that-without controlling for other school level characteristics - the average mathematics achievement in middle and high schools was lower than that in elementary schools. The MSLEVEL and HSLEVEL effects, however, did not maintain their significance once other school level characteristics entered the model in steps two and three. The overall results of the means-as-outcomes regression model indicated that-relative to other school-level predictors examined—only school proficiency and ELL effectiveness significantly related to mean mathematics achievement, $t(35)=10.99, p<.001$ and $t(35)=11.54, p<$ .001 , respectively. Taken together, school proficiency and ELL effectiveness accounted for $99.6 \%$ of the between-school variability in schools' mean mathematics achievement; the remaining ${ }^{63}$ school-level predictors were removed from further analysis estimating school means.

Next, the random-coefficient regression model (student-level model) regressed reading achievement on age, L1 literacy, prior schooling, mother formal education (MED1), mother postsecondary education (MED2), metacognitive strategy use (META), and English proficiency. Similar to the reading model, the results indicated that-relative to other predictors - prior school and mother postsecondary education did not reach

\footnotetext{
${ }^{63}$ Excluded variables: MSLEVEL, $t(31)=-0.39, p=.696$; HSLEVEL, $t(31)=1.59, p=.121$; POVR,$t(31)$ $=0.35, p=.731 ;$ and LLSEFF, $t(31)=-0.51, p=.615$.
} 
significance $(p=.510, p=.346$, respectively; see the discussion of these effects in the reading model section). Unlike in the reading model, metacognitive strategies did not significantly $(p=.404)$ contribute to students' mathematics scores $(p=.404)$. This result contradicts the results of the SEM analyses which found a positive link between metacognitive strategies and the academic achievement measured as a latent construct underlying student performance both in reading and mathematics. PRSCH, MED2, and META were removed from subsequent mathematics models. Four retained student-level variables-age, L1 literacy, MED1, and English proficiency-significantly $(p<.05)$ related to mathematics achievement and explained $29.7 \%$ of the within-school variability.

Finally, a full two-level model of academic achievement in mathematics was estimated. The Level 1 model included the intercept (the estimate of the average mathematics achievement) and four slopes (the estimates of student-level effects): age, L1 literacy, MED1, and English proficiency. School mathematics proficiency and ELL effectiveness served as predictors of Level 1 means in the Level 2 model. Based on preliminary analyses, L1 literacy and MED1 slopes were re-specified as fixed. The variance components of L1 literacy and MED1 slopes were not statistically different from zero $(p>.05)$ suggesting that these effects did not vary across schools. Only variables that predicted mathematics scores at $p<.05$ were retained for the final, explanatory model. Table 4.15 displays estimates produced by the full and the final models (variance components are reported in Table 4.16).

\section{Final explanatory model.}


Table 4.15

Full and Final Models of Mathematics Achievement: Fixed effects

\begin{tabular}{|c|c|c|c|c|}
\hline & \multicolumn{2}{|c|}{ Full Model } & \multicolumn{2}{|c|}{ Final Model } \\
\hline & Coefficient (SE) & tratio & Coefficient $(S E)$ & tratio \\
\hline \multicolumn{5}{|l|}{ School mean $\left(\beta_{0 \mathrm{j}}\right)$} \\
\hline Base $\left(\gamma_{00}\right)$ & $26.39(1.26)$ & $20.89 * * *$ & $26.38(1.25)$ & $21.08 * * *$ \\
\hline $\operatorname{PRMATH}\left(\gamma_{01}\right)$ & $0.53(0.05)$ & $10.68 * * *$ & $0.54(0.05)$ & $11.25 * * *$ \\
\hline $\operatorname{ELLEFF}\left(\gamma_{02}\right)$ & $0.49(0.05)$ & $9.61 * * *$ & $0.48(0.05)$ & $10.24^{* * *}$ \\
\hline \multicolumn{5}{|l|}{ Age slope $\left(\beta_{1 \mathrm{j}}\right)$} \\
\hline Base $\left(\gamma_{10}\right)$ & $-3.54(1.07)$ & $-3.31 * *$ & $-3.69(0.72)$ & $-5.12 * * *$ \\
\hline $\operatorname{MSLEVEL}\left(\gamma_{11}\right)$ & $-0.80(2.09)$ & -0.39 & & \\
\hline $\operatorname{HSLEVEL}\left(\gamma_{12}\right)$ & $3.45(3.56)$ & 0.97 & & \\
\hline $\operatorname{POVERTY}\left(\gamma_{13}\right)$ & $-0.05(0.06)$ & -0.86 & & \\
\hline $\operatorname{PRMATH}\left(\gamma_{14}\right)$ & $-0.02(0.08)$ & -0.20 & & \\
\hline $\operatorname{ELLEFF}\left(\gamma_{15}\right)$ & $-0.02(0.06)$ & -0.34 & & \\
\hline $\operatorname{LLSEFF}\left(\gamma_{16}\right)$ & $-0.51(2.08)$ & -0.24 & & \\
\hline
\end{tabular}




\begin{tabular}{|c|c|c|c|c|}
\hline & \multicolumn{2}{|c|}{ Full Model } & \multicolumn{2}{|c|}{ Final Model } \\
\hline & Coefficient (SE) & tratio & Coefficient (SE) & tratio \\
\hline \multicolumn{5}{|c|}{ L1 literacy slope $\left(\beta_{2 \mathrm{j}}\right)$} \\
\hline $\operatorname{Base}\left(\gamma_{20}\right)$ & $1.11(0.30)$ & $3.70 * * *$ & $1.11(0.30)$ & $3.72^{* * *}$ \\
\hline \multicolumn{5}{|l|}{ MED1 slope $\left(\beta_{3 j}\right)$} \\
\hline $\operatorname{Base}\left(\gamma_{30}\right)$ & $-3.32(1.52)$ & $-2.17^{*}$ & $-3.18(1.52)$ & $-2.10^{*}$ \\
\hline \multicolumn{5}{|c|}{ English proficiency slope $\left(\beta_{4 \mathrm{j}}\right)$} \\
\hline Base $\left(\gamma_{40}\right)$ & $0.37(0.05)$ & $8.10^{* * *}$ & $0.35(0.03)$ & $10.568^{* * *}$ \\
\hline $\operatorname{MSLEVEL}\left(\gamma_{41}\right)$ & $-0.11(0.09)$ & -1.25 & & \\
\hline $\operatorname{HSLEVEL}\left(\gamma_{42}\right)$ & $0.01(0.14)$ & 0.07 & & \\
\hline $\operatorname{POVERTY}\left(\gamma_{43}\right)$ & $0.004(0.002)$ & $1.72^{\dagger}$ & & \\
\hline $\operatorname{PRMATH}\left(\gamma_{44}\right)$ & $0.001(0.004)$ & 0.39 & & \\
\hline $\operatorname{ELLEFF}\left(\gamma_{45}\right)$ & $-0.001(0.002)$ & $-2.30^{*}$ & & \\
\hline $\operatorname{LLSEFF}\left(\gamma_{56}\right)$ & $-0.07(0.07)$ & -0.92 & & \\
\hline
\end{tabular}

Note. Values are reported in scale score points.

${ }^{* * *} p<.001 .{ }^{* *} p<.01 .{ }^{*} p<.05 .{ }^{\dagger} p<.10$ 
Table 4.16

Full and Final Models of Mathematics Achievement: Random effects

\begin{tabular}{|c|c|c|c|c|}
\hline & \multicolumn{2}{|c|}{ Full Model } & \multicolumn{2}{|c|}{ Final Model } \\
\hline & Variance $(d f)$ & Chi-square & Variance $(d f)$ & Chi-square \\
\hline Mean achievement $\left(\tau_{00}\right)$ & $6.02(35)$ & $54.49^{*}$ & $5.56(35)$ & $54.36^{*}$ \\
\hline Age slope $\left(\tau_{10}\right)$ & $3.84(31)$ & $57.35 * *$ & $6.17(37)$ & $63.59^{* *}$ \\
\hline English proficiency slope $\left(\tau_{40}\right)$ & $0.006(31)$ & $57.89 * *$ & $0.01(37)$ & $63.91 * *$ \\
\hline Level-1 effect $\left(\sigma^{2}\right)$ & 274.35 & & 274.64 & \\
\hline
\end{tabular}


Estimating the means. The results indicated that the average mathematics score for a reference student was 26.38 ( $\gamma_{00}$; see Table 4.15). This reference student was average in age and English proficiency, was not literate in his or her native language, had a mother with some education, and attended a school with average quality indicators (i.e., mathematics proficiency rate and ELL effectiveness). School mathematics proficiency rate $\left(\gamma_{01}\right)$ and the average mathematics score were positively related, with each percentage increase in mathematics proficiency rate predicting an increase in mathematics scores by 0.54 scale points. For example, in the school with the highest mathematics proficiency rate in the sample (i.e., a school in which the percentage of students scoring Proficient or Distinguished was higher than that in the average school by about $37 \%$ ), the average mathematics score was higher by 19.77 points. A similar relationship was found between the average mathematics score and ELL effectiveness $\left(\gamma_{02}\right)$ predicting an increase in mathematics scores of 0.48 scale points for each unit increase in ELL effectiveness (this amounted to a predicted total score difference of 36.64 scale points between the least and the most ELL effective schools in the sample).

Estimating the slopes. Results for the final models in Table 4.15 also display the unique effects associated with student-level predictors. The within-school effect of age was negative and significant: One year increase in age predicted a 3.69-point decline in students' mathematics scores $\left(\gamma_{10}\right)$. Higher language skills in both native and English language positively contributed to ELLs' mathematics scores: With each unit increase in L1 literacy and English proficiency, mathematics performance increased by $1.11\left(\gamma_{20}\right)$ and $0.35\left(\gamma_{40}\right)$ points, respectively. English proficiency was the strongest student-level contributor to ELLs' mathematics scores. Seemingly small, English proficiency effect 
translated into a sizable 35 -point $(0.35 \times 100)$ increase in mathematics score per 100point increase - a score roughly corresponding to one proficiency level—in English proficiency. Unlike in the reading model, MED1 significantly related to students' mathematics achievement. The predicted score of students whose mothers had some formal education was higher than that of students whose mothers had no formal education by $3.18\left(\gamma_{30}\right)$ points.

Practical significance. The final model explained $28 \%$ of within- and $93 \%$ of between-school variance in mathematics achievement suggesting that it may be fruitful to explore other student-, school-, as well as classroom-level variables not included in this study.

Summary. The results of bivariate correlational analyses (see Tables J3 and J4, Appendix J) indicated that - with the exception of poverty rate and LLS effectivenessall student- and school-level variables explored in this study were significantly related to ELLs' mathematics achievement. However, the results of final HLM model (see Table 4.15) indicated that — relative to other predictors — only four student-level and two school-level predictors remained significant.

Controlling for other variables in the model, metacognitive strategies and lack of prior education had no significant impact on ELLs' mathematics achievement. Whereas age was a negative predictor, each unit increase in L1 literacy and English proficiency predicted an increase in mathematics performance. The predicted mathematics score of students whose mothers had some formal education was higher than that of students whose mothers had no formal education; the non-significant postsecondary education 
effect suggested that some amount of maternal education, may have more impact on student achievement than her achieving higher educational degree.

The average mathematics score of ELLs was higher in schools with higher mathematics proficiency and ELL effectiveness rates. Although mathematics scores of middle and high school students tended to be lower than those of elementary students, these differences were not statistically significant once school quality indicators (i.e., school proficiency and ELL effectiveness rates) were controlled.

\section{Science Model}

The two-level science model was estimated using maximum-likelihood estimation procedure. The initially hypothesized model regressed science achievement on: (a) at Level 1: age, L1 literacy, prior schooling, mother formal education (MED1), mother postsecondary education (MED2), metacognitive strategy use (META), and English proficiency and (b) at Level 2: educational level (ESLEVEL [baseline], MSLEVEL and HSLEVEL), school poverty, school mathematics proficiency, ELL effectiveness, and LLS effectiveness. Table J5 and Table J6 (see Appendix J) display descriptive statistics and correlations among Level-1 and Level-2 variables.

Model Specifications. ${ }^{64}$ Similar to previous HLM analyses, the author began model specification by separately estimating the unconditional (one-way random-effects ANOVA; i.e., no student- or school-level predictors), Level 2 (means-as-outcomes regression model; i.e., no student-level predictors), and Level 1 (random-coefficient regression model; i.e., no school-level predictors) models. The results of the unconditional model estimated an average science score across schools of 27.30. The

\footnotetext{
${ }^{64}$ During model specification (exploratory) stage a less stringent criterion for significance testing (i.e., $p<$ .10) was applied for retaining the initial set of predictors.
} 
between-school variation was statistically significant, $\tau_{00}=104.81, \chi^{2}(33)=197.44, p<$ .001 , indicating significant differences among schools in their mean achievement levels. About $35 \%$ of the variance in science scores was due to schools. The within-school variation was $\sigma^{2}=194.69$.

The results of the stepwise means-as-outcomes regression model indicated that four variables-MSLEVEL, HSLEVEL, PRSC, and ELLEFF—- significantly $(p<.05)$ related to science achievement and accounted for $91 \%$ of the between-school variability in schools' mean science achievement. The remaining ${ }^{65}$ school-level predictors were removed from further analyses estimating school means. Of notice here, is that unlike in reading and mathematics models, MSLEVEL and HSLEVEL maintained their significance in steps 2 and 3 suggesting that the average science achievement in middle and high schools was lower than that in elementary schools, regardless of school quality indicators. Introducing school quality indicators, however, substantially mitigated the negative effects of educational level, from $\gamma_{\mathrm{MSLEVEL}}=-16.07$ and $\gamma_{\mathrm{HSLEVEL}}=-19.22$ (step 1) to $\gamma_{\text {MSLEVEL }}=-7.06$ and $\gamma_{\text {HSLEVEL }}=-9.07$ (step 3).

Next, the random-coefficient regression model (student-level model) regressed science achievement on age, L1 literacy, prior schooling, mother formal education (MED1), mother postsecondary education (MED2), metacognitive strategy use (META), and English proficiency. ${ }^{66}$ No school predictors entered this model. The results indicated that, similar to mathematics model, PRSCH, MED2, and META did not reach significance $(p=.793, p=.500$, and $p=.353$, respectively). Contrary to the reading and

\footnotetext{
${ }^{65}$ Excluded variables: POVR, $t(27)=-0.48, p=.637$ and LLSEFF, $t(27)=-0.67, p=.51$. 66 Contrary to reading and mathematics results, there was no significant within-school effect of age on student science scores. This may be attributed to the limited within-group variability (i.e., only one gradelevel within each educational level contributing to the estimation of the science model).
} 
mathematics results, there was no significant within-school effect of age $(p=.825)$ on student science scores. Of notice here is that—unlike reading and mathematics samplesscience sample included only one grade (Grade 4,7 , or 11) within each educational level (elementary, middle, high), suggesting that progression through grades rather than age per se was associated with decline in science scores. Age, PRSCH, MED2, and META were removed from subsequent mathematics models. Three retained student-level variables—L1 literacy, MED1, and English proficiency—were significantly related to science achievement at $p<.10$ or better and accounted for $36.6 \%$ of the within-school variability.

Finally, a full two-level model of academic achievement in science was estimated. The Level 1 model included the intercept (the estimate of the average science achievement) and three slopes (the estimates of student-level effects): L1 literacy, MED1, and English proficiency. Educational level (MSLEVEL and HSLEVEL) and school quality indicators (school science proficiency and ELL effectiveness) served as predictors of Level 1 means in the Level 2 model. Based on preliminary analyses L1 literacy and English proficiency slopes were re-specified as fixed; MED1 was re-specified as nonrandomly varying over schools as a function of school organizational and quality indicators. ${ }^{67}$ Only variables that predicted science scores at $p<.05$ were retained for the final, explanatory model. Table 4.17 displays estimates produced by the full and the final models (variance components are reported in Table 4.18).

Final explanatory model.

\footnotetext{
${ }^{67}$ The variance components of L1 literacy and L2 proficiency slopes were not statistically different from zero $(p>.05)$ suggesting that these effects were similar across schools, regardless of educational level and school quality indicators. The results of slope homogeneity tests also indicated that the variance associated with MED1 was "absorbed" (explained; Raudenbush \& Bryck, 2002) by school-level predictors.
} 
Table 4.17

Full and Final Models of Science Achievement: Fixed effects

\begin{tabular}{|c|c|c|c|c|}
\hline & \multicolumn{2}{|c|}{ Full Model } & \multicolumn{2}{|c|}{ Final Model } \\
\hline & Coefficient (SE) & tratio & Coefficient (SE) & tratio \\
\hline \multicolumn{5}{|l|}{ School mean $\left(\beta_{0 \mathrm{j}}\right)$} \\
\hline Base $\left(\gamma_{00}\right)$ & $33.94(1.85)$ & $18.307^{* * *}$ & $32.88(1.50)$ & $21.96 * * *$ \\
\hline $\operatorname{MSLEVEL~}\left(\gamma_{01}\right)$ & $-8.07(3.15)$ & $-2.562 *$ & $-8.13(2.98)$ & $-2.72^{*}$ \\
\hline $\operatorname{HSLEVEL~}\left(\gamma_{02}\right)$ & $-9.49(3.37)$ & $-2.821 * *$ & $-9.77(3.13)$ & $-3.12^{* *}$ \\
\hline $\operatorname{PRSC}\left(\gamma_{03}\right)$ & $0.37(0.08)$ & $4.557 * * *$ & $0.36(0.08)$ & $4.574 * * *$ \\
\hline $\operatorname{ELLEFF}\left(\gamma_{04}\right)$ & $0.33(0.09)$ & $3.917 * *$ & $0.29(0.08)$ & $3.54^{* *}$ \\
\hline \multicolumn{5}{|l|}{ L1 literacy slope $\left(\beta_{1 \mathrm{j}}\right)$} \\
\hline Base $\left(\gamma_{10}\right)$ & $-0.35(0.35)$ & -1.012 & & \\
\hline \multicolumn{5}{|l|}{$\operatorname{MED1}^{\mathrm{a}}$ slope $\left(\beta_{2 \mathrm{j}}\right)$} \\
\hline Base $\left(\gamma_{20}\right)$ & $-10.44(2.93)$ & $-3.56 * *$ & $-7.20(1.70)$ & $-4.24 * * *$ \\
\hline $\operatorname{MSLEVEL}\left(\gamma_{21}\right)$ & $3.53(5.06)$ & 0.70 & & \\
\hline
\end{tabular}




\begin{tabular}{|c|c|c|c|c|}
\hline & \multicolumn{2}{|c|}{ Full Model } & \multicolumn{2}{|c|}{ Final Model } \\
\hline & Coefficient (SE) & tratio & Coefficient (SE) & tratio \\
\hline $\operatorname{HSLEVEL}\left(\gamma_{22}\right)$ & $-1.87(5.49)$ & -0.34 & & \\
\hline $\operatorname{POVERTY}\left(\gamma_{23}\right)$ & $-0.39(0.28)$ & -1.43 & & \\
\hline $\operatorname{PRSC}\left(\gamma_{24}\right)$ & $-0.62(0.24)$ & $-2.63 * *$ & $-0.25(0.08)$ & $-3.021 * *$ \\
\hline $\operatorname{ELLEFF}\left(\gamma_{25}\right)$ & $-0.10(0.17)$ & -0.54 & & \\
\hline $\operatorname{LLSEFF}\left(\gamma_{26}\right)$ & $0.89(8.12)$ & 0.11 & & \\
\hline \multicolumn{5}{|c|}{ English proficiency slope $\left(\beta_{3 \mathrm{j}}\right)$} \\
\hline $\operatorname{Base}\left(\gamma_{30}\right)$ & $0.30(0.03)$ & $10.63 * * *$ & $0.30(0.03)$ & $10.494 * * *$ \\
\hline
\end{tabular}

Note. Values are reported in scale score points.

${ }^{a}$ MED1 is coded such that a higher value corresponds to less education $(0=$ some school; $1=$ no school $)$.

${ }^{* * *} p<.001 .{ }^{* *} p<.01 .{ }^{*} p<.05 .{ }^{\dagger} p<.10$. 
Table 4.18

Full and Final Models of Science Achievement: Random effects

\begin{tabular}{|c|c|c|c|c|}
\hline & \multicolumn{2}{|c|}{ Full Model } & \multicolumn{2}{|c|}{ Final Model } \\
\hline & Variance $(d f)$ & Chi-square & Variance $(d f)$ & Chi-square \\
\hline Mean achievement $\left(\tau_{00}\right)$ & $13.65(29)$ & $67.55 * * *$ & $15.13(29)$ & $70.37 * * *$ \\
\hline Level-1 effect $\left(\sigma^{2}\right)$ & 123.09 & & 125.45 & \\
\hline
\end{tabular}

Note. ${ }^{* * *} p<.001$ 
Estimating the means. The results indicated that the average science score for a reference student was $32.88\left(\gamma_{00} ;\right.$ see Table 4.17). This reference student had a mother with some education, was average in English proficiency, and attended an elementary school with average quality indicators (i.e., science proficiency rate and ELL effectiveness). Educational level predicted a decline in student average science score of 8.13 and 9.77 scale points for middle $\left(\gamma_{01}\right)$ and high school $\left(\gamma_{02}\right)$, respectively. School science proficiency rate $\left(\gamma_{03}\right)$ and the average science score were positively related, with each percentage increase in science proficiency rate predicting an increase in science scores by 0.36 scale points. For example, in the school with the highest science proficiency rate in the sample (i.e., a school in which the percentage of students scoring Proficient or Distinguished was higher than that in the average school by $30.4 \%$ ), the predicted science score was higher by 10.93 points. A similar relationship was found between the average science score and ELL effectiveness $\left(\gamma_{04}\right)$ predicting an increase in science scores of 0.29 scale points for each unit increase in ELL effectiveness (this amounted to a predicted total score difference of 19.59 scale points between the least and the most ELL effective schools in the sample).

Estimating the slopes. Results for the final models in Table 4.17 also display the unique effects associated with student-level predictors and their interactions, when present, with school-level predictors. English proficiency was the strongest contributor to ELLs' science scores: With each unit increase in English proficiency, science performance increased by $0.30\left(\gamma_{30}\right)$ points. This effect translates into a sizable 30 -point $(0.30 \times 100)$ increase in science score per 100-point increase-a score roughly corresponding to one proficiency level—in English proficiency. Unlike in reading model, 
but similar to mathematics model, mother education significantly related to students' science achievement. The predicted score of students whose mothers had no formal education was lower than that of students whose mothers had some formal education by $7.20\left(\gamma_{20}\right)$ points. This disadvantage was smaller in schools with smaller science proficiency rates: A $10 \%$ decrease in school proficiency rate predicted a 2.5 -point $(10 \mathrm{x}$ $\left.\gamma_{24}\right)$ decrease in MED1 effect. This result may be attributed to a stronger competition with more advanced peers in higher performing schools. Lastly, although the results of bivariate intercorrelation analyses (see Table J5, Appendix J) indicated that L1 literacy and science achievement were negatively and significantly related, the results of HLM analyses indicated that—after controlling for other variables in the model—L1 literacy $\left(\gamma_{10}\right)$ had no significant impact on ELLs' science achievement. The negative directionality of the relationship between L1 literacy and science scores (see Table 4.17, Full Model), however, contradicts the findings of the reading and mathematics models and requires additional research.

Practical significance. The final model explained $37 \%$ of within- and $86 \%$ of between-school variance in science achievement suggesting that it may be fruitful to explore other student-, school-, as well as classroom-level variables not included in this study.

Summary. The results of bivariate correlational analyses (see Tables J5 and J6, Appendix J) indicated that - with the exception of metacognitive strategy, poverty rate, and LLS effectiveness-all student- and school-level variables explored in this study were significantly related to ELLs' science achievement. However, the results of final 
HLM model (see Table 4.17) indicated that-relative to other predictors—only two student-level and four school-level predictors remained significant.

Controlling for other variables in the model, metacognitive strategies and lack of prior education had no significant impact on ELLs' science scores. English proficiency was the strongest student-level predictor of ELLs' science performance. Contrary to the reading and mathematics results, there was no significant within-school effect of age on student science scores, suggesting that progression through grades rather than age per se may be associated with decline in academic performance. The predicted score of students whose mothers had some formal education was higher than that of students whose mothers had no formal education. As indicated by a significant interaction effect (see Table 4.17), this advantage was larger in schools with higher science proficiency rates. From home-support perspective, this result suggests that in higher performing schools ELLs may need to rely to a greater extent on parental involvement to support their science learning. From school-support perspective, this result suggests that ELL students with undereducated mothers may require some additional help to support their science learning, particularly in higher performing schools. Similar to reading and mathematics models, the non-significant postsecondary education effect suggested that some amount of maternal education, may have more impact on student achievement than her achieving higher educational degree.

The average science score of ELLs was higher in schools with higher science proficiency and ELL effectiveness rates. Unlike in reading and mathematics models, the average science achievement in middle and high schools was lower than that in 
elementary schools, regardless of school quality indicators. Introducing school quality indicators, however, substantially mitigated the negative effects of educational level.

\section{Social Studies Model}

The two-level social studies model was estimated using maximum-likelihood estimation procedure. The initially hypothesized model regressed social studies achievement on: (a) at Level 1: age, L1 literacy, prior schooling, mother formal education (MED1), mother postsecondary education (MED2), metacognitive strategy use (META), and English proficiency and (b) at Level 2: educational level (ESLEVEL [baseline], MSLEVEL and HSLEVEL), school poverty, school social studies proficiency, ELL effectiveness, and LLS effectiveness. Table J7 and Table J8 (see Appendix J) display descriptive statistics and correlations among Level- 1 and Level-2 variables.

Model specifications. ${ }^{68}$ Similar to previous HLM analyses, the author began model specification by separately estimating the unconditional (one-way random-effects ANOVA; i.e., no student- or school-level predictors), Level 2 (means-as-outcomes regression model; i.e., no student-level predictors), and Level 1 (random-coefficient regression model; i.e., no school-level predictors) models. The results of the unconditional model estimated an average social studies score across schools of 23.80 . The between-school variation was statistically significant, $\tau_{00}=91.72, \chi^{2}(36)=176.72, p$ $<.001$, indicting significant differences among schools in their mean achievement levels. About $30 \%$ of the variance in social studies scores was due to schools. The within-school variation was $\sigma^{2}=210.26$.

\footnotetext{
${ }^{68}$ During model specification (exploratory) stage a less stringent criterion for significance testing (i.e., $p<$ .10 ) was applied for retaining the initial set of predictors.
} 
The results of the model produced by the first step of the stepwise means-asoutcomes regression model (school-level model) revealed a significant association between educational level and social studies achievement, $\gamma_{\mathrm{MSLEVEL}}=-9.62, t(34)=-2.29$, $p<.05$ and $\gamma_{\mathrm{HSLEVEL}}=-8.38, t(34)=-1.95, p<.10$. This suggested that - without controlling for other school level characteristics-the average social studies achievement in middle and high (at a less stringent alpha level) schools was lower than that in elementary schools. However, once other school level characteristics entered the model in steps two and three, the MSLEVEL and HSLEVEL effects did not maintain their significance. The overall results of the means-as-outcomes regression model indicated that-relative to other school-level predictors examined - only school social studies proficiency and ELL effectiveness significantly related to mean social studies achievement, $t(34)=6.52, p<.001$ and $t(34)=5.77, p<.001$, respectively. Taken together, school proficiency and ELL effectiveness accounted for $79 \%$ of the betweenschool variability in schools' social studies achievement; the remaining ${ }^{69}$ school-level predictors were removed from further analysis estimating school means.

Next, the random-coefficient regression model (student-level model) regressed social studies achievement on age, L1 literacy, prior schooling, mother formal education (MED1), mother postsecondary education (MED2), metacognitive strategy use (META), and English proficiency. No school predictors entered this model. The results indicated that age, L1 literacy, PRSCH, MED2, and META did not reach significance ( $p=.672, p$ $=.530, p=.958, p=.140, p=.798$. Two student-level variables-MED1 and English proficiency-were significantly related to social studies achievement at $p<.10$ or better.

${ }^{69}$ Excluded variables: MSLEVEL, $t(30)=0.03, p=.975$; HSLEVEL, $t(30)=0.24, p=.982$; POVR,$t(33)$ $=-1.55, p=.131 ;$ and LLSEFF, $t(30)=1.36, p=.184$. 
Taken together, the retained student-level variables explained about $41 \%$ of the withinschool variability.

Finally, a full two-level model of academic achievement in social studies was estimated. The Level 1 model included the intercept (the estimate of the average social studies achievement) and two slopes (the estimates of student-level effects): MED1 and English proficiency. School social studies proficiency and ELL effectiveness served as predictors of Level 1 means in the Level 2 model. Based on preliminary analyses MED1 slope was re-specified as fixed. ${ }^{70}$ Only variables that predicted social studies scores at $p<$ .05 were retained for the final, explanatory model. Table 4.19 displays estimates produced by the full and the final models (variance components are reported in Table 4.20).

\section{Final explanatory model.}

\footnotetext{
${ }^{70}$ The variance component of MED1 slope was not statistically different from zero $(p>.05)$ suggesting that this effect was similar across schools, regardless of educational level and school quality indicators.
} 
Table 4.19

Full and Final Models of Social Studies Achievement: Fixed effects

\begin{tabular}{|c|c|c|c|c|}
\hline & \multicolumn{2}{|c|}{ Full Model } & \multicolumn{2}{|c|}{ Final Model } \\
\hline & Coefficient (SE) & tratio & Coefficient (SE) & tratio \\
\hline \multicolumn{5}{|l|}{ School mean $\left(\beta_{0 \mathrm{j}}\right)$} \\
\hline Base $\left(\gamma_{00}\right)$ & $25.16(1.18)$ & $21.28^{* * *}$ & $24.52(1.11)$ & $22.16^{* * *}$ \\
\hline $\operatorname{PRSC}\left(\gamma_{01}\right)$ & $0.47(0.07)$ & $6.50^{* * *}$ & $0.49(0.07)$ & $6.87 * * *$ \\
\hline $\operatorname{ELLEFF}\left(\gamma_{02}\right)$ & $0.45(0.08)$ & $5.42 * * *$ & $0.47(0.08)$ & $5.83^{* * *}$ \\
\hline \multicolumn{5}{|l|}{ MED1 $^{\mathrm{a}}$ slope $\left(\beta_{1 \mathrm{j}}\right)$} \\
\hline $\operatorname{Base}\left(\gamma_{10}\right)$ & $-2.96(1.68)$ & $-1.76 \dagger$ & & \\
\hline \multicolumn{5}{|c|}{ English proficiency slope $\left(\beta_{2 j}\right)$} \\
\hline Base $\left(\gamma_{20}\right)$ & $0.32(0.05)$ & $5.81^{* * *}$ & $0.34(0.04)$ & $7.95 * * *$ \\
\hline $\operatorname{MSLEVEL}\left(\gamma_{21}\right)$ & $0.08(0.11)$ & 0.80 & & \\
\hline $\operatorname{HSLEVEL}\left(\gamma_{22}\right)$ & $-0.03(0.12)$ & -0.29 & & \\
\hline $\operatorname{POVERTY}\left(\gamma_{23}\right)$ & $0.01(0.004)$ & 1.11 & & \\
\hline
\end{tabular}




\begin{tabular}{|c|c|c|c|c|}
\hline & \multicolumn{2}{|c|}{ Full Model } & \multicolumn{2}{|c|}{ Final Model } \\
\hline & Coefficient (SE) & tratio & Coefficient $(S E)$ & tratio \\
\hline $\operatorname{PRSC}\left(\gamma_{24}\right)$ & $0.01(0.005)$ & $1.80 \dagger$ & & \\
\hline $\operatorname{ELLEFF}\left(\gamma_{25}\right)$ & $0.002(0.004)$ & 0.43 & & \\
\hline $\operatorname{LLSEFF}\left(\gamma_{26}\right)$ & $0.04(0.12)$ & 0.37 & & \\
\hline
\end{tabular}

Note. Values are reported in scale score points.

${ }^{a} \mathrm{MED} 1$ is coded such that a higher value corresponds to less education.

${ }^{* * *} p<.001 .{ }^{* *} p<.01 .{ }^{*} p<.05 .{ }^{\dagger} p<.10$. 
Table 4.20

Full and Final Models of Social Studies Achievement: Random effects

\begin{tabular}{llllll}
\hline & \multicolumn{2}{c}{ Full Model } & & \multicolumn{2}{c}{ Final Model } \\
\cline { 2 - 3 } \cline { 5 - 6 } & Variance $(d f)$ & Chi-square & & Variance $(d f)$ & Chi-square \\
\hline Mean achievement $\left(\tau_{00}\right)$ & $28.49(34)$ & $101.81 * * *$ & $27.21(34)$ & $98.42^{* * *}$ \\
English proficiency slope $\left(\tau_{20}\right)$ & $0.02(30)$ & $67.77^{* * *}$ & & $0.03(36)$ & $77.17 * * *$ \\
Level-1 effect $\left(\sigma^{2}\right)$ & 124.96 & & 127.57 & \\
\hline
\end{tabular}

Note. ${ }^{* * *} p<.001$. 
Estimating the means. The results indicated that the average social studies score for a reference student was $25.16\left(\gamma_{00} ;\right.$ see 4.19$)$. This reference had average English proficiency and attended a school with average quality indicators (i.e., social studies proficiency rate and ELL effectiveness). School social studies proficiency rate $\left(\gamma_{01}\right)$ and the average social studies score were positively related, with each percentage increase in social studies proficiency rate predicting an increase in social studies scores by 0.47 scale points. For example, in the school with the highest social studies proficiency rate in the sample (i.e., a school in which the percentage of students scoring Proficient or Distinguished was higher than that in the average school by $49.8 \%$ ), the predicted social studies score was higher by 23.42 points. A similar relationship was found between the average social studies score and ELL effectiveness $\left(\gamma_{02}\right)$ predicting an increase in social studies scores of 0.45 scale points for each unit increase in ELL effectiveness (this amounted to a total score difference of 30.31 scale points between the least and the most ELL effective schools in the sample).

Estimating the slopes. Results for the final models in 4.19 also display the unique effects associated with student-level predictors and their interactions, when present, with school-level predictors. English proficiency was the only significant contributor to ELLs' social studies scores: With each unit increase in English proficiency, social studies performance increased by $0.32\left(\gamma_{20}\right)$ points. This effect translated into a sizable 32-point $(0.30 \times 100)$ increase in social studies score per 100 -point increase-a score roughly corresponding to one proficiency level—in English proficiency. Relative to other predictors in the model (and similar to the results of the reading model), mother education did not significantly relate to students' social studies achievement. 
Practical significance. The final model explained $41 \%$ of within- and $70 \%$ of between-school variance in science achievement suggesting that it may be fruitful to explore other student-, school-, as well as classroom-level variables not included in this study.

Summary. The results of bivariate correlational analyses (see Tables $\mathrm{J} 7$ and $\mathrm{J} 8$, Appendix J) indicated that - with the exception of L1 literacy, metacognitive strategy use, school poverty rate, and LLS effectiveness-all student- and school-level variables explored in this study were significantly related to ELLs' social studies achievement. The results of the final HLM model, however, indicated that-relative to other predictorsonly one student-level and two school-level predictors remained significant (see Table 4.19).

Controlling for other variables, metacognitive strategies, disadvantaged educational backgrounds (i.e., student's lack of prior and his or her mother's lack of formal education), and mother college education had no significant impact on ELLs' social studies achievement. English proficiency was the sole student-level predictor of student social studies scores. Similar to science results, there was no significant withinschool effect of age on student social studies scores, suggesting that progression through grades rather than age per se may be associated with decline in academic performance.

The average social studies score of ELLs was higher in schools with higher social studies proficiency and ELL effectiveness rates. Although social studies scores of middle and high school students tended to be lower than those of elementary students, these differences were not statistically significant once school quality indicators (i.e., school proficiency and ELL effectiveness rates) were controlled. 


\section{Summary of Research Question 3 Results}

The results of the Research Question 3 are summarized below in accordance with the study conceptual framework. This framework distinguished four student- and schoollevel variable categories: (a) L2 profile (metacognitive strategy use and English proficiency); (b) background characteristics (prior formal schooling, mother education, L1 literacy, age); (c) school quality indicators (educational level and school proficiency, ELL effectiveness, and poverty rates); and (d) perceived importance of self-directed L2 learning (teacher LLS effectiveness ratings).

\section{L2 profile.}

- Metacognitive strategies significantly contributed to ELLs' reading, but not mathematics, science and social studies scores.

- Consistently across models, English proficiency was the strongest studentlevel predictor of ELLs' academic achievement.

\section{Background characteristics.}

- Consistently across models, the non-significant prior schooling effect indicated that — controlling for other student-level background characteristics, in particular, English proficiency - there were no significant differences in academic performance between ELL students with and without limited-or-no-formal-schooling history.

- Lack of mother formal education was a negative predictor of ELLs' mathematics and science — but not reading and social studiesperformance. 
- Consistently across models, mother college education did not significantly relate to ELLs' academic performance, suggesting that some amount of maternal formal education may have more impact on student achievement than higher educational degree achieved.

- L1 literacy positively contributed to ELLs' reading and mathematics-but not science and social studies—scores.

- The pooled, within-school effect of age negatively related to ELLs' reading and mathematics—but not science and social studies—scores, suggesting that decline in academic performance may be associated with progression through grades ${ }^{71}$ rather than with age per se.

\section{School organizational and quality indicators.}

- Across subjects, ELLs' academic achievement tended to decline from elementary to upper educational levels; this effect, however, was mitigated (science) or disappeared (reading, mathematics, and social studies) once school proficiency and ELL effectiveness rates were statistically controlled.

- Consistently across models, ELLs' academic performance was higher in schools with higher academic proficiency and ELL effectiveness rates.

- Consistently across models, school poverty rate did not significantly contribute to ELLs' academic performance beyond school proficiency and ELL effectiveness rates.

\footnotetext{
${ }^{71}$ Whereas in reading and mathematics models the average within-school effect of age was pooled-except for high school - from multiple grade-levels (elementary school reading and mathematics: Grades 3-5; middle school reading and mathematics: Grades 6-8; highs school reading: Grade 10; high school mathematics: Grade 11), in science and social studies models this effect was estimated based on a single grade-level within the same schools (science: Grades 4, 7, 11; social studies: Grades 5, 8, 11).
} 


\section{Perceived importance of self-directed L2 learning.}

- Consistently across models, ESL teacher ratings of LLS effectiveness did not significantly relate to ELLs' academic performance.

In the next chapter, conclusions and implications drawn from the results across all three research questions addressed by this study are discussed. 


\section{CHAPTER 5}

\section{CONCLUSIONS AND IMPLICATIONS}

The purpose of this study was to investigate the relationship between language learning strategies (LLS) and academic achievement among ELLs receiving ESL services. This general purpose was addressed by three research questions. This chapter first discusses the findings and conclusions by each individual research question. Then, the significance and implications of the findings across all three research questions addressed by the study are summarized.

\section{Research Question 1}

The purpose of Research Question 1 was to compare teacher perceptions of strategy effectiveness and student self-reported strategy use. The results of individualand school-level analyses are synthesized. Similar to a number of studies (Cohen \& Macaro, 2007; Lan \& Oxford, 2003; Magogwe \& Oliver, 2007; Rubin, 1975), this study found that language learners at all educational levels (elementary, middle, and high), used a large array of language learning strategies. Consistently across educational levels, ELL students reported a high rate of use of metacognitive strategies; none of the other strategy categories was reportedly used at a low rate of frequency. The results also suggest a strong awareness of the effectiveness of LLS among teachers working at all educational levels. This is an encouraging finding consistent with current trend reflecting the "growing awareness of the importance of language learning strategies in the language 
teaching and learning area generally" (Griffiths, 2007, p. 98; see also Cohen \& Macaro, 2007).

Similar to Griffiths and Parr (2001) and Griffiths (2007), comparison of the teacher and students LLS perceptions revealed both areas of agreement and of disagreement. Across educational levels, the within-school analyses revealed a consistent pattern of teacher-student agreement regarding metacognitive strategy use.

Encouragingly, teachers perceived as highly effective this strategy category which students across all educational levels reported using with high frequency and which was found by this study to significantly contribute to ELLs' English proficiency and reading achievement. Social and cognitive strategy use ratings showed a tendency for moderate agreement between teachers and students; Memory and compensation were consistently rated higher by the teachers than by the students. Further, individual-level analysis indicated that teacher and student strategy ratings differed qualitatively, with most of the teacher scores being above the high level benchmark and most of the students' scores within the medium level benchmark. These overall results suggest a need for the students to increase - when developmentally appropriate (see the discussion of Research Question 2 results below) - their strategy use in order to facilitate their L2 learning and highlight a potential role that teachers may play in this process (Oxford, 1990, 1999; McDonough, 1999).

Considering the results of both individual-level and within-school analyses, the overall agreement between teacher and student strategy ratings was the highest at the high school level. These results suggest that-unlike elementary and middle school participants - high school teachers and their students are more in agreement with each 
other in terms of their strategy rating profiles: This is an encouraging results because of the potentially "positive consequences in terms of classroom dynamics" (Griffiths, 2007, p. 96; Oxford, Ehrman, \& Lavine, 1991; Rivera-Mills \& Plonsky, 2007). The elementary and middle school results, however, suggest potentially higher levels of dissonance between teaching and learning styles at these educational levels. Such perceptual gaps, "if not properly addressed, could hinder strategy instruction" (Rivera-Mills \& Plonsky, 2007, p. 542) or may result in precluding L2 learners from effectively using LLS in school (Nunan, 1997).

One area of concern may be the discrepancies in individual-level elementary school teachers' and students' LLS rank orderings, particularly with regard to metacognitive (the top rank ordering among students) and memory (the top rank ordering among teachers) strategies (for similar results see Griffiths \& Parr, 2001). Such perceptual discrepancies continue to worry language educators because of a theoretical concern over a potential conflict in teacher-student classroom dynamics resulting from such disruptive mismatch (Oxford et al., 1991; Rivera-Mills \& Plonsky, 2007). For example, elementary teachers in this study may—reflecting their beliefs—emphasize memory strategy use over metacognitive strategy use. Yet—although previous research has found memory strategies to contribute to vocabulary knowledge (Takeuchi, 1993)metacognitive strategies have been linked with a broader range of language outcomes including overall proficiency (Nisbet et al., 2005; Takeuchi, 1993), listening and grammar (Peacock \& Ho, 2003; Takeuchi, 1993), reading (Peacock \& Ho, 2003; Schoonen, Hulstijn, \& Bossers, 1998), speaking and writing (Peacock \& Ho, 2003), as well as vocabulary knowledge (Takeuchi, 1993). 
Another area of concern is the large perceptual gap-revealed by within-school but not by individual-level analyses - at the middle school level. The results indicated little common ground in teacher and student perceptions of LLS, with only metacognitive and social strategies eliciting some degree of teacher-student agreement. Most worrisome is that while teachers gave high ratings to cognitive strategies-linked to higher student outcomes in reading (Clarke, 1979, 1980; Peacock \& Ho, 2003; Schoonen et al., 1998), listening and structures (Peacock \& Ho, 2003; Takeuchi, 1993), speaking (Ehrman \& Oxford, 1995; Peacock \& Ho, 2003), and writing (Takeuchi, 1993)—middle grade students reported using this strategy category only at a moderate rate and substantially less frequently than elementary students. This decline in cognitive strategy use by middle school students may plausibly be attributed to curricular and teacher influences, namely, to a decline in explicit reading strategy instruction—which includes explicit cognitive strategy instruction-typical of upper grades. Taken together, these findings suggest a need for the elementary and middle school teachers in the district to increase their awareness of both their students" strategy usage and strategy needs "in order to be able to facilitate language-learning process more effectively" (Griffiths \& Parr, 2001, p. 253; see also Oxford et al., 1991; Griffiths, 2007).

The last area of concern is that, across educational levels, none of the withinschool correlations between teacher and student strategy ratings were statistically significant. Although empirical (August \& Calderón, 2006; Zwiers, 2007) and theoretical (Oxford et al., 1991; Rivera-Mills \& Plonsky, 2007) research has suggested that teachers' beliefs underlie their instructional practices, the lack of significant, within-school correlations between teacher and student strategy ratings found in this study suggest that 
teacher beliefs regarding strategy effectiveness do not necessarily translate into classroom practice. This may be due to a lack of knowledge of and experience with strategy training ${ }^{72}$ among participating teachers and potentially suggests a need for incorporating strategy training techniques (e.g., Cognitive Academic Language Learning Approach; Chamot, 2009) into professional development for ESL teachers working in the district. Such professional development focus is warranted because explicit strategy training has been shown to increase student strategy knowledge (Nunan, 1997; Paris et al., 1984) and use (Hassan et al. 2005; Chamot \& O'Malley, 1994), and may ultimately result in higher language outcomes (Hassan et al. 2005; McDonough, 1999; O'Malley, 1987; Vandergrift \& Tafaghodtari, 2010). Further, drawing on Vygotsky's (1978) ideas, many educators (e.g., McDonough, 1999; Oxford, 1999) argued that strategies are internalized via social interactions between students and teachers and that, although some language learners deploy LLS spontaneously, others need instruction in order to operate strategies independently.

The results of correlational analyses, however, should be interpreted with caution due to a small sample size at the school level, possibly undermining the power of the statistical tests to detect any significant relationships. Future research with a larger number of participating schools may clarify this issue. Additional research is needed to examine the relationship among teacher beliefs regarding strategy effectiveness, student ratings of teacher strategy-training-and-support practices, and actual strategy use by the students. Such research may further clarify our understandings of the mediating role of teacher beliefs on their practices and, ultimately, on student learning.

\footnotetext{
${ }^{72}$ These two variables were not explored in this study. Currently, the district offers—on voluntary basisPD sessions on Sheltered Instruction Observation Protocol (SIOP; Echevarria, Vogt, \& Short, 2007), a model that incorporates some strategy training techniques.
} 


\section{Research Question 2}

The primary purpose of Research Question 2 was to examine structural relationships among ELL student background and linguistic profile characteristics and academic achievement. The explanatory power of Structural Equation Modeling analyses was strengthened by incorporating into statistical analyses academic achievement predictors identified by Second Language Acquisition (SLA) and academic achievement literature which allowed this study to extract, evaluate, and highlight the direct and indirect independent effects (above and beyond any of the other variables) as well as mediating effects of individual-level characteristics on ELLs' academic achievement. Encouragingly, the results identified four positive contributors to ELLs' achievementEnglish proficiency, metacognitive strategy use, language motivation, and native language literacy -all of which are instructionally manipulable. Thus, the most encouraging significance emerging from this study is the potential for additive effects to enhance ELLs' academic outcomes.

Expectedly, and consistently with previous research (Mahon, 2006; Suárez-

Orozco et al., 2008; Yoko, 2007; see also Solórzano, 2008), the results indicated that English proficiency was the strongest positive contributor to ELLs' academic achievement. Further-expanding on previous experimental research on academic outcomes in reading (Montes, 2002) and mathematics (Chamot et al., 1992; Montes, 2002) - this statistical modeling study found that metacognitive strategies significantly contributed to ELLs' academic achievement above and beyond student age, length of residence in the U.S. schools, and levels of native language and English proficiency. The positive effect of metacognitive strategies was further enhanced by the mediating effect 
of English proficiency; which, in turn, mitigated the negative impact of age, enhanced the positive effect of L1 literacy, and was itself enhanced by higher metacognitive strategy use.

The spontaneously developed metacognitive strategies - found in this study to strengthen student academic English proficiency above and beyond length of residence, age, and levels of native language proficiency —included: focusing attention, noticing, and planning and monitoring learning. These findings are consistent with theoretical (Robinson, 1995; Schmidt, 1990) and empirical (e.g., Long, Inagaki, \& Ortega, 1997; Mackey, 2006) SLA research suggesting that conscious learner behaviors such as noticing and focused attention facilitate L2 learning. Schmidt (1990), for example, emphasized the key role that attention and awareness play in retention of novel information in long term memory and highlighted empirical evidence linking selfreported noticing of L2 linguistic forms and their subsequent emergence in student linguistic output (i.e., speech and writing). Further, findings from two recent metaanalyses (Norris \& Ortega, 2000; Spada \& Tomita, 2010) have found a robust association between classroom instruction promoting noticing and focal awareness (i.e., focus on form, enhanced input, and interactive modifications including clarification requests and confirmation checks) and higher L2 outcomes (for earlier reviews see DeKeyser, 2003; Spada, 1997).

Further, the results indicated that metacognitive strategy use may be enhanced through enhanced language learning motivation, which, in itself, may be instructionally manipulable. That is—as suggested by theoretical (Deci \& Ryan, 1985; Dörnyei, 2005) and empirical (e.g., Noels, 2001; Noels et al., 1999; Wu, 2003) motivation research- 
more motivated behaviors may be stimulated by instructional environments that satisfy inherent human needs for competence (the know-how regarding attaining varied external and internal outcomes), autonomy (self-initiation and regulation of one's actions), and relatedness ("secure and satisfying relationships with others"; Deci, Vallerand, Pelletier, \& Ryan, 1991, p. 327). These findings highlight the potentially additive advantages of motivation, metacognitive strategies, and English proficiency and emphasize the importance of integrating content, language, and metacognitive strategy instruction for ELL students in a classroom that also stimulates motivation.

Notably, the positive contribution of metacognitive strategies to English achievement appeared to be stable (i.e., independent of student age and length of residence in the U.S. schools). This finding provides an indirect support to a recent LLS research emphasis on metacognition, a boarder concept that subsumes metacognitive strategies as part of one's strategic competence ("knowledge of processes that are effortful, planned, and consciously invoked to facilitate the acquisition and utilization of knowledge") along with knowledge of self, knowledge of task, and knowledge of learning goals (Schoonen et al., 1998, p. 75). Many (e.g., Cohen, 1998; Hsiao \& Oxford, 2002; Magogwe \& Oliver, 2007) argued that that it was not the frequency of strategy use-after all, "any strategy could lead to failure if used inappropriately" (Grenfell \& Macaro, 2007, p. 22)-but rather the ability to select and combine strategies relevant to a given language learning task that determined learning outcomes. As noted by Grenfell and Macaro, it was this shift in LLS conceptualization that brought about "an increasing interest in metacognition as the orchestrating mechanism for combining strategies effectively in any given situation" (p. 23). These theoretical considerations-supported, 
to some extent, by this study's findings - suggest that ELLs of any age and level of English proficiency would benefit from metacognitive strategy instruction.

Because of the intervening effects of age (for cognitive strategy) and length of residence (for social, memory, affective, and compensation strategy; see Research Question 2 results section), no definitive conclusions could be made regarding the relationship between these five strategies and ELLs academic and language outcomes. These results suggest a need to further examine the relationships among age, L2 proficiency levels, strategy use, and L2 outcomes. This could be achieved by longitudinal research (i.e., tracking individual ELL student patterns of strategy use over time). Alternatively, these intervening effects-which literature suggests may be interactive (Magogwe \& Oliver, 2007) or curvilinear (Phillips, 1992; Hong-Nam \& Leavell, $2006)^{73}$ — could be specified as product terms or estimated by analyzing the model fit across multiple samples (i.e., by breaking a sample into age and LOR subsamples; Kline, 2005 ) in future statistical modeling studies. Introducing such design features may clarify some inconsistencies regarding the relationship between LLS and L2 outcomes reported in previous studies (Gardner et al., 1997; Nisbet et al., 2005; Takeuchi, 1993).

Revealing the intervening effects of age and length of residence on the relationship between LLS and achievement in English is an interesting finding by itself which may be attributed to two unique features of this study. First, using MIMIC modeling techniques allowed specifying age and length of residence as predictors of the latent constructs in the model. Second, whereas previous studies typically included

\footnotetext{
${ }^{73}$ Although Phillips (1992) and Hong-Nam and Leavell (2006) found a curvilinear pattern, with intermediate proficiency students deploying more strategies than lower and higher proficiency students, Magogwe and Oliver (2007) found a similar patter for elementary, but not secondary students suggesting a possibility of a three-way (age-proficiency-strategy use) interaction.
} 
learners with more comparable ages and amounts of L2 instruction (Gardner et al., 1997; Nisbet et al., 2005), this study's Research Question 2 sample included L2 learners of varied ages ( 9 to 16 years of age) and length of residence ${ }^{74}$ ( 7 to 117 months; about 1 to 10 years). The results indicating decline in cognitive strategy use as a function of age and in memory, social, affective, and compensation strategy use as a function of length of residence suggested that with increase in English proficiency students may feel less need (or value) in using these particular strategies (Gardner et al., 1997). This explanation proposed by Gardner et al. has an intuitive appeal—particularly with regard to the latter fours strategy categories-because it is reasonable to expect that more advanced linguistic competence may lead to diminished needs to control language learning anxiety, to handle new linguistic information, to rely on peers for supplying missing linguistic information, and to compensate for English competencies gaps. (For an alterative explanation for the decline in cognitive strategy use, see the discussion of Research Question 1 results.)

These findings also suggest that the choice of strategies to be taught to ELLs should take into consideration the learner's current English proficiency level. This recommendation may be particularly relevant because previous research (Magogwe $\&$ Oliver, 2007) has linked higher overall strategy use to higher self-efficacy beliefs, particularly among younger and lower-English-proficiency students, ${ }^{75}$ suggesting that ELLs at early stages of English language development may still benefit from the instruction of cognitive, memory, social, affective, and compensation strategies, in

\footnotetext{
${ }^{74}$ In this study, LOR captured the amount of instruction in and through English-as-a-second language received by the students.

${ }^{75}$ Correlations were particularly high for elementary $(r=.70)$ and secondary $(r=.56)$ students; this relationship was less pronounced for older and higher-English-proficiency students.
} 
addition to metacognitive strategy instruction demonstrated by this study to benefit ELLs of different ages and levels of English proficiency.

One discouraging result is that length of residence and L1 literacy skills were significantly and negatively related indicating that longer tenure in the U.S. schools was associated with decline in L1 literacy skills. This result is discouraging because in this study-consistently with previous research (August \& Shanahan, 2006b; Cummins, 1981b; Genesee et al., 2005)—ELL students with higher native language literacy skills were found to be more successful academically and to have higher English proficiency. Theoretically (Cummins, 1981b), such positive relationship among L1 literacy skills and L2 outcomes have been attributed to transfer (i.e., transfer across two languages of linguistic and academic skills such as vocabulary knowledge or reading strategies; August \& Shanahan, 2006a, 2006b). Investing time and effort in supporting ELLs' native language skills development (e.g., encouraging home L1 literacy practices) may be particularly relevant for ELLs schooled in non-bilingual educational contexts-such as the one in this study-because of the noted decline in L1 literacy skills under this instructional model (Proctor, August, Carlo, \& Barr, 2010). This, in turn, may potentially limit opportunities for transfer of academic and literacy skills across languages (Clarke, 1979, 1980; Lee \& Schallert, 1997; Proctor et al., 2010; Schoonen et al., 1998).

\section{Research Question 3}

Although language learning strategies were focal to Research Question 3, the power of hierarchical analyses allowed this study to extract, evaluate, and highlight the independent - above and beyond any of the other variables —effects of a number of individual- and school-level characteristics on ELLs' academic achievement. At the 
student level, the findings highlight both student individual strengths and areas of need; at the school level, the findings offer some insights to inform administrative and policy decisions regarding education of ELL students.

Student L2 profiles and background characteristics effects. Consistent with the results produced by SEM analyses (Research Question 2), the results of HLM analyses indicated that English proficiency was the strongest student-level predictor of ELLs' academic achievement across all content areas examined. Further, as indicated by significant interaction effects, the predictive power of English proficiency on reading achievement was larger in middle schools and in schools with higher poverty and reading proficiency rates. The more pronounced positive impact of higher English proficiency for middle school students compared to elementary school students is consistent with the hypothesis that higher linguistic demands are placed on students who interact with more academically demanding texts in middle school (e.g., expository as opposed to narrative texts; Fang, 2008); demands that would be more easily met with stronger L2 proficiency. Interestingly, the same interaction effect was not found for high school students compared to elementary students. This may be due, in part, to the relatively small high school sample size in this study that may have caused the statistical analysis to miss the effect. Alternatively, high school students may be able to better adjust to higher language demands due to more advanced cognitive maturity (Cummins, 1981a) ${ }^{76}$ The stronger positive effects of English proficiency on reading outcomes for students in schools with higher poverty and higher reading proficiency rates were small but significant. These effects may be attributed to a stronger dependence on English proficiency in higher

\footnotetext{
${ }^{76}$ Cummins (1981a) found that ELLs who arrived in the country at the age of 14 to 15 acquired more English vocabulary in one year, than four-to-five-age-of-arrivals did in 7 years.
} 
"competition"- either with more advanced peers in higher performing schools or for more stretched resources (including teacher attention) in higher poverty schoolscontexts. In higher poverty schools, for instance, teachers may essentially be saturated with managing a multitude of complex instructional contexts and may be unable to assist lower English proficiency ELLs as strongly as teachers in lower poverty schools. These results suggest that ELLs—particularly middle school students and students schooled in higher poverty and proficiency rate schools-may benefit from additional support in English language development (e.g., after-school and summer programs; see also the discussion below).

Similar to Peacock and Ho (2003) and Schoonen et al. (1998), the results of HLM analyses indicated that metacognitive strategies spontaneously developed by ELLs significantly contributed to student reading scores. Although, no direct impact was found for mathematics, science, and social studies outcomes, the findings of this study are encouraging for two reasons. First, as indicated by the results of SEM analyses (see above), metacognitive strategies strengthened student academic English proficiency, which, in turn, had a separate positive impact on student academic outcomes across all content areas examined. This suggested that the positive effect of metacognitive strategies may be, in nature, direct and additive for reading an indirect-through enhancing English academic language skills—-for mathematics, science, and social studies. Second, as evidenced by strategy instruction research (O'Malley, 1987; Vandergrift \& Tafaghodtari, 2010; see also Hassan et al. 2005; McDonough, 1999) metacognitive strategies are a variable that is most immediately available for teachers and schools to impact. Such strategies-enhanced English language instruction may mitigate 
challenges of increasing language demands (Abedi, 2004; Fang, 2008) faced by ELLs as they progress through grade levels as well as challenges faced by ELLs with no prior formal education, who, as indicated by this study results, appear to perform on par with their more educated peers of comparable English proficiency.

The lack of a direct metacognitive strategies impact on mathematics, science, and social studies outcomes suggests—consistently with theoretical concerns advanced by LLS researchers (McDonough, 1999; Oxford, 1999) — that students may not necessarily and automatically transfer appropriate language learning ${ }^{77}$ strategies to content area learning tasks. This finding highlights a need not only for explicit metacognitive strategy instruction but also a need for teachers to help ELLs learn to transfer strategies both "across language tasks [and] across subject fields" (Oxford \& Leaver, 1996, p. 227). This recommendation is further supported by (a) this study's SEM results which found a positive link between metacognitive strategies and academic achievement (measured as a latent construct underlying student performance not only in reading but also in mathematics) and (b) previous research indicating that instructional models incorporating strategy instruction may improve student outcomes in content areas (Chamot et al., 1992; Montes, 2002). Montes, ${ }^{78}$ for example, outlined the following conditions for enhancing ELLs' academic success through strategy instruction: (a) collaborative planning by language and content-area teachers; (b) strong leadership commitment; and (c) integrated

\footnotetext{
${ }^{77}$ For example the strategy of monitoring ("I think about how well I am doing in English") may be effectively transferred to other subject areas (potential for transfer: "I think about how well I am doing in mathematics [science, social studies]").

${ }^{78}$ Montes (2002) found that enhancing content areas with strategy instruction enhanced not only ELLs' but also native-English speaking - particularly low-SES—-students' performance on state standardized tests in reading and mathematics.
} 
content and strategy instruction, including explicit strategy modeling, opportunities for practice, and strategy effectiveness evaluation by the students.

Beyond English proficiency and metacognitive strategies, a lack of mother formal education had a negative impact on ELLs' achievement in mathematics and science, whereas L1 literacy had a positive impact on ELLs' achievement in reading and mathematics. These results suggest that: (a) ELL students with undereducated mothers may require some additional help to support their mathematics and science learning and (b) encouraging and supporting L1 literacy maintenance and development (e.g., encouraging home L1 literacy practices and, when feasible, establishing bilingual programs; Rolstad, Mahoney, \& Glass, 2005; Slavin \& Cheung, 2005; see also August \& Shanahan, 2006b; Genesee et al., 2005) may enhance ELLs' reading and mathematics outcomes. Surprisingly, mother college education did not significantly relate to ELLs' academic performance, suggesting that some amount of maternal formal education may have more impact on student achievement than her achieving higher educational degree. ${ }^{79}$ This suggests a need to investigate if investing in providing some basic education to mothers of ELL students would pay dividends in terms of higher student achievement. This may be particularly relevant to the district where this study was conducted because of a recent influx of refugee populations from conflict zones associated with disrupted family educational histories: For example, over $20 \%$ of students in this study came from sub-Saharan Africa nations where 20 to $50 \%$ of the adult population have fewer than two years of education (United Nations Educational, Scientific and Cultural Organization [UNESCO], 2010).

\footnotetext{
${ }^{79}$ This effect, however, should be interpreted with caution due to a substantial amount of missing motherhighest-educational-level-attained data, plausibly leading to at least some highly educated mothers being coded as having less than college education.
} 
School organizational and quality indicators effects. Consistently with previous research (Carhill et al., 2008; Grubb, 2008; Suárez-Orozco et al., 2008; see also Kao \& Thompson, 2003) this study found strong school-level effects on ELLs' academic outcomes suggesting that reaching higher levels of achievement cannot be solely attributed to "a good student constellation of variables" (Lee \& Schallert, 1997, p. 732). Similar to Suárez-Orozco et al.'s (2008) findings, the results of hierarchical modeling analyses indicated that ELLs' academic performance was higher in schools with higher school quality indicators (i.e., academic proficiency and ELL effectiveness rates). Further, although ELLs' academic achievement tended to decline from elementary to upper educational levels - tendency attributed to higher language and academic demands in higher grades (Solórzano, 2008) - school quality indicators appeared to mitigate (science model) or "annihilate" (reading, mathematics, and social studies models) this decline. This results suggest that ELLs - particularly, most struggling ELLs-would benefit from placement in higher performing schools. Of notice here-as suggested by a negative correlation between school proficiency rates and ELL effectiveness (see Tables $\mathrm{J} 2$, J4, J6, and $\mathrm{J} 8$, Appendix J) - is that schools with higher overall academic performance and schools that are more successful in closing the achievement gap between native English-speaking and ELL students are not necessarily the same.

Further, school poverty rate did not significantly contribute to explaining ELLs' academic outcomes beyond school proficiency and ELL effectiveness rates. In other words-controlling for other school quality indicators—school poverty rate had no significant impact on ELLs' academic performance. This finding contradicts, to some extent, previous research (Fry, 2008; Yoko, 2007) and may be due to a greater amount of 
additional, compensatory educational resources available through Title I funding and aiming at improving student academic achievement in the district's higher poverty schools. Finally, a lack of significant relationship between ESL teacher ratings of LLS effectiveness and ELLs' academic performance suggests a need for additional research to explore the relationships among teacher beliefs, teacher practices, and student learning outcomes (see the discussion for Research Question 1 findings).

\section{Significance and Implications}

As evidenced by the current emphasis on Common Core State Standards in mathematics and English language arts, attention to student academic achievement remains a core interest of the education community in the United States: As of November 2010, 39 states and territories and the District on Columbia have adopted these common standards (Common Core State Standards Initiative, 2010). As the ELL population grows in the United States, research on how to best support these learners to succeed academically will continue to be a major issue for the education community, particularly for teacher preparation programs. Current reauthorization of the Higher Education Act of 1965 (Higher Education Opportunity Act, 2008), for example, requires that all higher education institution providing traditional or alternative teacher preparation programs demonstrate their ability to prepare future teachers to effectively teach students with limited English language skills. Within this context, examining variables that contribute to ELLs' academic achievement deserves greater attention.

The main purpose of this study was to evaluate plausible causal mechanisms that may explain ELLs' academic achievement. Explanatory power was strengthened by incorporating into statistical analyses academic achievement predictors identified by 
second language development and academic achievement literature. The power of statistical modeling analyses allowed this study to extract, evaluate, and highlight the independent effects (above and beyond any of the other variables) of individual and school characteristics on ELLs' achievement. However, the most encouraging significance emerging from this study is the identification of a host of instructionally manipulable variables and the potential for additive effects to enhance ELLs' academic outcomes. This information has potential significance for ELL instruction, teacher preparation programs, policy, and research.

From a practical perspective, the results of this study suggest that ELLs would benefit from: (a) integrated content, language, and metacognitive strategy instruction (e.g., Cognitive Academic Language Learning Approach; Chamot, 2009); (b) classrooms that stimulate motivation; (c) native language literacy maintenance and development (e.g., encouraging home L1 literacy practices and, when feasible, establishing bilingual programs), and (d) additional support in English language development (e.g., after-school and summer programs). The latter would be particularly beneficial for older-particularly middle school—-students as they progress from lower to upper grades where language and content demands are higher. The findings also suggest-though inconclusively-that ELLs at early stages of English language development may benefit from the instruction of other strategy categories and that ESL teachers may be able to better support student strategy use and needs if provided with professional development incorporating strategy training techniques.

From policy and administrative perspectives, the results of this study suggest that ELLs with disadvantaged educational backgrounds would benefit 
from placement in higher-performing schools. Of notice here is that schools with higher overall performance and schools that are more successful in closing the achievement gap between native English-speaking and ELL students are not necessarily the same. Thus, when making decisions regarding ELL student placement both factors should be considered. Further, the results suggest that ELL academic performance in individual content areas may benefit from school-wide efforts to improve the overall school proficiency (not just for ELL students) and emphasis on minimizing the ELL/non-ELL achievement gaps across all core content areas.

Additional research is needed to further investigate the relationships among ELL student individual characteristics, contextual variables, and L2 academic outcomes by (a) including other student- and school-level variables, (b) expanding the present study' 2-Level HLM models to 3-Level HLM models (student-classroom-school) to account for classroom variables effects (e.g., instructional methods, etc.) not investigated in this study; (c) exploring the intervening effects of age and length of residence on the relationships between langue learning strategies and L2 academic outcomes by conducting longitudinal research (i.e., tracking individual ELL student patterns of strategy use over time) or by specifying these intervening effects as product terms or by analyzing the model fit across multiple samples in future statistical modeling studies. Lastly, additional research is needed to examine the relationship among teacher beliefs regarding strategy effectiveness, student ratings of teacher strategy-training-andsupport practices, and actual strategy use by the students. Such research may 
further clarify our understandings of the mediating role of teacher beliefs on their practices and, ultimately, on student learning. 


\section{REFERENCES}

Abedi, J. (2004). The No Child Left Behind Act and English language learners:

Assessment and accountability issues. Educational Researcher, 33(1), 4-14.

Abedi, J., \& Lord, C. (2001). The language factor in mathematics tests. Applied Measurement in Education, 14(3), 219-234.

Amaral, O. M., Garrison, L., \& Klentschy, M. (2002). Helping English learners increase achievement through inquiry-based science instruction. Bilingual Researcher Journal, 26(2), 213-239.

Anderson, J. R. (1982). Acquisition of cognitive skills. Psychological Review, 89(4), $369-403$.

Anderson, J. R. (1989). A theory of human knowledge. Artificial Intelligence, 40, 313351.

Anderson, J. R. (1993). Problem solving and learning. American Psychologist, 48(1), 3544.

Ardasheva, Y., \& Tretter, T. R. (2010). Strategy Inventory for Language Learning (SILL): Testing for factorial validity for school-aged English Language Learners. Manuscript in preparation.

Ardasheva, Y., Tong, S., \& Tretter, T. R. (2010). English Language Learning Motivation Scale for school-aged ELLs: A validation study. Manuscript in preparation.

August, D., \& Calderón, M. (2006). Teacher beliefs and professional development. In D. August \& T. Shanahan (Eds.), Developing literacy in second-language learners: 
Report of the National Literacy Panel on Language-Minority Children and Youth (pp. 555-564). Mahwah, NJ: Lawrence Erlbaum.

August, D., \& Shanahan, T. (Eds.). (2006a). Developing literacy in second-language learners: Report of the National Literacy Panel on Language-Minority Children and Youth [Executive summary]. Retrieved December 1, 2008, from http://www.cal.org/projects/archive/nlpreports/Executive_Summary.pdf

August, D., \& Shanahan, T. (Eds.). (2006b). Developing literacy in second-language learners: Report of the National Literacy Panel on Language-Minority Children and Youth. Mahwah, NJ: Lawrence Erlbaum.

Ausubel, D. P. (1960). The use of advance organizers in the learning and retention of meaningful verbal material. Journal of Educational Psychology, 51, 267-272.

Bentler, P. M. (1990). Comparative fit indices in structural models. Psychological Bulletin, 107(2), 238-246.

Bialystok, E., \& Hakuta, K. (1999). Confounded age: Linguistic and cognitive factors in age differences for second language acquisition. In D. Birdsong (Ed.), Second language acquisition and the critical period hypothesis (pp.161-181). Mahwah, NJ: Lawrence Erlbaum Associates.

Brown, D. H. (2007). Principles of language learning and teaching (5th ed.). White Plains, NY: Pearson.

Brown, T. (2006). Confirmatory factor analysis for applied research. New York, NY: Guildford Press. 
Byrne, B. M. (1993). The Maslach Inventory: Testing the validity and invariance across elementary, intermediate, and secondary teachers. Journal of Occupational and Organizational Psychology, 66, 197-212.

Byrne, B. M. (2001). Structural equation modeling with Amos: Basic concepts, applications, and programming. Mahwah, NJ: Lawrence Erlbaum.

Carhill, A., Suárez-Orozco, C., \& Páez, M. (2008). Explaining English language proficiency among adolescent immigrant students. American Educational Research Journal, 45(4), 1155-1179.

Chamot, A. U. (1995). Implementing the Cognitive Academic Language Learning Approach: CALLA in Arlington Virginia. Bilingual Research Journal, 19 (3\&4), 379-394.

Chamot, A. U. (2005a). Language learning strategy instruction: Current issues and research. Annual Review of Applied Linguistics, 25, 112-130.

Chamot, A. U. (2005b). The Cognitive Academic Language Learning Approach (CALLA): An update. In P. A. Richard-Amato \& M. A. Snow (Eds.), Academic success for English language learners: Strategies for K-12 mainstream teachers (pp. 87-102). White Plains, NY: Longman.

Chamot, A. U. (2009). The CALLA handbook: Implementing the Cognitive Academic Language Learning Approach (2nd ed.). New York, NY: Addison-Wesley.

Chamot, A. U., \& O'Malley, J. M. (1994). The CALLA handbook: Implementing the cognitive academic language learning approach. Reading, MA: Addison-Wesley. 
Chamot, A. U., Dale, M., O'Malley, J. M., \& Spanos, G. A. (1992). Learning and problem solving strategies of ESL students. Bilingual Research Journal, 16 (3\&4), 1-38.

Chesterfield, R. A., \& Chesterfield, K. B. (1985). Natural order in children's use of second language learning strategies. Applied Linguistics, 6, 45-59.

Chomsky, N. (1959). A review of B. F. Skinner's "Verbal behavior". Language, 35, 2658.

City-data. (n.d). Kentucky - Languages. Retrieved December 22, 2008, from http:/www.city-data.com/states/Kentucky-Languages.html.

Clarke, M. A. (1979). Reading in Spanish and English: Evidence from adults ESL students. Language Learning, 29(1), 121-150.

Clarke, M.A. (1980). The short circuit hypothesis of ESL reading —or when language competence interferes with reading performance. The Modern Language Journal, 64(2), 203-209.

Cohen, A. D. (1998). Strategies in learning and using a second language. New York, NY: Addison Wesley Longman.

Cohen, A. D., \& Scott, K. (1996). A synthesis of approaches to assessing language learning strategies. In R. Oxford (Ed.), Language learning strategies around the world (Tech. Rep. No 13, pp. 76-89). Honolulu: University of Hawaii, Second Language Teaching \& Curriculum Center.

Cohen, A. D., Weaver, S. J., \& Li, T-Y. (1996). The impact of strategies based instruction on speaking a foreign language (Working Papers Series No 4). 
Minneapolis: University of Minnesota, Center for Advanced Research on Language Acquisition.

Cohen, A., \& Macaro, E. (Eds.). (2007). Language learner strategies: 30 years of research and practice. Oxford, England: Oxford University Press.

Collier, V. P. (1987). Age and rate of acquisition of second language for academic purposes. TESOL Quarterly, 21, 617-641

Collier, V. P., \& Thomas, W. P. (1989). How quickly can immigrants become proficient in school English? Journal of Educational Issues of Language Minority Students, $5,26-38$.

Common Core State Standards Initiative. (2010). In the States. Retrieved from http://www.corestandards.org/in-the-states.

Cook, H. G., \& Wilmes, C. (2007). Alignment between the Kentucky Core Content for Assessment and the WIDA Consortium English language proficiency standards. Madison, WI: University of Wisconsin, Wisconsin Center for Education Research.

Cummins, J. (1981a). Age on arrival and immigrant second language learning in Canada: A reassessment. Applied Linguistics, 11(2), 132-149.

Cummins, J. (1981b). Empirical and theoretical underpinnings of bilingual education. Journal of Education, 163(1), 16-30.

Cummins, J. (2005). Language proficiency, bilingualism, and academic achievement. In P. A. Richard-Amato \& M. A. Snow (Eds.), Fundamentals of teaching English to speakers of other languages in K-12 mainstream classrooms (pp. 76-86). White Plains, NY: Longman. (Reprinted from Bilingualism and special education: 
Issues in assessment and pedagogy pp. 136-151, by J. Cummins, 1984, San Diego, CA: College-Hill)

Cummins, J. (2008). BICS and CALP: Empirical and theoretical status of the distinction. In B. Street \& N. H. Hornberg (Eds.), Encyclopedia of language and education: Vol. 2. Literacy (2nd ed., pp. 71-83). New York: Springer.

Dale, T. C., \& Cuevas, G. (1992). Integrating mathematics and language learning. In P. Richard-Amato \& M. Snow (Eds.), The multicultural classroom (pp. 330 - 348). White Plains, NY: Longman.

Datnow, A., Stringfield, S., \& Castellano, M. (2005). School reform and the education of culturally and linguistically diverse students. In C. R. O’Donnell \& L. A. Yamauchi (Eds.), Culture and context in human behavior change: Theory, research, and application (pp. 179-204). New York: Peter Lang Publishers.

Deci, E. L., \& Ryan, R. M. (1985). Intrinsic motivation and self-determination in human behavior. New York: Plenum.

Deci, E. L., Vallerand, R. J., Pelletier, L.G., \& Ryan, R. M. (1991). Motivation in education: The self-determination perspective. The Educational Psychologist, 26 (3\&4), 325-346.

DeKeyser, R. M. (2003). Implicit and explicit learning. In C. J. Doughty \& M. H. Long (Eds.) Handbook of second language acquisition (pp. 313-348). Oxford, MA: Blackwell.

Delpit, L. (1995). Language diversity and learning. In Other people's children: Cultural conflict in the classroom (pp. 48-69). New York, NY: New Press. 
Diaz-Rico, L. T. (2008). A course for teaching English learners. Boston, MA: Allyn \& Bacon.

Dickinson Bacci, E., Koger, M. E., Hoffman, R. G., \& Thacker, A. A. (2003). Relationships among Kentucky's Core Content Tests, ACT Scores, and students' self-reported high school grades for the classes of 2000 through 2002 (Report No. HumRRO-FR-03-19). Louisville, KY: Human Resources Research Organization. Dillman, D. A. (2007). Mail and internet surveys: The tailored design method (2nd ed.). Hoboken, NJ: John Wiley \& Sons.

Dörnyei, Z. (1996). Moving language learning motivation to a larger platform for theory and practice. In R. L. Oxford (Ed.), Language learning motivation: Pathways to the new century (Tech. Rep. No 11, pp. 71-80). Honolulu, HI: University of Hawaii Press.

Dörnyei, Z. (2003). Attitudes, orientations, and motivations in language learning: Advances in theory, research, and applications. Language Learning, 53, 3-32. Dörnyei, Z. (2005). The psychology of the language learner. Mahwah, NJ: Lawrence Erlbaum.

Dreyer, C., \& Oxford, R. L. (1996). Learning strategies and other predictors of ESL proficiency among Afrikaans speakers in South Africa. In R. Oxford (Ed.), Language learning strategies around the world (Tech. Rep. No 13, pp. 62-74). Honolulu: University of Hawaii, Second Language Teaching \& Curriculum Center.

Dutro, S., \& Morgan, C. (2001). Rethinking English language instruction: An architectural approach. In G. Garcia (Ed.), English learners: Reaching highest 
levels of English literacy (pp. 227-258). Newark, DE: International Reading Association.

Echevarria, J., Vogt, M., \& Short, D. J. (2007). Making content comprehensible for English learners: The SIOP Model (3rd ed.). Boston, MA: Pearson.

Ehrman, M., \& Oxford, R. L. (1995). Cognition plus: Correlates of language learning success. The Modern Language Journal, 79, 67-89.

Fang, Z. (2008). Going beyond the Fab Five: Helping students cope with the unique linguistic challenges of expository reading in intermediate grades. Journal of Adolescent \& Adult Literacy, 51(6), 476-487.

Fillmore, L. W., \& Snow, C. E., (2005). What teachers need to know about language. In P. A. Richard-Amato \& M. A. Snow (Eds.), Academic success for English language learners: Strategies for K-12 mainstream teachers (pp. 47-75). White Plains, NY: Longman. (Reprinted from What teachers need to know about language, pp. 7-53, by C. Temple Adger, C. E. Snow, and D. Christian, Eds., 2002, Washington, DC: Center for Applied Linguistics)

Fromkin, V., Rodman, R., \& Hyams, N. (2007). An introduction to language (8th ed.). Boston, MA: Thomson Wadsworth.

Fry, R. (2007). How far behind in math and reading are English language learners? Washington, DC: Pew Hispanic Center.

Fry, R. (2008). The role of schools in the English language learner achievement gap. Washington, DC: Pew Hispanic Center. 
Galguera, T., \& Hakuta, K. (1997). Linguistically diverse students. In H. J. Walberg \& G. D. Haertel (Eds.), Psychology and educational practice (pp. 387-407). Berkeley, CA: McCutchan Publishers.

Gardner, R. C. (2006). The socio-educational model of Second Language Acquisition: A research paradigm. EUROSLA Yearbook, 6, 237-260.

Gardner, R. C., Tremblay, P. F., \& Masgoret, A.-M. (1997). Towards a full model of second language learning: An empirical investigation. The Modern Language Journal, 81, 344-362.

Gass, S. M., \& Seliker, L. (2008). Second language acquisition: An introductory course. (3rd ed.). New York: Taylor \& Francis.

Gay, G. (2000). Culturally responsive teaching: Theory, research, and practice. New York: Teachers College Press.

Genesee, F., Lindholm-Leary, K., Saunders, W., \& Christian, D. (2005). English language learners in U.S. schools: An overview of research findings. Journal of Education for Students Placed at Risk, 10(4), 363-386.

Gersten, B. F., \& Hudelson, S. (2005). Developments in Second Language Acquisition research and theory: From structuralism to social participation. In P. A. RichardAmato \& M. A. Snow (Eds.), Academic success for English language learners: Strategies for K-12 mainstream teachers (pp. 22-47). White Plains, NY: Longman. (Reprinted from Implementing the ESL standards for pre-K-12 students through teacher education, pp. 75-102, by M. A. Snow, Ed., 2000, Alexandria, VA: TESOL) 
Goldenberg, C. (2008). Teaching English language learners: What the research does and does not say. American Educator, 33(2), 8-23.

Gottlieb, M., \& Kenyon, D. M. (2006). The Bridge study between tests of English language proficiency and ACCESS for ELLs (Tech. Rep. No. 2). Madison, WI: University of Wisconsin, Wisconsin Center for Education Research.

Gregg, K. (1984). Krashen's monitor and Occam's razor. Applied Linguistics, 5(2), 79100.

Grenfell, M., \& Macaro, E. (2007). Claims and critiques. In A. Cohen \& E. Macaro (Eds.), Language learner strategies: 30 years of research and practice (pp. 9-29). Oxford, England: Oxford University Press.

Grenfell, M., \& Macaro, E. (2007). Claims and critiques. In A. Cohen \& E. Macaro (Eds.), Language learner strategies: 30 years of research and practice (pp. 9-29). Oxford, England: Oxford University Press.

Griffiths, C. (2007). Language learning strategies: students' and teachers' perceptions. ELT Journal, 6l(2), 91-99.

Griffiths, C., \& Parr, J. M. (2001). Language learning strategies: Theory and perception. ELT Journal, 55(3), 247-254.

Grubb, W. N. (2008). Multiple resources, multiple outcomes: Testing the "improved" school finance with NELS88. American Educational Research Journal, 45(1), $104-144$.

Hakuta, K., Bialystok, E., \& Wiley, E. (2003). Critical evidence: A test of the criticalperiod hypothesis for second-language acquisition. Psychological Science, 14(1), $31-38$. 
Hakuta, K., Butler, Y., \& Witt, D. (2000). How long does it take English learners to attain proficiency? (Policy Report 2000-1). San Francisco, CA: University of California, Linguistic Minority Research Institute.

Hassan, X., Macaro, E., Mason, D., Nye, G., Smith, P., \& Vanderplank, R. (2005). Strategy training in language learning: a systematic review of available research. London: University of London, EPPI-Centre.

Higher Education Opportunity Act of 2008, Pub. L. No. 110-315, § 201, 122 Stat. 3149 (2008).

Hong-Nam, K., \& Leavell, A. G. (2006). Language learning strategy use of ESL students in an intensive English learning context. System, 34(3), 399-415.

Hsiao, T-Y., \& Oxford, R. (2002). Comparing theories of language learning strategies: A confirmatory analysis. The Modern Language Journal, 86, 365-383.

Hu, L., \& Bentler, P. M. (1999). Cutoff criteria for fit indexes in covariance structure analysis: Conventional criteria versus new alternatives. Structural Equation Modeling, 6(1), 1-55.

Kao, G., \& Thompson, J. S. (2003). Racial and ethnic stratification in education achievement and attainment. Annual Review of Sociology, 29(1), 417-442.

Kaufman, D., \& Crandall, J. (2005). Content-based instruction in primary and secondary school settings. Alexandria, VA: Teachers of English to Speakers of Other Languages (TESOL).

Kaylani, C. (1996). The influence of gender and motivation on EFL learning strategy use. In R. Oxford (Ed.), Language learning strategies around the world: Cross- 
cultural perspectives (Tech. Rep. No 13, pp. 75-88). Honolulu: University of Hawaii, Second Language Teaching \& Curriculum Center.

Kentucky Board of Education (2004). Inclusion of special populations in the staterequired assessment and accountability programs: 703 KAR 5:070. Frankfort, KY: Author.

Kentucky Department of Education (2008). 703 KAR 5:001: Assessment and Accountability Definitions. Retrieved November 16, 2008, from http://education.ky.gov/kde/instructional+ resources/high+school/language+learning/english+language+learning/assessment +information+and+regulations ++ lep.htm.

Kentucky Department of Education. (2005). Kentucky Core Content Tests: 2004 Technical Report. Frankfort, KY: Author.

Kenyon, D. M. (2006). Development and field test of ACCESS for ELLs® (Tech. Rep. No. 1). Madison, WI: University of Wisconsin, Wisconsin Center for Education Research.

Kidd, R., \& Marquardson, B. (1996). The Forsee Approach for ESL strategy instruction in an academic-proficiency context. In R. Oxford (Ed.), Language learning strategies around the world (Tech. Rep. No 13, pp. 189-204). Honolulu: University of Hawaii, Second Language Teaching \& Curriculum Center.

Kline, R. B. (2005). Principles and practice of structural equation modeling (2nd ed.). New York: The Guilford Press.

Krashen, S. (1985). The input hypothesis: Issues and implications. London: Longman. 
Krashen, S. (1987). Applications of psycholinguistic research to the classroom. In M. H. Long \& J. C. Richards (Eds.), Methodology in TESOL: A book of readings (pp. 33-45). New York: Newbury House Publishers.

Kwon, E-Y. (2005). The "Natural Order" of morpheme acquisition: A historical survey and discussion of three putative determinants. Working Papers in TESOL \& Applied Linguistics, 5(1). Retrieved June 20, 2008, from http://journals.tclibrary.org/index.php/tesol/article/ view/112/110.

Lan, R., \& Oxford, R. L. (2003). Language learning strategy profiles of elementary school students in Taiwan. International Review of Applied Linguistics in Language Teaching, 4l(4), p. 339-379.

Lee, J-W., \& Schallert, D. (1997). The relative contribution of L2 language proficiency and $L 1$ reading ability to $L 2$ reading performance: $A$ test of the threshold hypothesis in an EFL context. TESOL Quarterly, 31(4), 713-739.

Lee, O., Maerten-Rivera, J., Penfield, R. D., LeRoy, K., Secada, W. G. (2008). Science achievement of English language learners in urban elementary schools: Results of a first-year professional development intervention. Journal of Research in Science Teaching, 45(1), 31-52.

Leong, D., \& Bodrova, E. (1995). Tools of the mind: A Vygotskian approach to early childhood education. Upper Saddle River, NJ: Prentice Hall.

Long, M. H. (1983). Native speaker/non-native speaker conversation and the negotiation of comprehensible input. Applied Linguistics, 4, 126-161.

Long, M. H. (1987). Native speaker/non-native speaker conversation in the second language classroom. In M. H. Long \& J. C. Richards (Eds.), Methodology in 
TESOL: A book of readings (pp. 339-354). New York: Newbury House Publishers.

Long, M. H. (1990). Maturational constraints on language development. Studies in Second Language Acquisition, 12, 251-285.

Long, M. H. (2006). Problems in SLA. Mahwah, NJ: Lawrence Erlbaum Associates.

Long, M. H., Inagaki, S., \& Ortega, L. (1997). The role of implicit negative feedback in SLA: Models and recasts in Japanese and Spanish. The Modern Language Journal, 82, 357-371.

Lucas, T., \& Gringberg, J. (2008). Responding to the linguistic reality of mainstream classrooms: Preparing all teachers to teach English language learners. In M. Cochran-Smith, S. Freiman-Nemser, \& J. McIntyre (Eds.), Handbook of research on teacher education: Enduring issues in changing contexts (3rd. ed., pp. $606-$ 636). Mahwah, NJ: Lawrence Erlbaum.

Macaro, E. (2006). Strategies for language learning and strategy use: Revising the theoretical framework. The Modern Langue Journal, 90(3), 320-337.

MacCallum, R. C., \& Browne, M. W. (1993). The use of causal indicators in covariance structure models: Some practical issues. Psychological Bulletin, 114, 533-541.

MacIntyre, P. D, \& Noels, K. A. (1996). Using social-psychological variables to predict the use of language learning strategies. Foreign Language Annals, 29, 373-386.

Mackey, A. (2006). Feedback, noticing and instructed second language learning. Applied Linguistics, 27, 405-430. 
MacSwan, J., \& Pray, L. (2005). Learning English bilingually: Age of onset of exposure and rate of acquisition among English language learners in a bilingual education program. Bilingual Research Journal, 29(3), 653-678.

Magogwe, J. M., \& Oliver, R. (2007). The relationship between language learning strategies, proficiency, age, and self-efficacy beliefs: A study of language learners in Botswana. System, 35, 338-352.

Mahon, E. A. (2006). High-stakes testing and English language learners: Questions of validity. Bilingual Research Journal, 30(2), 479-497.

Marsh, H. W., \& Hau, K. T. (1996). Assessing goodness of fit: Is parsimony always desirable? The Journal of Experimental Education, 64(4), 364-390.

Masgoret, A. M., \& Gardner, R. C. (2003). Attitudes, motivation, and second language learning: A meta-analysis of studies conducted by Gardner and associates. Language Learning, 53(1), 167-210.

McDonough, S. (1999). Learner strategies. Language Teaching, 32, 1-18.

Montes, F. (2002). Enhancing content area through a Cognitive Academic Language Learning based collaborative in South Texas. Bilingual Research Journal, 26(3), $697-716$.

National Council of Teachers of English (2008, March). English language learners: A policy research brief. Retrieved June 13, 2008, from www.ncte.org/library/files/Publications/ Newspaper/Chron0308PolicyBrief.pdf.

National Council of Teachers of Mathematics (2008, September). Teaching mathematics to English language learners: A position of the National Council of Teachers of 
Mathematics Retrieved December 20, 2008, from

http://www.nctm.org/about/content.aspx?id=16135.

Newport, E. L. (1990). Maturational constraints on language learning. Cognitive Science, $14,11-28$.

Nieto, S. (2005). We speak many tongues: Language diversity and multicultural education. In P. A. Richard-Amato \& M. A. Snow (Eds.), Academic success for English language learners: Strategies for K-12 mainstream teachers (pp. 133149). White Plains, NY: Longman. (Reprinted from culture language and teaching: Critical perspectives for a new century, pp. 81-97, by S. Nieto, 2002, Mahwah, NJ: Erlbaum Associates).

Nisbet, D. L., Tindall, E. R., \& Arroyo, A. A. (2005). Language learning strategies and English proficiency of Chinese university students. Foreign Language Annals, $38(1), 100-107$.

Noels, K. A. (2001). Learning Spanish as a second language: Learners' orientations and perceptions of their teachers' communication style. Language Learning, 5l(1), $107-144$.

Noels, K. A., Clément, R., \& Pelletier, L.G. (1999). Perceptions of teachers' communicative style and students' intrinsic and extrinsic motivation. The Modern Language Journal, 83(1), 23-34.

Noels, K. A., Pelletier, L. G., Clément, R., \& Vallerand, R. J. (2000). Why are you learning a second language? Motivational orientations and self-determination theory. Language Learning, 50(1), 57-88. 
Norris, J. M., \& Ortega, L. (2000). Effectiveness of L2 Instruction: A research synthesis and quantitative meta-analysis. Language Learning, 50(3), 417-528.

Nunan, D. (1997). Strategy training in the language classroom: An empirical investigation. RELC Journal, 28 (2), 56-76.

O'Malley, J. M. (1987). The effects of training in the use of learning strategies on acquiring English as a second langue. In A. Wenden \& J. Rubin (Eds.), Learner strategies in language learning (pp. 133-144). Englewood Cliffs, NY: Prentice Hall.

O'Malley, M. J., Chamot, A. U., \& Walker, C. (1987). Some applications of cognitive theory to second language acquisition. Studies in Second Language Acquisition, 9, 287-306.

O’Malley, M. J., Chamot, A. U., Stewner-Manzanares, G., Kupper, L., \& Russo, R. (1985a). Learning strategies used by beginning and intermediate ESL students. Language Learning, 35, 21-46.

O’Malley, M. J., Chamot, A. U., Stewner-Manzanares, G., Russo, R., \& Kupper, L. (1985b). Learning strategy applications with students of English as a second language. TESOL Quarterly, 19, 557-584.

Oxford, R. L. (1990). Language learning strategies: What every teacher should know. Boston, MA: Heinle \& Heinle.

Oxford, R. L. (1999). Relationship between second language strategies and proficiency in the context of learner autonomy and self-regulation. Revista Canaria de Estudios Ingleses [Canarian Journal of English Studies], 38, 109-126. 
Oxford, R. L., \& Burry-Stock, J. A. (1995). Assessing the use of language learning strategies worldwide with the ESL/EFL version of the strategy inventory for language learning (SILL). System, 23, 1-23.

Oxford, R. L., \& Leaver, B. L. (1996). A synthesis of strategy instruction for language learners. In R. L. Oxford (Ed.), Language learning strategies around the world: Cross-cultural perspectives (Tech. Rep. No 13, pp. 227-246). Honolulu: University of Hawaii, Second Language Teaching \& Curriculum Center.

Oxford, R. L., \& Nyikos, M. (1989). Variables affecting choice of language learning strategies by university students. The Modern Language Journal, 73(3), 291-301.

Oxford, R. L., Ehrman, M. E., \& Lavine, R. Z. (1991). Style wars: Teacher-student style conflicts in the language classroom. In S. Magnan (Ed.), Challenges in the 1990s for college foreign language programs (1-25). Boston MA: Heinle \& Heinle.

Pae, T.-I., (2008). Second language orientation and Self-Determination Theory: A structural analysis of the factors affecting second language achievement. Journal of Language \& Social Psychology, 27(1), 5-27.

Páez, M. (2002). Language and the immigrant child: Predicting English language proficiency for Chinese, Dominican, and Haitian students. Dissertation Abstracts International, 62(11), 3717A. (AAT No. 3034903)

Paris, S. G., Cross, D. R., \& Lipson, M. Y. (1984). Informed strategies for learning: A program to improve children's reading awareness and comprehension. Journal of Educational Psychology, 76, 1239-1252.

Peacock, M., \& Ho, B. (2003). Student language learning strategies across eight disciplines. International Journal of Applied Linguistics, 13(2), 179-200. 
Peregoy, S. F., \& Boyle, O. F. (2005). Reading, writing and learning in ESL: A resource book for $K$ - 12 teachers (4th ed.). Boston, MA: Pearson.

Phillips, V. J. (1992). English as a Second Language learner strategies of adult Asian students using the Strategy Inventory for Language Learning (SILL). Dissertation Abstracts International, 53(1), 90A. (AAT No. 9207924)

Pienemann, M. (1985). Psychological constrains of the teachability of languages. Studies in Second Language Acquisition, 6(2), 186-214.

Pinker, S. (2007). The language instinct: How the mind creates language. New York: Harper Perennial Modern Classics.

Pressley, M., Woloshyn, V., \& Associates (2000). Cognitive strategy instruction that really improves children's academic performance (2nd ed.). Cambridge, MA: Brookline Books.

Proctor, C. P., August, D., Carlo, M., \& Barr, C. (2010). Language maintenance versus language of instruction: Spanish reading development among Latino and Latina bilingual learners. Journal of Social Issues, 66(1), 79-94.

Raudenbush, S. W., \& Bryk, A. S. (2002). Hierarchical linear models: Applications and data analysis methods (2nd ed.).Thousands Oaks, CA: Sage Publications.

Richardson Bruna, K., Roberta, V., \& Perales Escudero, M. (2007). What's language got to do with it?: A case study of academic language instruction in a high school "English Learner Science" class. Journal of English for Academic Purposes, 6(1), $36-54$ 
Rivera-Mills, S. V., \& Plonsky, L. (2007). Empowering students with language learning strategies: A critical review of current issues. Foreign Language Annals, 40(3), 535-548.

Robinson, P. (1995). Attention, memory, and 'noticing' hypothesis. Language Learning, $45(2), 283-331$.

Rolstad, K., Mahoney, K., \& Glass, G. V. (2005). The big picture: A meta-analysis of program effectiveness research on English language learners. Educational Policy, 19(4), 572-594.

Rothenberg, C., \& Fisher, D. (2007). Teaching English language learners: A differentiated approach. Upper Saddle River, NJ: Merrill Prentice Hall.

Rubin, J. (1975). What the "good language learner" can teach us. TESOL Quarterly, 9(1), 41-51.

Rubin, J. (1981). Study of cognitive processes in second language learning. Applied linguistics, 11(2), 118-131.

Saville-Troike, M. (2006). Introducing second language acquisition. New-York: Cambridge University Press.

Scarcella, R. (2003). Academic English: A conceptual framework (Tech. Rep. No. 20031). Irvine: University of California, Linguistic Minority Research Institute.

Schleppegrell, M. J. (2004). The language of schooling: A functional linguistic perspective. Mahwah, NJ: Lawrence Erlbaum.

Schmidt, R. (1990). The role of consciousness in second language learning. Applied Linguistics, 11(2), 129-158. 
Schmidt, R., \& Watanabe, Y. (2001). Motivation, strategy use, and pedagogical preferences in foreign language learning. In Z. Dörnyei \& R. Schmidt (Eds.), Motivation and second language acquisition (pp. 313-359). Honolulu, HI: University of Hawaii Press.

Schoonen, R., Hulstijn, J., \& Bossers, B. (1998). Metacognitive and language-specific knowledge in native and foreign language reading comprehension: An empirical study among Dutch students in grades 6, 8 and 10. Language Learning, 48(1), 71-106.

Shadish, W. R., Cook, T. D., \& Campbell, D.T. (2002). Experimental and quasiexperimental designs for generalized causal inference. Boston, MA: Houghton Mifflin.

Shannon, S., \& Hakuta, K. (1991). Challenges for limited English proficient students and the schools. In M. Reynolds, H. Walberg, \& M. Wang (Eds.), Handbook of special education: Research and practice: Vol. 4. Emerging programs (pp. 215233). New York: Pergamon Press.

Shavelson, R. J. (1996). Statistical reasoning for the behavioral sciences (3rd ed.). Needham Height, MA: Allyn \& Bacon.

Shevlin, M. \& Miles, J. N. V. (1998). Effects of sample size, model specification, and factor loadings on the GFI in confirmatory factor analysis. Personality and Individual Differences, 25, 85-90.

Skehan, P. (1998). A cognitive approach to language learning. Oxford, England: Oxford University Press.

Skinner, B. F. (1957). Verbal Behavior. New York: Appleton-Century-Crofts. 
Slavin, R. E., \& Cheung, A. (2005). A synthesis of research on language of reading instruction for English language learners. Review of Educational Research, 75 , $247-284$.

Snow, M. A. (2001). Content-based and immersion models for second and foreign language teaching. In M. Celce-Murcia (Ed.), Teaching English as a second or foreign language (3rd ed., pp. 303-318). Boston, MA: Heinle \& Heinle.

Solórzano, R. W. (2008). High stakes testing: Issues, implications, and remedies for English language learners. Review of Educational Research, 78(2), 260-329.

Spada, N. (1997). Form-focused instruction and second language acquisition: A review of classroom and laboratory research. Language Teaching, 30, 73-87.

Spada, N., \& Tomita, Y. (2010). Interactions between type of instruction and type of language feature: A meta-analysis. Language Learning, 60(2), 263-308.

Stevens, J. P. (2002). Applied multivariate statistics for the social sciences (4th ed.). Mahwah, NJ: Lawrence Erlbaum.

Suárez-Orozc, C., Suárez-Orozc, M., \& Todorova, I. (2008a). Learning a new land: Immigrant students in American society. Cambridge, MA: Harward University Press.

Suárez-Orozc, C., Suárez-Orozc, M., \& Todorova, I. (2008b). On-line supplement notes for "Learning a new land: Immigrant students in American society". Retrieved December 20, 2008, from http://steinhardt.nyu.edu/immigration/pubs/Online $\% 20$ Supplemental $\% 20$ Notes.pdf. 
Swain, M. (2005). The Output hypothesis: Theory and research. In E. Hinkel (Ed.), Handbook of research in second language teaching and learning (pp. 471-483). Mahwah, NJ: Lawrence Erlbaum Associates.

Takeuchi, O. (1993). Language learning strategies and their relationship to achievement in English as a foreign language. Language Laboratory, 30, 17-34.

Tashakorri, A., \& Teddlie, C. (1998). Mixed methodology: Combining qualitative and quantitative approaches (Vol. 46). Thousand Oaks: Sage.

The National Center for Public Policy and Higher Education. (2005, November). Income of U.S. workforce projected to decline if education doesn't improve. Retrieved September 20, 2008, from http://www.highereducation.org/reports/pa_decline/pa decline.pdf\# search=\%22 minorities $\% 22$.

Thomas, W. P., \& Collier, V. (1997). School effectiveness for language minority students (NCBE Resource Collection Series, No. 9). George Washington University, Center for the Study of Language and Education: National Clearinghouse for Bilingual Education. (ERIC Document Reproduction Service No. ED436087)

Thomas, W. P., \& Collier, V. P. (2002). A national study of school effectiveness for language minority students' long-term academic achievement. Santa-Cruz: University of California, Center for Research on Education, Diversity and Excellence.

U.S. Census Bureau. (2006, June 23). U.S. Census Bureau: State and County QuickFacts. Retrieved September 20, 2006, from http://quickfacts.census.gov/qfd/states/00000.html 
United Nations Educational, Scientific, and Cultural Organization [UNESCO] (2010). EFA global monitoring report: Reaching the marginalized. Retrieved from http://unesdoc. unesco.org/images/0018/001866/186606E.pdf

Vandergrift, L., \& Tafaghodtari, M. H. (2010). Teaching L2 learners how to listen does make a difference: An empirical study. Language Learning, 60(2), 470-497.

Vygotsky, L. S. (1978). Mind in society: The development of higher psychological processes. Cambridge, MA: Harvard University Press.

Wardhaugh, R. (2006). An Introduction to sociolinguistics (5th ed.). Malden, MA: Blackwell.

World-Class Instructional Design and Assessment (WIDA) Consortium (2008). Assessing Comprehension and Communication in English State-to-State for English Language Learners, ACCESS for ELLs ${ }^{\circledR}$ : Interpretative guide for score reports. Madison, WI: University of Wisconsin, Wisconsin Center for Education Research.

World-Class Instructional Design and Assessment (WIDA) Consortium (2007). The WIDA English Language Proficiency Standards, 2007 Edition: Pre-Kindergarten through Grade 12. Madison, WI: University of Wisconsin, Wisconsin Center for Education Research.

Wright, W. E. (2005). Evolution of federal policy and implications of No Child Left Behind for language minority students. Tempe, AZ: Arizona State University, Educational Policy Studies Laboratory.

$\mathrm{Wu}, \mathrm{X}$. (2003). Intrinsic motivation and young language learners: The impact of the classroom environment. System, 31(4), 501-517. 
Yoko, M. (2007). High-stakes test performance of limited English proficient students in Ohio. Dissertation Abstracts International, 67(11), n.p.A. (AAT No. 3241764)

Zwiers, J. (2006). Integrating academic language, thinking, and content: Learning scaffolds for non-native speakers in the middle grades. Journal of English for Academic Purposes, 5(4), 317- 332.

Zwiers, J. (2007). Teacher practices and perspectives for developing academic language. International Journal of Applied Linguistics, 17(1), 93-116. 


\title{
APPENDICES
}

\author{
Appendix A
}

Permission to use SILL

Date: $\quad$ Monday - January 5, 2009 8:43 PM

From: $\quad$ Rebecca Oxford <rebecca_oxford@yahoo.com>

To: Yuliya Y Ardasheva <yyarda01@gwise.louisville.edu>

Subject: $\quad$ Re: permission request

Dear Yuliya,

I was glad to receive your message and discover that you are planning to use

SEM in your study. I hope more people can use powerful statistical techniques such as that. You have my permission to use the SILL as long as you are willing to share your results with me. I am very interested in finding out about results using SEM.

One of my doctoral students used latent variable path analysis just recently to uncover influences, including strategies and other variables, on proficiency.

Warm wishes,

Dr. Oxford

Rebecca L. Oxford

Professor, Second Language Education and Culture

University Distinguished Scholar-Teacher

Senior Fellow, Confucius Institute at the University of Maryland

2311 Benjamin Building

University of Maryland

College Park, MD 20742

Email addresses: roxford@umd.edu, rebeccaoxford@gmail.com, rebecca_oxford@yahoo.com 


\section{Appendix B}

Strategy Inventory for Language Learning (SILL)-ELL Student Form

Directions: We want to know HOW students learn English. Please read each sentence and circle the answer $(1,2,3,4$, or 5$)$ that best describes how true the sentence if of you. For example, if the sentence in never or almost never true of you, circle (1). When selecting your answer, use this answer key:

$1=$ Never or almost never true of me

$2=$ Usually not true of me

$3=$ Somewhat true of me

$4=$ Usually true of me

$5=$ Always or almost always true of me

Part A: Memory Strategies

1. I think of relationships between what I already know and new things I learn in English.

2. I use new English words in a sentence so I can remember them.

3. I connect the sound of a new English word and an image or picture of the word to help me remember the word.

4. I remember a new English word by making a mental picture of a situation in which the word might be used.

5. I use rhymes to remember new English words.

6. I use flashcards to remember new English words.

7. I physically act out new English words.

8. I review English lessons often. 
9. I remember new English words or phrases by remembering their location on the page, on the board, or on a street sign.

Part B: Cognitive Strategies

10. I say or write new English words several times.

11. I try to talk like native English speakers.

12. I practice the sounds of English.

13. I use the English words I know in different ways.

14. I start conversations in English.

15. I watch English language TV shows spoken in English or go to movies spoken in English.

16. I read for pleasure in English.

17. I write notes, messages, letters, or reports in English

18. I first skim an English passage (read over the passage quickly) then go back and read carefully

19. I look for words in my own language that are similar to new words in English.

20. I try to find patterns in English.

21. I find the meaning of an English word by dividing it into parts that I understand.

22. I try not to translate word for word.

23. I make summaries of information that I hear or read in English.

Part C: Compensation strategies

24. To understand unfamiliar English words, I make guesses.

25. When I can't think of a word during a conversation in English, I use gestures. 
26. I make up new words if I do not know the right ones in English.

27. I read English without looking up every new word.

28. I try to guess what the other person will say next in English.

29. If I can't think of an English word, I use a word or phrase that means the same thing.

Part D: Metacognitive Strategies

30. I try to find as many ways as I can to use my English.

31. I notice my English mistakes and use that information to help me do better.

32. I pay attention when someone is speaking English.

33. I try to find out how to be a better learner of English.

34. I plan my schedule so I will have enough time to study English.

35. I look for people I can talk to in English.

36. I look for opportunities to read as much as possible in English.

37. I have clear goals for improving my English skills.

38. I think about my progress in learning English.

Part E: Affective Strategies

39. I try to relax whenever I feel afraid of using English

40. I encourage myself to speak English even when I am afraid of making a mistake.

41. I give myself a reward or treat when I do well in English.

42. I notice if I am tense or nervous when I am studying or using English.

43. I write down my feelings in a language learning dairy.

44. I talk to someone else about how I feel when I am learning English. 


\section{Part F: Social Strategies}

45. If I do not understand something in English, I ask the other person to slow down or say it again.

46. I ask English speakers to correct me when I talk.

47. I practice English with other students.

48. I ask for help from English speakers.

49. I ask questions in English.

50. I try to learn about the culture of English speakers

Part G: Background

1. What is your grade?

2. What is your gender?

3. What is your age?

4. What is your ethnicity? (a) American Indian or Alaskan native, (b) Asian, (c)

Black, (d) Hispanic, (e) Pacific Islander, (f) White, (g) Other, please specify

5. What is your country of birth?

6. What language(s) do you speak at home?

7. What is your mother tongue (first language)?

a. How well do understand your native language?

b. How well do you speak your native language?

c. How well do you read your native language?

d. How well do you write your native language?

8. Did your mother go to school? 
9. If yes, what school did she finish?
a. Elementary school
b. Middle school
c. High school diploma (or about 12 years in school)
d. Some college or university (or 1-2 years in a college or a university)
e. College or university diploma (or 4 or more years in a college or a university)
f. I don't know

10. Did your father go to school?

11. If yes, what school did he finish?
a. Elementary school
b. Middle school
c. High school diploma (or about 12 years in school)
d. Some college or university (or 1-2 years in a college or a university)
e. College or university diploma (or 4 or more years in a college or a university)
f. I don't know 


\section{Appendix C}

Strategy Inventory for Language Learning (SILL)-ESL Teacher Form DIRECTIONS: This form contains a list of language learning strategies that ELL students may use on their own to learn English. Please read each statement and circle the response $(1,2,3,4$, or 5$)$ that best describes HOW YOU RATE THE EFFECTIVENESS OF EACH LEARNING STRATEGY FOR ENGLISH LANGUAGE DEVELOPMENT. For example, if you believe that the strategy is very unlikely to be effective, select 1 . When selecting your answer, think of an average ELL student and refer to the following scale:

$1=$ Very unlikely

$2=$ Unlikely

$3=$ Neither unlikely or likely

$4=$ Likely

$5=$ Very likely

Part A: Memory Strategies

1. Students think of relationships between what they already know and new things they learn in English.

2. Students use new English words in a sentence so they can remember them.

3. Students connect the sound of a new English word and an image or picture of the word to help them remember the word.

4. Students remember a new English word by making a mental picture of a situation in which the word might be used.

5. Students use rhymes to remember new English words. 
6. Students use flashcards to remember new English words.

7. Students physically act out new English words.

8. Students review English lessons often.

9. Studnets remember new English words or phrases by remembering their location on the page, on the board, or on a street sign.

Part B: Cognitive Strategies

10. Students say or write new English words several times.

11. Students try to talk like native English speakers.

12. Students practice the sounds of English.

13. Students use the English words they know in different ways.

14. Students start conversations in English.

15. Students watch TV shows spoken in English or go to movies spoken in English.

16. Students read for pleasure in English.

17. Students write notes, messages, letters, or reports in English.

18. Students first skim an English passage (read over the passage quickly) then go back and read carefully.

19. Students look for words in their own language that are similar to new words in English.

20. Students try to find patterns in English.

21. Students find the meaning of an English word by dividing it into parts that they understand.

22. Students try not to translate word for word. 
23. Students make summaries of information that they hear or read in English.

Part C: Compensation strategies

24. To understand unfamiliar English words, students make guesses.

25. When students can't think of a word during a conversation in English, they use gestures.

26. Students make up new words if they do not know the right ones in English.

27. Students read English without looking up every new word.

28. Students try to guess what the other person will say next in English.

29. If students can't think of an English word, they use a word or phrase that means the same thing.

Part D: Metacognitive Strategies

30. Students try to find as many ways as they can to use their English.

31. Students notice their English mistakes and use that information to help them do better.

32. Students pay attention when someone is speaking English.

33. Students try to find out how to be a better learner of English.

34. Students plan their schedule so they will have enough time to study English.

35. Students look for people they can talk to in English.

36. Students look for opportunities to read as much as possible in English.

37. Students have clear goals for improving their English skills.

38. Students think about their progress in learning English.

Part E: Affective Strategies

39. Students try to relax whenever they feel afraid of using English. 
40. Students encourage themselves to speak English even when they are afraid of making a mistake.

41. Students give themselves a reward or treat when they do well in English.

42. Students notice if they are tense or nervous when they are studying or using English.

43. Students write down their feelings in a language learning dairy.

44. Students talk to someone else about how they feel when they are learning English.

Part F: Social Strategies

45. If students do not understand something in English, they ask the other person to slow down or say it again.

46. Students ask English speakers to correct them when they talk.

47. Students practice English with other students.

48. Students ask for help from English speakers.

49. Students ask questions in English.

50. Students try to learn about the culture of English speakers.

Part G: Demographic Questionnaire

1. What is your gender?

2. How many years have you been a school teacher (including this year)?

3. What is your area of teaching certification?

4. What grade(s) are you currently teaching?

5. Is English your native language?

6. Do you speak a second language? 
If yes, please estimate your highest ability level attained: (a) Beginner, (b) Intermediate, (c) Advanced.

7. What is your ethnicity? (a) American Indian or Alaskan native, (b) Asian, (c)

Black, (d) Hispanic, (e) Pacific Islander, (f) White, (g) Other, please specify

8. What subject area(s) do you teach or assist in teaching? (if more than one, please list your primary area first) 
Appendix D

Permission to use LLOS-IEA

Date: $\quad$ Monday - January 5, 2009 2:05 PM

From: <knoels@ualberta.ca $>$

To: <yyarda01@gwise.louisville.edu>

Subject: $\quad$ Re: SPN Profile Message: permission request

Hello Yuliya,

Thank you for your message and for your interest in our instrument. It's always nice to hear from people with common research interests. Yes, you do have my permission to use the instrument and adapt it as you see fit. All I ask is that the original is cited (e.g., adapted from Noels et al., 2000). I would be very interested to receive a copy of the instrument when it is completed (we are working on our own adult ESL version as well, and if we are able to complete the psychometric analyses soon, I will forward a copy to you). I would also be very happy to receive a copy of your final report. I wish you much success with your research.

Kim

P.S. You may find the Self-Determination website useful. It has several scales that are geared for younger people that might be better for your purposes than our adult-oriented instrument. The URL is http:/www.psych.rochester.edu/SDT/

Kimberly A. Noels

Professor, Social and Cultural Psychology Area

Department of Psychology

P220 Biological Sciences Building, University of Alberta,

Edmonton, AB, Canada, T6G 2E9

Office: $780-492-4717$

Fax: 780-492-1768

Website: http://www.psych.ualberta.ca/ knoels/personal/ 


\section{Appendix E}

\section{English Language Learning Motivation Scale (ELLMS):}

Intrinsic and Extrinsic Motivation Subscales from LLOS-IEA

Directions: We want to know WHY students learn English. Please read each sentence and circle the answer $(1,2,3,4$, or 5$)$ that best describes how strongly you agree or disagree with the sentence. For example, if you strongly disagree with the sentence, circle (1).

When selecting your answer, use this answer key:

$1=$ Strongly disagree

$2=$ Disagree

$3=$ Unsure

$4=$ Agree

$5=$ Strongly agree

Part A: Intrinsic Motivation-Knowledge

I learn a second language ...

1. For the pleasure that I experience in knowing more about the literature of the second language group.

2. For the satisfied feeling I get in finding out new things.

3. Because I enjoy the feeling of acquiring knowledge about the second language community and their way of life.

Part B: Intrinsic Motivation-Accomplishment

4. For the pleasure I experience when surpassing myself in my second language studies. 
5. For the enjoyment I experience when I grasp a difficult construct in the second language.

6. For the satisfaction I feel when I am in the process of accomplishing difficult exercises in the second language.

Part C: Introjected Regulation

7. To show myself that I am a good citizen because I can speak a second language.

8. Because I would feel ashamed if I couldn't speak to my friends from the second language community in their native tongue.

9. Because I would feel guilty if I didn't know a second language.

Part D: External Regulation

10. Because I have the impression that it is expected of me.

11. In order to get a more prestigious job later on.

12. In order to have a better salary later on. 


\section{Appendix F}

English Language Learning Motivation Scale (ELLMS; Modified)

Part A: Intrinsic Motivation

I learn English because ...

1. It is fun to learn a new language.

2. I like learning new things.

3. I like to learn about Americans and how they live.

4. I like it when I do well in English.

5. I like it when I can understand difficult things in English.

6. I like doing difficult things in English.

Part B: Introjected Regulation

I learn English because ...

7. I'll feel bad about myself if I couldn't speak English in my school.

8. I'll feel bad about myself if I couldn't speak to my American friends in English.

Part C: External Regulation

I learn English because ...

9. I want to show my teachers that I can learn English.

10. I want to find a good job when I grow up.

11. My parents and teachers want me to learn English.

12. Everybody in school has to learn English. 
Appendix G

Strategy Inventory for Language Learning (SILL)-ELL Student Form (Modified)

Part A: Memory Strategies

1. I use flashcards to learn new English words.

2. I use rhymes to help me learn new English words.

3. I act out new English words.

4. I use new English words in a sentence to help me learn them.

5. I learn new words by thinking about when I can use them.

6. When I hear a new English word I think of a picture to help me learn the word.

7. I learn new words by thinking about where I first saw them on the page, on the board, or on a street sign.

Part B: Cognitive strategies

8. I read for fun in English.

9. I first read a page (a text) quickly and then go back and read it carefully.

10. I look for words in English that are like my own language.

11. I break long words into small parts to figure out what they mean.

12. I make summaries of things I hear or read in English.

Part C: Compensation strategies

13. If I can't think of an English word, I show what I mean with my hands.

14. I make up a new word if I can't think of an English word.

15. When I read in English, I don't look up every new word in a dictionary.

16. I try to guess (predict) what people will say next in English. 
17. If I can't think of an English word, I use a word that means the same thing. Part D: Metacognitive strategies

18. I see my English mistakes and try to do better.

19. I listen well (carefully) when people speak English.

20. I look for ways to be a better student of English.

21. I think about how well I am doing in English.

Part E: Affective strategies

22. I give myself a gift or a treat when I do well in English.

23. I write about how I feel when I am learning English in my journal.

24. I talk to people about how I feel when I am learning English.

Part F: Social strategies

25. If I don't understand, I ask English speakers to slow down or say it again.

26. I ask English speakers to correct me when I talk.

27. I practice English with other students.

28. I ask for help from English speakers. 


\section{Appendix $\mathrm{H}$}

Strategy Inventory for Language Learning (SILL)-ESL Teacher Form (Modified)

Part A: Memory Strategies

1. Students use flashcards to remember new English words. [Students use

flashcards to learn new English words. $]^{80}$

2. Students use rhymes to remember new English words. [Students use rhymes to help themselves learn new English words.]

3. Students physically act out new English words. [Students act out new English words.]

4. Students use new English words in a sentence so they can remember them. [Students use new English words in a sentence to help themselves learn the new words.]

5. Students remember a new English word by making a mental picture of a situation in which the word might be used. [Students learn new words by thinking about when they can use the new words.]

6. Students connect the sound of a new English word and an image or picture of the word to help themselves remember the word. [When students hear a new English word they think of a picture to help themselves learn the new word.]

7. Students remember new English words or phrases by remembering their location on the page, on the board, or on a street sign. [Students learn new words by thinking about where they first saw them on the page, on the board, or on a street sign.]

\footnotetext{
${ }^{80}$ Statements in [square brackets] replicate the wording of the items as they appear on SILL-ELL Student form; these statement were available to the teachers during instrument administration.
} 
Part B: Cognitive Strategies

8. Students read for pleasure in English. [Students read for fun in English.]

9. Students first skim an English passage then go back and read carefully. [Students first read a page (a text) quickly and then go back and read it carefully.]

10. Students look for words in their own language that are similar to new words in English. [Students look for words in English that are like their own language.]

11. Students find the meaning of an English word by dividing it into parts that they understand. [Students break long words into small parts to figure out what they mean.]

12. Students make summaries of information that they hear or read in English. [Students make summaries of things they hear or read in English.]

Part C: Compensation strategies

13. When students can't think of a word during a conversation in English, they use gestures. [If students can't think of an English word, they show what they mean with their hands.]

14. Students make up new words if they do not know the right ones in English. [Students make up a new word if they can't think of an English word.]

15. Students read English passages without looking up every new word. [When students read in English, they don't look up every new word in a dictionary.]

16. Students try to guess what the other person will say next in English. [Students try to guess (predict) what people will say next in English.] 
17. If students can't think of an English word, they use a word or phrase that means the same thing. [If students can't think of an English word, they use a word that means the same thing.]

Part D: Metacognitive Strategies

18. Students notice their English mistakes and use that information to help them do better. [Students see their English mistakes and try to do better.]

19. Students pay attention when someone is speaking English. [Students listen well when people speak English.]

20. Students try to find out how to be a better learner of English. [Students look for ways to be a better student of English.]

21. Students think about their progress in learning English. [Students think about how well they are doing in English.]

Part E: Affective Strategies

22. Students give themselves a reward or treat when they do well in English. [Students give themselves a gift or a treat when they do well in English.]

23. Students write down their feelings in a language learning dairy. [Students write about how they feel when they are learning English in their journals.]

24. Students talk to someone else about how they feel when they are learning English. [Students talk to people about how they feel when they are learning English.]

Part F: Social Strategies 
25. If students do not understand something in English, they ask the other person to slow down or say it again. [If students don't understand, they ask English speakers to slow down or say it again.]

26. Students ask English speakers to correct them when they talk. [Students ask English speakers to correct them when they talk.]

27. Students practice English with other students. [Students practice English with other students.]

28. Students ask for help from English speakers. [Students ask for help from English speakers.] 


\section{Appendix I}

Individual Level Comparison of Teacher and Student Ratings of Learning

Strategies Effectiveness by Educational Level
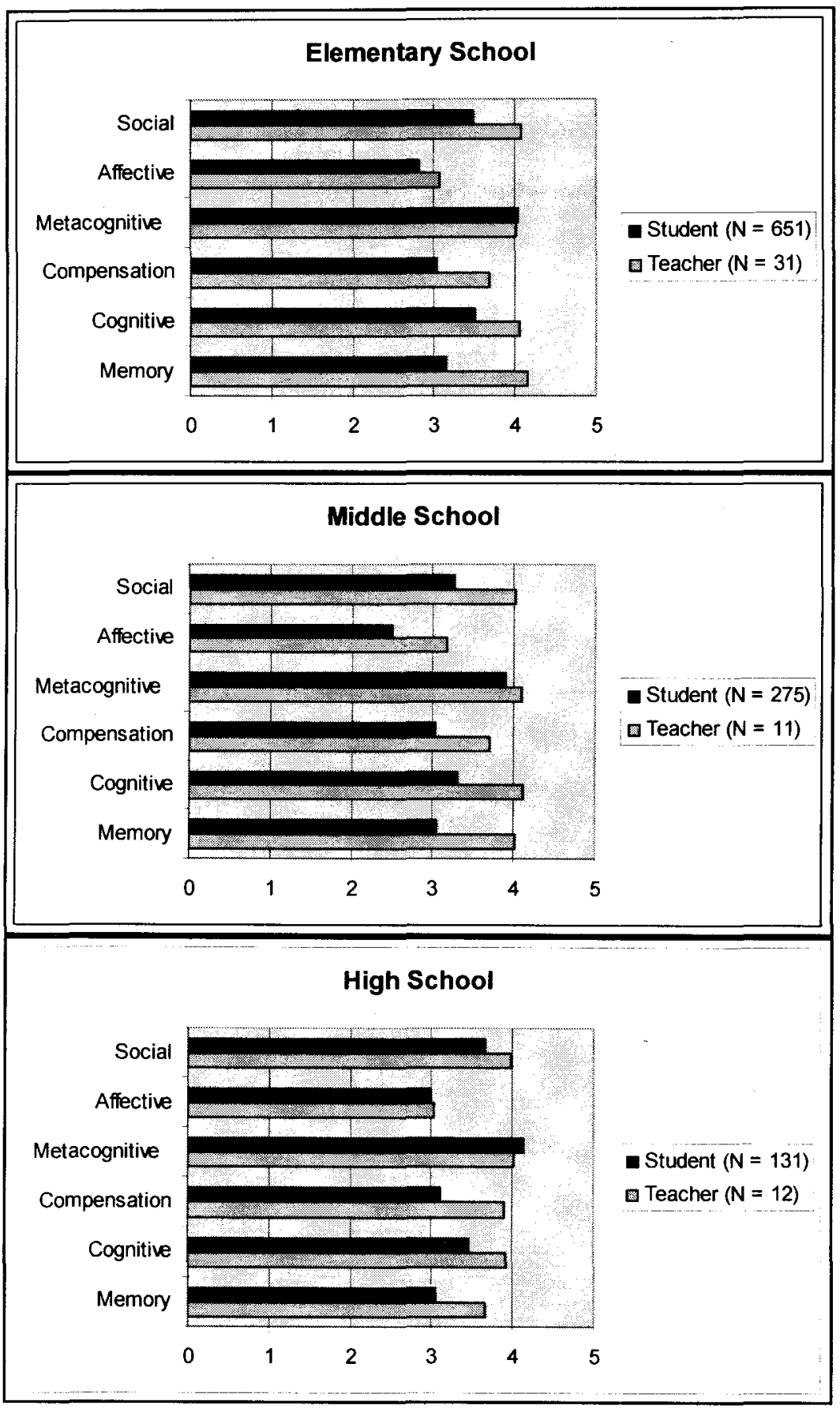

Figure I1. Average student and teacher SILL scores (possible range: 1-5) disaggregated by strategy category and educational level. 


\section{Appendix J}

Correlations and Descriptive Statistics for HLM Reading, Mathematics, Science and Social Studies Model Variables

Table J1

Unadjusted Bivariate Correlations (Pearson, Point-Biserial), Means, and Standard Deviations ${ }^{\mathrm{a}}$ for Reading Model, Level 1 Variables

\begin{tabular}{|c|c|c|c|c|c|c|c|c|}
\hline Variables & $\mathrm{RACH}$ & Age & PRIORSC $^{b}$ & $\mathrm{MEDI}^{\mathrm{b}}$ & MED2 & L1 literacy & META & ENPROF \\
\hline 1. $\mathrm{RACH}$ & - & & & & & & & \\
\hline 2. Age & $-.20^{* * *}$ & - & & & & & & \\
\hline 3. PRIORSC & $-.32^{* * *}$ & $.20^{* * *}$ & - & & & & & \\
\hline 4. $\mathrm{MEDI}^{\mathrm{c}}$ & $-.24 * * *$ & $.09^{* *}$ & $.40^{* * *}$ & - & & & & \\
\hline 5. MED2 & $.13 * * *$ & -.02 & $-.18 * * *$ & $-.26^{* * *}$ & - & & & \\
\hline 6. L1 literacy & $.11^{* *}$ & $.13 * * *$ & $-.18 * * *$ & $-.22 * * *$ & $.16^{* * *}$ & - & & \\
\hline 7. META & $.13^{* * *}$ & -.03 & -.01 & -.05 & $.06 \dagger$ & .04 & - & \\
\hline 8. ENPROF & $.42 * * *$ & $.43 * * *$ & $-.24 * * *$ & $-.16^{* * *}$ & $.20^{* * *}$ & $.12 * *$ & $.06 \dagger$ & - \\
\hline$M$ & 33.21 & 11.85 & - & - & - & 3.04 & 16.04 & 341.31 \\
\hline$S D$ & 17.45 & 2.23 & - & - & - & 2.05 & 3.27 & 28.44 \\
\hline
\end{tabular}

Note,$N_{\text {students }}=840$. RACH $=$ score in reading. META $=$ Metacognitive strategies. MED1 = Mother formal education. MED2= Mother postsecondary education. PRIORSC $=$ Prior education. ENPROF $=$ English proficiency. ${ }^{a}$ Means and standard deviations are reported only for continuous variables. ${ }^{b}$ Prior education is and MED1 are coded such that a higher value corresponds to less education. ${ }^{* * *} p<.001 .{ }^{* *} p<.01 .{ }^{*} p<.05 .{ }^{\dagger} p<.10$. 
Table J2

Unadjusted Bivariate Correlations (Pearson, Spearman), Means, and Standard Deviations ${ }^{a}$ for Reading Model, Level 2 Variables

\begin{tabular}{|c|c|c|c|c|c|c|}
\hline Variables & AVRRACH & Level & POVR & PRREAD & ELLEFF & LLSEFF \\
\hline 1. AVRRACH & - & & & & & \\
\hline 2. Level & $-.44^{* *}$ & - & & & & \\
\hline 3. POVR & -.16 & -.09 & - & & & \\
\hline 4. PRREAD & $.40^{*}$ & -.30 & $-.70 * * *$ & - & & \\
\hline 5. ELLEFF & $.45^{* *}$ & -.24 & $.54^{* *}$ & $-.44 * *$ & - & \\
\hline 6. LLSEFF & .20 & -.20 & .05 & .20 & -.01 & - \\
\hline$M$ & 34.10 & - & 69.66 & 54.50 & -17.85 & 3.87 \\
\hline$S D$ & 8.23 & - & 17.38 & 13.30 & 14.99 & 0.39 \\
\hline
\end{tabular}

Note. $N_{\text {schools }}=37$. AVRRACH $=$ average (within-school) score in reading. $P O V R=$ School poverty rate. $P R R E A D=$ School proficiency rate in reading.

ELLEFF $=$ School ELL effectiveness. LLS eff. = LLS effectiveness. ${ }^{b}$ Reported only for continuous variables. ${ }^{* * *} p<.001 .{ }^{* *} p<.01 .{ }^{*} p<.05 .{ }^{\dagger} p<.10$. 
Table J3

Unadjusted Bivariate Correlations (Pearson, Point-Biserial), Means, ${ }^{\text {a }}$ and Standard Deviations for Mathematics Model, Level 1 Variables

\begin{tabular}{|c|c|c|c|c|c|c|c|c|}
\hline Variables & $\mathrm{MACH}$ & Age & PRIORSC $^{b}$ & $\mathrm{MED}^{\mathrm{b}}{ }^{\mathrm{b}}$ & MED2 & Ll literacy & META & ENPROF \\
\hline 1. $\mathrm{MACH}$ & - & & & & & & & \\
\hline 2. Age & $-.28 * * *$ & - & & & & & & \\
\hline 3. PRIORSC & $-.26^{* * *}$ & $.19 * * *$ & - & & & & & \\
\hline 4. MED1 & $-.23 * * *$ & $.17^{* * *}$ & $.37^{* * *}$ & - & & & & \\
\hline 5. MED2 & $.11^{* *}$ & $-.09 *$ & $-.17^{* * *}$ & $-.26 * * *$ & - & & & \\
\hline 6. L1 literacy & $.10^{* *}$ & $.15^{* * *}$ & $-.17^{* * *}$ & $-.18^{* *}$ & $.12 * * *$ & - & & \\
\hline 7. META & $.07 \dagger$ & .02 & .00 & -.04 & $.06 \dagger$ & .05 & - & \\
\hline 8. ENPROF & $.24 * * *$ & $.42^{* * *}$ & $-.21^{* * *}$ & $-.11^{* *}$ & $.16^{* * *}$ & $.12 * * *$ & $.07^{*}$ & - \\
\hline$M$ & 29.45 & 12.09 & - & - & - & 3.06 & 16.09 & 341.59 \\
\hline$S D$ & 21.49 & 2.65 & - & - & $\ldots$ & 2.05 & 3.26 & 28.32 \\
\hline
\end{tabular}

Note. $N_{\text {students }}=858 . \mathrm{MACH}=$ score in mathematics. META $=$ Metacognitive strategies. $\mathrm{MED1}=$ Mother formal education. MED2 $=$ Mother postsecondary education. PRIORSC $=$ Prior education. ENPROF $=$ English proficiency.

${ }^{a}$ Means and standard deviations are reported only for continuous variables. ${ }^{b}$ Prior education and MED1 are coded such that a higher value corresponds to less education. ${ }^{* * *} p<.001 .{ }^{* *} p<.01 .{ }^{*} p<.05 .{ }^{\dagger} p<.10$. 
Table J4

Unadjusted Bivariate Correlations (Pearson, Spearman), Means, ${ }^{\text {a }}$ and Standard Deviations for Mathematics Model, Level 2 Variables

\begin{tabular}{|c|c|c|c|c|c|c|}
\hline Variables & AVRMACH & Level & POVR & PRMATH & ELLEFF & LLSEFF \\
\hline 1. AVRMACH & - & & & & & \\
\hline 2. Level & $-.64 * * *$ & - & & & & \\
\hline 3. POVR & -.01 & -.14 & - & & & \\
\hline 4. PRMATH & $.54 * * *$ & $-.66^{* * *}$ & $-.54 * * *$ & - & & \\
\hline 5. ELLEFF & $.52 * *$ & $-.29 \dagger$ & $.56 * * *$ & $-.29 \dagger$ & - & \\
\hline 6. LLSEFF & .11 & -.13 & .01 & .20 & -.07 & - \\
\hline$M$ & 29.13 & - & 69.07 & 46.45 & -18.67 & 3.88 \\
\hline$S D$ & 10.81 & - & 17.53 & 16.58 & 15.63 & 0.39 \\
\hline
\end{tabular}

Note. $N_{\text {schools }}=38$. PRMATH $=$ School proficiency rate in mathematics. ELLEFF $=$ School ELL effectiveness. LLSEFF $=$ LLS effectiveness. ${ }^{a}$ Means and standard deviations are reported only for continuous variables. ${ }^{* *} p<.001 .{ }^{* *} p<.01 .{ }^{*} p<.05 .{ }^{\dagger} p<.10$. 


\section{Table J5}

Unadjusted Bivariate Correlations (Pearson, Point-Biserial), Means, and Standard Deviations ${ }^{\mathrm{a}}$ for Science Model, Level 1 Variables

\begin{tabular}{|c|c|c|c|c|c|c|c|c|}
\hline Variable & $\mathrm{SACH}$ & Age & PRIORSC $^{\mathrm{b}}$ & $\mathrm{MED}^{\mathrm{b}}$ & MED2 & L1 literacy & META & L2 proficiency \\
\hline 1. $\mathrm{SACH}$ & - & & & & & & & \\
\hline 2. Age & $-.43^{* * *}$ & - & & & & & & \\
\hline 3. PRIORSC & $-.26^{* * *}$ & $.16^{* *}$ & - & & & & & \\
\hline 4. MED1 & $-.37 * * *$ & $.19^{* *}$ & $.33^{* * *}$ & - & & & & \\
\hline 5. MED2 & $.16^{* *}$ & $-.10 \dagger$ & $-.14 *$ & $-.28 * * *$ & - & & & \\
\hline 6. L1 literacy & $-.12^{*}$ & $.22 * * *$ & -.06 & -.07 & .02 & - & & \\
\hline 7. META & -.02 & .04 & .01 & $-12 *$ & $.11 \dagger$ & .07 & - & \\
\hline 8. L2 proficiency & $.18^{* *}$ & $.43 * * *$ & $-.18^{* *}$ & -.08 & $.13^{*}$ & $.12^{*}$ & .04 & - \\
\hline$M$ & 26.26 & 13.10 & - & - & - & 3.28 & 16.30 & 347.49 \\
\hline$S D$ & 17.23 & 3.32 & - & 一 & - & 2.09 & 3.11 & 27.16 \\
\hline
\end{tabular}

Note. $N_{\text {students }}=312 . \mathrm{SACH}=$ score in science. META $=$ Metacognitive strategies. MED1 = Mother formal education. MED2 = Mother postsecondary education. PRIORSC $=$ Prior education

${ }^{a}$ Means and standard deviations are reported only for continuous variables. ${ }^{b}$ Prior education and MED1 are coded such that a higher value corresponds to less education. ${ }^{* * *} p<.001 .{ }^{* *} p<.01 .{ }^{*} p<.05 .{ }^{\dagger} p<.10$. 
Table J6

Unadjusted Bivariate Correlations (Pearson, Spearman), Means, and Standard Deviations ${ }^{\mathrm{a}}$ for Science Model, Level 2 Variables

\begin{tabular}{|c|c|c|c|c|c|c|}
\hline Variables & AVRSACH & Leve! & POVR & PRSC & ELLEFF & LLSEFF \\
\hline 1. AVRSACH & - & & & & & \\
\hline 2. Level & $-.79 * * *$ & - & & & & \\
\hline 3. POVR & -.30 & -.04 & - & & & \\
\hline 4. PRSC & $.51^{* *}$ & $-.52 * *$ & $-.67^{* * *}$ & - & & \\
\hline 5. ELLEFF & $.49^{* *}$ & -.26 & $.59^{* * *}$ & $-.31 \dagger$ & - & \\
\hline 6. LLSEFF & .08 & -.13 & -.04 & $.30 \dagger$ & -.11 & - \\
\hline$M$ & 27.49 & - & 67.64 & 41.20 & -19.07 & 3.87 \\
\hline$S D$ & 11.69 & - & 17.97 & 18.37 & 15.15 & 0.40 \\
\hline
\end{tabular}

Note. $N_{\text {schools }}=34$. Level = Educational level (elementary, middle, high). AVRSACH = average (within-school) score in science. POVR $=$ School poverty rate. PRSC $=$ School proficiency rate in science. ELLEFF $=$ School ELL effectiveness. LLSEFF $=$ LLS effectiveness. ${ }^{\text {a }}$ Means and standard deviations are reported only for continuous variables. ${ }^{* * *} p<.001 .{ }^{* *} p<.01 .{ }^{*} p<.05 .{ }^{\dagger} p<.10$. 
Table J7

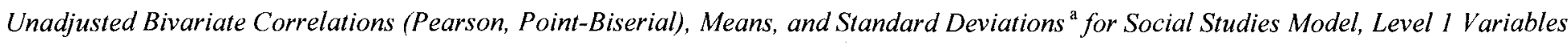

\begin{tabular}{|c|c|c|c|c|c|c|c|c|}
\hline Variable & SSACH & Age & PRIORSC $^{b}$ & $\mathrm{MEDI}^{\mathrm{b}}$ & MED2 & L1 literacy & META & ENPROF \\
\hline 1. $\mathrm{SSACH}$ & - & & & & & & & \\
\hline 2. Age & $-.21^{* * *}$ & - & & & & & & \\
\hline 3. PRIORSC & $-.27^{* * *}$ & $.13^{*}$ & - & & & & & \\
\hline 4. MEDI & $-.20^{* * *}$ & $.20^{* * *}$ & $.40^{* * *}$ & - & & & & \\
\hline 5. MED2 & $.18^{* *}$ & $-.15^{* *}$ & $-.20 * * *$ & $-.28 * * *$ & - & & & \\
\hline 6. L1 literacy & .01 & $.21^{* * *}$ & $-.17^{* *}$ & $-.15^{* *}$ & $.10 \dagger$ & - & & \\
\hline 7. META & .06 & .07 & .05 & .04 & .03 & .02 & - & \\
\hline 8. ENPROF & $.46^{* * *}$ & $.28 * * *$ & $-.32 * * *$ & $-.13^{*}$ & $.14^{*}$ & $.12^{* *}$ & $.15 * *$ & - \\
\hline$M$ & 33.21 & 13.96 & - & - & - & 3.47 & 16.10 & 352.72 \\
\hline$S D$ & 17.30 & 2.87 & - & - & - & 2.03 & 3.33 & 28.75 \\
\hline
\end{tabular}

Note. $N_{\text {students }}=332 . \mathrm{SSACH}=$ score in social studies. $\mathrm{META}=$ Metacognitive strategies. MED1 $=$ Mother formal education. MED2 $=$ Mother postsecondary education. PRIORSC $=$ Prior education. ENPROF $=$ English proficiency.${ }^{a}$ Means and standard deviations are reported only for continuous variables. ${ }^{b}$ Prior education andMED1 are coded such that a higher value corresponds to less education. ${ }^{* *} p<.001 .{ }^{* *} p<.01 .{ }^{*} p<.05 .{ }^{\dagger} p<.10$. 
Table J8

Unadjusted Bivariate Correlations (Pearson, Spearman), Means, and Standard Deviations ${ }^{\text {a }}$ for Social Studies Model, Level 2 Variables

\begin{tabular}{|c|c|c|c|c|c|c|}
\hline Variables & AVRSSACH & Level & POVR & PRSS & ELLEFF & LLSEFF \\
\hline 1. AVRSSACH & - & & & & & \\
\hline 2. Level & $-.37^{*}$ & - & & & & \\
\hline 3. POVR & -.25 & -.08 & - & & & \\
\hline 4. PRSS & $.48^{* *}$ & $-.34^{*}$ & $-.64^{* * *}$ & - & & \\
\hline 5. ELLEFF & $.28+$ & -.23 & $.55^{* * *}$ & $-.39 *$ & - & \\
\hline 6. LLSEFF & .21 & -.15 & -.001 & .20 & -.10 & - \\
\hline$M$ & 23.94 & - & 68.59 & 38.93 & -19.60 & 3.87 \\
\hline$S D$ & 10.93 & - & 17.52 & 17.43 & 14.74 & 0.39 \\
\hline
\end{tabular}

Note. $N_{\text {schools }}=37$. Level $=$ Educational level $($ elementary, middle, high $)$. AVRSSACH $=$ average $($ within-school) score in social studies. POVR $=$ School poverty rate. PRSS $=$ School proficiency rate in social studies. ELLEFF $=$ School ELL effectiveness. LLSEFF $=$ LLS effectiveness. ${ }^{\text {a }}$ Means and standard deviations are reported only for continuous variables. ${ }^{* * *} p<.001 .{ }^{* *} p<.01 .{ }^{*} p<.05 .{ }^{\dagger} p<.10$. 


\section{CURRICULUM VITAE}

403 West Bloom St., Apt. 8

Yuliya Ardasheva

Louisville, KY 40208

jearda@gmail.com yyarda01@louisville.edu

\section{EDUCATION}
$2006-2010$
Ph.D., Curriculum and Instruction, Specialization in Teaching English to Speakers of Other Languages (TESOL), University of Louisville, Louisville, KY.
$1990-1995$
M.A., French, Perm State Pedagogical University, Perm, Russia.
$1990-1995$
B.A., Secondary Education, Perm State Pedagogical University, Perm, Russia.

\section{AWARDS}

Graduate Dean's Citation, University of Louisville, Louisville, KY, 2010

\section{PROFESSIONAL AFFILIATIONS}

American Educational Research Association; Second Language Research SIG (2006 present)

Teachers of English to Speakers of Other Languages (2006 - present)

\section{PUBLICATIONS}

Ardasheva, Y., Tretter, R. T., \& Kinny, M. (in press). English language learners and academic achievement: Revisiting the threshold hypothesis. Language Learning.

Howell, P. B., Thomas, S., \& Ardasheva, Y. (2010). Talk in the classroom: Meeting the developmental, cultural, and academic needs of middle school students. Manuscript under revise and resubmit, Middle Grades Research Journal.

Ardasheva, Y. (2007, March). The green funds-of-knowledge approach to environmental education. JCPS Global Connections, 1(7). Retrieved from http://www.jefferson .k12.ky.us/Programs/mcconnections/GlobalConnect/GlobalConnect/Archives/060 7Issues/March07.html\#greenfunds.

\section{Manuscripts in Preparation for Submission}


Ardasheva, Y., \& Tretter, R. T., Strategy Inventory for Language Learning (SILL):

Testing for factorial validity for school-aged ELLs. Manuscript in preparation for submission.

Ardasheva, Y. \& Howell, P. B., Building Academic Capital among English Language Learners through Accountable Talk. Manuscript in preparation for submission.

\section{Work in Progress}

Ardasheva, Y., Tong, S., \& Tretter, R. T., Examining language learning motivation among school-aged ELLs through the lens of Self-Determination Theory. Manuscript in preparation.

Ardasheva, Y., \& Brown, S., Content-area teachers seeking ESL preparation: What motivates them? Manuscript in preparation.

Jones, J. H., Rudasill, K. M., Bush, W. S., Bay-Williams, J., Ghosh, R., Ardasheva, Y., \& McGatha, M. College-going expectations and awareness among middle school students in low-income schools. Manuscript in preparation.

\section{CONFERENCE PRESENTATIONS}

\section{National Conferences}

Ardasheva, Y., Tretter, R. T., \& Kinny, M. (2010, April-May). Re-designated fluent English proficient students: Closing the academic achievement gap? Paper presented at the annual meeting of the American Educational Research Association, Denver, CO.

Ardasheva, Y., \& Howell, P. B. (2010, April-May). Building academic capital among English language learners through Accountable Talk. Roundtable presentation presented at the annual meeting of the American Educational Research Association, Denver, CO.

Howell, P. B., \& Ardasheva, Y. (2009, November). Teaching early adolescents how to talk: Creating productive class discussion in any content area. Paper presented at the 36th National Middle School Association Annual Conference, Indianapolis, IN.

Ardasheva, Y., Tretter, R. T., \& Kinny, M. (2009, October). Academic achievement among middle school re-designated fluent English proficient students: Closing the gap? Paper presented at the $15^{\text {th }}$ National Evaluation Institute, Consortium for Research on Educational Accountability and Teacher Evaluation, Louisville, KY.

Ardasheva, Y., \& Brown, S. (2009, April). Content-area teachers and ESL preparation: Motivational considerations. Paper presented at the annual meeting of the American Educational Research Association, San Diego, CA.

Howell, P. B., \& Ardasheva, Y. (2009, April). Accountable talk in the middle school math classroom. Paper presented at the annual meeting of the American Educational Research Association, San Diego, CA.

Howell, P. B., Thomas, S., Holman, T., \& Ardasheva, Y. (2008, March). Talk in the classroom: Meeting the developmental, cultural, and academic needs of middle 
school students. Paper presented the annual meeting of the American Educational Research Association, New York, NY.

Ardasheva, Y., \& Brown, S. (2008, January). Motivation of general and content area teachers seeking training in educating English Language Learners. Paper presented at the Association for Science Teacher Education conference, St. Louis, MO.

Hulan, N., Vanderhaar, J. E., \& Ardasheva, Y. (2007, November). Culturally responsive teaching. Workshop presented at the National Kappa Delta Pi Bi-Annual Convocation, Louisville, KY.

\section{Regional Conferences}

Ardasheva, Y., \& Brown, S. (2008, September). Mainstream teachers' motivation to obtain ESL training. Paper presented at the annual meeting of South East Teachers of English to Speakers of Other Languages, Birmingham, AL.

Howell, P. B., \& Ardasheva, Y. (2008, April). Accountable talk in middle school mathematics: Perspectives and practices. Poster presented at the University of Louisville, University of Kentucky, and University of Cincinnati Spring Research Conference, University of Cincinnati, $\mathrm{OH}$.

\section{Presentation Proposals Accepted}

Ardasheva, Y., \& Tretter, R. T.. The relationships among individual differences, school characteristics, and $L 2$ reading achievement of school-aged ELL students: An empirical investigation using Hierarchical Linear Modeling. Paper presentation accepted for the annual meeting of the American Educational Research Association, New Orleans, LA, April 2011.

Ardasheva, Y.. Examining the lower level Threshold Hypothesis in a secondary ESL context. Paper presentation accepted for the 45th Annual Teachers of English to Speakers of Other Languages Convention, New Orleans, LA, March 2011.

\section{TECHNICAL REPORTS}

Ardasheva, Y. (2010). Perceptions of language learning strategies among ESL students and teachers: Technical Report [prepared for the ESL Department of the Jefferson County Public Schools District]. University of Louisville, Louisville, $\mathrm{KY}$.

Ardasheva, Y. (2010). Contributions of background and school characteristics to English language learners' (ELLs) reading achievement: Executive summary [prepared for the ESL Department of the Jefferson County Public Schools District]. University of Louisville, Louisville, KY.

Ardasheva, Y., \& Tretter, R. T. (2010). Contributions of background and school characteristics to English Language Learners' (ELLs) Reading Achievement: Technical Report [prepared for the ESL Department of the Jefferson County Public Schools District]. University of Louisville, Louisville, KY. 
Ardasheva, Y. (2010). Re-defining success for English language learners: Executive summary [prepared for the ESL Department of the Jefferson County Public Schools District]. University of Louisville, Louisville, KY.

Bush, W. S., Jones, J. H., Ardasheva, Y., \& Rudasill, K. M. (2010). GEAR UP Kentucky2: Final Report for Years 2 through 5 [prepared for the Kentucky Council on Postsecondary Education]. University of Louisville, Louisville, KY.

Ardasheva, Y. (2010). GEAR UP Kentucky-2: 2006-2010 student, parent, teacher, and counselor survey evaluation report (Technical supplements) [prepared for the Kentucky Council on Postsecondary Education]. University of Louisville, Louisville, KY.

Ardasheva, Y. (2009). GEAR UP Kentucky-2: 2006-2009 student, parent, teacher and counselor survey evaluation report (Technical supplements) [prepared for the Kentucky Council on Postsecondary Education]. University of Louisville, Louisville, KY.

\section{SELECTED GRANT ACTIVITIES}

Student Development Grant. College of Education and Human Development Research \& Faculty Development Grant, University of Louisville, 2010, \$695 awarded. Role on grant: Author.

English Language Learners in Focus: Predictors of Academic Achievement. University of Louisville Intramural Research Incentive Grant, 2009-2010, \$2,000 awarded. Role on grant: Co-Author.

\section{Grant Proposals Submitted}

Enhancing Science Learning and Reasoning for Young English Language Learners (ELL) and Other Young Children by Embedding Literacy Practices in Science Instruction. Grant proposal submitted to the National Science Foundation (NSF), Research and Evaluation on Education in Science and Engineering (REESE) program, 2011-2014, \$1.5 million. Role on grant: Co-PI. 